Rodrigo de Oliveira Preti

\title{
MODELAGEM E SIMULAÇÃO DE UM SISTEMA HIDRÁULICO PROPOSTO PARA FUNCIONAR COMO UM AMORTECEDOR PARA PEQUENAS AMPLITUDES
}

Dissertação apresentada à Escola de Engenharia de São Carlos da Universidade de São Paulo, para obtenção do título de Mestre em Engenharia Mecânica.

Área de Concentração: Dinâmica de Máquinas e Sistemas

ORIENTADOR: Prof. Dr. Luiz Carlos Felício 
AUTORIZO A REPRODUÇÃO E DIVULGAÇÃO TOTAL OU PARCIAL DESTE TRABALHO, POR QUALQUER MEIO CONVENCIONAL OU ELETRÔNICO, PARA FINS DE ESTUDO E PESQUISA, DESDE QUE CITADA A FONTE.

Ficha catalográfica preparada pela Seção de Tratamento da Informação do Serviço de Biblioteca - EESC/USP

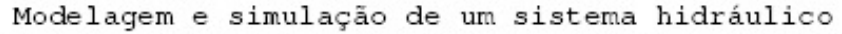
amplitudes / Rodrigo de Oliveira Preti ; orientador Luiz Carlos Felício. -- São Carlos, 2007.

Dissertação (Mestrado) - Programa de Pós-Graduação em Engenharia Mecânica e Área de Concentração em Dinâmica de Máquinas e Sistemas. -- Escola de Engenharia de São Carlos da Universidade de São Paulo.

1. Amortecedor. 2. Modelagem dinâmica. 3. Simulação. 4. Baixas amplitudes. I. Título. 


\section{FOLHA DE JULGAMENTO}

Candidato: Engenheiro RODRIGO DE OLIVEIRA PRETI

Dissertação defendida e julgada em 27/09/2007 perante a Comissão Julgadora:

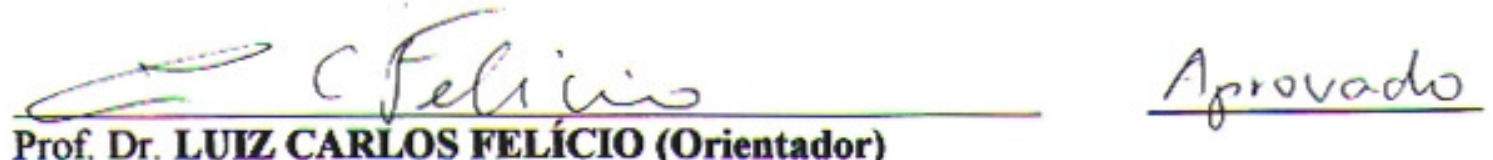

Prof. Dr. LUIZ CARLOS FELICIO (Orientador)

(Escola de Engenharia de São Carlos/USP)

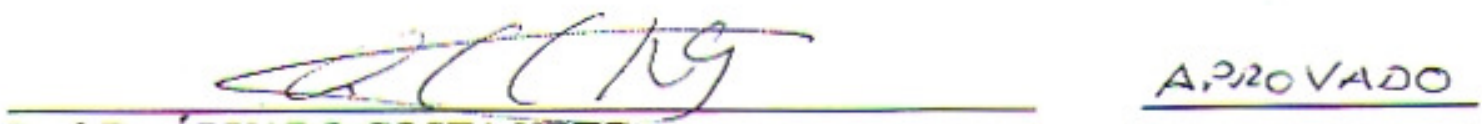

Prof. Dr. ÁlVARO COSTA NETO

(Escola de Engenharia de São Carlos/USP)

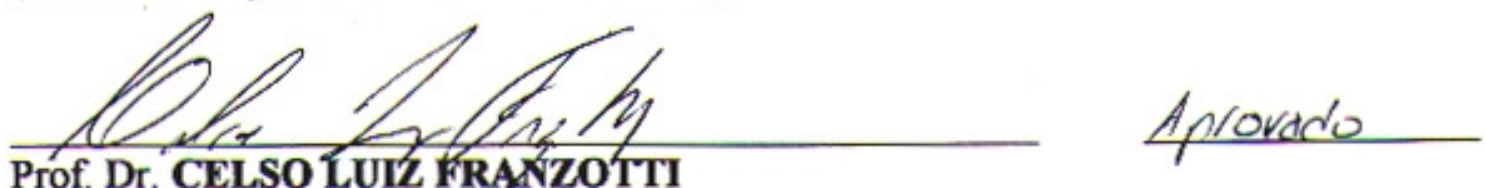

Prof. Dr. CELSO luIz FRANZOTTI

(Instituto de Ensino Superior COC/UNICOC)

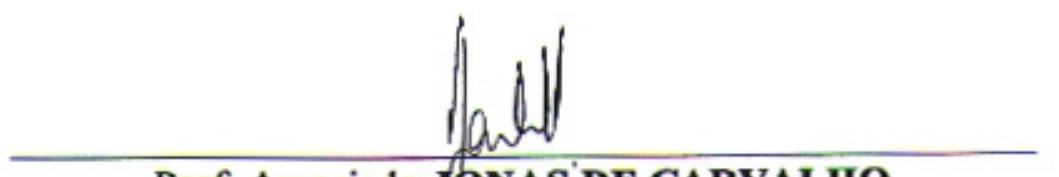

Prof. Associado JONAS DE CARVALHO

Coordenador do Ptograma de Pós-Graduação

em Engenharia Mecânica

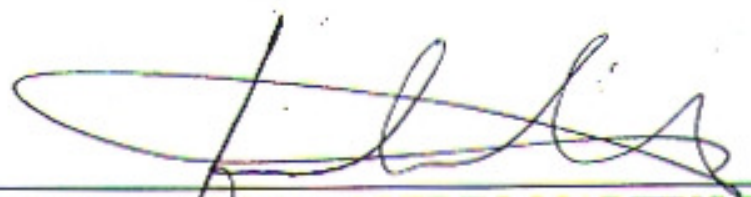

Prof. Associado GERALDO ROBERTO MARTINS DA COSTA

Presidente da Lomissão da Pós-Graduação da EESC 



\section{AGRADECIMENTOS}

Agradeço primordialmente a Deus por ter me guiado e me dado forças para que esse trabalho fosse realizado.

Aos meus pais pelo carinho e por ter acreditado em mim.

A minha esposa por ter me encorajado nas horas mais difíceis e por ter compreendido por diversas vezes a minha ausência.

Agradeço ao Prof. Dr. Luiz Carlos Felício pela orientação neste trabalho.

Agradeço a CAPES pelo apoio financeiro.

Aos meus amigos de pós-graduação Fabiano, Carlos Eduardo, Israel, Ferezin, Luis Mauro e tantos outros que não estão nesta lista que contribuíram para o meu trabalho.

Ao professor Luis Carlos Passarini pelo apoio e direcionamento.

Aos funcionários da USP, Ana Paula, Xina, José Roberto Bogni (Zé). 


\section{RESUMO}

PRETI, R. O. (2007). Modelagem e simulação de um sistema hidráulico proposto para funcionar como um amortecedor para pequenas amplitudes. São Carlos. 78 f. Dissertação (Mestrado) - Escola de Engenharia de São Carlos, Universidade de São Paulo.

Este trabalho apresenta um modelo matemático linear para um sistema hidráulico proposto para funcionar como um amortecedor para pequenas amplitudes de deslocamento, da ordem de décimos de milímetros. As dimensões para o sistema hidráulico foram adotadas e parâmetros foram determinados. Foram escolhidos dois conjuntos de parâmetros dimensionais e dois valores para o bulk modulus equivalente, o que permitiu fazer o estudo de quatro situações. A verificação das características dinâmicas do sistema foi efetuada utilizando o conceito de função descritiva. Um programa em Matlab/Simulink com um filtro de Fourier foi implementado para obtenção das curvas da resposta em freqüência. A eficiência deste programa computacional foi comprovada através de sua aplicação a sistemas cujas respostas em freqüência são conhecidas. As curvas das respostas em freqüência do sistema hidráulico e do amortecedor ideal foram comparadas. Considerando tolerância de \pm 1 grau para a fase e de $\pm 1 \mathrm{db}$ para magnitude, o sistema hidráulico simulado, com bulk modulus equivalente de 100000 psi teve comportamento similar ao amortecedor ideal na faixa de freqüência de $0,1 \mathrm{a}$ 
$150 \mathrm{rad} / \mathrm{seg}$. No caso do bulk modulus de 30000 psi, a faixa foi estendida, isto é, de 0,1 a 200 $\mathrm{rad} / \mathrm{seg}$.

Palavras-chaves: Amortecedor. Modelagem dinâmica. Simulação. Baixas amplitudes. 


\begin{abstract}
PRETI, R. O. (2007) Modeling and simulation for a proposed hydraulic system intended to work as a damper for small amplitudes. São Carlos. 78 f. Dissertation (Master) Escola de Engenharia de São Carlos, Universidade de São Paulo.

This work presents a linear mathematical model for a proposed hydraulic system intended to work as a damper for small displacement, of the order of decimals of millimeters. The dimensions of the hydraulic system were adopted and parameters were determined. Two sets of the dimensions and two values for the equivalent bulk modulus were chosen and that allowed the study of four situations. The system dynamic properties were verified using the concept of describing function. A Matlab/Simulink program applying the concept of a Fourier filter was carried out in order to obtain the frequency response curves. The efficiency of this program was verified through its application in systems which frequency responses are known. The systems and the ideal damper frequency response curves were compared. Considering tolerance of \pm 1 degree for the phase and $\pm 1 \mathrm{db}$ for magnitude, the simulated hydraulic system with an equivalent bulk modulus of 100000 psi showed to be similar to an ideal damper, for the frequency range from 0.1 to $150 \mathrm{rad} / \mathrm{sec}$. For the equivalent bulk modulus of $30000 \mathrm{psi}$, the frequency range was extended from 0.1 to $200 \mathrm{rad} / \mathrm{sec}$.
\end{abstract}

Keywords: Damper. Dynamic modeling. Simulation. Small amplitudes. 


\section{LISTA DE FIGURAS}

FIGURA 2.1 - Simbologia do amortecedor de translação ideal...........................................23

FIGURA 2.2 - Simbologia do amortecedor rotacional ideal ................................................. 24

FIGURA 2.3 - Esboço dos gráficos das respostas em frequiência dos amortecedores ideais de

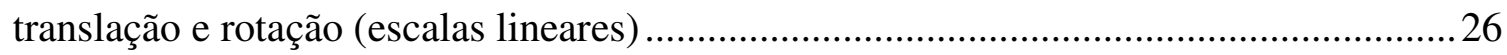

FIGURA 2.4 - Gráficos das características de operação para o amortecedor hidráulico do tipo orifício constante e pressão variável (ELLIS; KARBOWNICZEK, 1962). .28

FIGURA 2.5 - Gráficos das características de operação para o amortecedor hidráulico do tipo orifício variável e pressão constante (ELLIS; KARBOWNICZEK, 1962)...... 28

FIGURA 2.6 - Amortecedor de orifício variável com pino cônico (ELLIS; KARBOWNICZEK, 1962) .29

FIGURA 2.7 - Amortecedor de pino cilíndrico afilado para produzir orifício de área orifício variável (ELLIS; KARBOWNICZEK, 1962). .30

FIGURA 2.8 - Amortecedor com pino e cavidade interna com orifícios distribuídos ao longo de sua cavidade para produzir orifício de área variável (ELLIS; KARBOWNICZEK, 1962) 30

FIGURA 2.9 - Amortecedor com cilindro interno cheio de furos para produz orifício de área variável (ELLIS; KARBOWNICZEK, 1962).

FIGURA 2.10 - Amortecedor de dupla haste com parede interna do cilindro em formato côncavo (ELLIS; KARBOWNICZEK, 1962) 
FIGURA 2.11 - Amortecedor com a parede interna do cilindro com ranhuras côncavas produzindo variação da área do orifício (ELLIS; KARBOWNICZEK, 1962) 32

FIGURA 2.12 - Amortecedor com entalhes em sua parede interna para provocar variação de área do orifício (ELLIS; KARBOWNICZEK, 1962). .33

FIGURA 2.13 - Amortecedor de orifício de área constante (ELLIS; KARBOWNICZEK, 1962) 34

FIGURA 2.14 - Componente da suspensão de motocicleta mostrando o amortecedor estudado por Audenino e Belingardi (1995) 35

FIGURA 2.15 - Arranjo dos testes realizados por Audenino e Belingardi (1995) 36

FIGURA 2.16 - Diagramas de forças versus velocidade e força versus deslocamento Experimentais obtidos pelo amortecedor de motocicleta de Audenino e Belingardi (1995) para três níveis de excitação $(3,10$ e $20 \mathrm{~Hz})$

FIGURA 2.17 - Desenho esquemático do amortecedor de tubo simples modelado por Molica (1997) 38

FIGURA 2.18 - Desenho esquemático do amortecedor hidráulico semi-ativo (SAVA) de Patten et al (1998) 40

FIGURA 2.19 - Corte transversal do D-Strut (DAVIS et al, 1994). 42

FIGURA 2.20 - Resposta em freqüência do modelo de três parâmetros do D-Strut (DAVIS et $a l, 1994)$

FIGURA 2.21 - Esquema dos testes realizados no D-Strut (DAVIS et al, 1994). 45

FIGURA 2.22 - Desenho esquemático do protótipo de amortecedor MR estudado por Wang e Gordaninejad (2001) .46

FIGURA 2.23 - Desenho esquemático do amortecedor MR de Spencer et al (1996)..... 47

FIGURA 2.24 - Arranjo de teste do amortecedor MR de Spencer et al (1996). 47 
FIGURA 2.25 - Força medida experimentalmente para uma excitação senoidal de 2.5 Hz com uma amplitude de 1,5 cm para o amortecedor MR de Spencer et al (1996). 48

FIGURA 2.26 - Configuração de amortecedor ER de Hong et al (2005).

FIGURA 2.27 - Diagrama de força de amortecimento versus velocidade para uma excitação de $1 \mathrm{~Hz}$ e vários valores de campos magnéticos (HONG et al, 2005). .50

FIGURA 2.28 - Diagrama de força versus velocidade para um campo magnético de 6 KW/mm e várias frequiências de excitação (HONG et al, 2005).

FIGURA 3.1 - Desenho esquemático do sistema hidráulico proposto para funcionar como um amortecedor para baixas amplitudes.

FIGURA 4.1 - Fluxograma do programa em Matlab e Simulink para obtenção da resposta em freqüência. 62

FIGURA 4.2 - Arquitetura do programa no Simulink 63

FIGURA 4.3 - Blocos contidos no subsystem "Filtro de Fourier" do Simulink. 64

FIGURA 4.4 - Blocos contidos no subsystem Sinal de controle dentro do subsystem Resposta em Freqüência no Simulink. 66

FIGURA 4.5 - Blocos para o teste do derivador simples. 68

FIGURA 4.6 - Gráficos da RF obtidos através do filtro de Fourier implementado no Simulink, para o derivador simples. 68

FIGURA 4.7 - Gráficos de Bode do derivador simples. 69

FIGURA 4.8 - Gráfico da diferença (da Fase e Magnitude) entre o obtido pela função bode e pelo filtro de Fourier para o derivador simples. 70

FIGURA 4.9 - Blocoss para o teste do integrador simples. 70

FIGURA 4.10 - Gráficos da RF obtidos através do filtro de Fourier implementado pelo Simulink, para o integrador simples. 71

FIGURA 4.11 - Gráficos de Bode do integrador simples. 71 
FIGURA 4.12 - Gráfico da diferença (da Fase e Magnitude) entre o obtido pela função bode e pelo filtro de Fourier para o integrador simples.

FIGURA 4.13 - Blocos para o teste da onda quadrada

FIGURA 4.14 - Gráficos da RF obtidos através do filtro de Fourier implementado no Simulink, para a componente harmônica fundamental da onda quadrada. 74

FIGURA 4.15 - Gráficos de Bode para a componente harmônica fundamental da onda quadrada. 74

FIGURA 4.16 - Gráfico da diferença (da Fase e Magnitude) entre o obtido pela função Bode e pelo filtro de Fourier para a componente harmônica fundamental da onda quadrada..... 75

FIGURA 4.17 - Blocos para o teste do sistema de primeira ordem. 76

FIGURA 4.18 - Gráficos da RF para o sistema de primeira ordem com $\tau=1$ seg obtido pelo filtro de Fourier, implementado no Simulink. 77

FIGURA 4.19 - Gráficos da RF para o sistema de primeira ordem $\operatorname{com} \tau=0,1 \mathrm{seg}$ obtido pelo filtro de Fourier, implementado no Simulink. 77

FIGURA 4.20 - Gráficos da RF para o sistema de primeira ordem com $\tau=0,01$ seg obtido pelo filtro de Fourier, implementado no Simulink. 78

FIGURA 4.21 - Gráficos de Bode para o sistema de primeira ordem com $\tau=1 \mathrm{seg}$ 78

FIGURA 4.22 - Gráficos de Bode para o sistema de primeira ordem com $\tau=0,1$ seg 79

FIGURA 4.23 - Gráficos de Bode para o sistema de primeira ordem com $\tau=0,01$ seg 79

FIGURA 4.24 - Gráfico da diferença (da Fase e Magnitude) entre obtido pelo filtro de Fourier e com o uso da função bode para sistema de primeira ordem com $\tau=1$ seg 80

FIGURA 4.25 - Gráfico da diferença (da Fase e Magnitude) entre obtido pelo filtro de Fourier e com o uso da função bode para sistema de primeira ordem com $\tau=0,1 \mathrm{seg}$ 81 
FIGURA 4.26 - Gráfico da diferença (da Fase e Magnitude) entre obtido pelo filtro de Fourier e com o uso da função bode para sistema de primeira ordem com $\tau=0,01 \mathrm{seg}$

FIGURA 4.27 - Blocos para o teste do sistema de segunda ordem. 82

FIGURA 4.28 - Gráficos da RF obtidos através do Filtro de Fourier implementado no Simulink para o sistema de segunda ordem com $\omega_{n}=10 \mathrm{rad} / \mathrm{seg}$ e $\zeta=0,1$

FIGURA 4.29 - Gráficos da RF obtidos através do Filtro de Fourier implementado no Simulink para o sistema de segunda ordem com $\omega_{n}=10 \mathrm{rad} / \mathrm{seg}$ e $\zeta=0,01$ 83

FIGURA 4.30 - Gráficos da RF obtidos através do Filtro de Fourier implementado no Simulink para o sistema de segunda ordem com $\omega_{n}=10 \mathrm{rad} / \mathrm{seg}$ e $\zeta=0,004$ 84

FIGURA 4.31 - Gráficos da RF obtidos através do Filtro de Fourier implementado no Simulink para o sistema de segunda ordem com $\omega_{n}=10 \mathrm{rad} / \mathrm{seg}$ e $\zeta=0,001$ 84

FIGURA 4.32 - Gráficos de Bode para o sistema de segunda ordem com $\omega_{n} 10 \mathrm{rad} / \mathrm{seg}$ $\zeta=0,1$ 85

FIGURA 4.33 - Gráficos de Bode para o sistema de segunda ordem com $\omega_{n} 10 \mathrm{rad} / \mathrm{seg}$ $\zeta=0,01$ 86

FIGURA 4.34 - Gráficos de Bode para o sistema de segunda ordem com $\omega_{n} 10 \mathrm{rad} / \mathrm{seg}$ $\zeta=0,004$ 86

FIGURA 4.35 - Gráficos de Bode para o sistema de segunda ordem com $\omega_{n} 10 \mathrm{rad} / \mathrm{seg}$ e $\zeta=0,001$ 87

FIGURA 4.36 - Gráfico da diferença entre o obtido pelo filtro de Fourier e com o uso da função bode para um sistema de segunda ordem com $\omega_{n} 10 \mathrm{rad} / \mathrm{s}$ e $\zeta=0,1$ 88

FIGURA 4.37 - Gráfico da diferença entre o obtido pelo filtro de Fourier e com o uso da função bode para um sistema de segunda ordem com $\omega_{n} 10 \mathrm{rad} / \mathrm{s}$ e $\zeta=0,01$. 88 
FIGURA 4.38 - Gráfico da diferença entre o obtido pelo filtro de Fourier e com o uso da função bode para um sistema de segunda ordem com $\omega_{n} 10 \mathrm{rad} / \mathrm{s}$ e $\zeta=0,004$

FIGURA 4.39 - Gráfico da diferença entre o obtido pelo filtro de Fourier e com o uso da função bode para um sistema de segunda ordem com $\omega_{n} 10 \mathrm{rad} / \mathrm{s}$ e $\zeta=0,001$

FIGURA 5.1 - Esquema do amortecedor proposto. 91

FIGURA 5.2 - Diagrama de corpo livre do conjunto pistão-haste, na direção de $x_{0}$ 94

FIGURA 6.1 - Desenho esquemático da parte inferior do sistema hidráulico 104

FIGURA 6.2 - Barra sob ação de uma força aplicada de $3000 \mathrm{Kgf} / \mathrm{cm}^{2}$ 106

FIGURA 6.3 - Desenho representativo do orifício. 113

FIGURA 6.4 - Deslocamento senoidal do conjunto pistão-haste. 115

FIGURA 6.5 - Orifício desenvolvido para a folga entre o pistão e o cilindro 120

FIGURA 7.1 - Blocos do Simulink utilizados para simular o modelo 123

FIGURA 7.2 - Blocos contidos no bloco "Modelo do Sistema Hidráulico" 124

FIGURA 7.3 - Gráficos da RF do Sistema Hidráulico 1 para um Bulk Modulus equivalente igual a 100000psi. 126

FIGURA 7.4 - Gráficos da RF do Sistema Hidráulico 1 para um Bulk Modulus equivalente igual a 30000psi. 126

FIGURA 7.5 - Gráficos da RF do Sistema Hidráulico 2 para um bulk modulus equivalente iguala a $100000 \mathrm{psi}$ 129

FIGURA 7.6 - Gráficos da RF do Sistema Hidráulico 2 para um bulk modulus equivalente iguala a 30000psi 129

FIGURA C1 - Implementação da equação (5.14) no Simulink 155

FIGURA C2 - Implementação da equação (5.27) no Simulink. 155

FIGURA C3 - Implementação da equação (5.29) no Simulink. 156

FIGURA C4 - Implementação da equação (5.31) no Simulink 156 
FIGURA C5 - Implementação da equação (5.33) no Simulink ............................................. 156 


\section{SUMÁRIO}

\section{Resumo}

\section{Abstract}

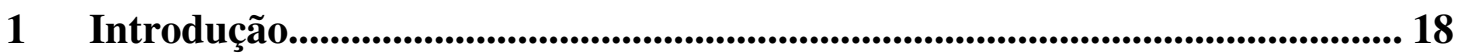

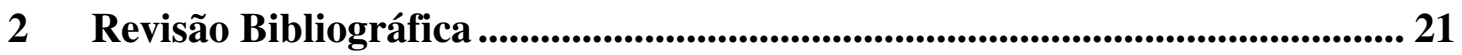

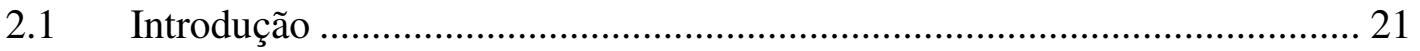

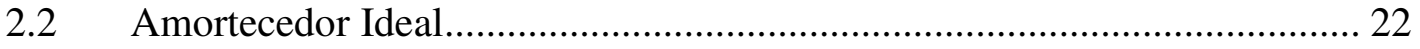

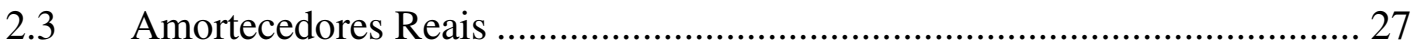

2.4 Análise por Função Descritiva ............................................................. 52

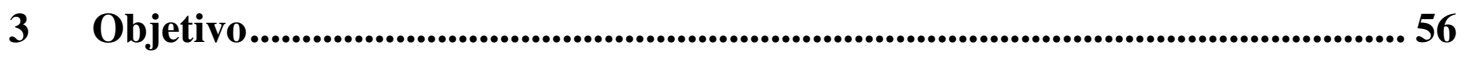

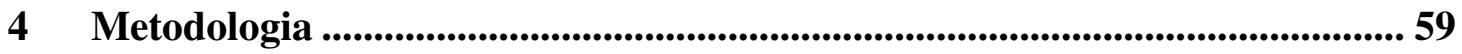

4.1 Método computacional para obtenção da Resposta em Freqüência ............ 59

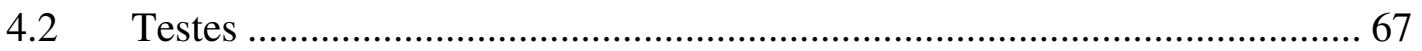

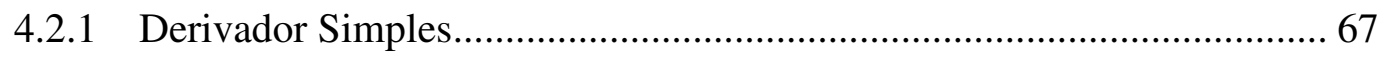

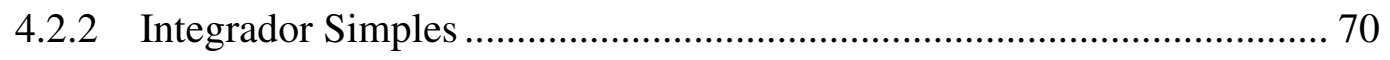

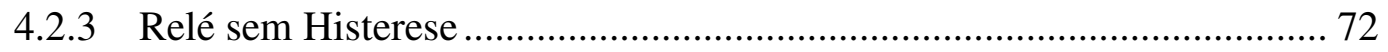

4.2.4 Sistema de Primeira Ordem ………..................................................... 75

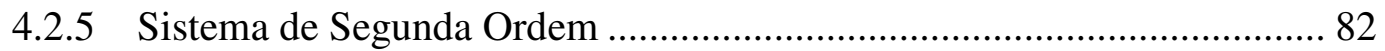

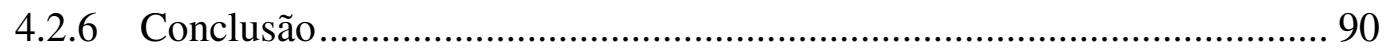

$5 \quad$ Modelagem Matemática ..................................................................................................... 91 
6 Dimensionamento de Peças e Definição de Parâmetros Propostos para um Sistema Hidráulico ....................................................................................................104

7 Simulação do Sistema Hidráulico Proposto .......................................................122

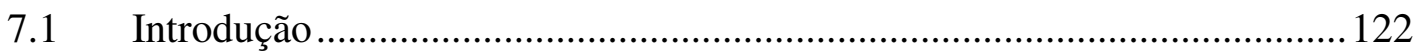

7.2 Simulação do Sistema Hidráulico 1 ...................................................... 125

7.3 Simulação do Sistema Hidráulico 2 ......................................................... 127

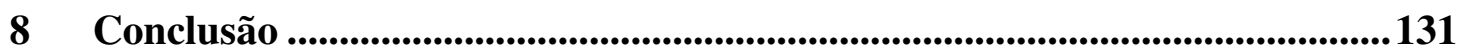

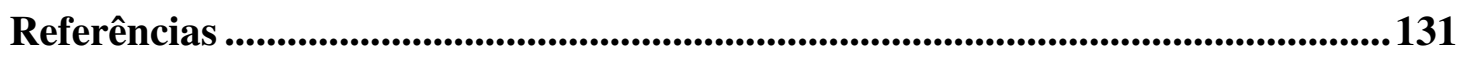

Apêndice A - Programa do Matlab para os testes dos sistemas ..........................133

Apêndice B - Programa do Matlab para a simulação do Sistema Hidráulico ... 150

Apêndice C - Programa do Simulink Contendo as Equações do Modelo ............. 155 


\section{INTRODUÇÃO}

Os amortecedores, como elementos de atenuação de vibrações e impactos são dispositivos que geralmente utilizam algum tipo de atrito para converter a energia cinética fornecida a eles em energia térmica. Amortecedores podem também ser utilizado para representar uma característica intrínseca das estruturas, isso devido a todas as estruturas possuírem um certo grau de amortecimento, mesmo não possuindo qualquer dispositivo de amortecimento acoplado.

Os dispositivos de amortecimento são muito importantes, o que é facilmente constatado devido a sua ampla aplicação, estando presente em quase todos os seguimentos da indústria como, por exemplo, na indústria automotiva, de construção civil (em pontes, viadutos, edifícios, etc), de bens de consumo (calçados, eletrodomésticos, eletro-eletrônico, etc), de instrumentação (bancadas de instrumentação), de aviação (trens de pouso, assentos), aeroespacial (veículos de exploração, satélites), dentre muitas outras. No caso de veículos, pode-se citar como benéficos trazidos pelos amortecedores, a melhoria do conforto e controle de automóveis. Estes atenuam vibrações indesejadas sofridas pela carroceria devido a imperfeições no solo, que se não fossem atenuadas, causariam desconforto e instabilidade do veículo, afetando sua dirigibilidade. Nas estruturas é muito importante que vibrações sejam amortecidas, pois elas podem causar sérios danos às mesmas, podendo até mesmo destruí-las. Em países onde são comuns as atividades sísmicas, como no Japão e nos Estados Unidos, os 
amortecedores minimizam os efeitos das vibrações durante a atividade sísmica, procurando evitar que muitas vidas humanas sejam ceifadas e também minimizando prejuízos materiais.

Portanto, o conhecimento das características e do comportamento dinâmico dos amortecedores e o desenvolvimento de novos dispositivos que contribuam para atenuação de vibrações são uma imensa fonte de pesquisa acadêmica e industrial. Neste contexto, esse trabalho vem dar sua contribuição, verificando o modelo de um sistema hidráulico proposto para funcionar para pequenas amplitudes de excitação, na casa dos décimos de milímetro. Esse sistema hidráulico foi proposto pelo professor da Escola de Engenharia de São Carlos, da Universidade de São Paulo, Dr. Luiz Carlos Felício.

Este trabalho está divido em cinco partes.

$\mathrm{Na}$ primeira parte foi feita uma revisão bibliográfica sobre os amortecedores mais utilizados, bem como o estudo sobre o amortecedor ideal. Foi também incluída nesta parte do trabalho, uma base teórica conhecida como análise de sistemas não-lineares por função descritiva, que é uma extensão do conceito da resposta em freqüência para sistemas nãolineares.

A segunda parte descreve um programa em Matlab/Simulink que se baseia em análise de sistemas não-lineares por função descritiva, que tem por objetivo obter as respostas em frequiência do sistema hidráulico proposto. A eficiência do programa é comprovada através de teste em sistema cujas respostas em freqüência eram previamente conhecidas.

A terceira parte compreende a obtenção do modelo matemático do sistema hidráulico proposto para funcionar como um amortecedor para pequenas amplitudes de excitação. Foi obtido um modelo linear, isto é, composto somente por equações diferencias ordinárias lineares a coeficientes constantes, onde os efeitos que causam não-linearidades foram desprezados. 
A quarta parte envolve a escolha e cálculo de parâmetros bem como o dimensionamento de partes do sistema hidráulico onde foram atribuídas algumas dimensões básicas para o sistema hidráulico como, por exemplo, o comprimento e diâmetro dos orifícios. A escolha dos materiais e do fluído empregado foram também incluídos nesta etapa do trabalho.

A quinta parte é dedicada à obtenção da resposta em freqüência do sistema e comparação com as curvas da resposta em freqüência do amortecedor ideal. Foram escolhidos dois conjuntos de parâmetros dimensionais e dois valores para o bulk modulus equivalente para o sistema proposto, o que permitiu fazer o estudo de quatro situações. As equações diferencias do modelo matemático do sistema proposto foram inseridas no Simulink. Uma vez feito isto, o programa em linguagem Matlab foi executado para excitar virtualmente (em um microcomputador) o modelo matemático. Através de um filtro de Fourier implementado também no Simulink, a resposta à excitação do sistema hidráulico proposto foi obtida, isto é, a relação de amplitudes e a fase. Os dados foram colocados na forma de gráfico para uma fácil visualização. Feito isso, comparou-se à resposta em frequiência do sistema hidráulico proposto com a do amortecedor ideal.

Concluiu-se que o sistema hidráulico proposto neste trabalho, com bulk modulus equivalente de 100000 psi funcionou como um amortecedor para pequenas amplitudes de excitação na faixa de frequiência que vai de 0,1 a te $150 \mathrm{rad} / \mathrm{seg}$ quando se considera uma tolerância de $\pm 1 \%$ para a fase e a magnitude, respectivamente. O sistema hidráulico com bulk modulus equivalente de 30000 psi teve comportamento dinâmico parecido com o amortecedor ideal para uma maior faixa de freqüência, isto é, de 0,1 até $200 \mathrm{rad} / \mathrm{seg}$. 


\section{REVISÃO BIBLIOGRÁFICA}

\subsection{INTRODUÇÃO}

Esta revisão aborda o estudo dos amortecedores mais utilizados e uma metodologia para estudo de suas respostas. Os amortecedores foram divididos, para efeitos didáticos, em dois grupos: em amortecedor ideal e em amortecedores reais.

A primeira parte está dedicada à modelagem matemática e ao estudo da resposta tanto no domínio do tempo quanto no domínio da freqüência do amortecedor ideal. Apesar do amortecedor ideal, como o próprio nome diz, ser uma idealização, portanto não existindo na realidade, o seu modelo é muitas vezes adotado. Na maioria dos casos esse modelo simples simplifica a compreensão de um sistema mais complexo gerando análises rápidas e com uma boa aproximação do comportamento real. Neste trabalho particularmente, o modelo de amortecedor ideal, através de suas curvas de resposta em freqüência, serve como parâmetro para concluir se o sistema hidráulico proposto se comporta como um dispositivo de amortecimento para pequenas amplitudes de excitação.

A segunda parte compreende o estudo dos amortecedores reais que é uma coletânea sobre trabalhos que caracterizaram dispositivos de amortecimento. Esta parte faz uma análise, com base na bibliografia existente, dos principais parâmetros que influenciam o comportamento dinâmico dos amortecedores, analisando como e em que grau esses mesmos parâmetros contribuem na alteração ou modificação do seu comportamento dinâmico. As 
curvas de resposta em freqüência e também no domínio do tempo dos amortecedores foram estudadas, principalmente próximos à região de velocidade zero e de amplitudes bem pequenas.

Uma base teórica para o estudo da resposta que pode ser empregada tanto para sistema lineares quanto para não-lineares também é apresentada que posteriormente será implementada em um programa de computador para obtenção da resposta em freqüência do sistema hidráulico proposto.

\subsection{AMORTECEDOR IDEAL}

Segundo Felício (2007), amortecedor ideal é todo amortecedor puro e linear. Entendese por amortecedor puro aquele que não tem massa e nem comportamento de mola (elasticidade). Já amortecedor linear é todo aquele que possui a força de amortecimento proporcional a velocidade. Segundo Doebelin (1998), um amortecedor ideal ou puro dissipa toda a energia que é fornecida a ele, transformando-a em outra forma de energia, ou seja, em energia térmica ou simplesmente calor, o qual é transferida para o ambiente. Desta forma, a energia não pode ser aproveitada para realizar trabalho. O amortecimento é conseguido através de mecanismos associados a algum tipo de atrito. A simbologia para o amortecedor translacional, juntamente com os sentidos positivos da força externa $F$ aplicada sobre o amortecedor, a velocidade $V$ do ponto 1 e o coeficiente de amortecimento do amortecedor de translação $B$ estão ilustrados na FIGURA 2.1 


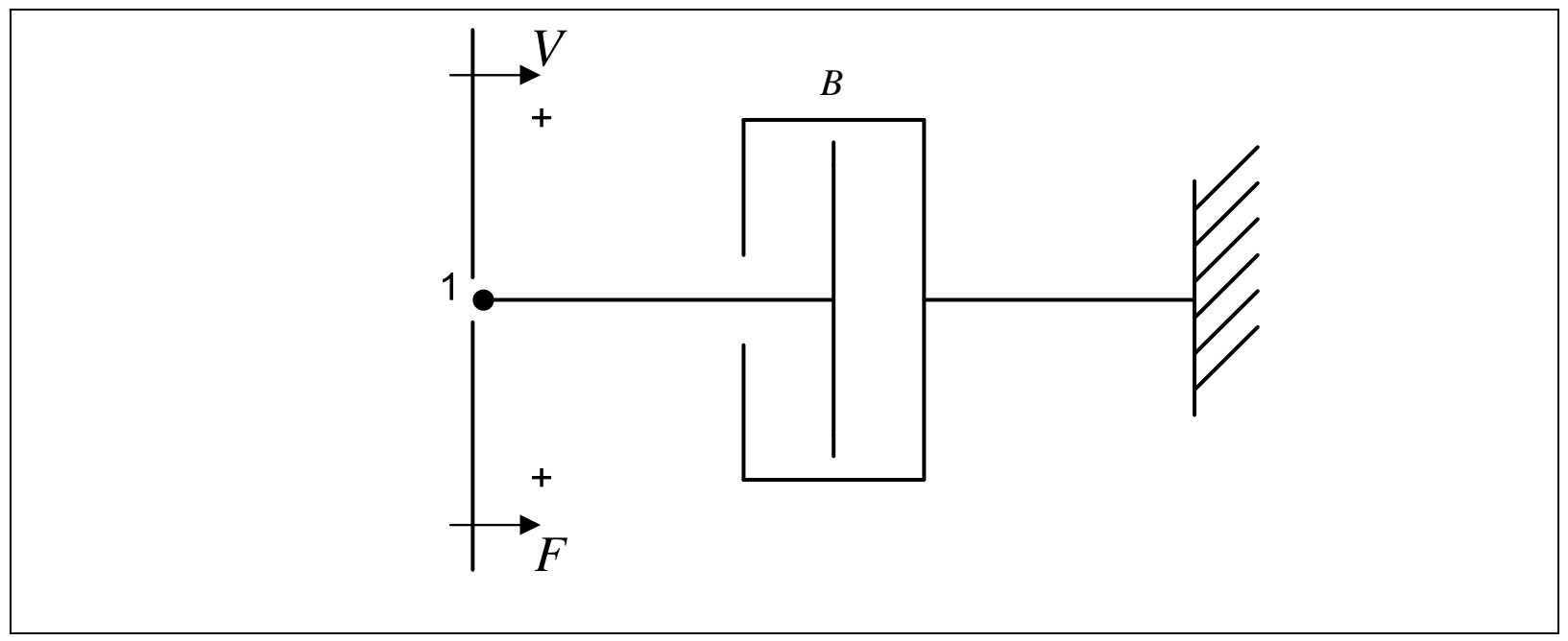

FIGURA 2.1 - Simbologia do amortecedor de translação ideal.

Definindo o amortecedor de translação ideal, a força $F$ é proporcional a velocidade $V$, então:

$$
F=B V
$$

Para o caso do amortecedor rotacional tem-se a FIGURA 2.2. A figura mostra a simbologia deste tipo de amortecedor, considerando os sentidos positivos adotados para o torque externo $T$, aplicado sobre o amortecedor, a velocidade angular $\omega_{1}$ no ponto $1 \mathrm{e} o$ coeficiente de amortecimento torcional $B_{t}$. 


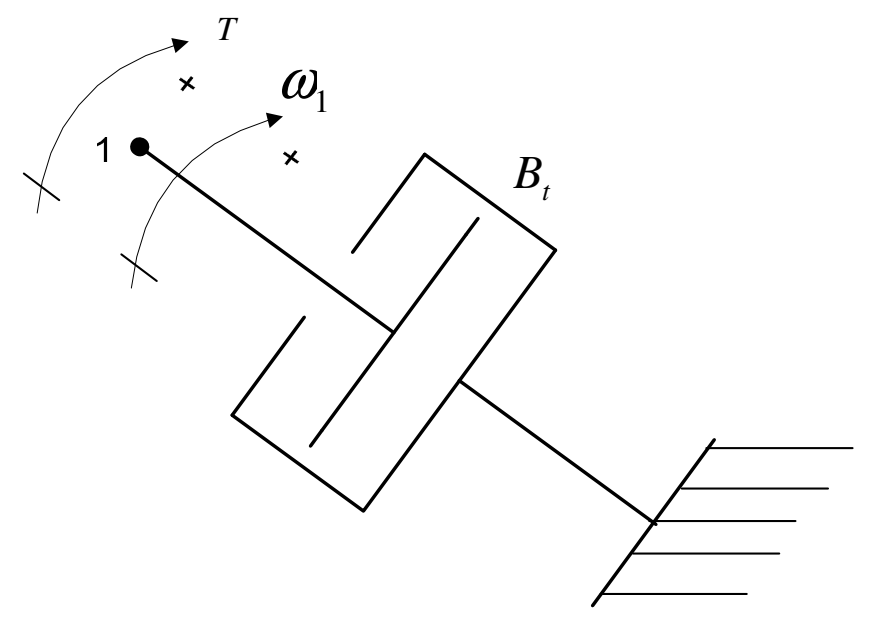

FIGURA 2.2 - Simbologia do amortecedor rotacional ideal

Para um amortecedor rotacional tem-se uma relação análoga, que em termos da velocidade angular fica:

$$
T=B_{t} \omega_{1}
$$

Determinando as funções de transferência operacionais $V / F(s)$ para o amortecedor de translação e $\omega_{1} / T(s)$ para o amortecedor rotacional obtêm-se:

$$
\frac{V}{F}(s)=\frac{1}{B}
$$

ou

$$
\frac{\omega_{1}}{T}(s)=\frac{1}{B_{t}}
$$

em que

$$
s \stackrel{\Delta}{=} \text { variável de Lalace. }
$$


A resposta em freqüência pode ser determinada através da função de transferência senoidal, fazendo a substituição de $s$ por $i \omega$, que passa a ser uma função complexa. Então das equações (2.3) e (2.4), obtem-se :

$$
\begin{gathered}
\frac{V}{F}(i \omega)=\frac{1}{B} \\
\frac{\omega_{1}}{T}(i \omega)=\frac{1}{B_{t}}
\end{gathered}
$$

Logo, as relações de amplitude e as fases ficam:

- Para o amortecedor linear:

$$
\begin{gathered}
\left|\frac{V}{F}(i \omega)\right|=\frac{A_{V}}{A_{F}}=\frac{1}{B} \\
\phi_{V / F}=0^{\circ}
\end{gathered}
$$

- Para o amortecedor torcional:

$$
\begin{gathered}
\left|\frac{\omega_{1}}{T}(i \omega)\right|=\frac{A_{\omega_{1}}}{A_{T}}=\frac{1}{B_{t}} \\
\phi_{\omega_{1} / T}=0^{\circ}
\end{gathered}
$$

em que

$\omega \stackrel{\Delta}{=}$ freqüência da onda senoidal da entrada;

$A_{V} \stackrel{\Delta}{=}$ amplitude da onda senoidal, no regime permanente, da velocidade do ponto 1, FIGURA 2.1;

$A_{F} \stackrel{\Delta}{=}$ amplitude da força externa aplicada ao amortecedor (entrada);

$A_{\omega} \stackrel{\Delta}{=}$ amplitude da onda senoidal, no regime permanente, da velocidade angular do ponto 1 da FIGURA 2.2; 
$A_{T} \stackrel{\Delta}{=}$ amplitude do torque externo aplicada ao amortecedor (entrada);
$\phi_{V / F} \stackrel{\Delta}{=}$ fase entre a velocidade, no regime permanente em relação a força externa aplicada ao amortecedor;

$\phi_{\omega / T} \stackrel{\Delta}{=}$ fase entre a velocidade angular, no regime permanente, em relação ao torque externo aplicado ao amortecedor.

A FIGURA 2.3 ilustra o as curvas das respostas em freqüência para os amortecedores ideais de translação e rotação.

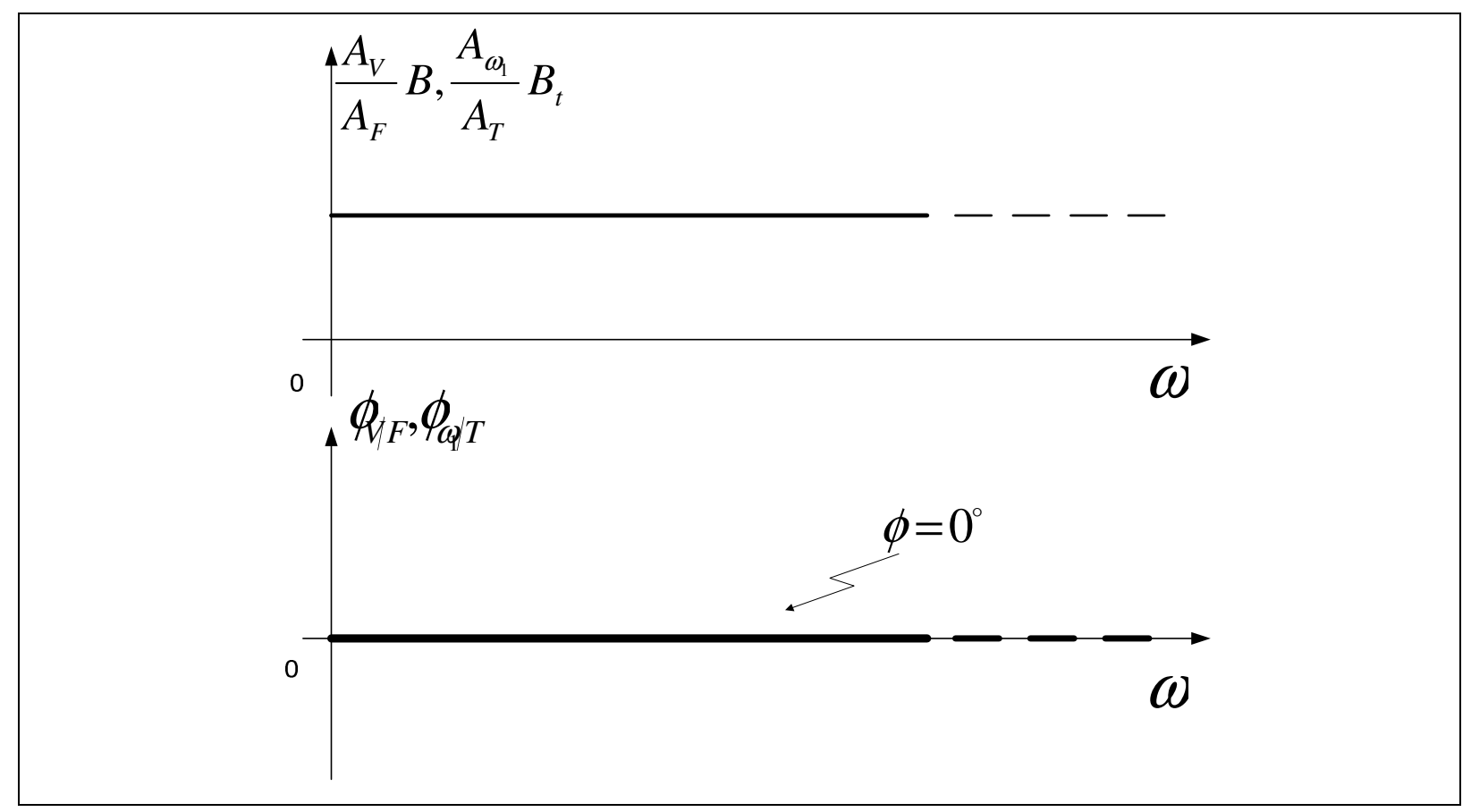

FIGURA 2.3 - Esboço dos gráficos das respostas em frequiência dos amortecedores ideais de translação e rotação (escalas lineares).

Como pode-se observar nas curvas das Respostas em Freqüências (RF) dos amortecedores ideais de translação e rotação, as relações de amplitudes $\frac{A_{V}}{A_{F}}$ e $\frac{A_{\omega_{1}}}{A_{T}}$ são planas de $\omega=0$ até $\omega \rightarrow \infty$. As fases para ambos os casos também são planas e iguais a $0^{\circ}$. Isto 
significa que a velocidade está em fase com a força ou o torque aplicado ao amortecedor, não importando a freqüência.

\subsection{AMORTECEDORES REAIS}

Poucos trabalhos na literatura se dedicam a dividir os amortecedores segundo algum critério seja ele funcional, de tipo de fluído utilizado, de aplicação, etc. Ellis e Karbowniczek (1962), realizou essa tarefa dividindo os amortecedores hidráulicos funcionalmente em duas categorias: (1) orifício constante e pressão variável; (2) orifício variável e pressão constante. Segundo ele, embora haja pequena diferença construtiva entre os dois tipos, existe uma grande diferença em sua performance. A vantagem de uma construção do tipo orifício constante e pressão variável é contrabalançada pela sua característica de operação pouco desejada. As figuras 2.1 e 2.2 mostram os gráficos das características de operação para o tipo orifício constante e pressão variável e orifício variável e pressão constante, respectivamente. 


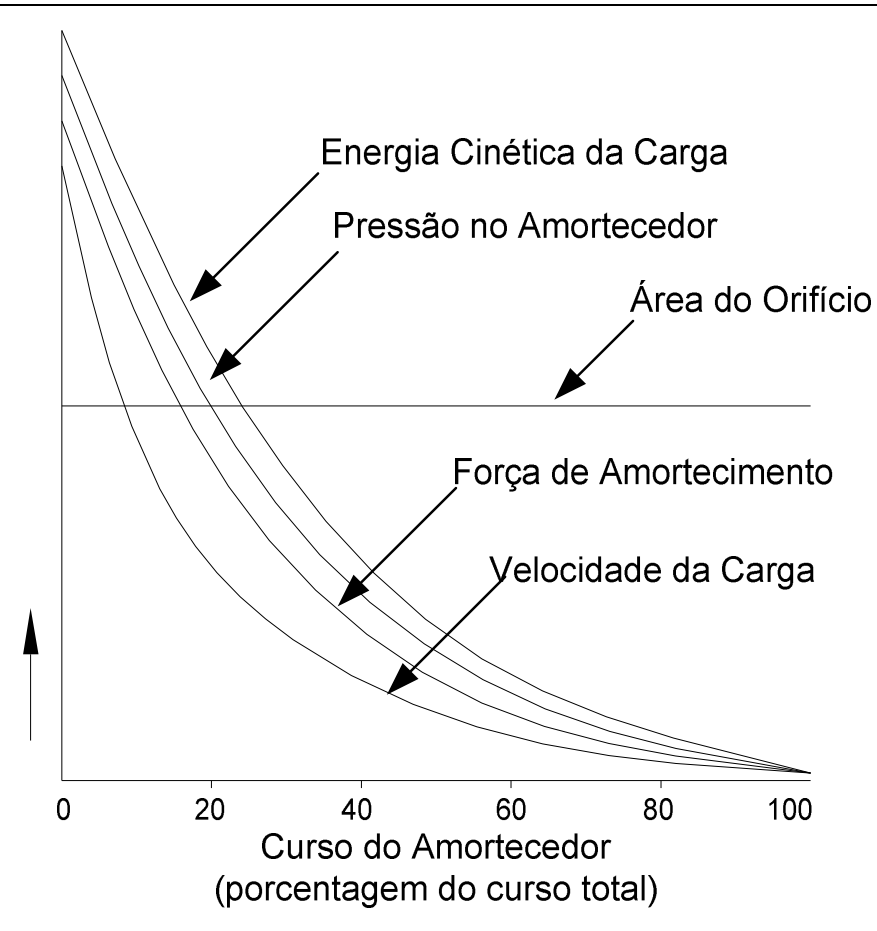

FIGURA 2.4 - Gráficos das características de operação para o amortecedor hidráulico do tipo orifício constante e pressão variável (ELLIS; KARBOWNICZEK, 1962)

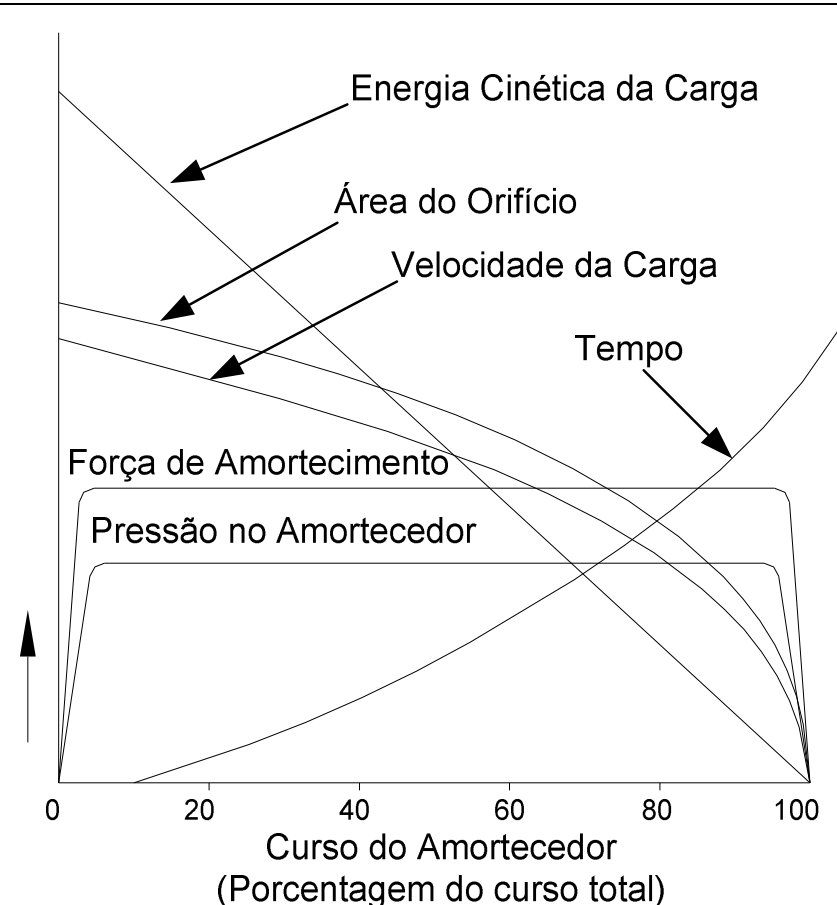

FIGURA 2.5 - Gráficos das características de operação para o amortecedor hidráulico do tipo orifício variável e pressão constante (ELLIS; KARBOWNICZEK, 1962)). 
Na FIGURA 2.1 pode se ver que a maior parte da energia cinética da carga é gasta durante a parte inicial do curso do amortecedor, portanto, ela não decai uniformemente. Já no amortecedor hidráulico de orifício variável e pressão constante, a energia cinética decai uniformemente durante o curso do amortecedor, como pode ser observado nos gráficos da FIGURA 2.2, conseqüentemente, a desaceleração da carga, a pressão interna do amortecedor e a força de amortecimento são uniformes. Ellis eKarbowniczek (1962) mostrou alguns tipos de amortecedores do tipo orifício variável e pressão constante. As figuras 2.3 e 2.4 mostram esses amortecedores que fazem variar a área do orifício devido à inserção de um pino no orifício, durante a inserção da haste para dentro do amortecedor quando o mesmo é submetido a uma força que causa velocidade relativa entre suas extremidades.

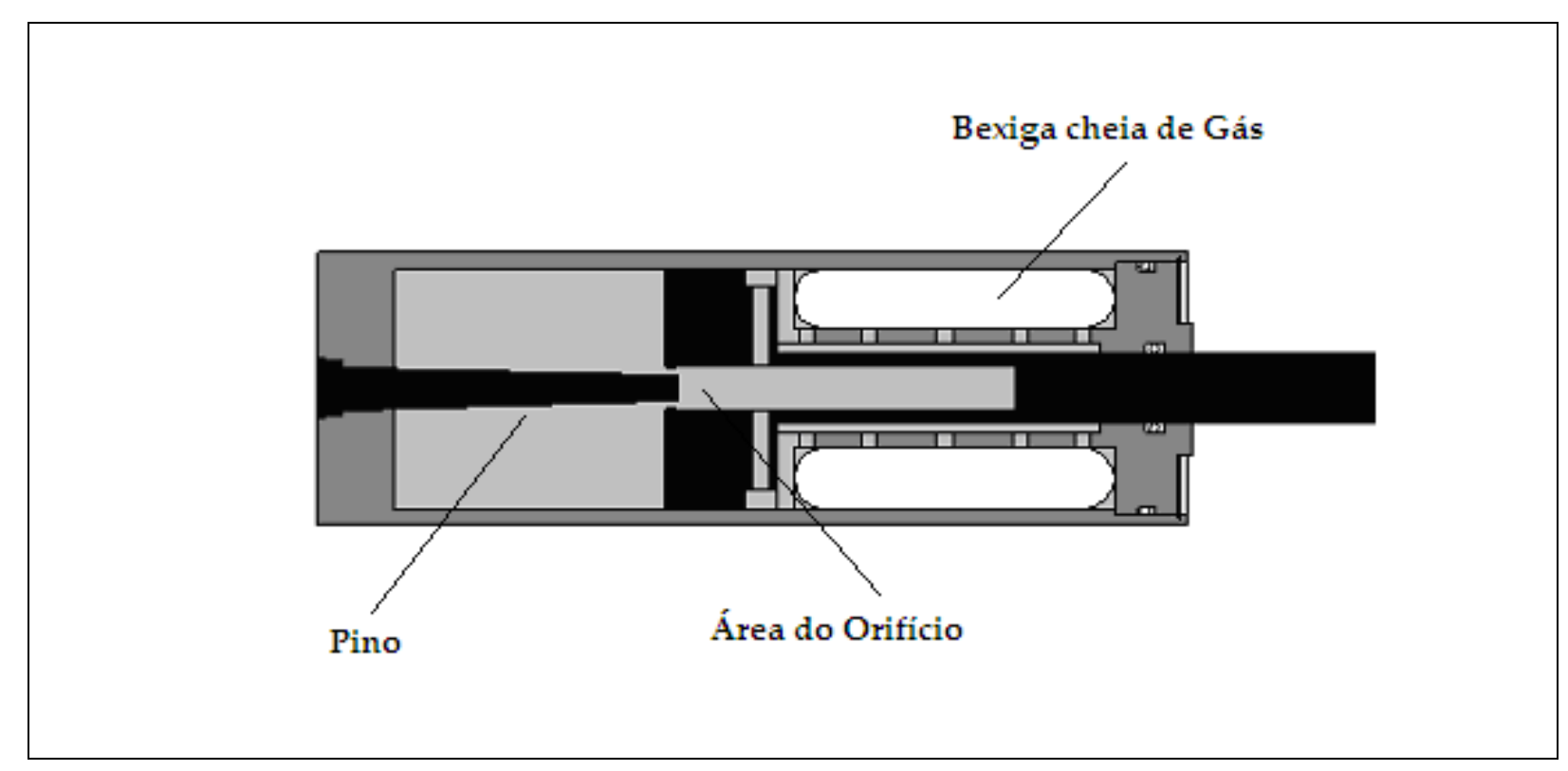

FIGURA 2.6 - Amortecedor de orifício variável com pino cônico (ELLIS; KARBOWNICZEK, 1962). 


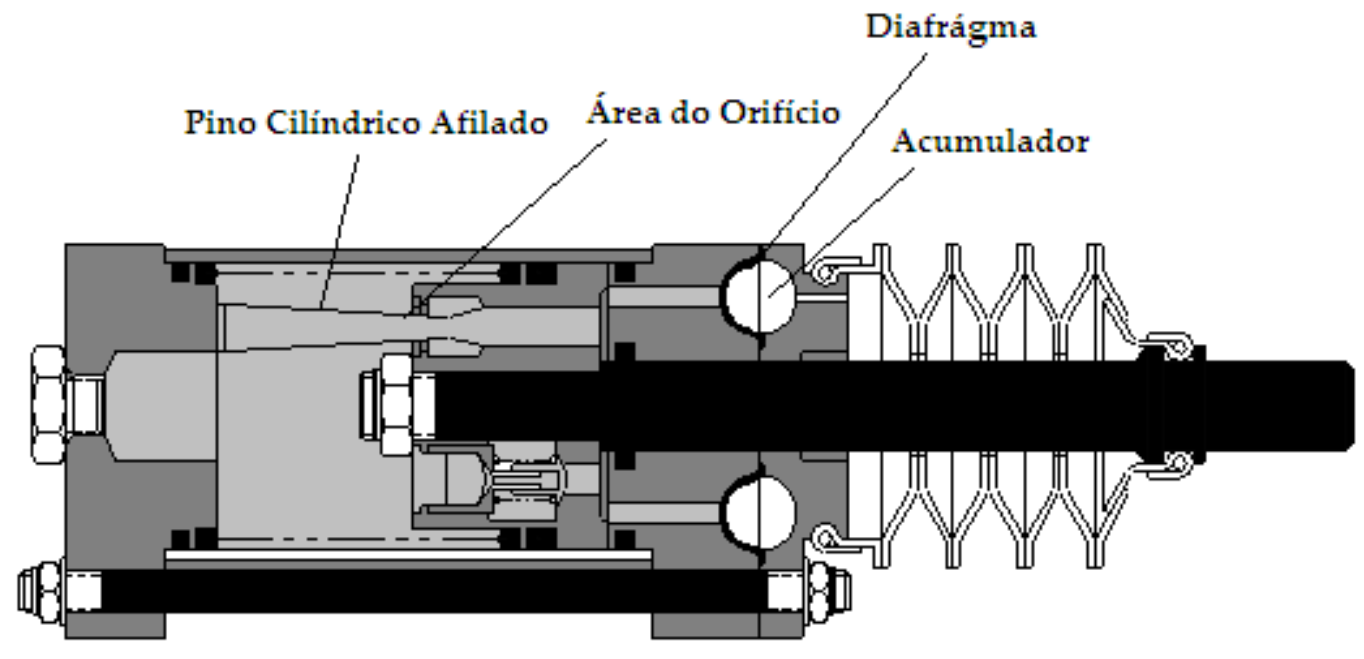

FIGURA 2.7 - Amortecedor de pino cilíndrico afilado para produzir orifício de área orifício variável (ELLIS; KARBOWNICZEK, 1962).

A FIGURA 2.5 traz um amortecedor do tipo orifício variável que conta com um pino oco (com cavidade interna) com orifícios distribuídos ao longo da cavidade (ELLIS; KARBOWNICZEK, 1962).

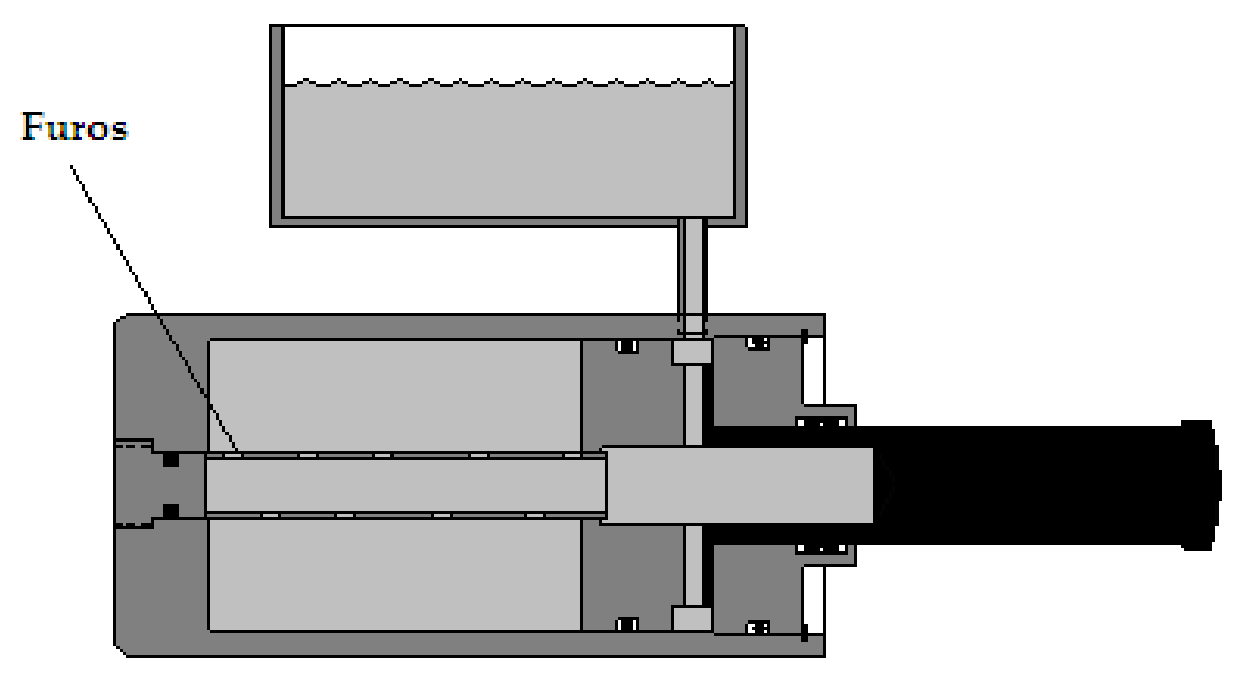

FIGURA 2.8 - Amortecedor com pino e cavidade interna com orifícios distribuídos ao longo de sua cavidade para produzir orifício de área variável (ELLIS,1962). 
Uma variação do amortecedor da FIGURA 2.5 é o amortecedor para produzir orifício de área variável com um cilindro pressurizado interno e com vários furos em suas paredes, por onde o fluído é forçado a passar quando há a inserção da haste para dentro do amortecedor. Essa configuração de amortecedor pode ser vista na FIGURA 2.6.

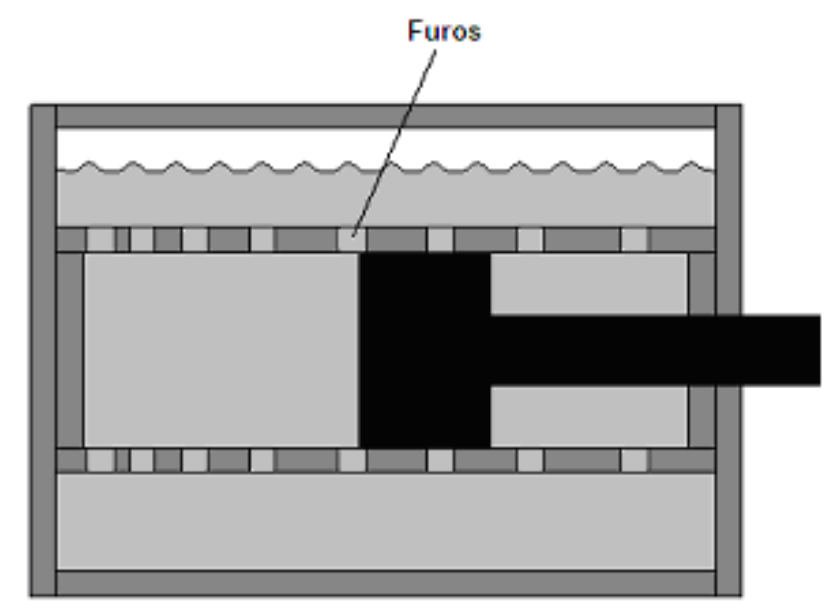

FIGURA 2.9 - Amortecedor com cilindro interno cheio de furos para produz orifício de área variável (ELLIS; KARBOWNICZEK, 1962).

Esse arranjo faz com que a área total do orifício seja reduzida assim que o pistão se aproxima do fim de seu curso. Os furos podem ser igualmente espaçados ao longo do comprimento do tubo, com os seus diâmetros aumentando em direção ao fim de curso ou podem ser todos do mesmo diâmetro, mas com o espaço entre eles diminuindo conforme se aproxima o fim do curso do amortecedor. Um outro tipo de amortecedor de orifício variável apresentado por Ellis (1962) é o projetado com a parede interna do cilindro côncava. Na FIGURA 2.7 pode ser observado este tipo de amortecedor. 


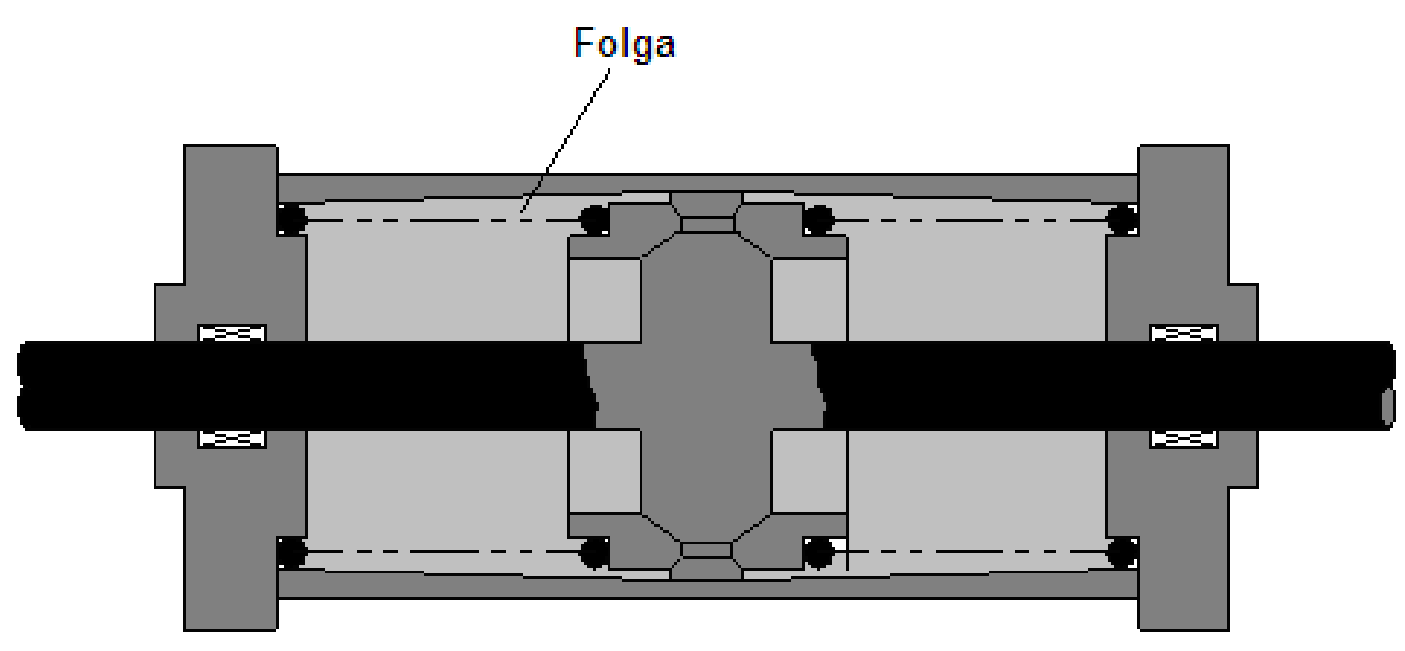

FIGURA 2.10 - Amortecedor de dupla haste com parede interna do cilindro em formato côncavo (ELLIS; KARBOWNICZEK, 1962)2).

O autor cita como principais vantagens do amortecedor da FIGURA 2.7 a sua simplicidade de projeto e a não necessidade de um acabamento superficial bem liso da parede internas do cilindro, contudo o pistão precisa de um segundo ponto de apoio por ser de dupla haste.

Ellis e Karbowniczek (1962) também apresenta um outro tipo de amortecedor de orifício variável que pode ver visto na FIGURA 2.8.

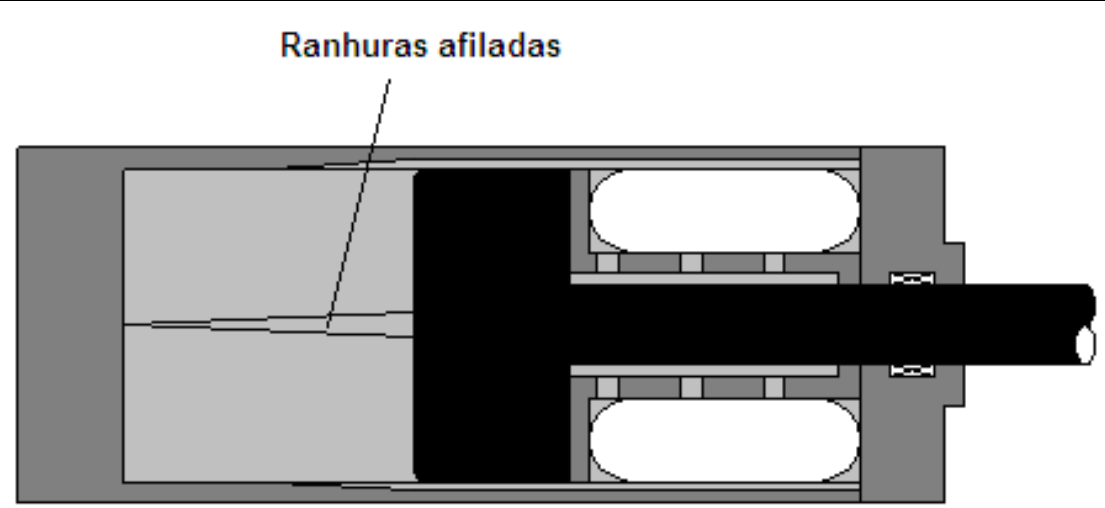

FIGURA 2.11 - Amortecedor com a parede interna do cilindro com ranhuras côncavas produzindo variação da área do orifício (ELLIS; KARBOWNICZEK, 1962). 
O amortecedor da FIGURA 2.8 tem a parede interna do cilindro com ranhuras usinadas longitudinalmente. Essas ranhuras possuem afilamento com abertura máxima no inicio do curso do pistão do que no fim de curso. O autor cita a dificuldades de usinagem das ranhuras como dificuldade construtiva deste tipo de amortecedor.

O último tipo de amortecedor que faz variar a área do orifício apresentado por Ellis (1962) é o amortecedor com entalhes em sua parede interna, que é uma variação do amortecedor da FIGURA 2.8. Este amortecedor pode ser visto na FIGURA 2.9.

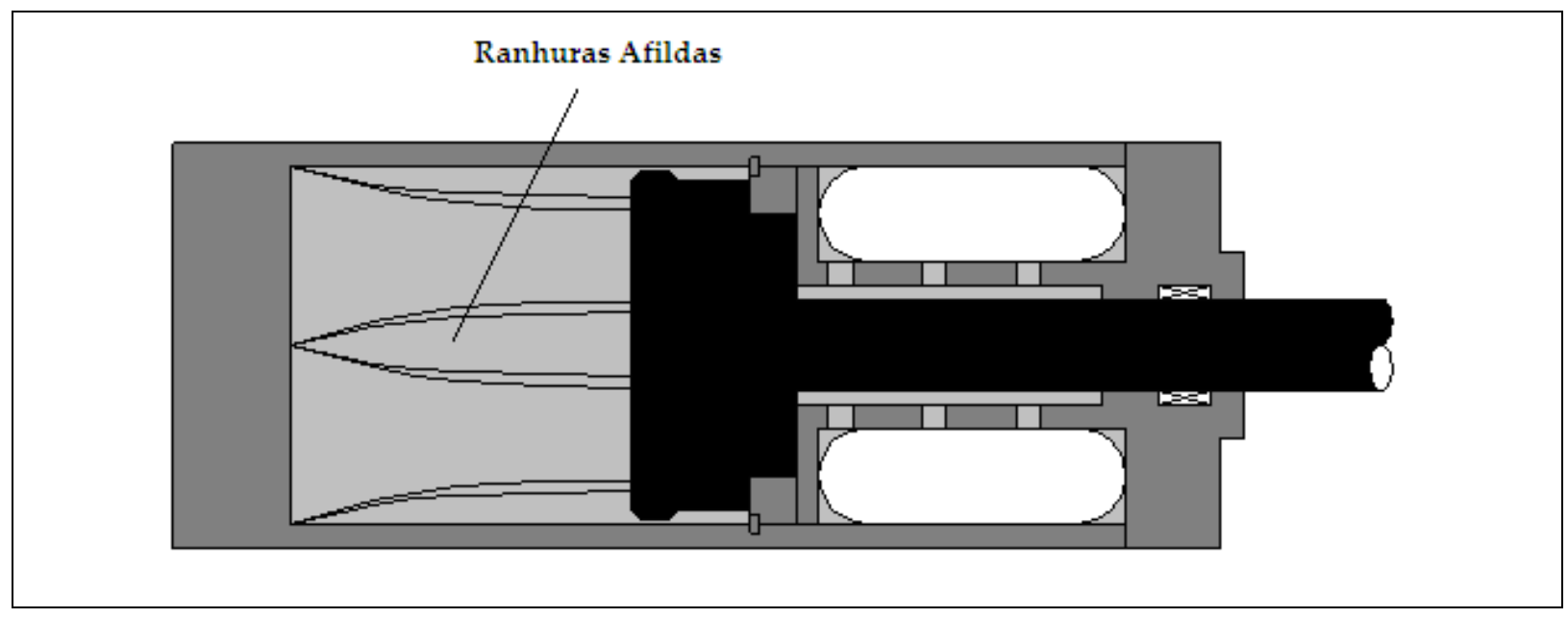

FIGURA 2.12 - Amortecedor com entalhes em sua parede interna para provocar variação de área do orifício (ELLIS; KARBOWNICZEK, 1962).

Ellis e Karbowniczek (1962) também apresenta um amortecedor de orifícios de área constante. Esse amortecedor pode ser visto nas FIGURAS 2.10. 


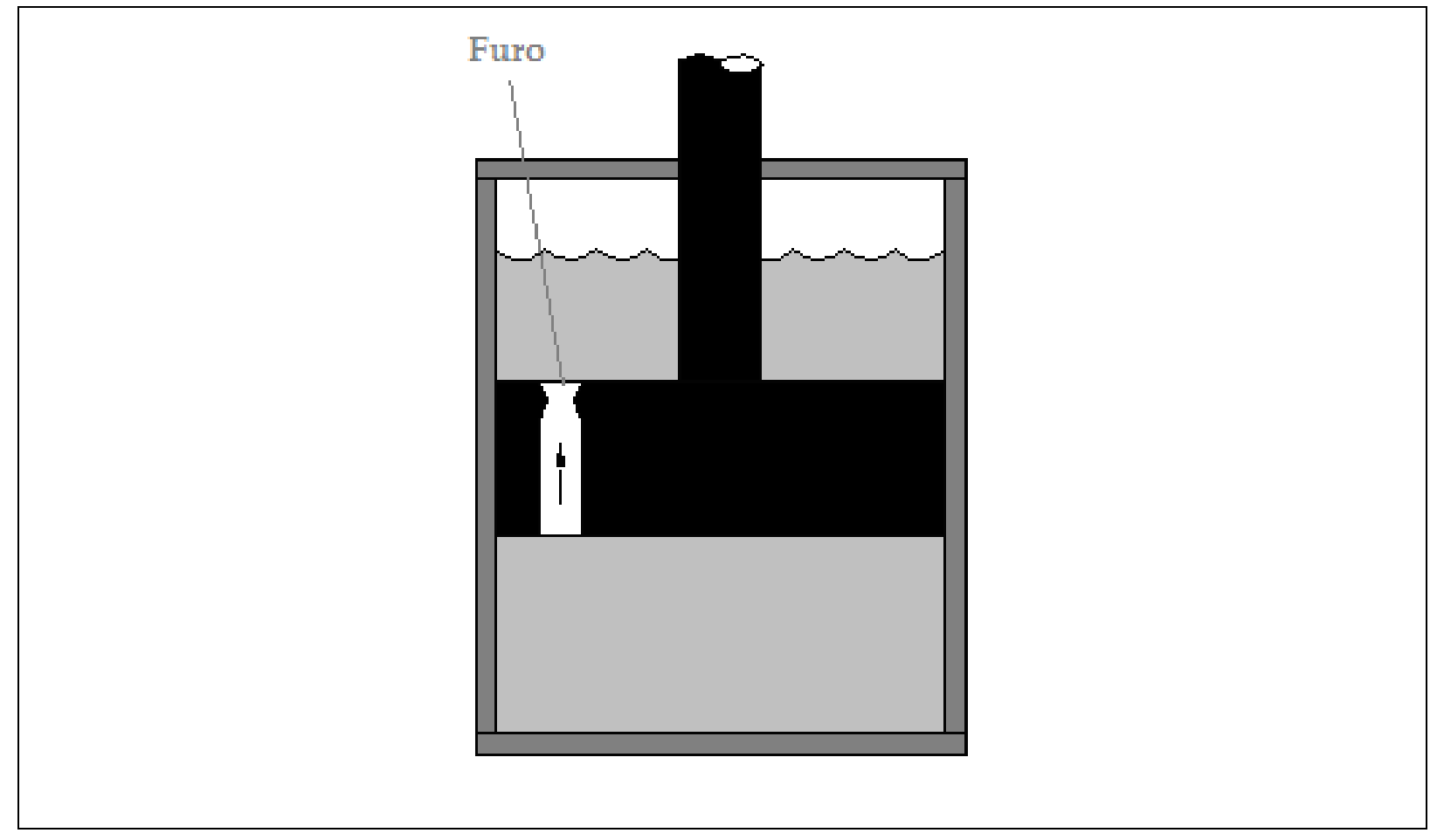

FIGURA 2.13 - Amortecedor de orifício de área constante (ELLIS; KARBOWNICZEK, 1962)

A FIGURA 2.10 traz um amortecedor bem simples que produz o efeito de amortecimento quando o fluído é forçado a passar de um lado para o outro pelo orifício no pistão. Uma outra forma de se obter um amortecedor de orifício de área constante bem simples é construindo um pistão com folga radial entre o cilindro e o pistão que permita que o fluído passe entre a parede interna do cilindro e o pistão.

Audenino e Belingardi (1995) modelaram um amortecedor do tipo duplo tubo, usado em motocicleta e validaram o modelo, pois obtiveram através dele uma boa concordância com os dados experimentais obtidos através de testes em laboratório. O artigo dos dois pesquisadores analisava modelos matemáticos, sempre aumentando sua complexidade que representavam o fenômeno de vazão pressão que ocorria dentro do amortecedor. 


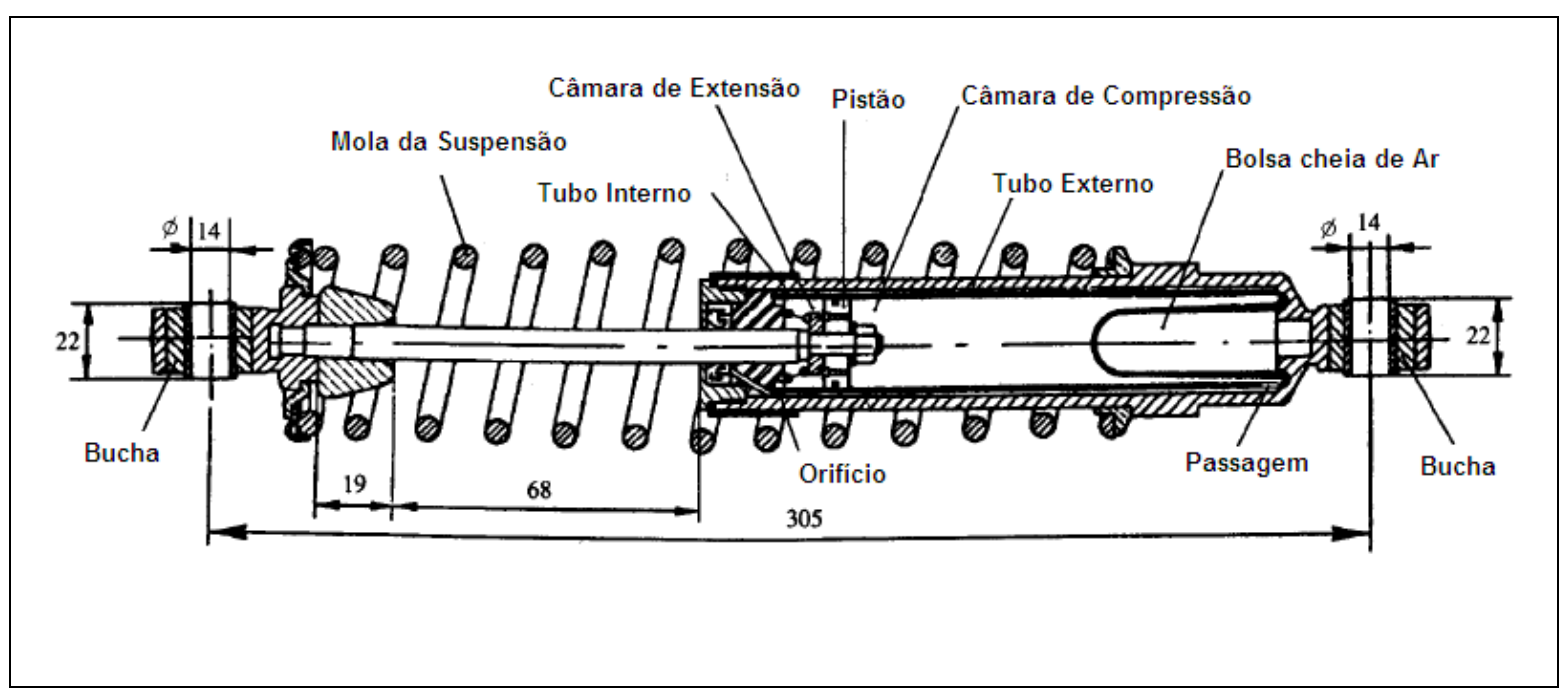

FIGURA 2.14 - Componente da suspensão de motocicleta mostrando o amortecedor estudado por Audenino e Belingardi (1995)

Os modelos matemáticos foram simulados através do método de diferenças finitas. Os testes em laboratório foram realizados com o amortecedor cheio de óleo, cheio de água e cheio de ar. A influência da amplitude e da freqüência da excitação senoidal assim como a influência da densidade e viscosidade do fluido e também do atrito foram investigados. $\mathrm{O}$ amortecedor foi montado em um shaker eletrodinâmico que era controlado por um acelerômetro enquanto o histórico no tempo das variáveis de entradas e da força de saída eram adquiridas por meio de três sensores e um sistema de aquisição de dados de três canais, sendo tudo armazenado em um computador. Uma célula de carga do tipo strain-gauge media a força de saída do amortecedor. Um vibrômetro a laser tipo Doppler media a velocidade de excitação da mesa do shaker e um LVDT (transformador diferencial de voltagem linear) media o deslocamento da mesa do shaker. Na FIGURA 2.12 pode ser visto o arranjo experimental realizado pelos pesquisadores. 


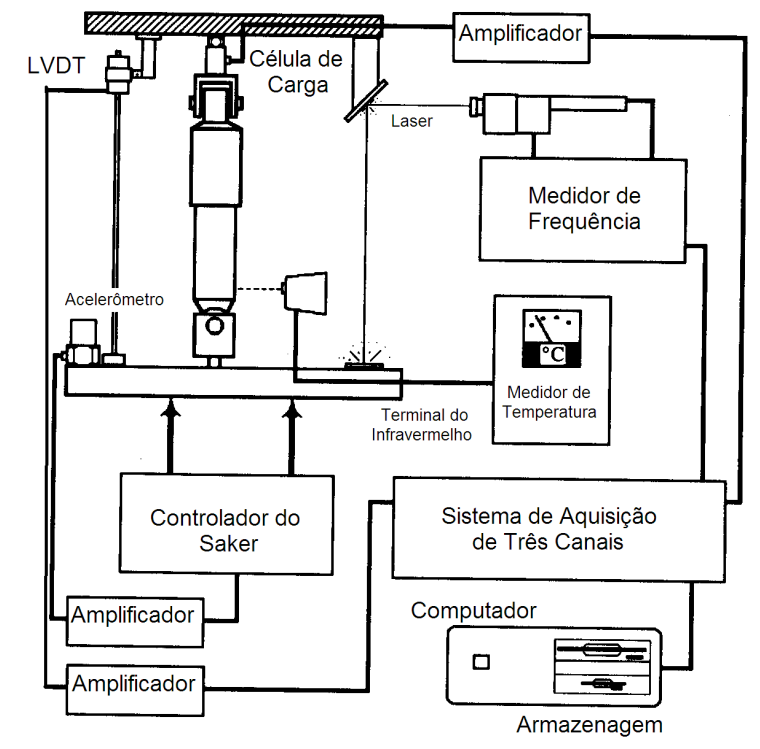

FIGURA 2.15 - Arranjo dos testes realizados por Audenino e Belingardi (1995)

Segundo Audenino e Belingardi (1995), com relação à resposta a excitação senoidal, um laço algumas vezes impropriamente chamado de histerese, foi medido no diagrama de força versus velocidade. Eles perceberam nesses diagramas que aumentando a freqüência de excitação faziam com que o laço aumentasse em magnitude e concluíram que este fenômeno claramente significava que a força não estava perfeitamente em fase com a velocidade e que o amortecedor não se comportava somente como um dispositivo de amortecimento, mas também armazenava energia elástica. Esse fenômeno pode ser observado pelos diagramas de força versus velocidade da FIGURA 2.13. Os autores ainda observaram que a influência da amplitude de excitação era considerável para uma mesma freqüência na forma do ciclo, particularmente no diagrama de força versus velocidade. Ainda, os autores perceberam que o efeito do atrito era evidente para pequenas amplitudes de excitação e que progressivamente ia desaparecendo conforme a amplitude ia aumentando e ainda que quanto maior a freqüência menor era a força de saída para um ponto de velocidade máxima. 


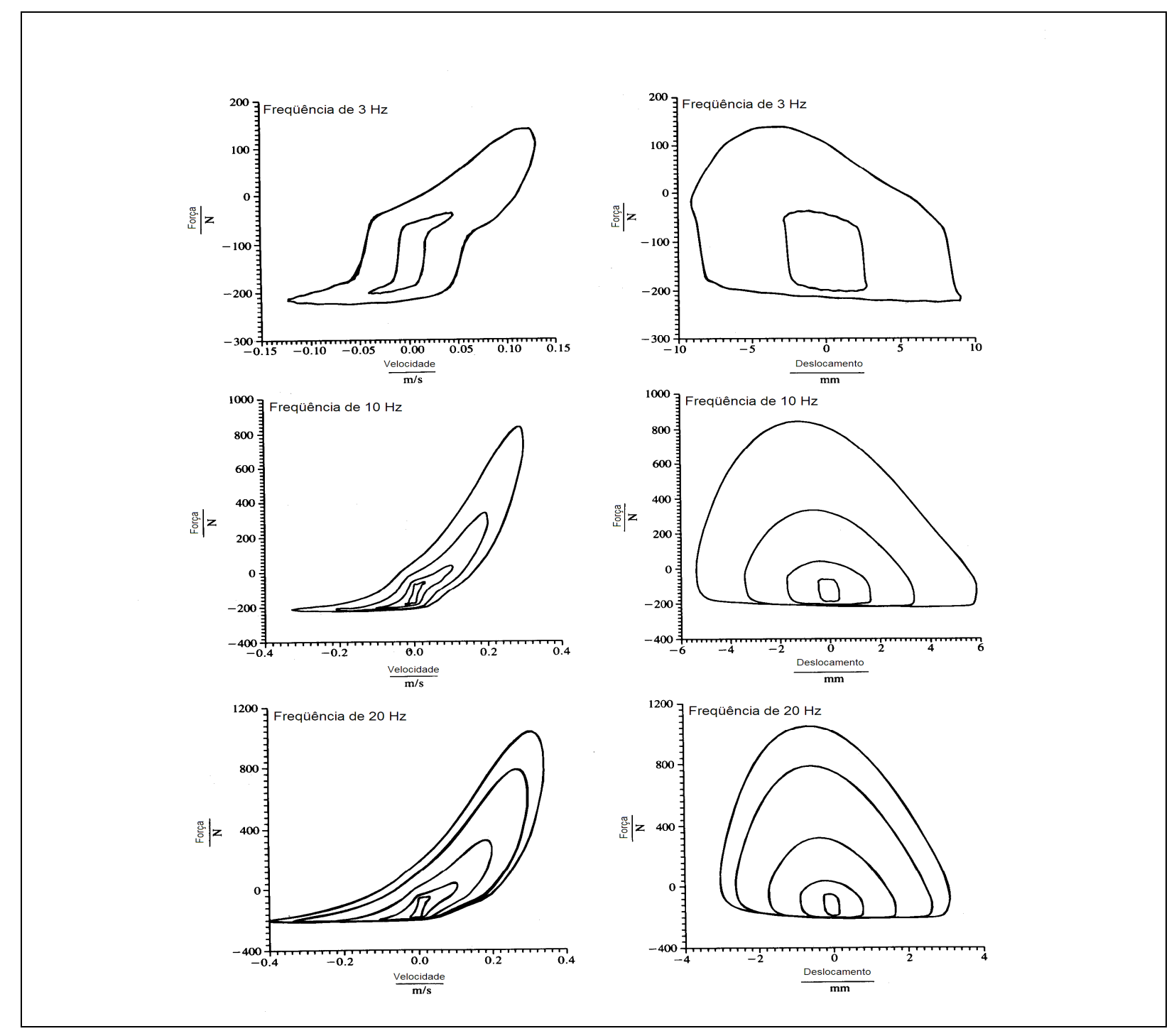

FIGURA 2.16 - Diagramas de forças versus velocidade e força versus deslocamento Experimentais obtidos pelo amortecedor de motocicleta de Audenino e Belingardi (1995) para três níveis de excitação $(3,10$ e $20 \mathrm{~Hz})$

Molica (1997), também modelou um amortecedor automotivo, porém do tipo monotubo de alta pressão. Ele utilizou a técnica do "bond graph" (grafo de ligação), que emprega os princípios físicos que descreve a dinâmica dos elementos. Ele utilizou o programa Matlab para integrar as equações não-lineares de estado e comparou com os dados de teste do sistema real. Conclusões foram tiradas com relação a acuracidade do modelo de simulação, da dinâmica dos amortecedores automotivos em geral, e do papel dos modelos baseados nos 
princípios físicos. Na FIGURA 2.14 pode-se ver o desenho esquemático do amortecedor modelado por Molica (1997).

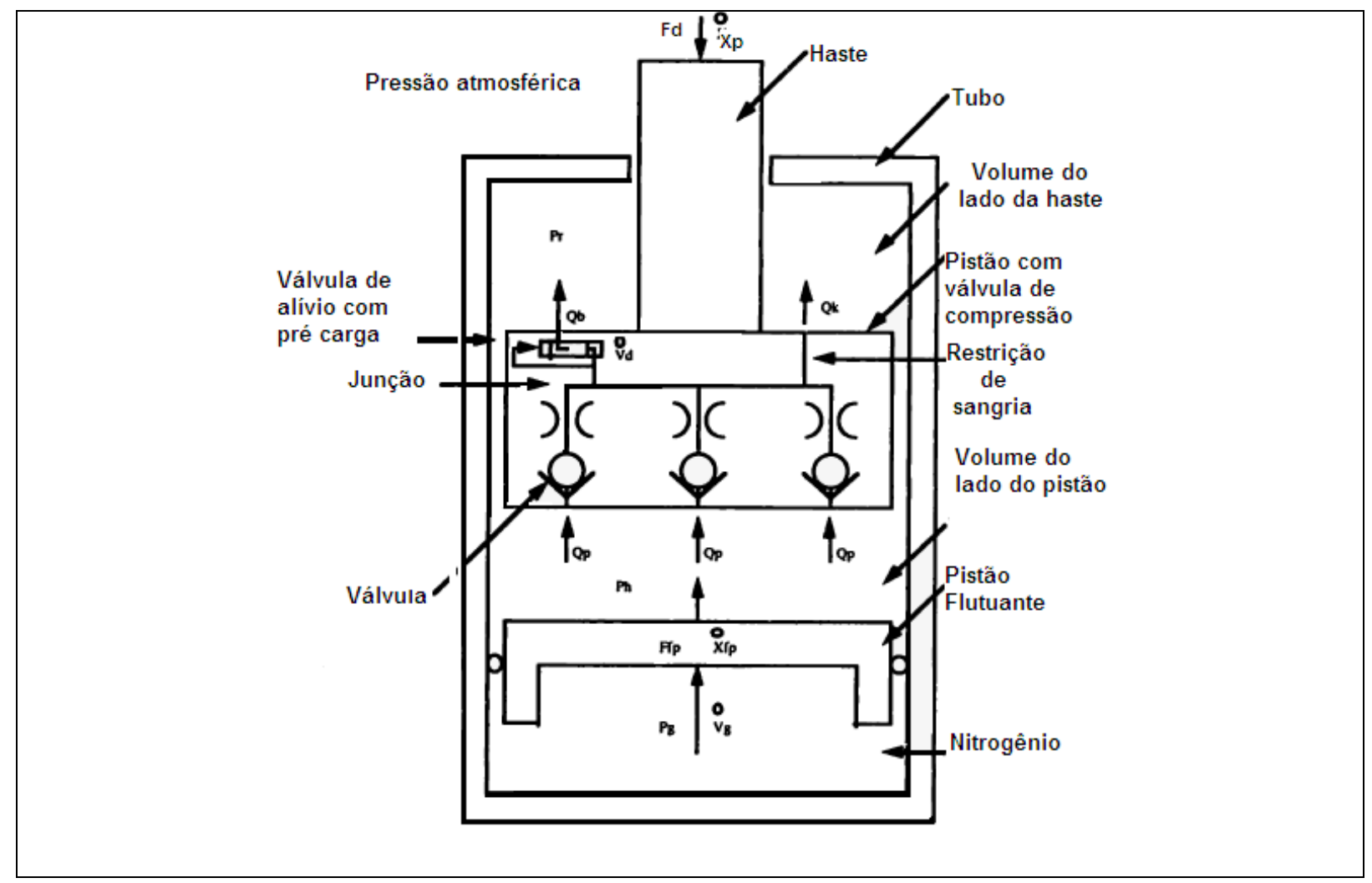

FIGURA 2.17 - Desenho esquemático do amortecedor de tubo simples modelado por Molica (1997).

Detalhando a análise de Molica (1997), ele obteve oito equações de estado para simular a dinâmica do amortecedor. O modelo continha todos os elementos necessários para caracterizar o comportamento dinâmico desse sistema de amortecimento. Os volumes de fluído, as molas das válvulas e o reservatório de gás eram os dispositivos de armazenamento de energia cinética que na notação do grafo de ligação são conhecidos como capacitores. As massas do pistão, do pistão flutuante e do tubo, bem como a inércias fluídicas da vazão através do pistão eram elementos de armazenamento de energia potencial. Os orifícios dentro e em volta do pistão e as interfaces entre superfícies de borracha foram considerados resistores que dissipavam energia durante o movimento. As vazões de vazamento do pistão e 
através do pistão foram calculadas pelos coeficientes de perda baseados no número de Reynolds para considerar tanto o regime laminar quanto o regime turbulento. As equações de estado juntavam os elementos fluídicos, mecânicos e termodinâmicos necessários para produzirem o comportamento não-linear caracterizado por ciclos de histerese dependentes da freqüência, observados mos diagramas de força versus velocidade e força versus deslocamento. O pesquisador concluiu que a interação entre os elementos resistivos e capacitivos, no amortecedor, é responsável pela dependência da freqüência da histerese nos diagramas característicos de força versus velocidade. Segundo o pesquisador, a interação das relações não-lineares enumeradas abaixo causa o fenômeno da histerese:

- a compressibilidade efetiva do fluido, do tubo e do ar infiltrado;

- a compressibilidade do volume de nitrogênio;

- a compressibilidade devido à pré carga em certas válvulas;

- o efeito resistivo do fluido através dos orifícios do pistão;

- o atrito que age no pistão flutuante;

Segundo Molica (1997), o amortecedor para altas frequiências e grandes deslocamentos comporta-se como uma mola, ou seja, em termos dos elementos dos grafos de ligação comportam-se como um capacitor. Ainda, ele observou que a força de atrito que age no pistão flutuante causa histerese próximo a região de velocidade zero.

Patten et al (1998), modelou, baseando-se no comportamento fluido dinâmico, um amortecedor hidráulico semi-ativo (Semiactive Vibration Absorber - SAVA) projetado para atenuar vibrações de estruturas sujeitas a terremotos, ação da força do vento e de tráfego de veículo, entre outros distúrbios. A FIGURA 2.15 mostra o SAVA de Patten et al (1998). 


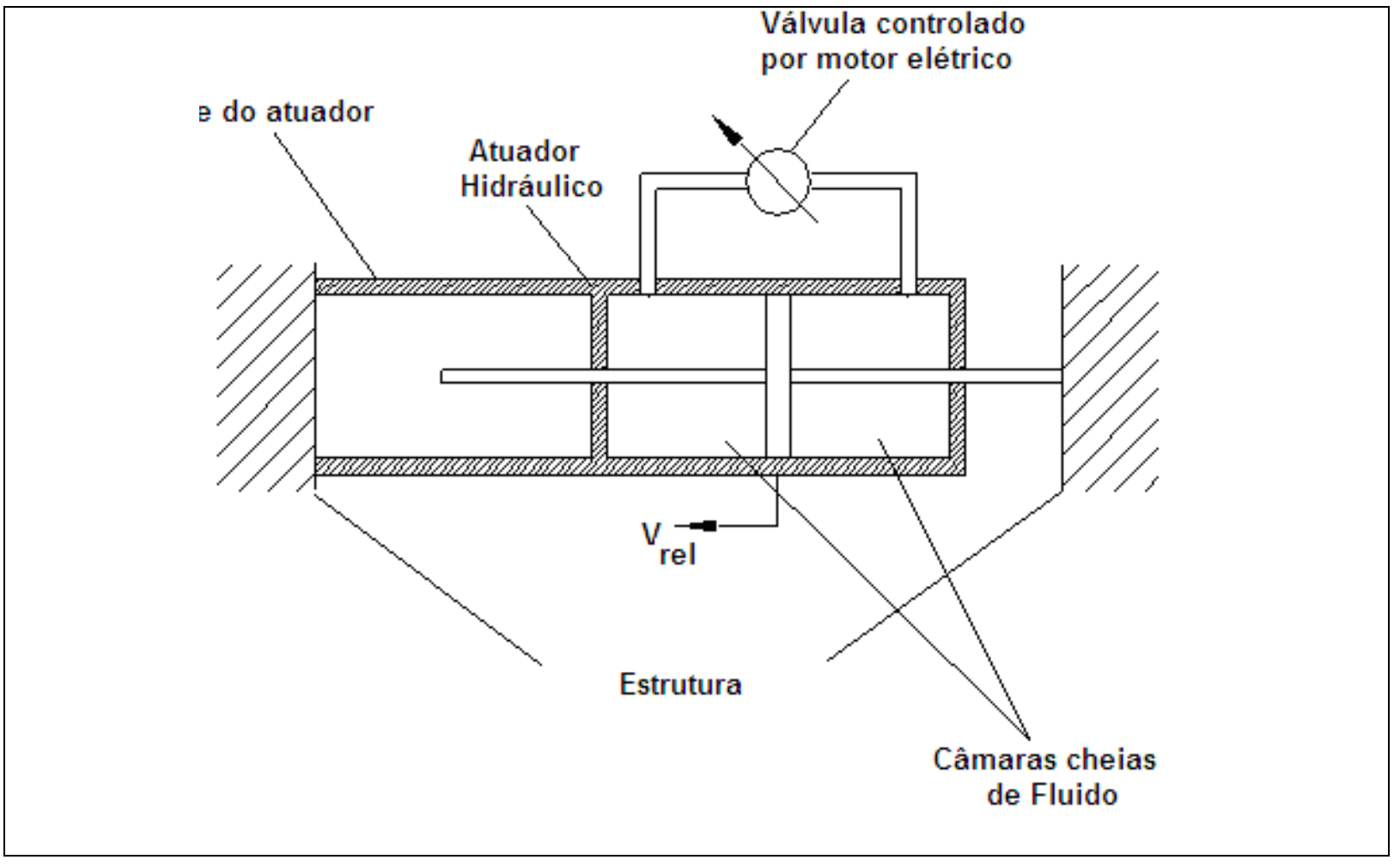

FIGURA 2.18 - Desenho esquemático do amortecedor hidráulico semi-ativo (SAVA) de Patten et al (1998).

Como pode ser observado na FIGURA 2.15, o SAVA é composto por um atuador hidráulico que tem a sua base engastada na estrutura que se deseja atenuar as vibrações. O atuador é composto por duas câmaras interligadas por um tubo, onde se encontra também uma válvula operada por um motor elétrico segundo uma estratégia de controle desenvolvida por Patten et al (1998). Quando a estrutura se move há um deslocamento de fluído de uma câmara para outra, devido a velocidade relativa $V_{\mathrm{Re} l}$. Esse fluído é forçado a passar de uma câmara para outro por esse tubo e pela válvula controlada. Com a variação da abertura da válvula, consegue-se variar o coeficiente de amortecimento sem a necessidade de modificação construtiva do dispositivo de amortecimento. A perda de carga, devido ao atrito viscoso do fluido quando é forçado a entrar pelo tubo e quando passa pela válvula, juntamente com o vazamento entre as câmaras causa o efeito desejado de amortecimento. 
Patten et al (1998), em seu trabalho também explica as vantagens e desvantagens dos sistemas passivos e ativos. Segundo eles, os sistemas passivos são mais úteis em projetos onde o conteúdo de freqüências e amplitudes da fonte de excitação não são bem definidos. Já os sistemas ativos podem ser robusto para uma ampla faixa do espectro da fonte excitação, porém, sistemas ativos requerem altos custos com manutenção e são bem mais caros que os passivos dentre outras desvantagens. Mas a característica mais restritiva dos sistemas ativos para uso em atenuação de estruturas é a necessidade de energia para funcionarem. Por exemplo, em um prédio sob ação de um terremoto há falta de energia no momento mais crítico. Em estruturas como pontes construídas em lugares remotos, onde não há linhas de transmissão de energia, a implantação de sistemas ativos de atenuação de vibrações também é inviável. As limitações dos sistemas ativos e passivos levaram pesquisadores a procura de um novo método de controle de estruturas. Os sistemas semi-ativos possuem a característica de variar a sua resposta (modificando a rigidez e o amortecimento do sistema) sem contar com linhas de transmissão de energia. Segundo Patten et al (1998), por definição, sistemas semiativos são aqueles que podem variar automaticamente suas características dinâmicas necessitando de nenhuma ou pouca energia, com relação a energia dissipada pela estrutura.

Patten et al (1998) concluíram, através de seus experimentos em laboratório, que o modelo desenvolvido por eles teve ótima concordância com os dados obtidos experimentalmente e que o SAVA é capaz tanto de armazenar energia elástica quanto dissipar energia do fluído, devido ao efeito de bulk modulus equivalente do sistema.

Davis et al (1994) modelaram, construíram e testaram um amortecedor passivo com amortecimento variável chamado $\mathrm{D}-$ Strut $^{\circledR}$. O amortecedor foi desenvolvido para amortecer vibrações de estruturas de veículos espaciais que estão sujeitos a variação de massa, por exemplo, devido à queima de combustível durante sua viagem, o que requer um dispositivo com amortecimento variável. Davis et al (1994) estudaram vários conceitos que podiam fazer 
variar o amortecimento de um amortecedor hidráulico passivo. O conceito de abertura anular cônica com abertura regulável foi o escolhido por ser um dispositivo de conceito mecânico simples e produzir uma ampla faixa de ajuste de amortecimento. Outro fator que levou os autores a escolherem este conceito de ajuste de amortecimento foi devido ao amortecedor (DStrut) poder operar com ou sem energia externa tendo a capacidade de manter a regulagem e continuar funcionando no caso de uma falha elétrica. Segundo Davis et al (1994), o motor elétrico convencional foi escolhido para variar o ajuste da abertura anular cônica devido:

- sua relativa simplicidade de implementação;

- manter sua posição mesmo na falta de energia;

- não necessitar de altas voltagens para funcionar;

- ter sido utilizado muitas vezes para uso espacial.

A FIGURA 2.16 mostra o corte transversal do amortecedor D-Strut.

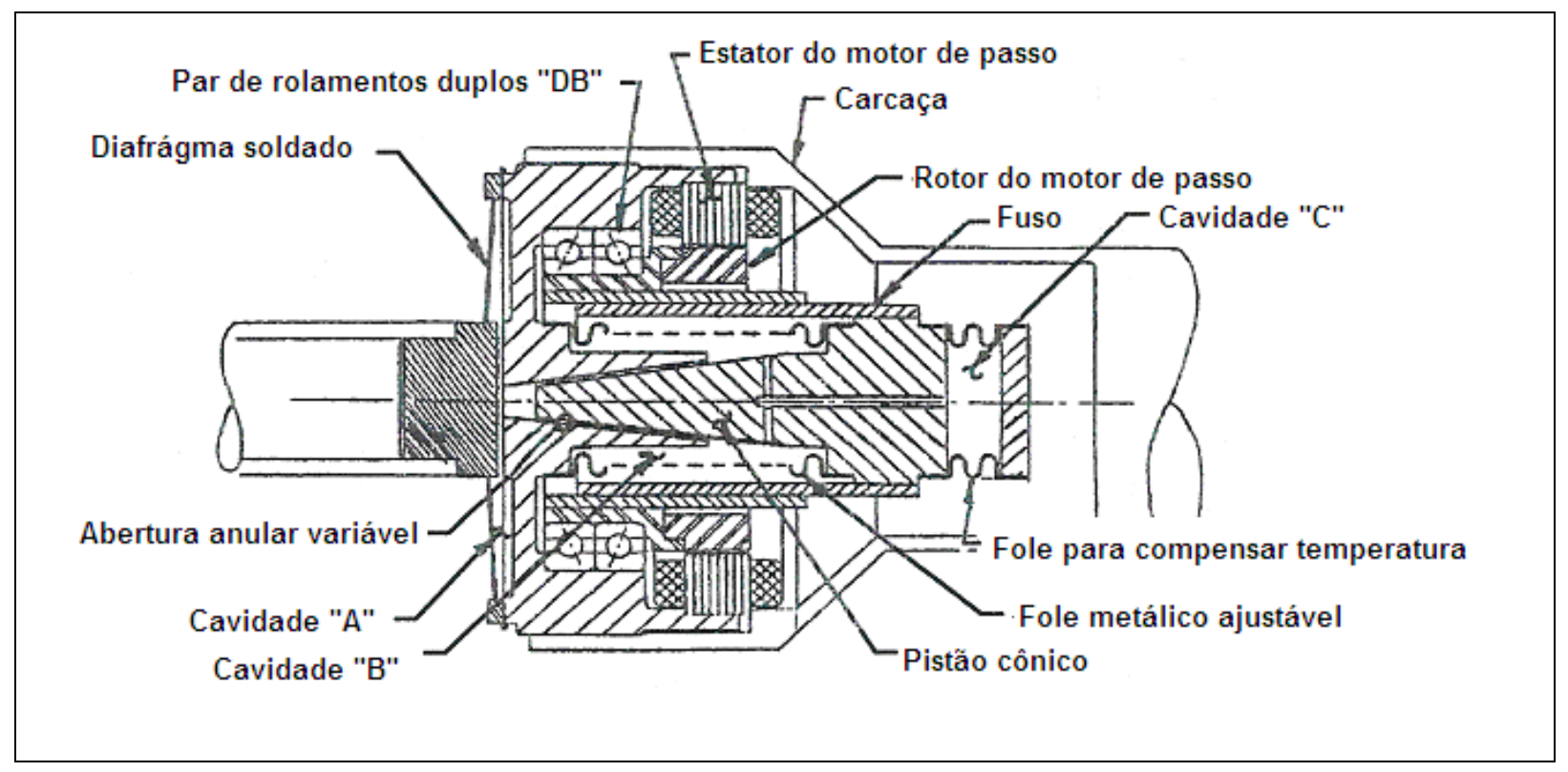

FIGURA 2.19 - Corte transversal do D-Strut (DAVIS et al, 1994).

O D-Strut possui duas cavidades metálicas (A e B) conectadas a um pequeno filamento anular. Essas cavidades são hermeticamente vedadas por um diafragma e por um 
fole metálico. $\mathrm{O}$ fole metálico é pressurizado internamente de tal forma que produz a pressão do fluido e também permite a expansão do fluido devido à variação de temperatura ambiente. Quando é submetido a um deslocamento relativo em relação as suas extremidades, o D-Strut força o fluido passar através do orifício anular, causando um cisalhamento do fluido. Esse cisalhamento produz a força de amortecimento e a dissipação da energia. A força de amortecimento é linearmente proporcional à velocidade relativa entre as duas extremidades do D-Strut. O motor elétrico é responsável por mover um fuso que também move um atuador auxiliar nas duas direções, mudando assim a área do orifício anular e conseqüentemente mudando o coeficiente de amortecimento do D-Strut (DAVIS et al, 1994).

Davis et al (1994) utilizou um modelo com três parâmetros para modelar o D-Strut que foi modelado como uma mola ideal em paralelo com um amortecedor e uma outra mola também ideais em série. Na FIGURA 2.17 podem ser vistas as curvas da resposta em freqüência deste modelo obtido pelos autores para o D-Strut. 


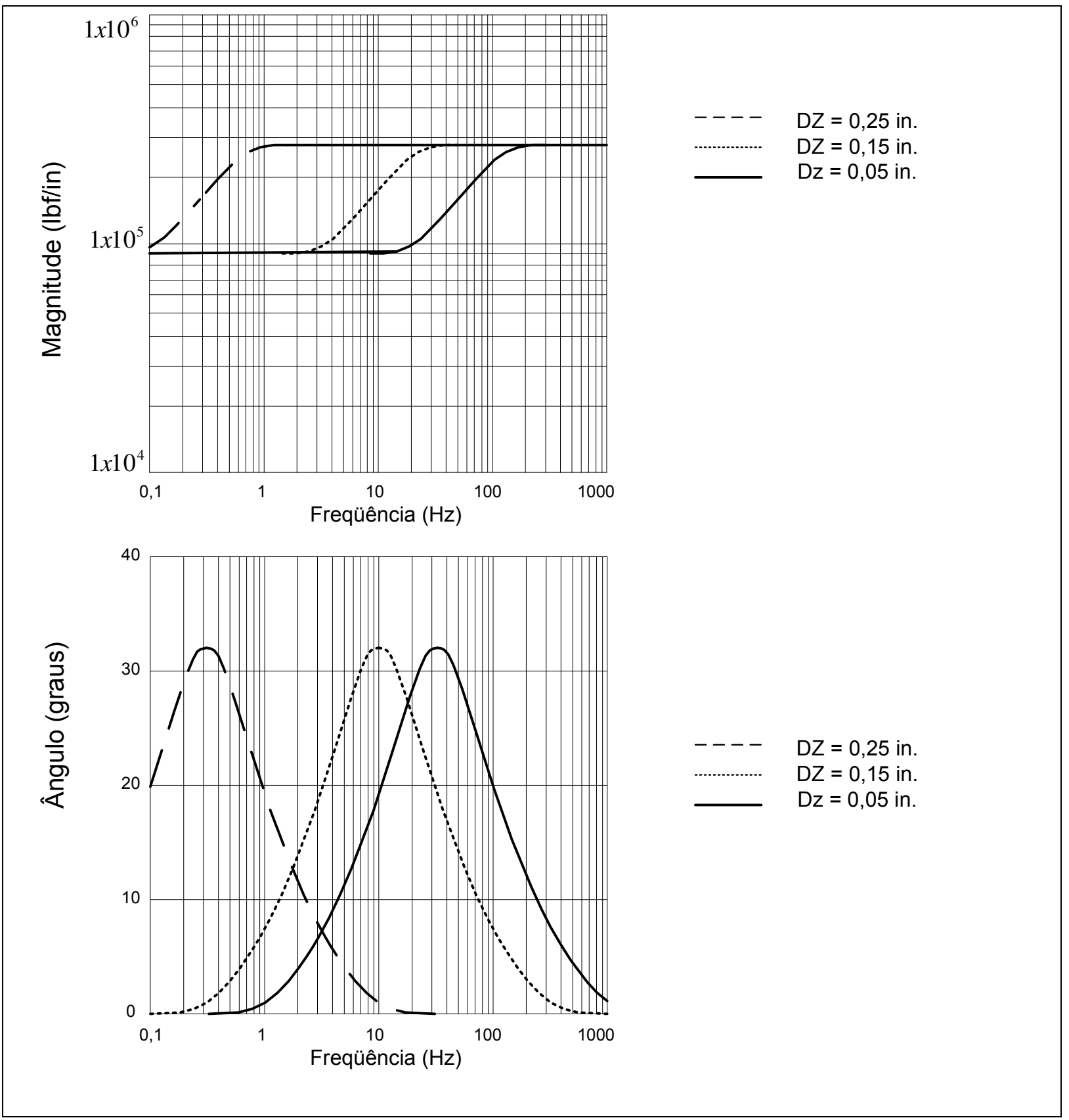

FIGURA 2.20 - Resposta em freqüência do modelo de três parâmetros do D-Strut (DAVIS et al, 1994)

Davis et al (1994) obtiveram as curvas da resposta em freqüência (o gráfico da magnitude, tendo a força com saída e deslocamento como entrada, e o gráfico da fase entre essa duas grandezas) para freqüências que variam de 0,1 a $1000 \mathrm{~Hz}$ para três ajustes de amortecimento DZ. 
A FIGURA 2.18 traz o esquema dos testes realizados no D-Strut.

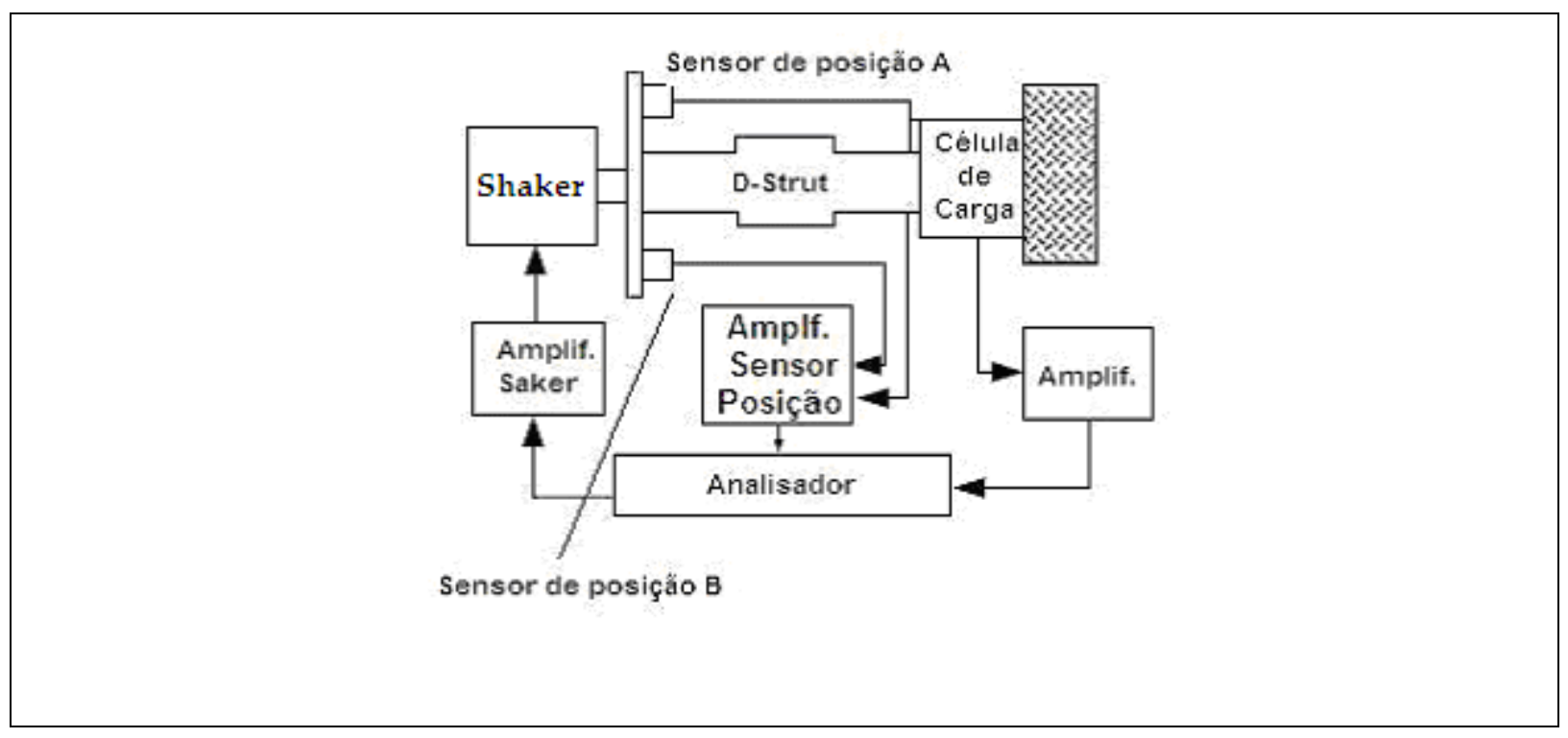

FIGURA 2.21 - Esquema dos testes realizados no D-Strut (DAVIS et al 1994).

Davis et (1994) montaram o D-Strut entre um shaker e um suporte rígido. A carga aplicada pelo shaker era medida por uma célula de carga. Dois sensores de posição mediam a translação axial do D-Strut. Um analisador de tempo real fornecia a excitação ao shaker e então computava a função de transferência entre a força medida e o deslocamento usando um software de FFT.

Davis et al (1994) comparou as curvas obtidas através dos testes realizados com o Dstrut com as curvas do modelo desenvolvido por eles e constatou uma ótima concordância entre elas.

Outro tipo de amortecedor que possui uma ampla aplicação e vem sendo muito estudado por pesquisadores são aqueles que utilizam fluídos controláveis, que são os constituídos por fluídos do tipo eletro-reológico (ou simplesmente ER) e magneto-reológico (ou simplesmente MR). Esses tipos de amortecedores são considerados amortecedores semiativos, pois podem variar o amortecimento utilizando pouca energia.

Segundo Wang e Gordaninejad (2001), amortecedores com fluido ER e MR podem variar rapidamente o amortecimento com a variação do campo elétrico ou campo magnético, 
respectivamente, pois esses fluídos mudam sua viscosidade passando do estado liquido para pastoso em apenas alguns milisegundos. Isto garante uma ampla faixa de força amortecimento.

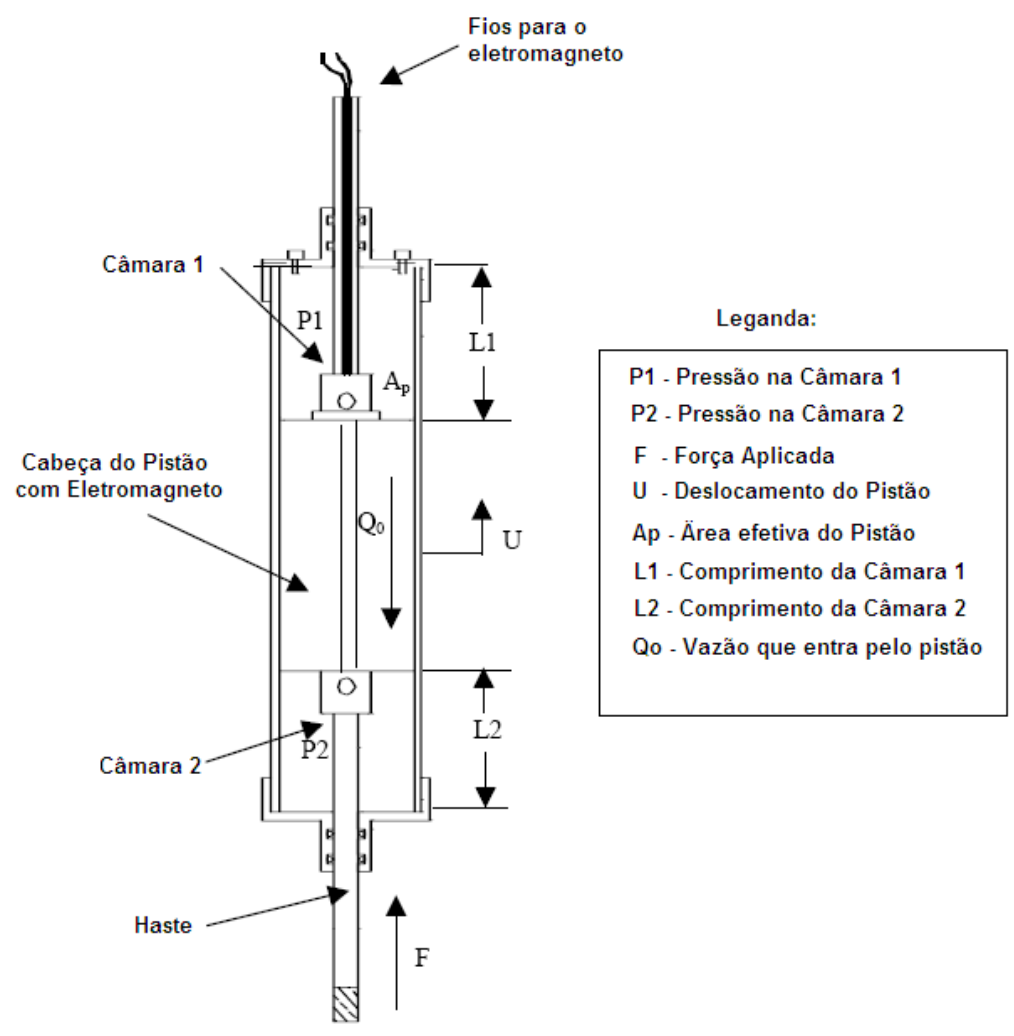

FIGURA 2.22 - Desenho esquemático do protótipo de amortecedor MR estudado por Wang e Gordaninejad (2001).

Segundo Spencer et al (1996), os dispositivos semi-ativos tem recebido significantiva atenção recentemente por oferecer a adaptabilidade dos dispositivos ativos sem necessitarem de uma fonte robusta de energia para fazê-los funcionar. Eles definem dispositivos semiativos como sendo dispositivos que possuem propriedade que podem ser ajustadas em tempo real oferecendo pouca energia ao sistema que se deseja controlar. Os pesquisadores 
modelaram e simularam um amortecedor do tipo MR, empregado na atenuação de vibrações em estruturas de engenharia civil como prédios e pontes.

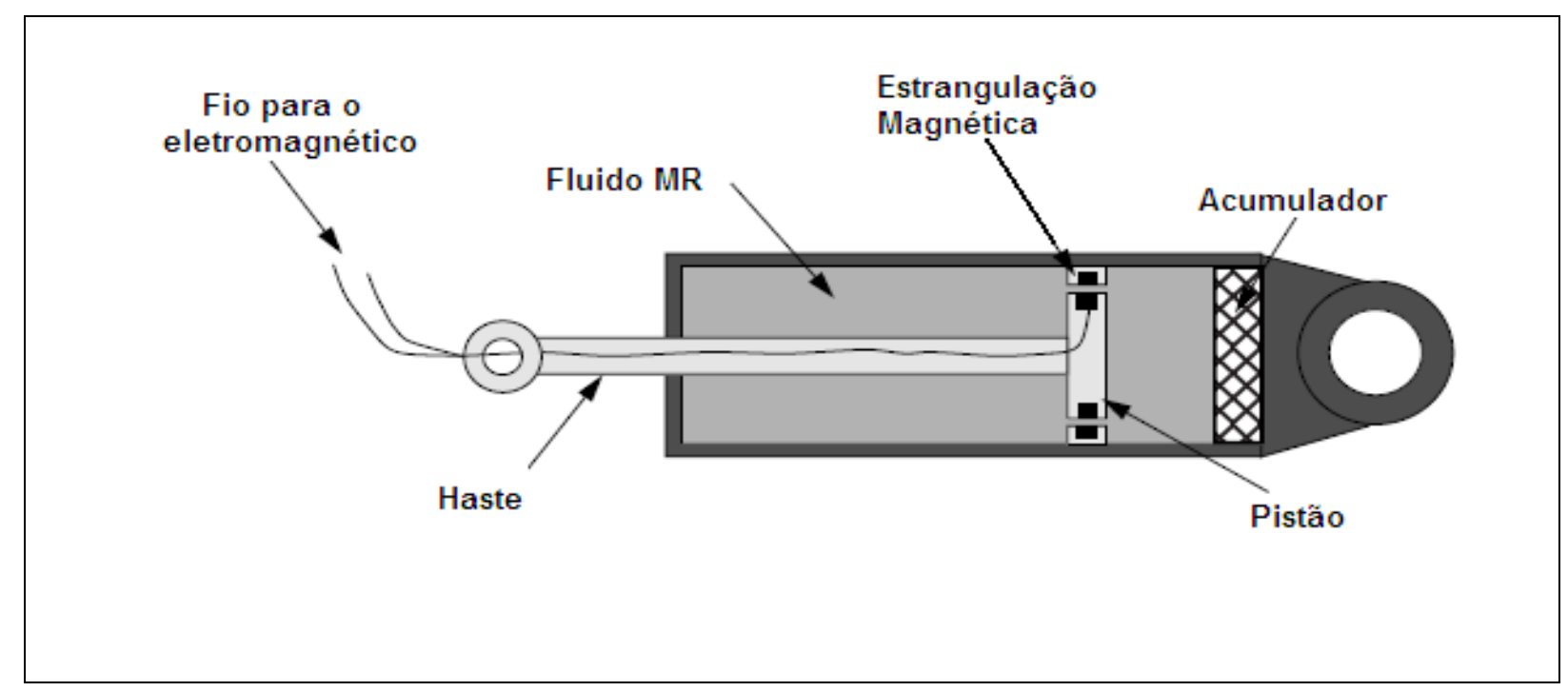

FIGURA 2.23 - Desenho esquemático do amortecedor MR de Spencer et al (1996).

A FIGURA 2.21 mostra o esquema da bancada usada para ensaiar o amortecedor estudado por Spencer et al (1996).

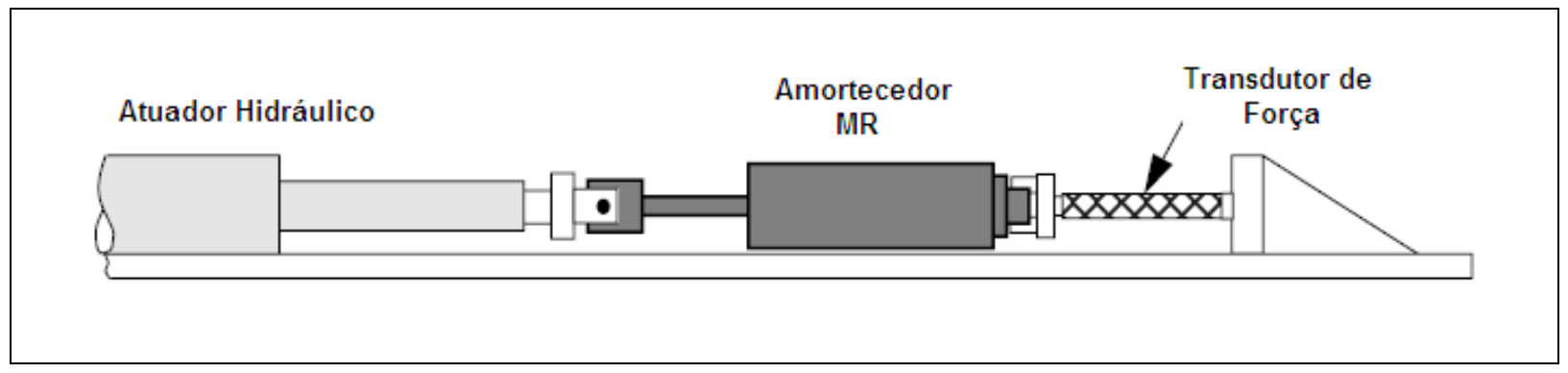

FIGURA 2.24 - Arranjo de teste do amortecedor MR de Spencer et al (1996).

Na FIGURA 2.22 pode-se notar os efeitos das mudanças no campo magnético do amortecedor com fluido MR. 


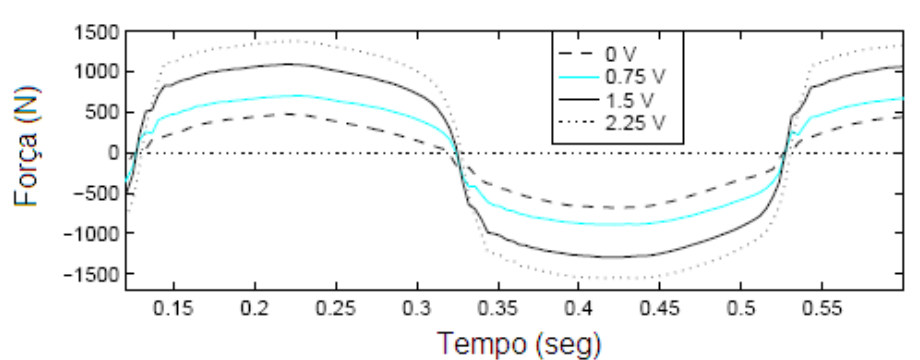

a) Força versus Tempo

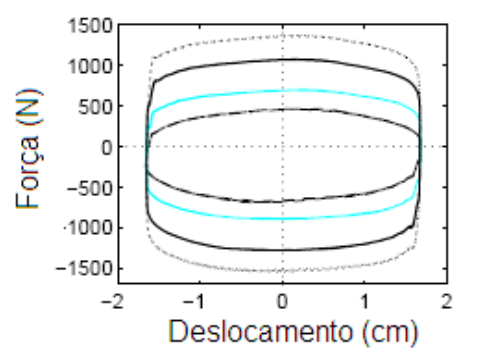

b) Força versus Deslocamento

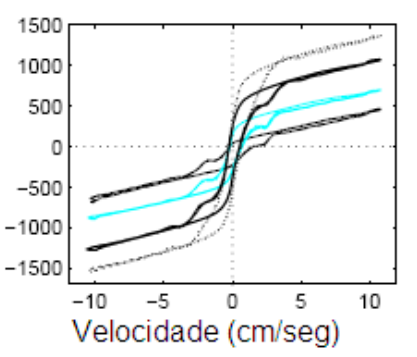

c) Força versus Velocidade

FIGURA 2.25 - Força medida experimentalmente para uma excitação senoidal de $2.5 \mathrm{~Hz}$ com uma amplitude de $1,5 \mathrm{~cm}$ para o amortecedor MR de Spencer et al (1996).

Para um campo magnético nulo, ou seja, aplicando-se 0 volts, o amortecedor comporta-se como um amortecedor de fluido viscoso, isto é, o diagrama de força versus velocidade é aproximadamente elíptico e o diagrama de força versus velocidade é quase linear. Contudo, aumentando-se a voltagem, a força de amortecimento também aumenta devido à associação em paralelo da característica de atrito viscoso com a de material plástico. Pode-se notar também que o aumento de força de amortecimento para uma dada voltagem aplicada é aproximadamente linear para voltagens entre 0 a 2,5 volts. Além disso, pode-se notar na FIGURA 2.22 que a força produzida pelo amortecedor não está centrada em zero. Isso se deve a presença de um acumulador dentro do amortecedor MR. $\mathrm{O}$ acumulador consiste de uma bexiga que fica dentro do cilindro do amortecedor, que está cheia de gás nitrogênio a 300 psi. A função do acumulador é ajudar a prevenir a cavitação do fluido durante a operação e acomodar o volume de fluido deslocado pela haste do pistão assim como a expansão térmica 
do fluido. Do ponto de vista fenomenológico, o acumulador comporta-se como uma mola, no amortecedor. Nos dados experimentais da FIGURA 2.22 mostram que a presença do acumulador produz um offset nas forças de amortecimento medidas e um pequeno alargamento no laço da resposta no diagrama de força versus velocidade.

Hong et al (2005) modelou e testou em laboratório um amortecedor de fluído controlável do tipo ER que pode ser aplicado a veículos de passeio de pequeno porte. A FIGURA 2.23 mostra a o amortecedor ER modelado e testado em laboratório pelos autores.

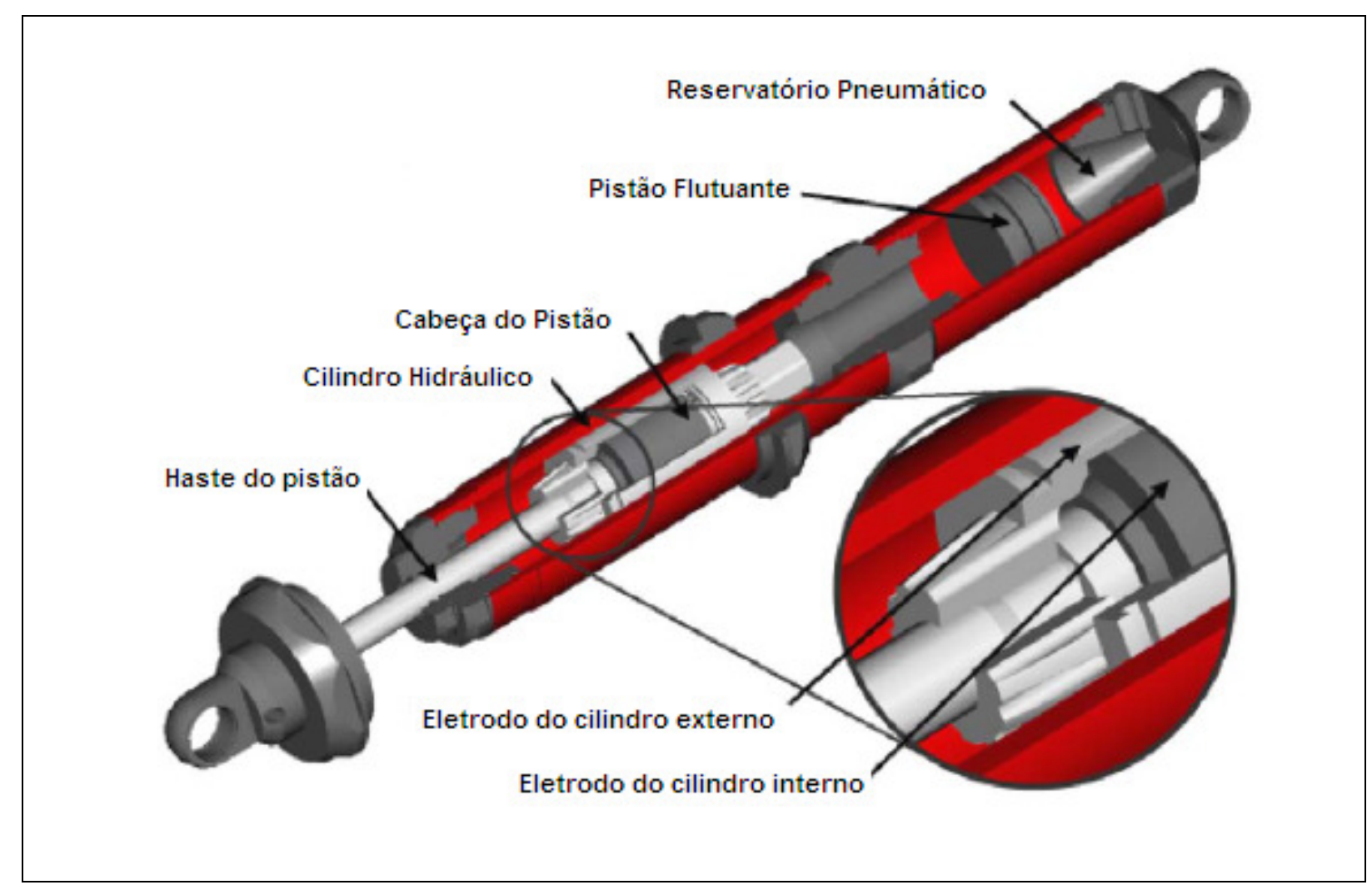

FIGURA 2.26 - Configuração de amortecedor ER de Hong et al (2005)

O amortecedor é constituído de um reservatório pneumático contendo gás nitrogênio pressurizado separado por um pistão flutuante do reservatório hidráulico que contém o fluido ER. Durante o movimento do pistão, o fluido ER flui através de uma abertura entre os eletrodos do cilindro interno e externo na cabeça do pistão que pode ser energizado por um campo elétrico aplicado. Na FIGURA 2.24 podem ser vistas as curvas da força de 
amortecimento medida do amortecedor ER da FIGURA 2.23 em função da velocidade para uma excitação de freqüência igual a $1 \mathrm{~Hz}$.

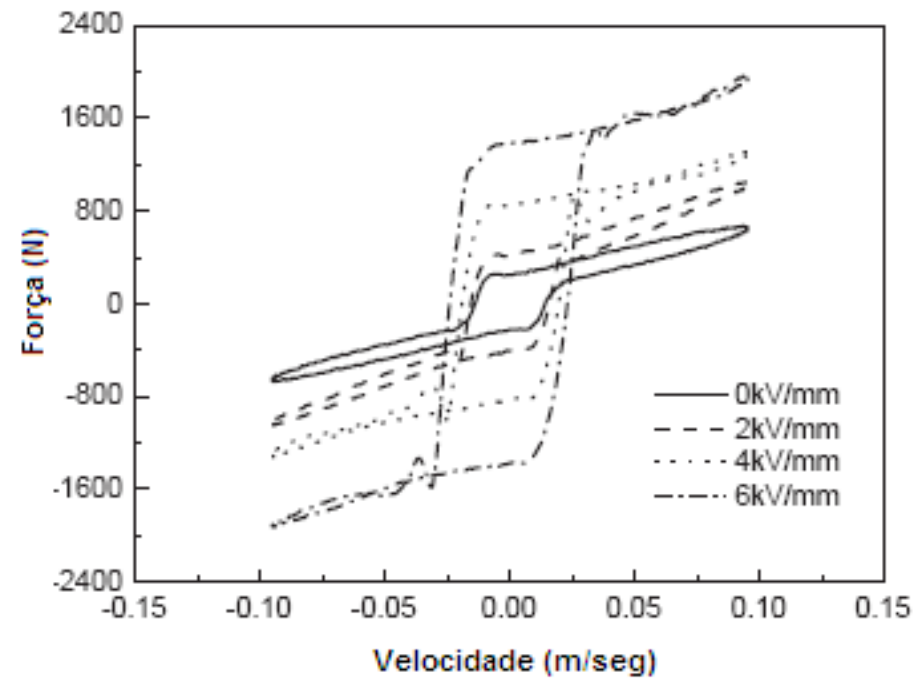

FIGURA 2.27 - Diagrama de força de amortecimento versus velocidade para uma excitação de 1 Hz e vários valores de campos magnéticos (HONG et al, 2005)

Pode-se notar na FIGURA 2.24 conforme o campo elétrico é aumentado a força de amortecimento também aumenta. Na região próxima a velocidade igual a zero pode-se notar um laço de histerese que se torna maior ainda quando se aumenta o campo elétrico no amortecedor. Também nota-se um aumento da inclinação do laço de histerese quando se aumenta o campo elétrico aplicado ao fluído ER dentro do amortecedor,

Na FIGURA 2.25 pode ser visto o diagrama de força versus velocidade para um mesmo campo elétrico aplicado $(6 \mathrm{kV} / \mathrm{mm})$ para várias freqüências de excitação. 


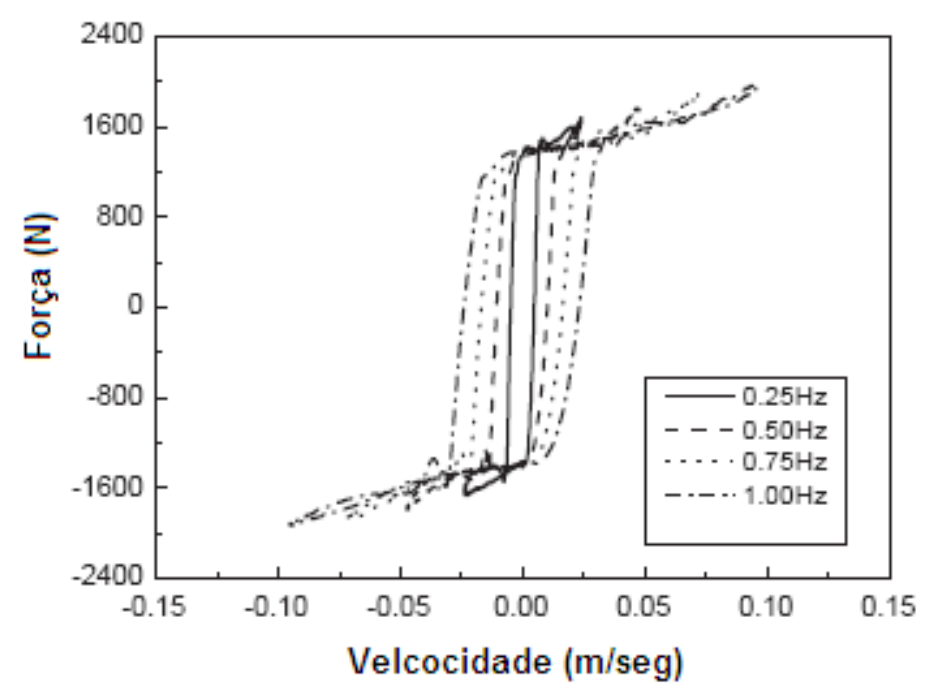

FIGURA 2.28 - Diagrama de força versus velocidade para um campo magnético de $6 \mathrm{KW} / \mathrm{mm}$ e várias freqüências de excitação (HONG et al, 2005).

Nos diagramas da FIGURA 2.25 observa-se que quanto maior a freqüência de excitação maior o alargamento da histerese e menor a sua inclinação.

Analisando os trabalhos descritos acima e a bibliografia pesquisada nota-se uma ausência de trabalhos dedicados ao estudo da resposta do amortecedor para baixas amplitudes, seja porque os amortecedores estudados pelos pesquisadores citados neste trabalho não funcionem como dispositivo de amortecimento para este tipo de excitação, ou seja pela ausência de interesse em estudar tal situação. Pelo exposto, esse trabalho vem preencher essa lacuna estudando o comportamento dinâmico de um sistema hidráulico proposto para atuar como um dispositivo de amortecimento de vibrações para pequenas amplitudes de excitação. 


\subsection{ANÁLISE POR FUNÇÃO DESCRITIVA}

Quando o sistema contém não-linearidades como, por exemplo, de Coulomb, o modelo precisa ser analisado a luz da teoria de sistemas não-lineares. Uma metodologia utilizada para análise é o uso da função descritiva. Essa metodologia está apresentada nesta subsecção, com base no livro de Felício (2007).

A análise por função descritiva é a extensão da técnica para obtenção da Resposta em Freqüência de sistemas lineares ao estudo de sistemas não-lineares. A técnica consiste em fazer com que a entrada do elemento-não-linear seja uma onda senoidal. Geralmente, a saída é uma onda periódica com o mesmo período da entrada, porém não senoidal. A saída conterá harmônicas superiores além da componente harmônica fundamental. Supõe-se que apenas a componente harmônica fundamental da saída seja significativa. Essa hipótese é muitas das vezes válida, pois as amplitudes das harmônicas superiores da saída dos elementos nãolineares são geralmente de menor amplitude quando comparadas com a amplitude da harmônica fundamental. Além disso, a parte linear do sistema se comporta como filtro do tipo passa baixa, o que causa uma atenuação das amplitudes das harmônicas superiores. A função descritiva é definida como a relação complexa entre a componente harmônica fundamental da saída e a amplitude da entrada, isto é:

$$
F_{D}=\frac{A_{1}}{A_{i}} \angle \phi_{1}
$$

onde: 
$F_{D} \stackrel{\Delta}{=}$ Função descritiva;

$A_{i} \stackrel{\Delta}{=}$ Amplitude da senóide de entrada;

$A_{1} \stackrel{\Delta}{=}$ Amplitude da componente harmônica fundamental da saída, na condição de regime permanente;

$\phi_{1} \stackrel{\Delta}{=}$ Defasagem da componente harmônica fundamental da saída, em relação a entrada, na condição de regime permanente;

Para encontrar a função descritiva do sistema necessita-se calcular a componente harmônica fundamental da saída, na condição de regime. Para uma entrada senoidal $x(t)=A_{i} \operatorname{sen}(\omega t)$, geralmente a saída $y(t)$, em regime permanente, pode ser expandida em série de Fourier. Assim, a resposta permanente fica:

$$
y(t)=a_{0}+\sum_{n=1}^{\infty}\left(a_{n} \cos (n \omega t)+b_{n} \operatorname{sen}(n \omega t)\right)
$$

$\mathrm{ou}$

$$
y(t)=a_{0}+\sum_{n=1}^{\infty} A_{n} \operatorname{sen}\left(n \omega t+\phi_{n}\right)
$$

em que

$$
\begin{aligned}
& n \stackrel{\Delta}{=} \text { posição do harmônico } \\
& a_{n}=\frac{2}{T} \int_{-T / 2}^{T / 2} y(t) \cos (n \omega t) d t \\
& b_{n}=\frac{2}{T} \int_{-T / 2}^{T / 2} y(t) \operatorname{sen}(n \omega t) d t
\end{aligned}
$$




$$
\phi_{n}=\tan ^{-1}\left(\frac{a_{n}}{b_{n}}\right)
$$

em que

$\mathrm{t} \stackrel{\Delta}{=}$ tempo;

$T \stackrel{\Delta}{=}$ período da onda permanente $y(t)$;

A componente harmônica fundamental da saída é

$$
y_{1}(t)=a_{1} \cos (\omega t)+b_{1} \operatorname{sen}(\omega t)
$$

ou

$$
y_{1}(t)=A_{1} \operatorname{sen}\left(\omega t+\phi_{1}\right)
$$

A função descritiva é então dada por:

$$
F_{D}=\frac{A_{1}}{A_{i}} \angle \phi_{1}=\frac{\sqrt{a_{1}^{2}+b_{1}^{2}}}{A_{i}} \angle \operatorname{arctg} \frac{a_{1}}{b_{1}}
$$

Neste trabalho o modelo do amortecedor proposto será linear, porém a determinação da resposta em freqüência será feita usando o conceito de Função Descritiva. Na implementação desta metodologia será usado o filtro de Fourier que se baseia nas seguintes equações:

$$
\begin{aligned}
& \frac{1}{N_{C} T} \int_{0}^{N_{C} T} \operatorname{sen}(\omega t+\phi) \cos (\omega t) d t=\frac{\operatorname{sen} \phi}{2} \\
& \frac{1}{N_{C} T} \int_{0}^{N_{C} T} \operatorname{sen}(\omega t+\phi) \operatorname{sen}(\omega t) d t=\frac{\cos \phi}{2}
\end{aligned}
$$




$$
\begin{aligned}
& \frac{1}{N_{C} T} \int_{0}^{N_{C} T} \operatorname{sen}(n \omega t+\phi) \operatorname{sen}(\omega t) d t=0 ; n=2,3,4, \ldots . \\
& \frac{1}{N_{C} T} \int_{0}^{N_{C} T} \operatorname{sen}(n \omega t+\phi) \cos (\omega t) d t=0 ; n=2,3,4, \ldots
\end{aligned}
$$

em que

$N_{C} \stackrel{\Delta}{=}$ número de ciclos considerados; 


\section{OBJETIVO}

O objetivo deste trabalho é obter o modelo teórico de um sistema hidráulico proposto como um amortecedor para amplitudes baixíssimas, na casa dos décimos de milímetros de curso e estudar o seu comportamento dinâmico. O sistema proposto é composto por um atuador e um arranjo de orifícios, alimentado por uma bomba, que fornecerá pressão constante ao sistema.

As características do modelo do sistema hidráulico serão comparadas com o comportamento dinâmico de um amortecedor ideal.

A revisão bibliográfica apresentada anteriormente mostra que os parâmetros (1) bulk modulus equivalente (compressibilidade do fluído, deformação de partes mecânicas e infiltração de ar no óleo) e (2) o atrito entre as superfícies deslizantes influenciam o comportamento dinâmico dos sistemas de amortecimento. Estes parâmetros, juntamente com os detalhes construtivos causam o fenômeno da histerese nos sistemas de amortecimento.

Com o objetivo de minimizar o efeito do bulk modulus equivalente na histerese, o sistema é pressurizado.

Na modelagem, o efeito do atrito seco é desprezado com o intuito de obter um modelo linear.

O trabalho irá modelar o sistema hidráulico, levantando as equações que predizem as características dinâmicas do sistema, através do estudo do comportamento fluido-dinâmico 
que represente bem o esquema hidráulico. As características dinâmicas das vazões, pressões e do movimento do êmbolo serão estudados aplicando a lei da conservação da massa, lei de Newton e relações de vazão-pressão dos orifícios.

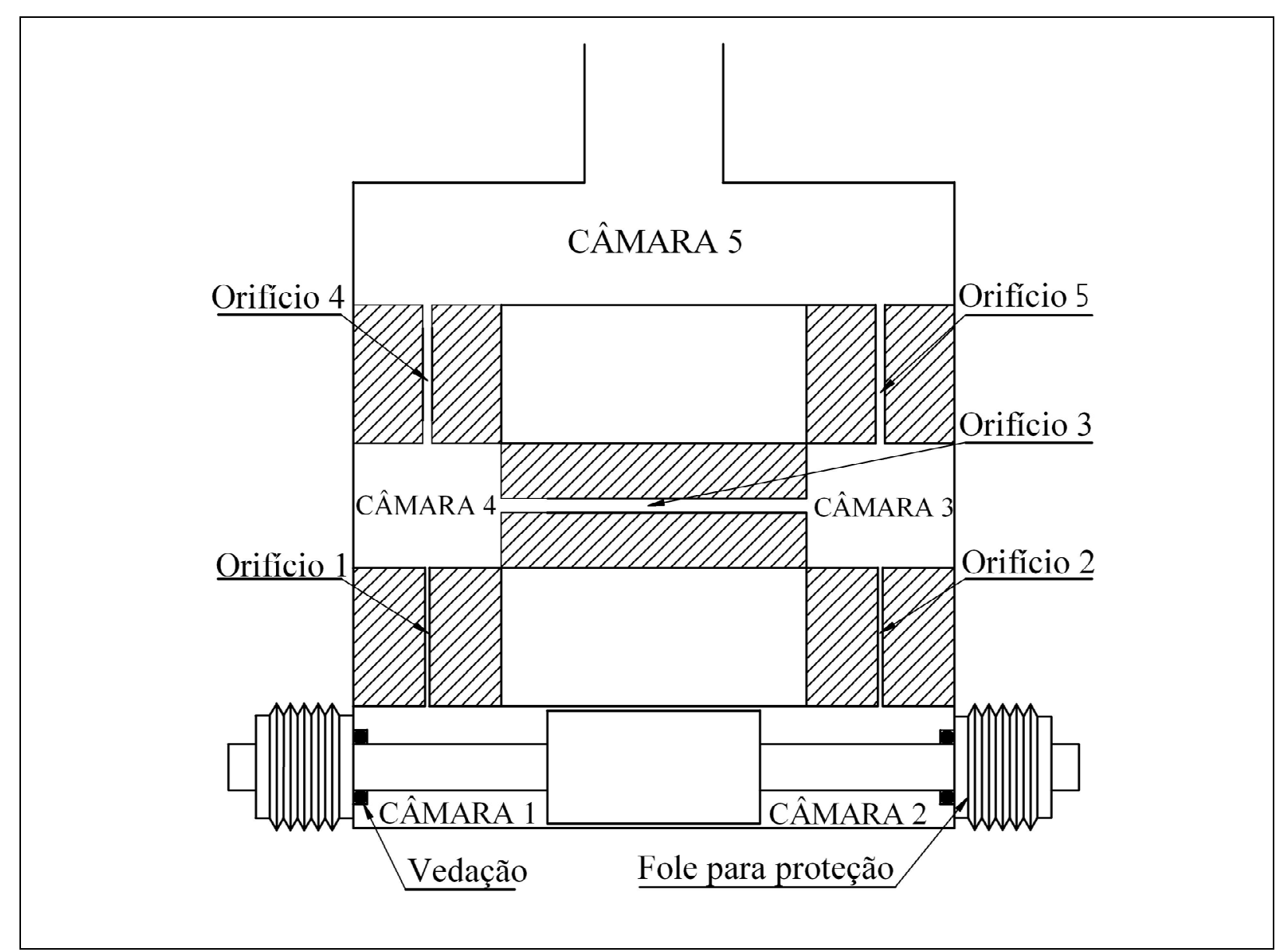

FIGURA 3.1 - Desenho esquemático do sistema hidráulico proposto para funcionar como um amortecedor para baixas amplitudes

Depois da elaboração do modelo, contendo equações para representar o comportamento do sistema proposto, passou-se ao próximo estágio que é o dimensionamento de peças e a definição de parâmetros propondo um sistema com dimensões. Em seguida, o modelo com as dimensões propostas foi simulado. A simulação do modelo foi executada no MATLAB $^{\circledR}$, da MathWorks, onde foram geradas as curvas de resposta em frequiência do 
sistema proposta. Entradas senoidais excitaram o sistema e da resposta permanente foram obtidos gráficos da resposta em freqüência para mostrar o seu o comportamento dinâmico. 


\section{METODOLOGIA}

Este capítulo tem por objetivo explicar a metodologia aplicada na obtenção da resposta em frequiência $(\mathrm{RF})$ para sistemas lineares e não-lineares, a qual será empregada no modelo do sistema proposta para funcionar com um amortecedor para pequenas amplitudes de excitação. A programação em Matlab e Simulink para obtenção da RF é apresentada e seus passos explicados. Para medir a acuracidade e a eficácia do método computacional, sistemas cujas respostas em freqüência são conhecidas foram comparados com os resultados obtidos da simulação.

\subsection{MÉTODO COMPUTACIONAL PARA OBTENÇÃO DA RESPOSTA EM FREQÜÊNCIA}

Para analisar o comportamento dinâmico do sistema proposto para funcionar como um amortecedor para pequenas amplitudes foi desenvolvido um programa em computador. Este programa realiza a tarefa de obter os gráficos da resposta em frequiência, isto é, os gráficos da relação de amplitudes e o ângulo de fase, em função da freqüência, foi desenvolvido com base na análise de sistemas não-lineares. O software escolhido para obtenção da resposta em freqüência foi o Matlab e o seu pacote de simulação dinâmica incorporado, o Simulink. O 
modo de programação do Simulink é do tipo gráfico, construído a partir de uma biblioteca interna de blocos funcionais. Um programa em linguagem Matlab foi necessário para fazer variar uma faixa de freqüência, para que a resposta em frequiência fosse efetivamente obtida. Isso foi conseguido através de um laço, dentro do programa do Matlab, que também geram os gráficos da resposta em frequiência. Outra tarefa do programa em Matlab é carregar e calcular variáveis que alimentarão o diagrama do Simulink e extrair elementos de vetores gerados também pelo Simulink. Essa troca de dados entre o Matlab e o Simulink é uma característica que facilita a implementação de soluções para problemas dinâmicos.

Com o intuito de medir a acuracidade do método computacional de obtenção da resposta em freqüência foram realizados testes com sistemas cujas respostas em freqüência eram conhecidas e os resultados comparados com a as curvas geradas pela função bode do Matlab. Esse processo foi implementado no programa do Matlab pelo cálculo das diferenças dos valores ente a relação de amplitudes e fase obtidas através do filtro de Fourier, implementado no Simulink, e as obtidas através da função bode, para uma mesma freqüência.

A FIGURA 4.1 mostra um fluxograma global do método para obtenção da resposta em freqüência envolvendo a troca de dados entre o Matlab e o Simulink. O programa do Matlab para teste de sistemas conhecidos pode ser visto no APÊNDICE A deste trabalho. Primeiramente, todas as variáveis necessárias são definidas e criadas no Matlab. Logo em seguida, a interface com o usuário solicita a amplitude da excitação e o tipo de sistema que se deseja obter a resposta em freqüência. Dependendo do sistema escolhido, o programa pergunta também parâmetros do sistema que se deseja obter a Resposta em Freqüência (RF). De posse desses dados, já dentro do laço do programa no Matlab, há o cálculo e o armazenamento das variáveis necessárias à execução do programa no Simulink. Essas variáveis são o tempo final de execução da simulação e o período do sinal. O valor do período 
do sinal, que será utilizada nos cálculos no Simulink, também é calculado para cada uma dessas freqüências. Através da função sin, também dentro do laço no programa do Matlab, o programa no Simulink é executado. O laço dentro do programa no Matlab executa a simulação para uma faixa de freqüência que varia de 0,1 a $100 \mathrm{rad} / \mathrm{s}$, espaçadas logaritmamente. Quando o tempo final de execução do Simulink é atingido, o programa do Matlab solicita o último valor dos vetores de fase e magnitude. Apenas os últimos valores dos vetores da fase e magnitude são armazenados em uma matriz (que também contém a freqüência de excitação), pois correspondem a valores que convergiram provenientes das integrais da série de Fourier, depois de um certo número de passo. Depois que todas as freqüências excitaram o sistema que se deseja obter a RF, o programa do Matlab gera os gráficos da relação de amplitudes e da fase, juntamente com o gráfico da diferença entre o simulado (implementado no Simulink) e o gerado pela função bode, do Matlab. Através desse último gráfico pode-se constatar a acuracidade do modelo computacional implementado.

Quando o programa do Simulink é acionado para ser executado, dentro do laço do programa do Matlab, o sinal senoidal da entrada é injetado no bloco que contém o sistema que se deseja obter a resposta em freqüência. O computador solicita do usuário a amplitude da senóide. A freqüência varia logaritmamente dentro do laço, varrendo um faixa de freqüência pré-definida (no caso dos testes de 0,1 a $100 \mathrm{rad} / \mathrm{s}$ ). A saída do sistema testado vai para o bloco "Filtro de Fourier" que executará a tarefa de extrair a amplitude e o ângulo de fase da componente harmônica fundamental da saída do sistema em teste A divisão da amplitude da harmônica fundamental do sinal de saída pela amplitude da entrada também é operada dentro do bloco "Filtro de Fourier". 


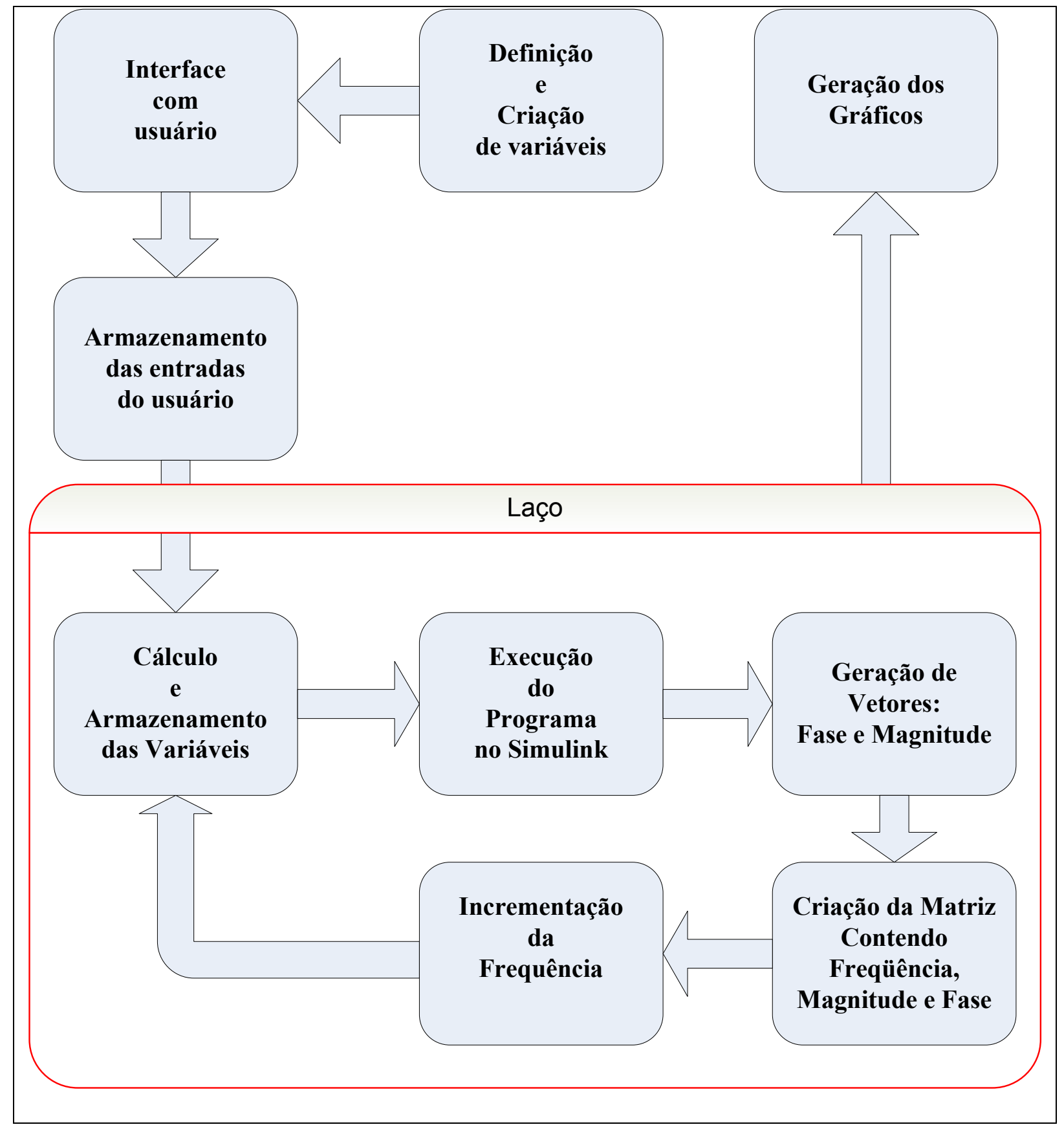

FIGURA 4.1 - Fluxograma do programa em Matlab e Simulink para obtenção da resposta em freqüência.

Na FIGURA 4.2, pode-se ver a arquitetura construída no Simulink utilizada para os testes. A figura mostra que o programa contém três blocos principais: o bloco da "entrada", que é do tipo senoidal, comum a todos os sistemas testados; o bloco "sistema", que contém o 
sistema que se deseja obter a resposta em freqüência; e o bloco "Filtro de Fourier", que implementa os cálculos da série de Fourier para a primeira harmônica.

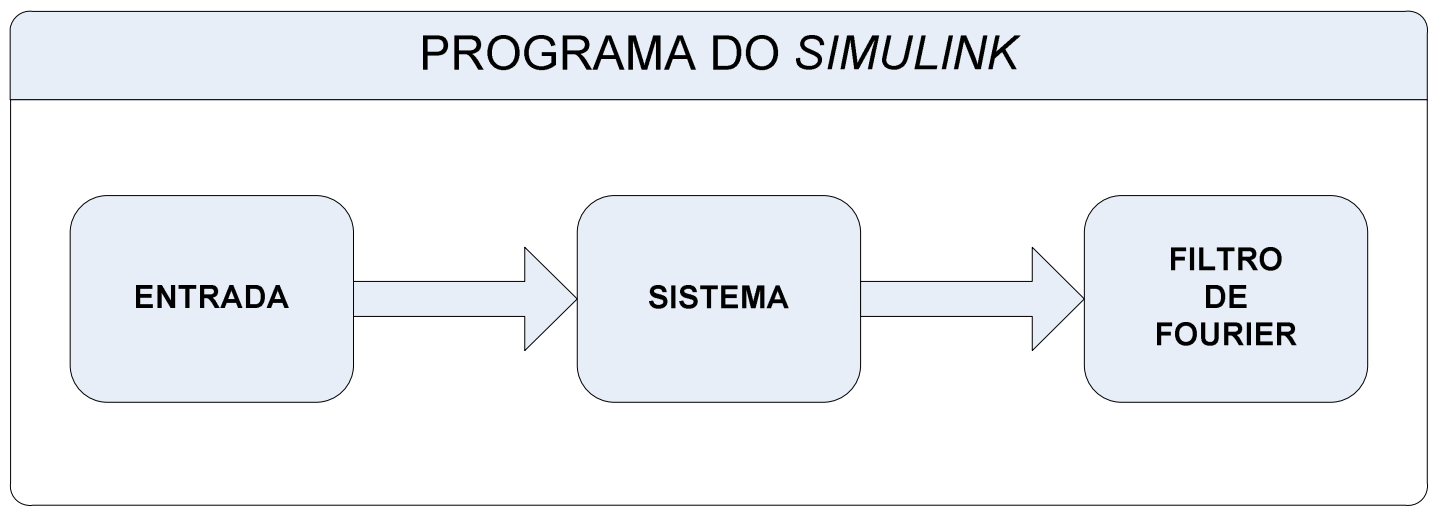

FIGURA 4.2 - Arquitetura do programa no Simulink

O bloco sine wave do Simulink foi o bloco utilizado como entrada e o bloco do tipo subsystem contém o código do filtro de Fourier. O filtro de Fourier foi implementado no Simulink com base no trabalho de Felício (1981 p.302). O bloco do tipo subsystem é um bloco do Simulink que contém vários blocos e serve para organizar e tomar menos espaço na tela do computador, melhorando a visualização global do sistema a ser simulado. A FIGURA 4.3 mostra os blocos agrupados no subsystem "Filtro de Fourier" do Simulink. Os blocos dentro desse subsystem contêm a implementação das equações (2.20), (2.21), (2.22) e (2.23). 


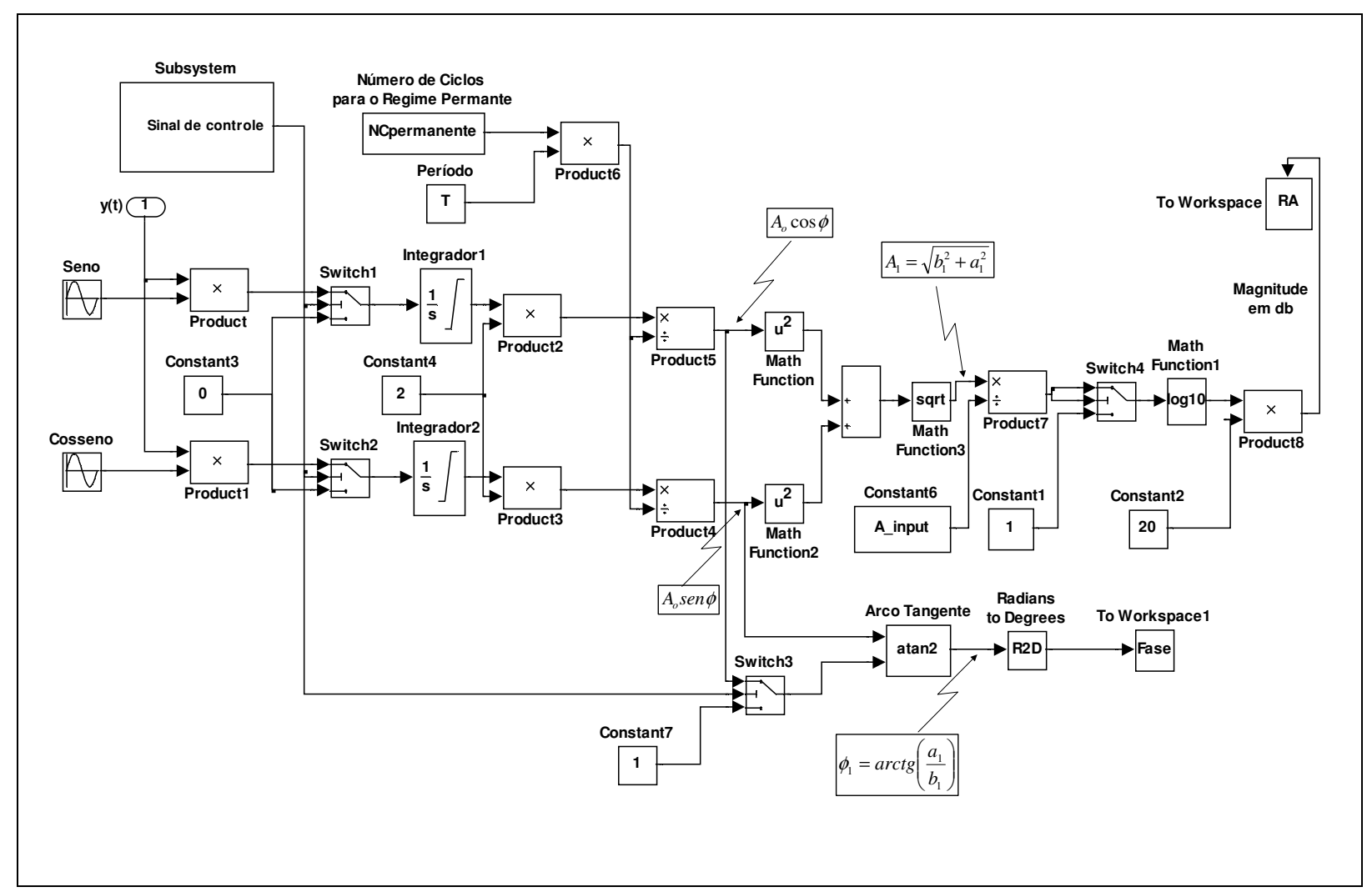

FIGURA 4.3 - Blocos contidos no subsystem "Filtro de Fourier" do Simulink.

O diagrama da FIGURA 4.3 tem que ser aprimorado se a fase do sistema que se deseja obter a resposta em frequiência possuir valores fora do intervalo de $-180^{\circ} \mathrm{a}+180^{\circ}$ graus devido a limitações do bloco atan2.

Dentro do bloco "Filtro de Fourier" há um outro bloco do tipo subsystem chamado "Sinal de Controle". Esse subsystem contém blocos que implementam um sinal de controle lógico (zero ou um) que serão aplicados aos blocos Switch1, Switch2 e Switch4. O "Sinal de Controle' que chega aos Switch1 e Switch2 irão controlar o início da integração. O controle dos integradores se fez necessário, pois o sistema testado tem como saída, no início da simulação, uma resposta completa, isto é, resposta permanente mais resposta transitória. $\mathrm{Na}$ Resposta em Freqüência, apenas a resposta permanente dever ser considerada. Portanto, os Switch1 e 2 devem ser operados pelo "Sinal de Controle" para que os integradores comecem a integração somente depois que a resposta transitória tornar-se nula. A FIGURA 4.4 mostra os 
blocos do subsystem "Sinal de Controle". O bloco Relational operator compara o tempo de simulação com o tempo pré-definido (constante) do bloco Tempo_fim_trans (seu valor está definido no programa do Matlab). Se o tempo do clock for maior ou igual a constante Tempo_fim_trans, o bloco Relational operator solta como sinal de saída o valor 1, caso contrário o sinal da saída será igual a zero. Esse sinal vai para os dois Switch's que controlam os integradores. Enquanto o tempo do clock for menor que o Tempo_fim_trans, o sinal de controle que chegará aos Switch's será zero. Isso fará com que o sinal que será integrado seja uma constante igual a zero, resultando em um valor nulo de integração. No decorrer da simulação, quando o tempo do clock for maior ou igual ao Tempo_fim_trans, o "Sinal de Controle" dos Switch's será 1, e estes mudarão as chave para que as operações dos dois produtos, do seno e do co-seno, com o sinal da saída do sistema y(t) sejam operados.

O Switch3 possibilita que valores nulos de $b_{1}$, que farão a divisão por $a_{1}$ no bloco atan2 sejam barrados. São nulos os valores de $b_{1}$ gerados pela integração da constante zero, no período pré-definido para que os transientes desapareçam. O bloco atan2, calcula o arco tangente levando em conta o quadrante no intervalo de $-\pi$ a $\pi$. Os resultados do bloco atan2 são convertidos de radianos para graus pelo bloco radians to degrees e são alocados no bloco to workspacel. Este bloco armazena os ângulos de fase, para cada passo da simulação, criando o vetor Fase no workspace. O workspace é uma interface gráfica do Matlab que contém as variáveis alocadas na memória durante a execução do programa e serve como um ambiente de troca de dados entre o Simulink e o Matlab. Assim como nos Switch's 1 e 2, o Switch3 também é controlado pelo "Sinal de Controle". O Switch4 evita uma outra operação não definida matematicamente que é o logaritmo (na base dez) de zero. A aplicação do produto dos blocos math function, contendo a função logaritmo na base dez, e constant2, contendo o valor 20 pela magnitude faz a conversão da mesma para db. O resultado vai para o 
bloco to workspace 2 que contém o vetor $\boldsymbol{R} \boldsymbol{A}$, que é igual ao vetor $\boldsymbol{F a s e}$, porém armazena as relações de amplitudes transformadas em $\mathrm{db}$.

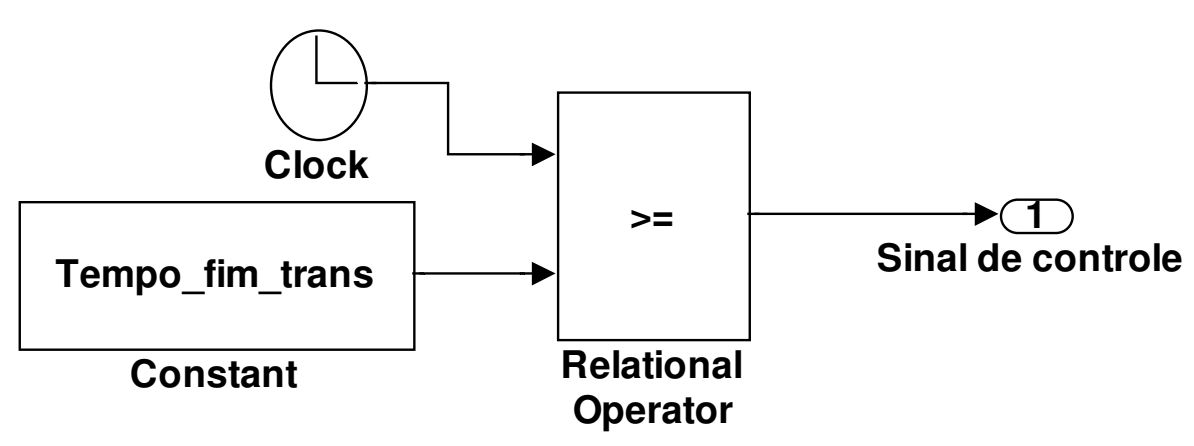

FIGURA 4.4 - Blocos contidos no subsystem Sinal de controle dentro do subsystem Filtro de Fourier.

Os parâmetros que o Simulink utiliza na simulação, como o método de integração numérica e o tempo de simulação são acessados na barra de tarefas, opção Simulation. No subitem Simulation Parameters, no painel Solver, o tempo de simulação foi configurado para começar em zero segundo e terminar em Timefim, que é uma variável calculada dentro do programa do Matlab. A variável Timefim é a soma do tempo pré-estabelecido para que os transientes desapareçam (valor da variável Time_fim_trans) mais o período da onda de excitação, que foi calculado com base na freqüência, vezes o número de ciclos (valor da variável NCpermanente) pré-definido também dentro do programa do Matlab. Foi escolhido um número grande de ciclos (500 ciclos) para que os erros referentes à integração numérica fossem minimizados. O tempo final de simulação final (variável Timfim) foi configurado para que a simulação parasse quando a onda completasse um número inteiro de ciclos, já que a integrais que geram os coeficientes de Fourier $a_{1}$ e $b_{1}$ são definidas para tempos que resultam de um número inteiro de ciclos. O passo variável de integração numérica foi adotado para otimizar o tempo real gasto na simulação. De todos os métodos de integração com passo variável disponíveis no Simulink, o escolhido foi o ode45[Domand Price], que se mostrou 
mais eficiente, demandando menos tempo de simulação e produziu menor erro, com relação aos outros métodos de integração. O máximo comprimento do passo de simulação (Max step size) adotado foi o período da onda dividido por 200, que foi escolhido para todos os sistemas testados, visando a acuracidade com a resposta em frequiência obtida com a função bode do Matlab e a otimização da simulação, pois quanto menor o tamanho do passo máximo maior o tempo real gasto para simular o sistema.

\subsection{TESTES}

Os testes para medir a acuracidade do modelo computacional foram realizados nos seguintes sistemas:

- Derivador simples;

- Integrador simples;

- Relé sem histerese;

- Sistema de Primeira Ordem;

- Sistema de Segunda Ordem.

\subsubsection{Derivador Simples}

A FIGURA 4.5 mostra os blocos usados na simulação para obtenção da resposta em freqüência do derivador simples. 


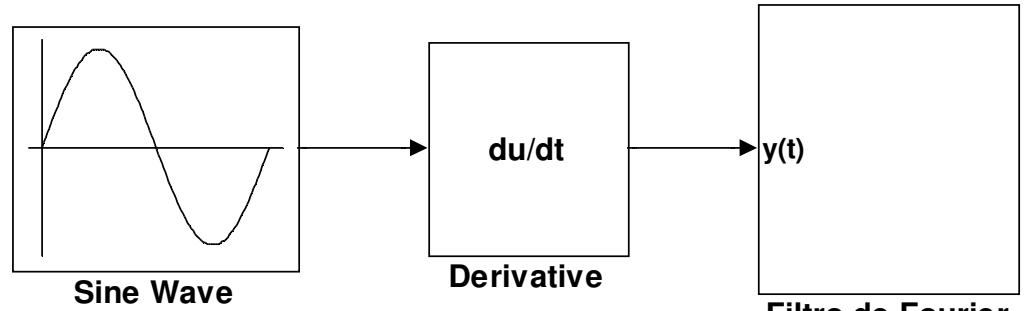

Filtro de Fourier

FIGURA 4.5 - Blocos para o teste do derivador simples.

Na FIGURA 4.6 são apresentados os gráficos da relação de amplitudes e da fase, da resposta em freqüência, gerados pela simulação.
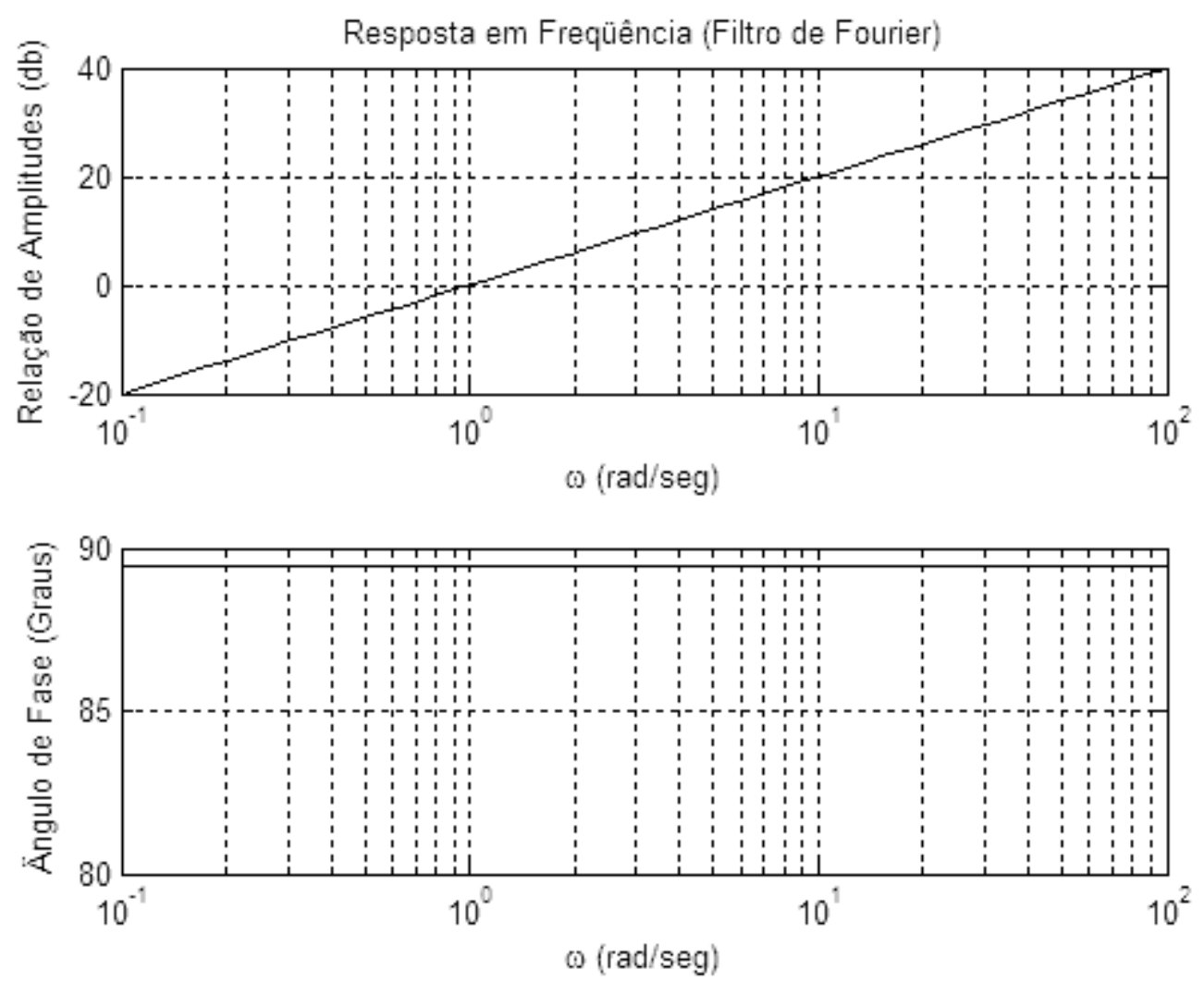

FIGURA 4.6 - Gráficos da RF obtidos através do filtro de Fourier implementado no Simulink, para o derivador simples. 
Os gráficos da RF gerados pela função bode para o derivador simples pode ser visto na FIGURA 4.7. A magnitude é uma reta que sobe $20 \mathrm{db}$ a cada década e passa em $0 \mathrm{db}$ na frequiência igual a $1 \mathrm{rad} / \mathrm{seg}$. A fase é plana, igual a $90^{\circ}$ graus para, toda a faixa de frequiência.

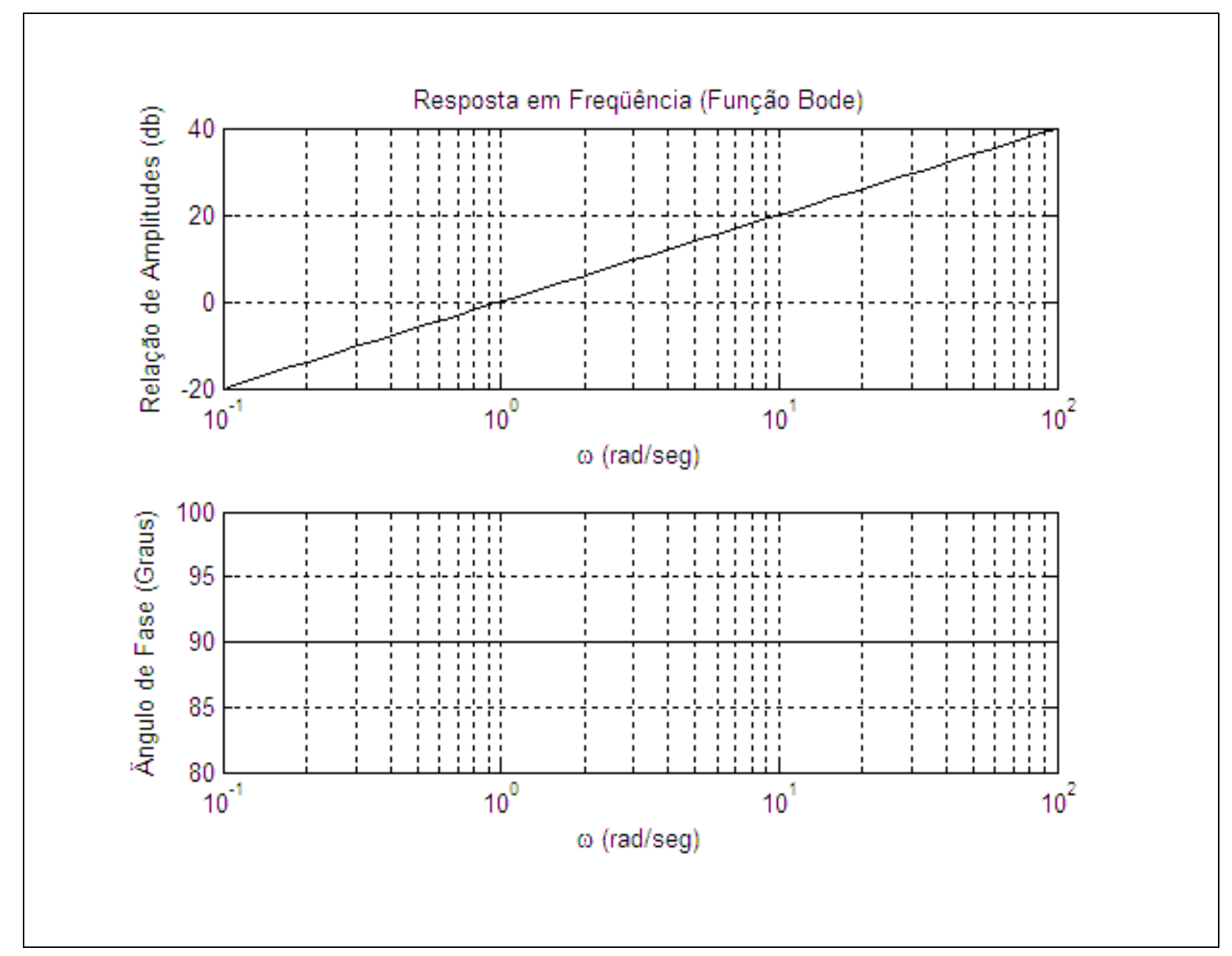

FIGURA 4.7 - Gráficos de Bode do derivador simples.

A comparação das respostas em freqüência geradas pela simulação e pela função bode pode se ver na FIGURA 4.8.

A fase apresentou uma pequena diferença da ordem de $0,5^{0}$ em toda a faixa de freqüência dos testes, o que corresponde a um erro percentual de um pouco maior que $0,5 \%$. Portanto, através dos testes pode-se dizer que para o derivador simples tem-se boa concordância entre os valores teóricos e os obtidos na simulação. 


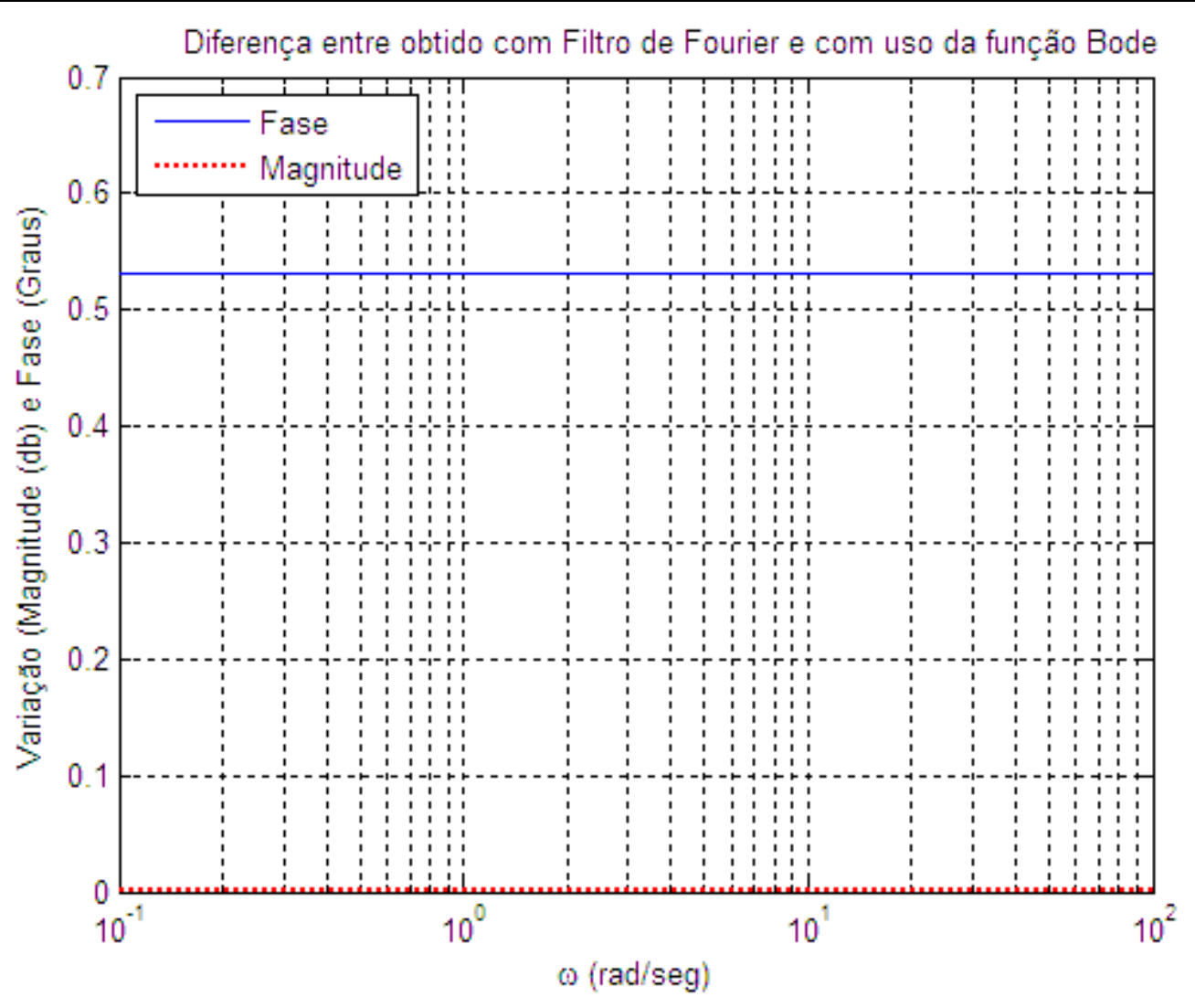

FIGURA 4.8 - Gráfico da diferença (da Fase e Magnitude) entre o obtido pela função bode e pelo filtro de Fourier para o derivador simples.

\subsubsection{Integrador Simples}

O segundo sistema utilizado no teste foi o integrador simples. Na FIGURA 4.9 podem ser observados os blocos empregados na simulação.

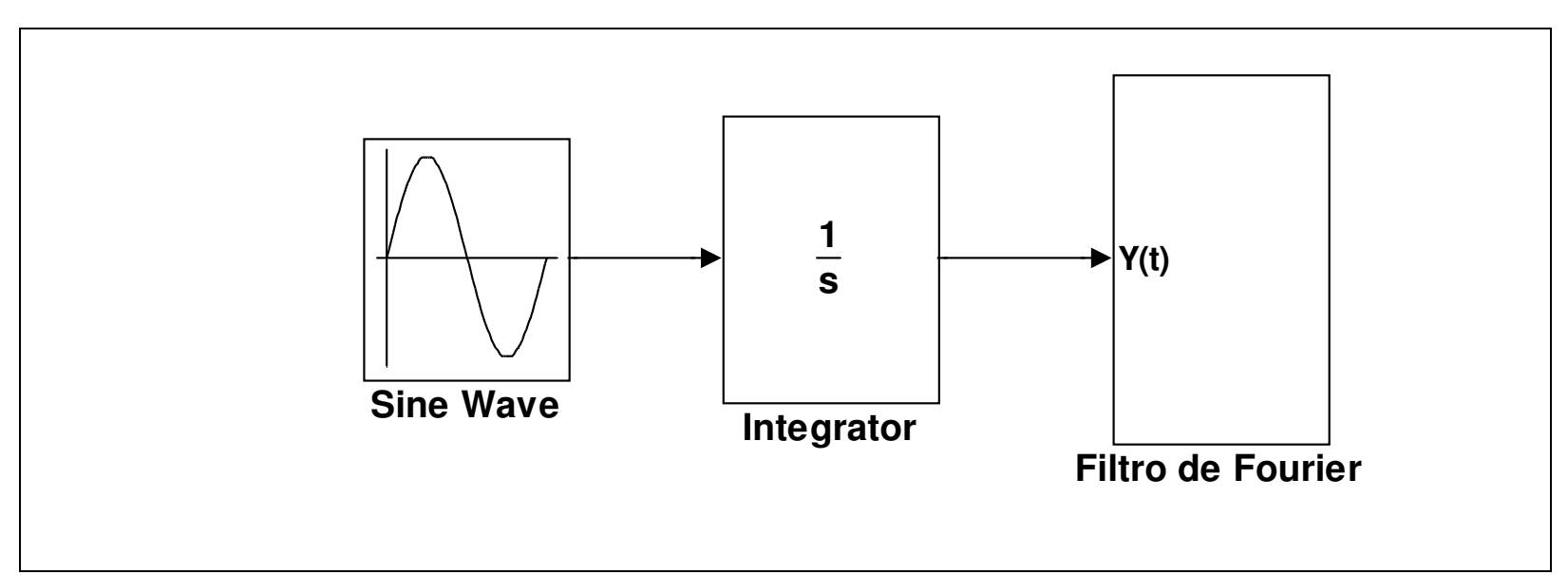

FIGURA 4.9 - Blocoss para o teste do integrador simples. 
A FIGURA 4.10 mostra os gráficos da resposta em freqüência obtida pela simulação para o integrador simples.
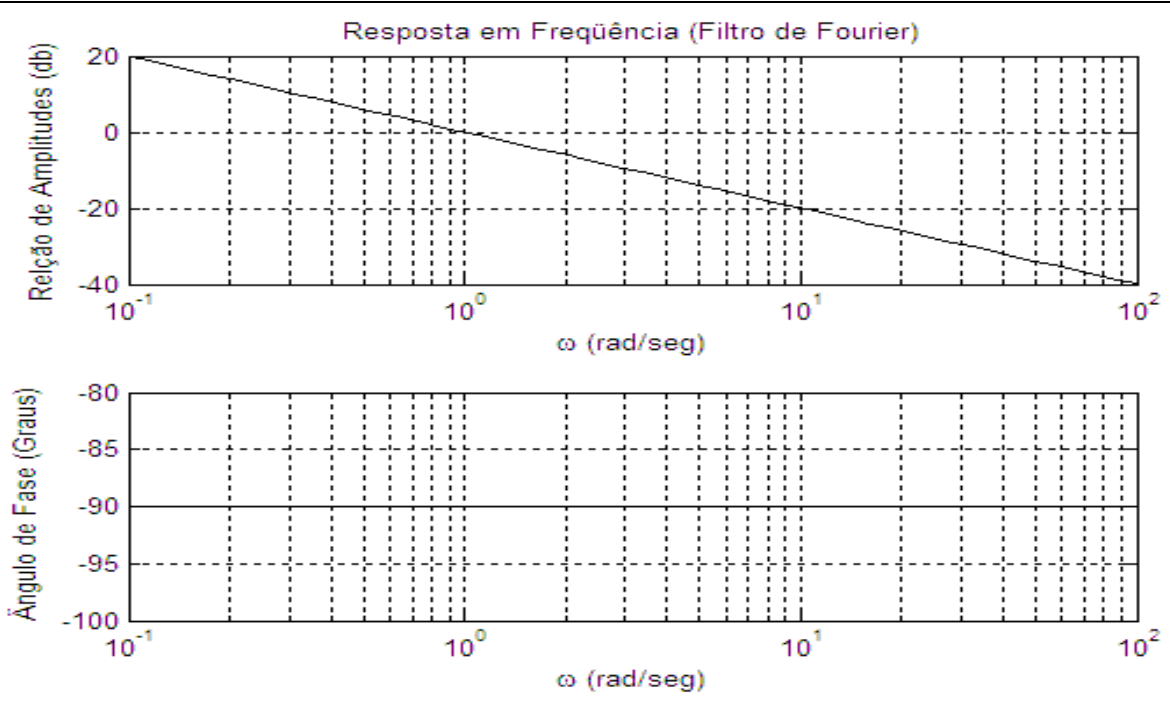

FIGURA 4.10 - Gráficos da RF obtidos através do filtro de Fourier implementado pelo Simulink, para o integrador simples.

Os gráficos da FIGURA 4.11 mostram os gráficos da RF gerados pela função bode para o integrador simples.

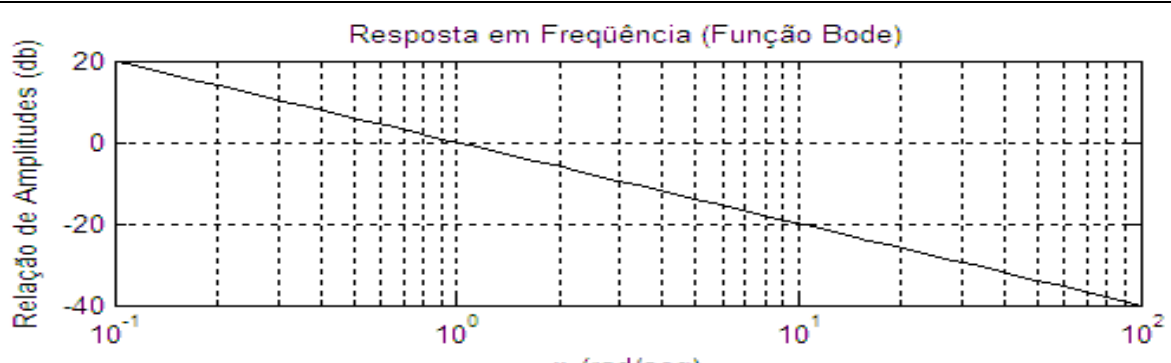

$\omega(\mathrm{rad} / \mathrm{seg})$

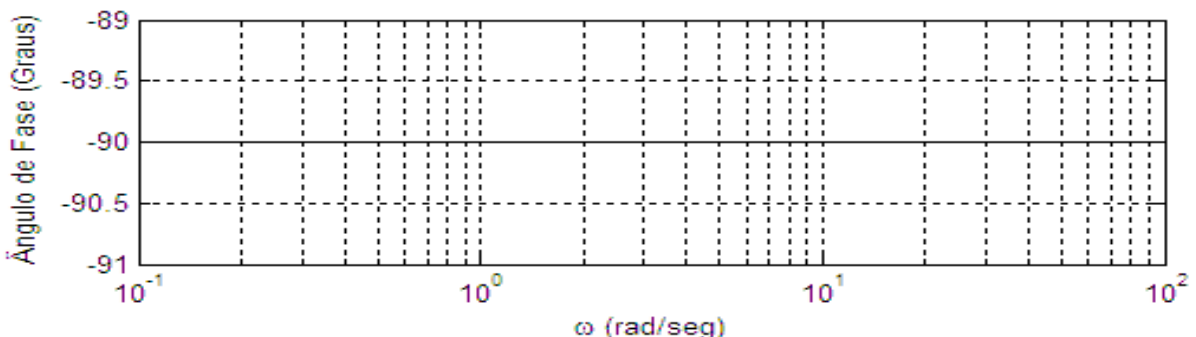

FIGURA 4.11 - Gráficos de Bode do integrador simples. 
Pode-se observar que o gráfico da magnitude em função da freqüência é uma reta descendente, que passa por $0 \mathrm{db}$ em $1 \mathrm{rad} / \mathrm{seg}$ com inclinação de $20 \mathrm{db}$ por década. Já o gráfico da fase é pala em $-90^{\circ}$, para toda a faixa de freqüência.

O gráfico da FIGURA 4.12 mostra a ótima concordância entre a resposta obtida na simulação e o teórico, obtido através da função bode.

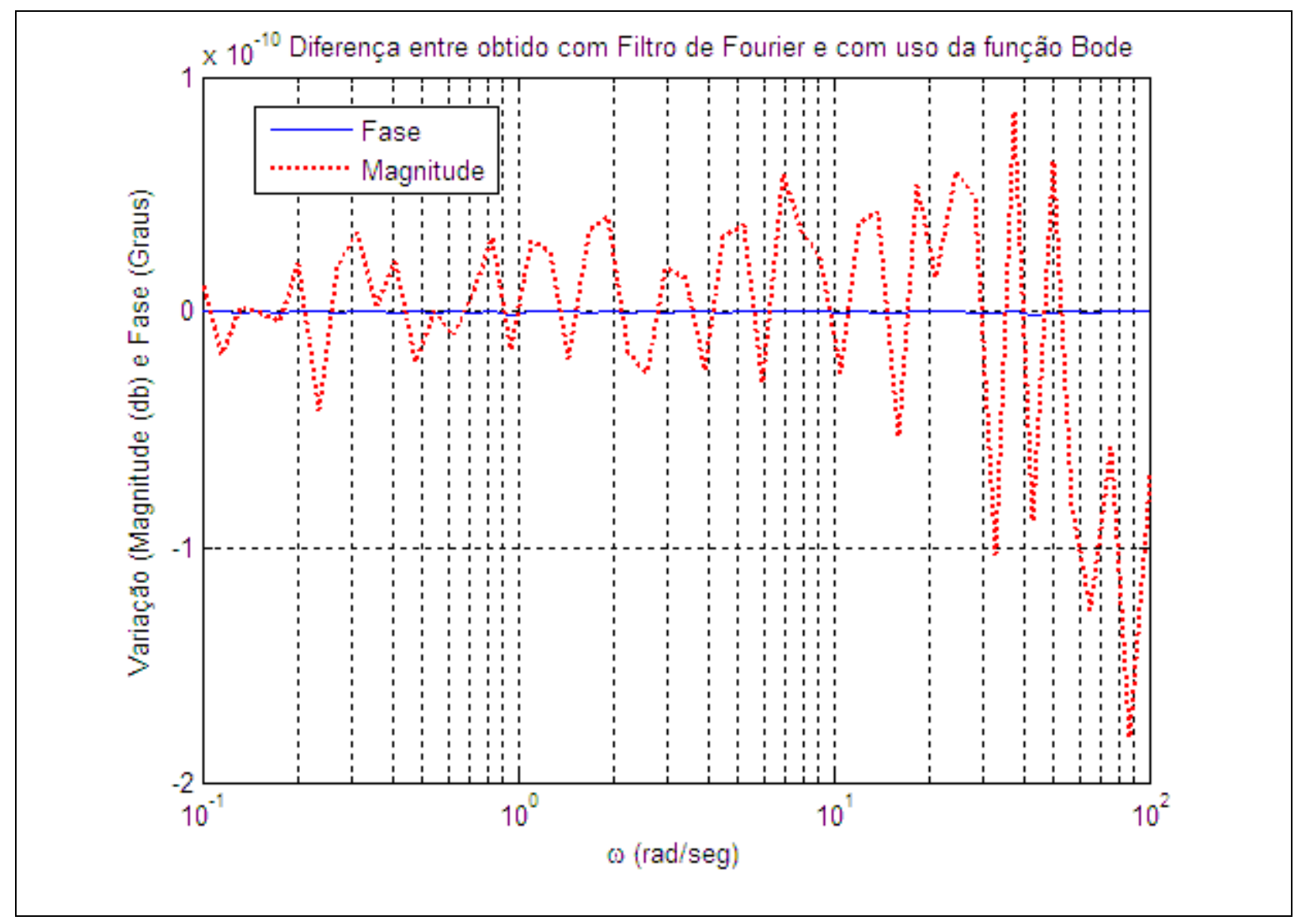

FIGURA 4.12 - Gráfico da diferença (da Fase e Magnitude) entre o obtido pela função bode e pelo filtro de Fourier para o integrador simples.

\subsubsection{Relé sem Histerese}

Injetando-se uma onda senoidal em um bloco relay devidamente ajustado pode-se reproduzir uma onda quadrada. A configuração que pode ser vista na FIGURA 4.13, produz uma onda quadrada simétrica em relação ao eixo x. 


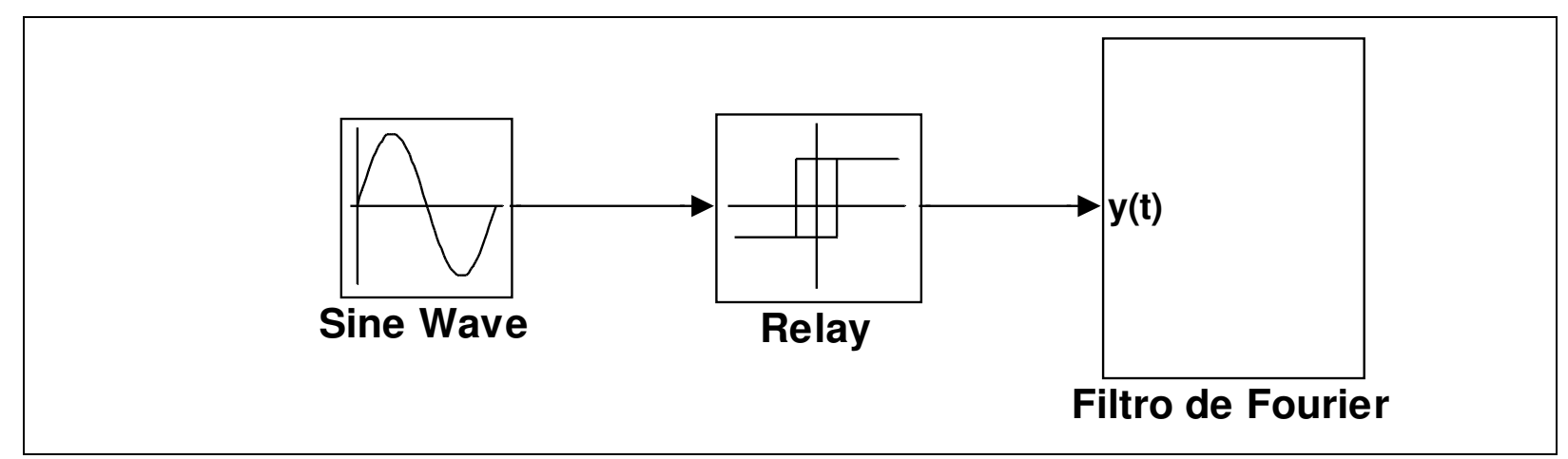

FIGURA 4.13 - Blocos para o teste da onda quadrada

Segundo Felicio (2007), a amplitude da componente fundamental da onda quadrada $A_{0 \text { quad }}$ é:

$$
A_{0}=\frac{4 b}{\pi}
$$

em que

$b \stackrel{\Delta}{=}$ módulo da saída do relê quando ligado (saída é $+\mathrm{b}$ ou $-\mathrm{b}$, para entrada diferente de zero).

O bloco relay foi configurado sem histerese e com $b$ igual a \pm 1 , portanto a equação 4.1 fica:

$$
A_{0}=\frac{4}{\pi}
$$

A FIGURA 4.14 mostra os gráficos da amplitude e da fase da componente harmônica fundamental da onda quadrada, com as características descritas acima, obtidos através da simulação, 

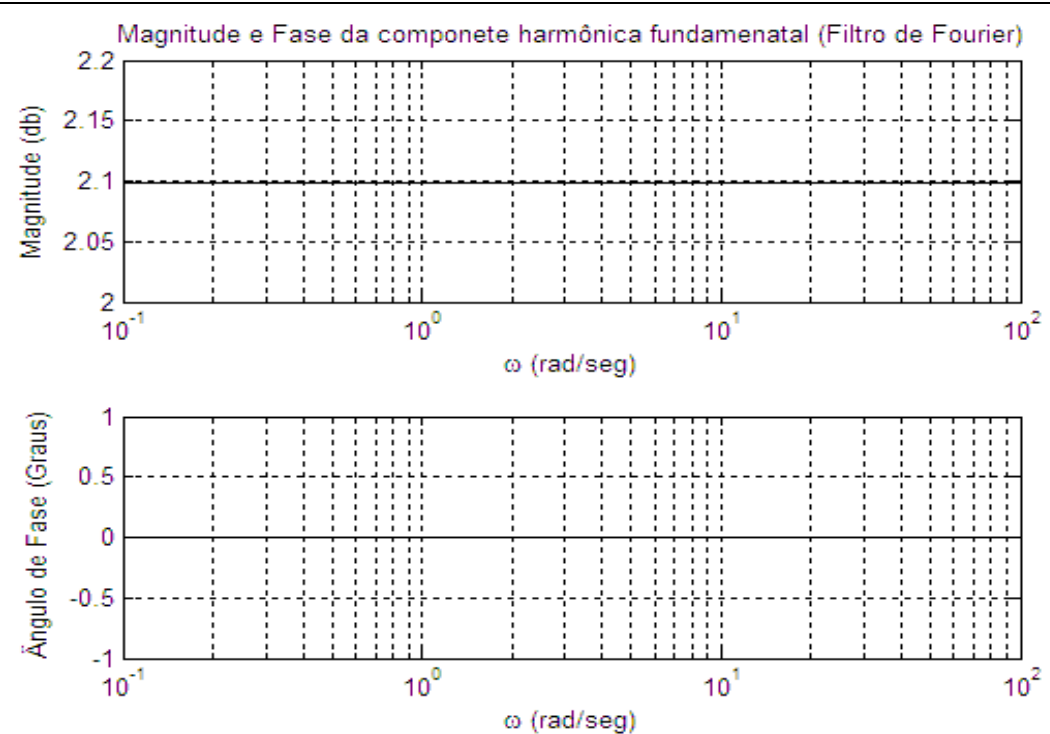

FIGURA 4.14 - Gráficos da RF obtidos através do filtro de Fourier implementado no Simulink, para a componente harmônica fundamental da onda quadrada.

Na FIGURA 4.15 podem ser observados os gráficos da magnitude e da fase, da componente harmônica fundamental da onda quadrada, obtida analiticamente por Felício (2007).
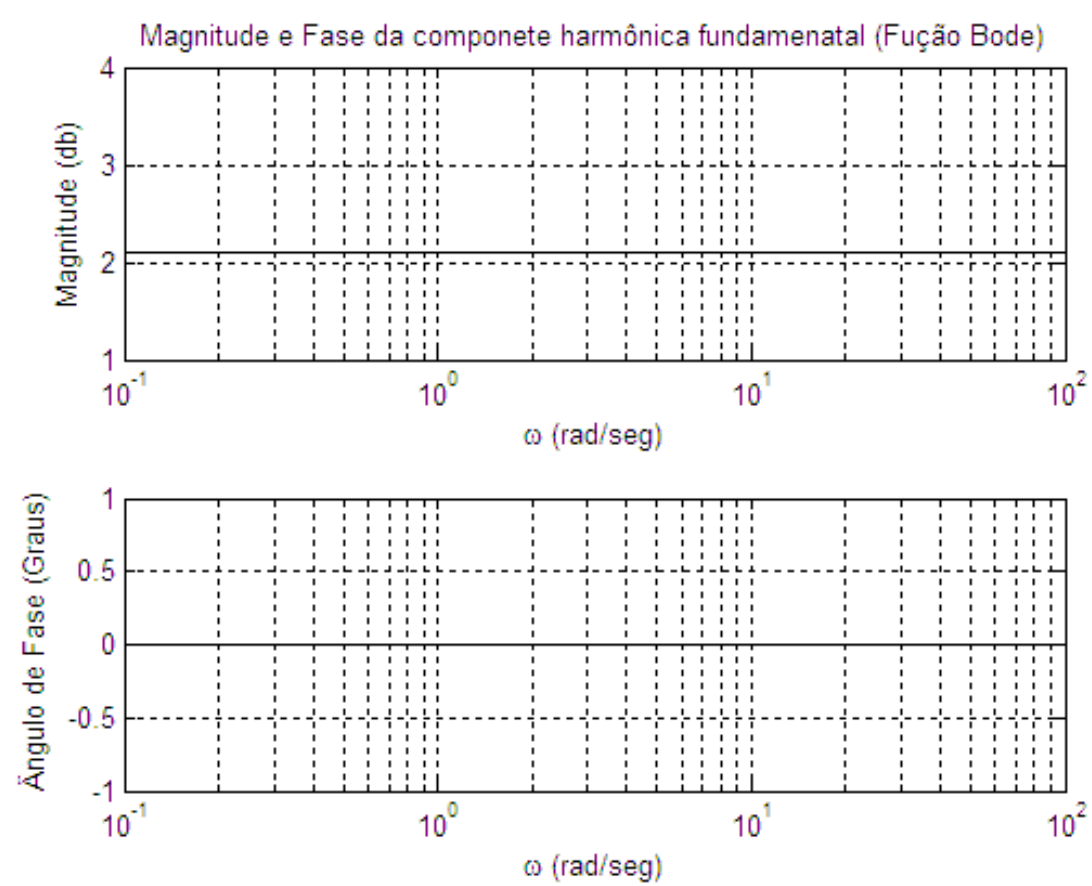

FIGURA 4.15 - Gráficos de Bode para a componente harmônica fundamental da onda quadrada. 
Os gráficos da FIGURA 4.16 mostram uma ótima concordância entre os resultados obtidos pelo filtro de Fourier e analiticamente por Felício (2007), para os valores de fase e magnitude da componente harmônica fundamental da onda quadrada.

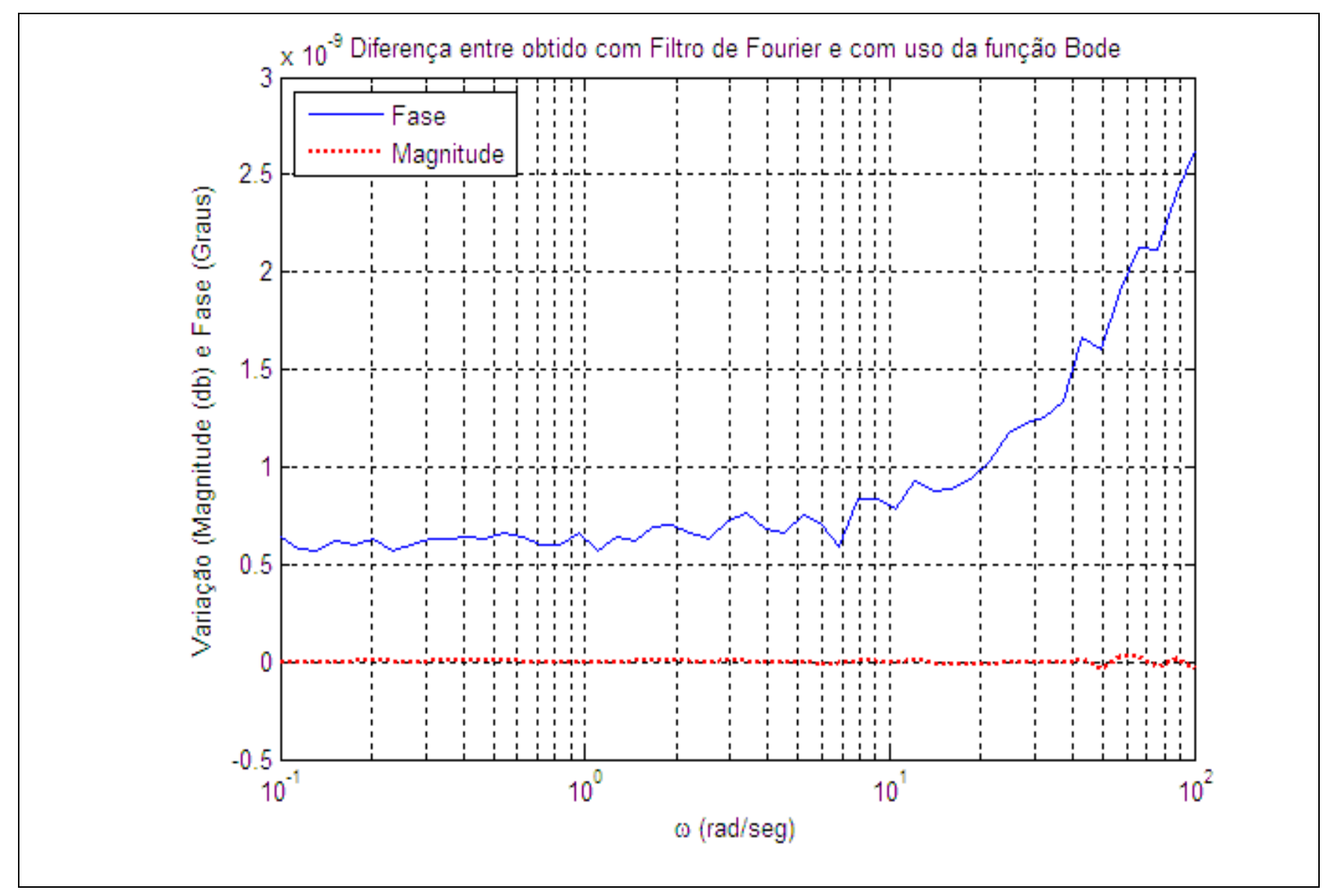

FIGURA 4.16 - Gráfico da diferença (da Fase e Magnitude) entre o obtido pela função Bode e pelo filtro de Fourier para a componente harmônica fundamental da onda quadrada.

\subsubsection{Sistema de Primeira Ordem}

Para a obtenção da resposta em freqüência do sistema de primeira ordem foram utilizados os blocos que podem ser visto na FIGURA 4.17. 


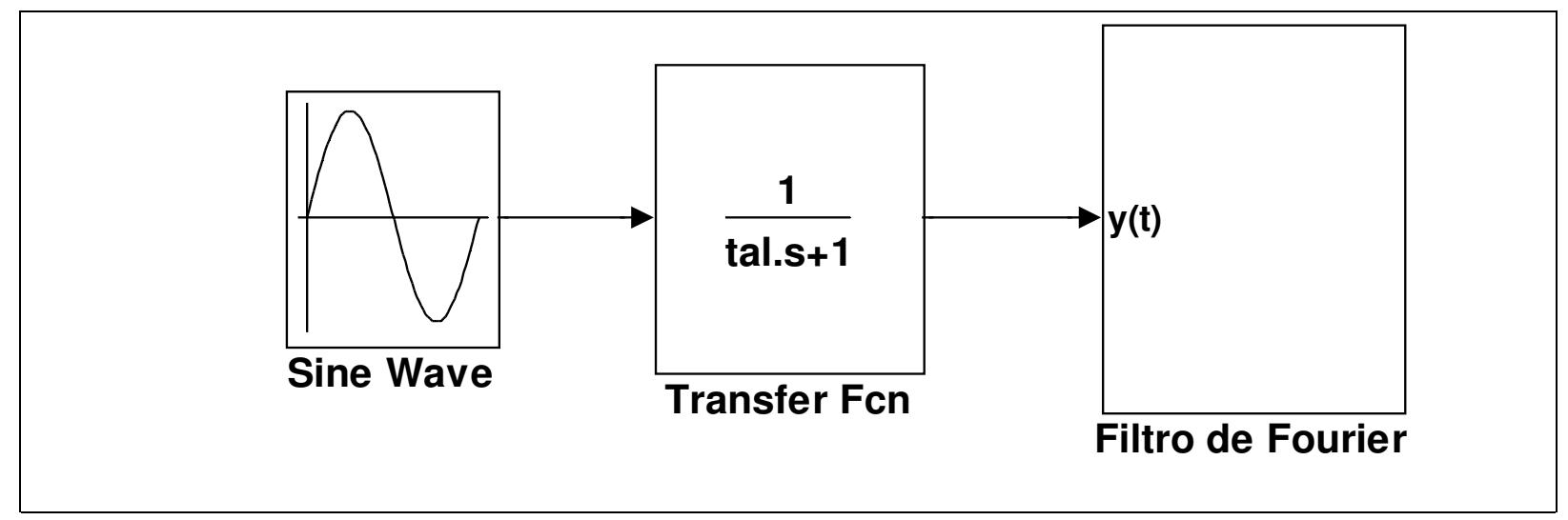

FIGURA 4.17 - Blocos para o teste do sistema de primeira ordem.

A constante de tempo tal, que é um parâmetro do sistema de primeira ordem, é requisitada pelo programa antes de ser executada a simulação no Simulink. Depois que o usuário digita o valor da constante, ela é carregada na memória para ser usada pelo bloco Transfer Fcn. Foram obtidas os gráficos da resposta em freqüências para três constantes de tempo.

As FIGURAS 4.18, 4,19 e 4,20 mostram os gráficos da RF para o sistema de primeira ordem com constante de tempo igual a $1 ; 0,1$ e 0,01 segundos, respectivamente, obtidos através do filtro de Fourier. 

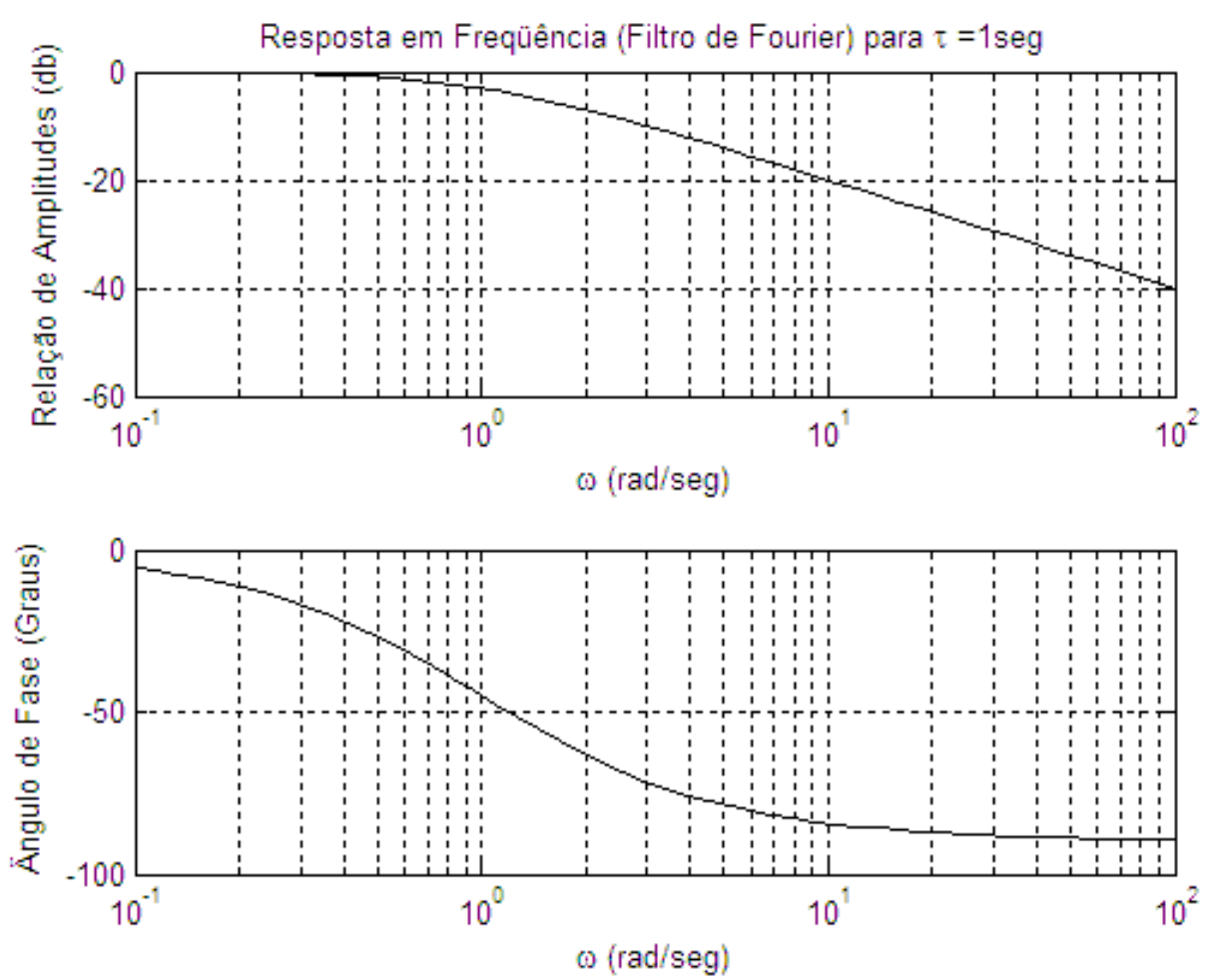

FIGURA 4.18 - Gráficos da RF para o sistema de primeira ordem com $\tau=1 \mathrm{seg}$ obtido pelo filtro de Fourier, implementado no Simulink.

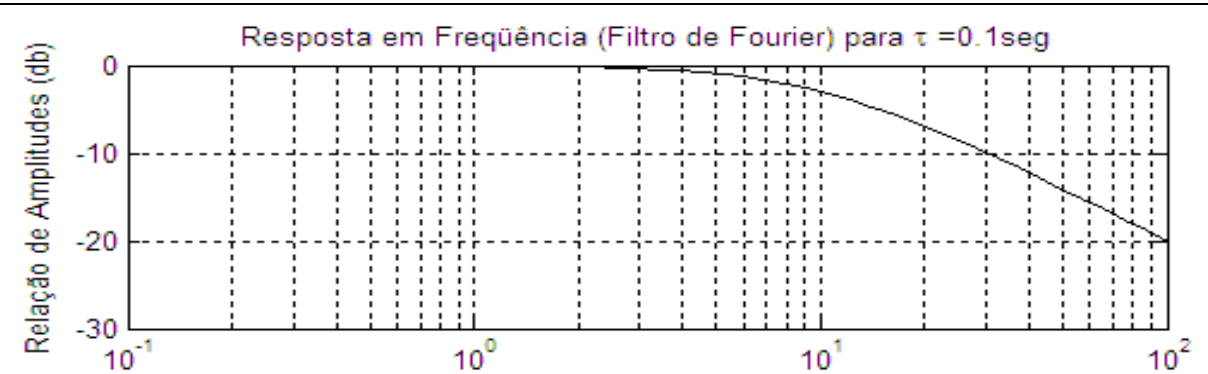

$\omega(\mathrm{rad} / \mathrm{seg})$

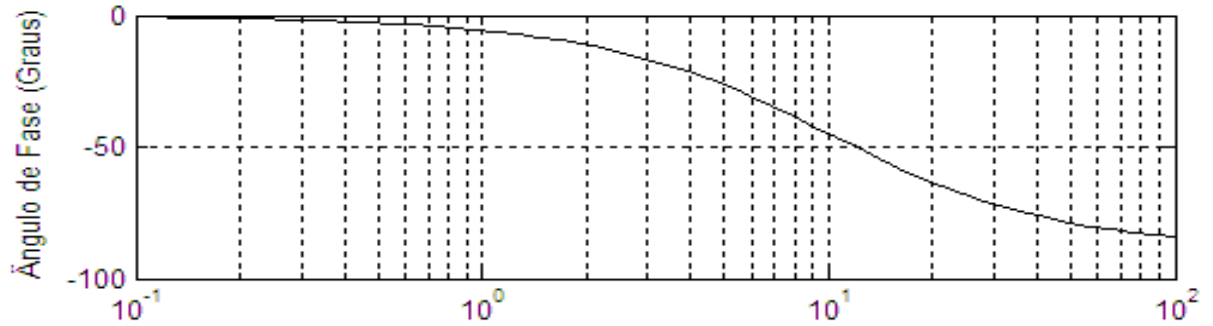

$\omega(\mathrm{rad} / \mathrm{seg})$

FIGURA 4.19 - Gráficos da RF para o sistema de primeira ordem com $\tau=0,1$ seg obtido pelo filtro de Fourier, implementado no Simulink. 

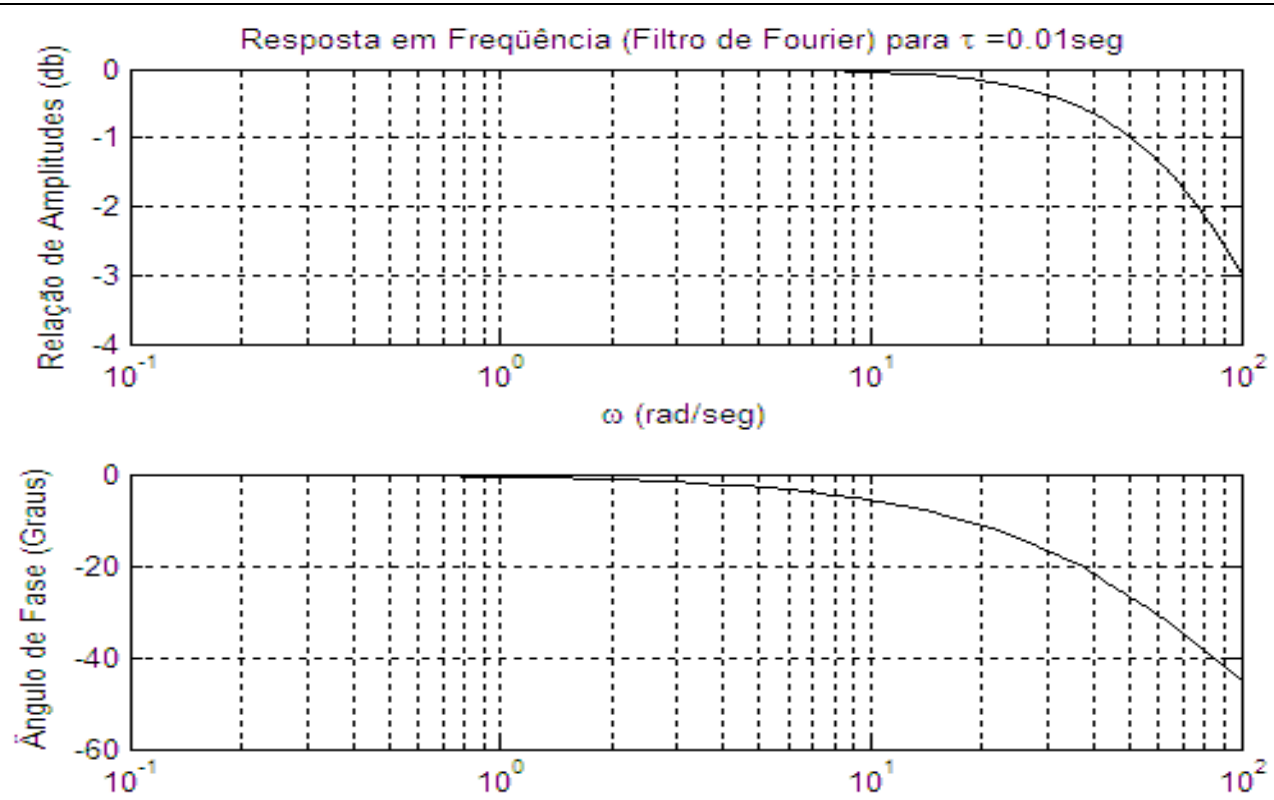

$\omega(\mathrm{rad} / \mathrm{seg})$

FIGURA 4.20 - Gráficos da RF para o sistema de primeira ordem com $\tau=0,01 \mathrm{seg}$ obtido pelo filtro de Fourier, implementado no Simulink.

Nas FIGURAS 4.21, 4.22 e 4.23 podem ser observadas as curvas da RF para o sistema de primeira onde, obtidos através da função bode do Matlab, para as constantes de tempo iguais a 1; 0,1 e 0,01 segundos, respectivamente.
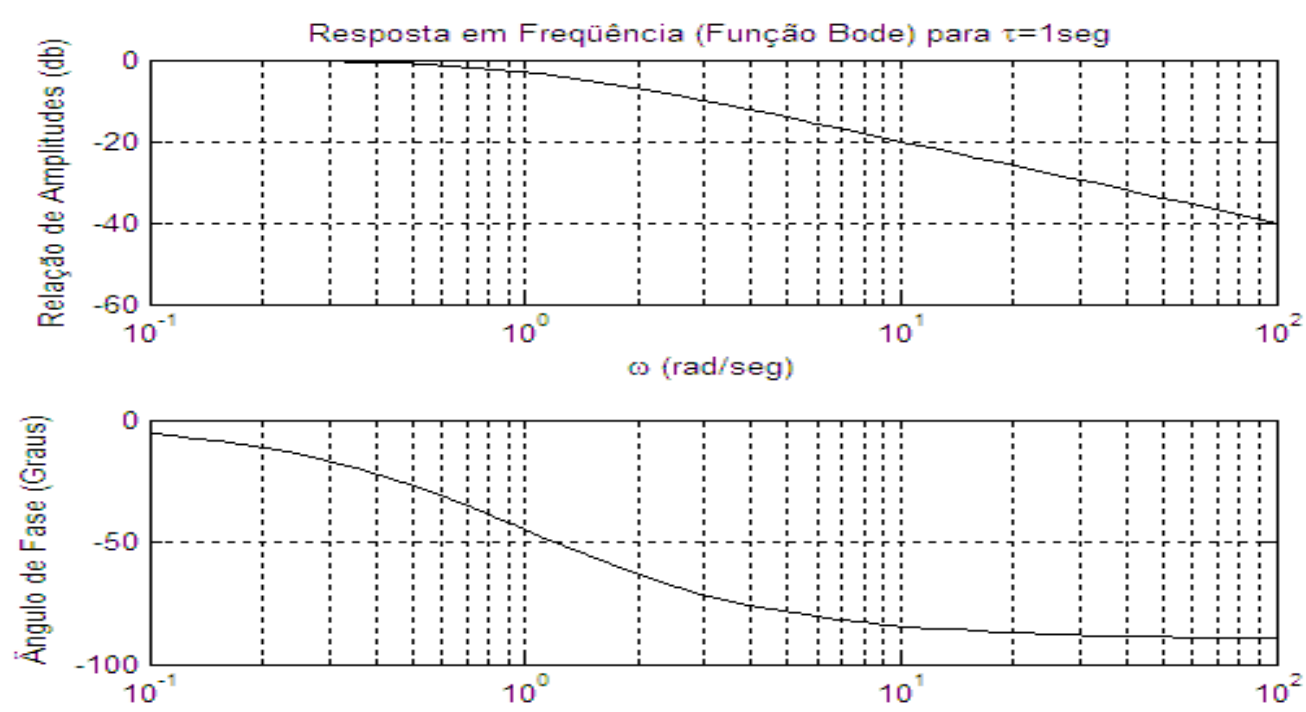

$\omega(\mathrm{rad} / \mathrm{seg})$

FIGURA 4.21 - Gráficos de Bode para o sistema de primeira ordem com $\tau=1 \mathrm{seg}$ • 


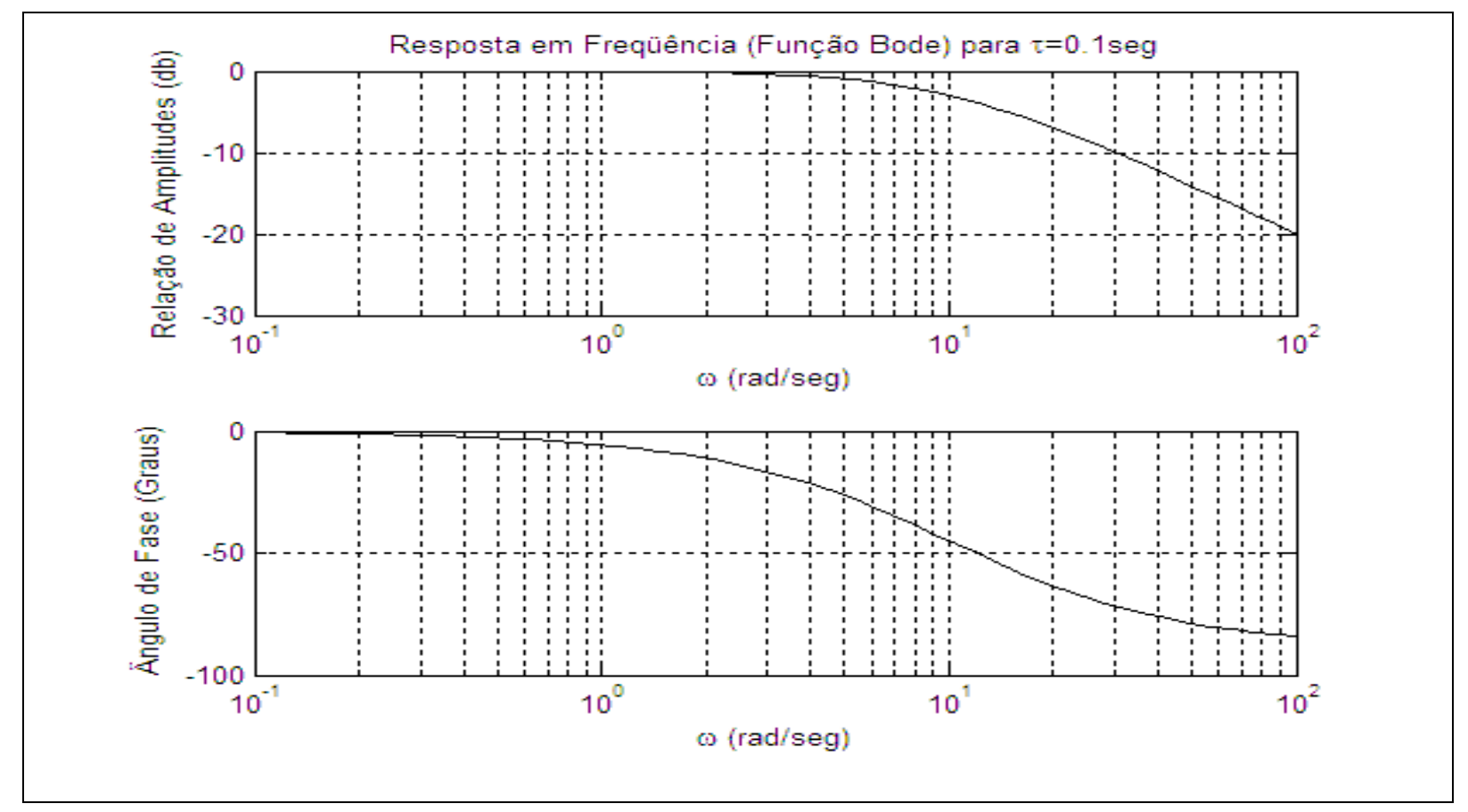

FIGURA 4.22 - Gráficos de Bode para o sistema de primeira ordem com $\tau=0,1 \mathrm{seg}$

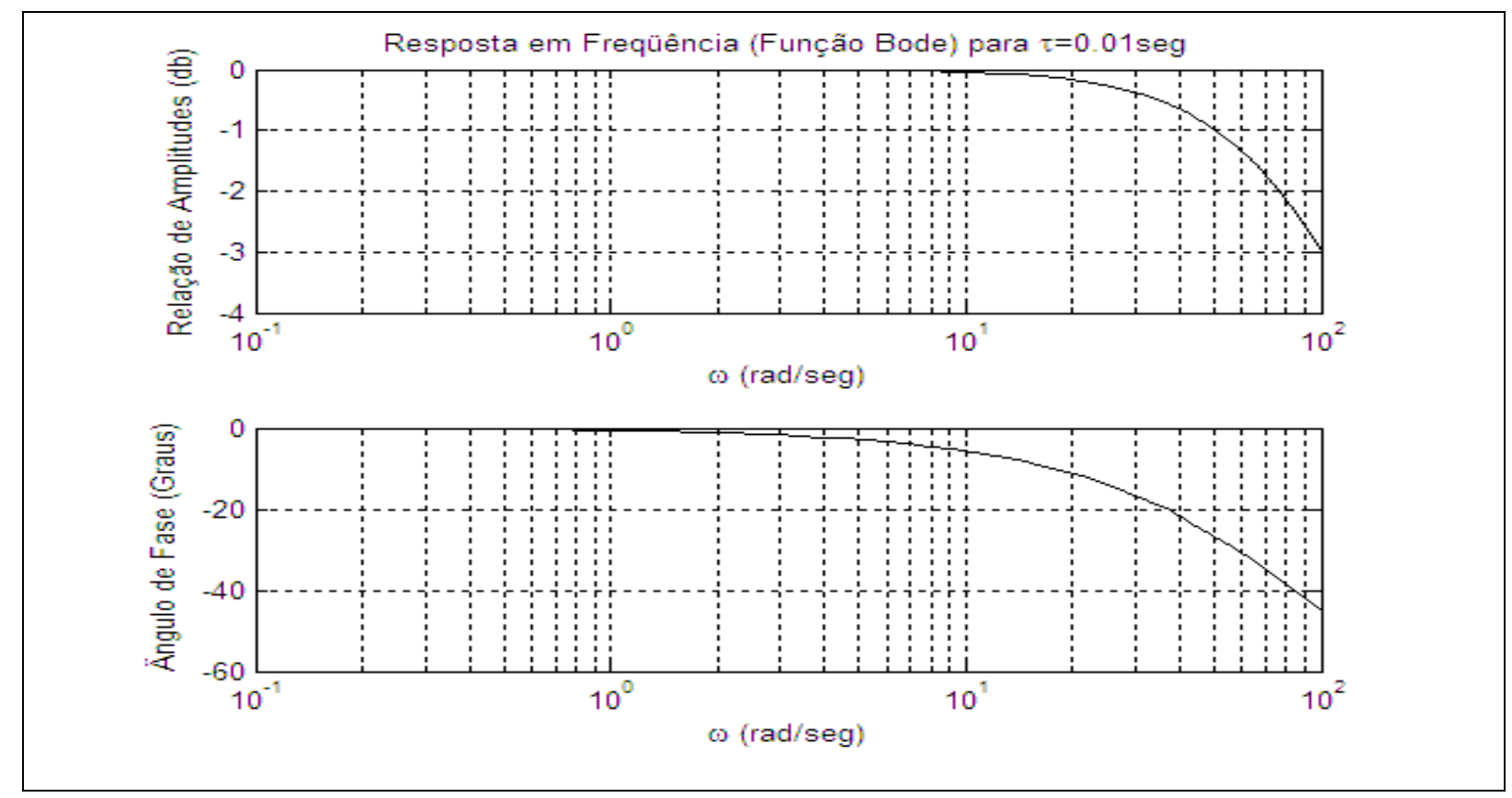

FIGURA 4.23 - Gráficos de Bode para o sistema de primeira ordem com $\tau=0,01 \mathrm{seg}$

Como pode ser observado nos gráficos das FIGURAS 4.24, 4.25 e 4.26 os resultados obtidos através da simulação e pela função bode do Matlab apresentaram uma ótima 
concordância visto que os valores nos gráficos da variação da fase e da magnitude em função da freqüência são muito pequenos.

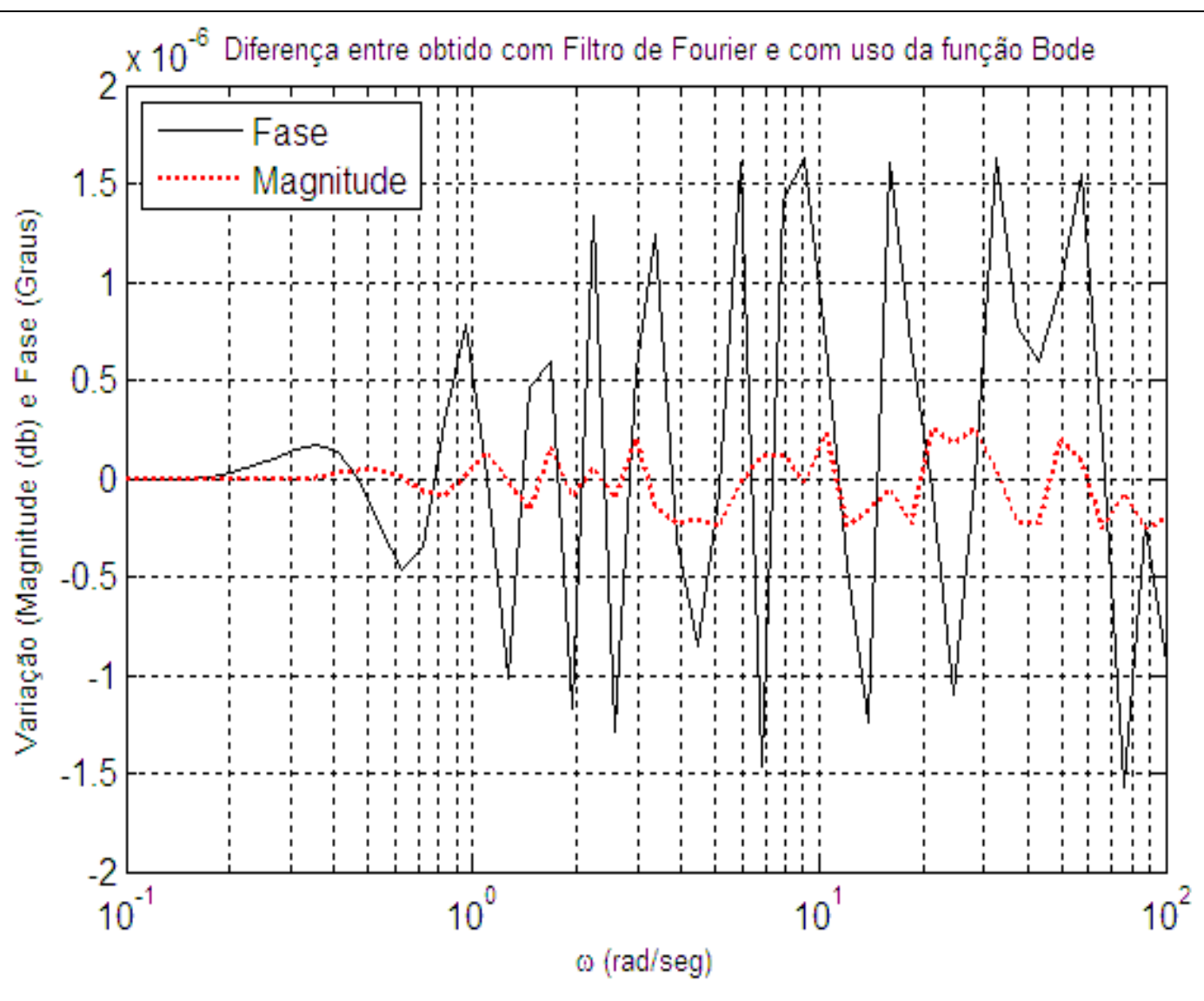

FIGURA 4.24 - Gráfico (da Fase e Magnitude) entre obtido pelo filtro de Fourier e com o uso da função bode para sistema de primeira ordem com $\tau=1 \mathrm{seg}$. 


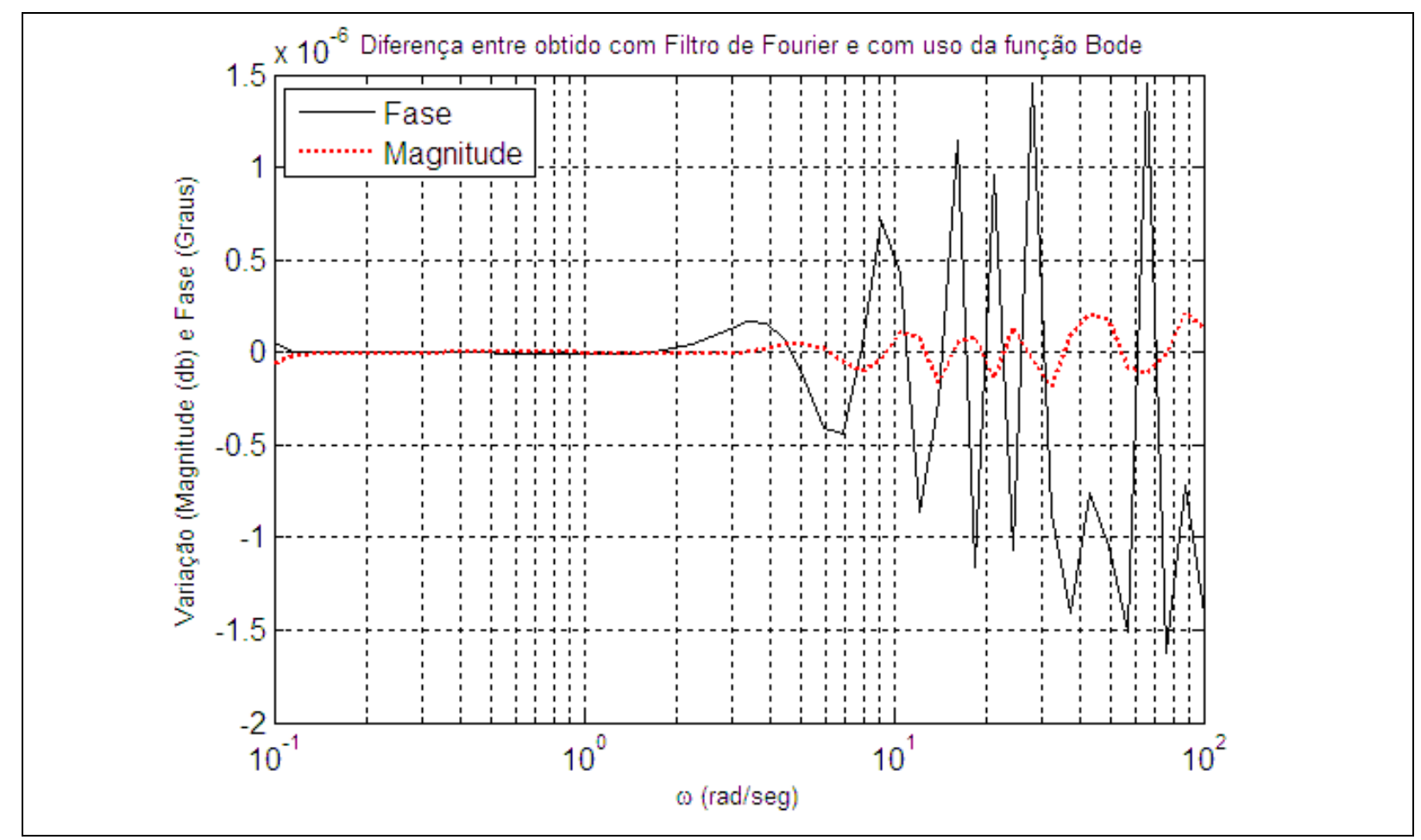

FIGURA 4.25 - Gráfico da diferença (da Fase e Magnitude) entre obtido pelo filtro de Fourier e com o uso da função bode para sistema de primeira ordem com $\tau=0,1 \mathrm{seg}$.

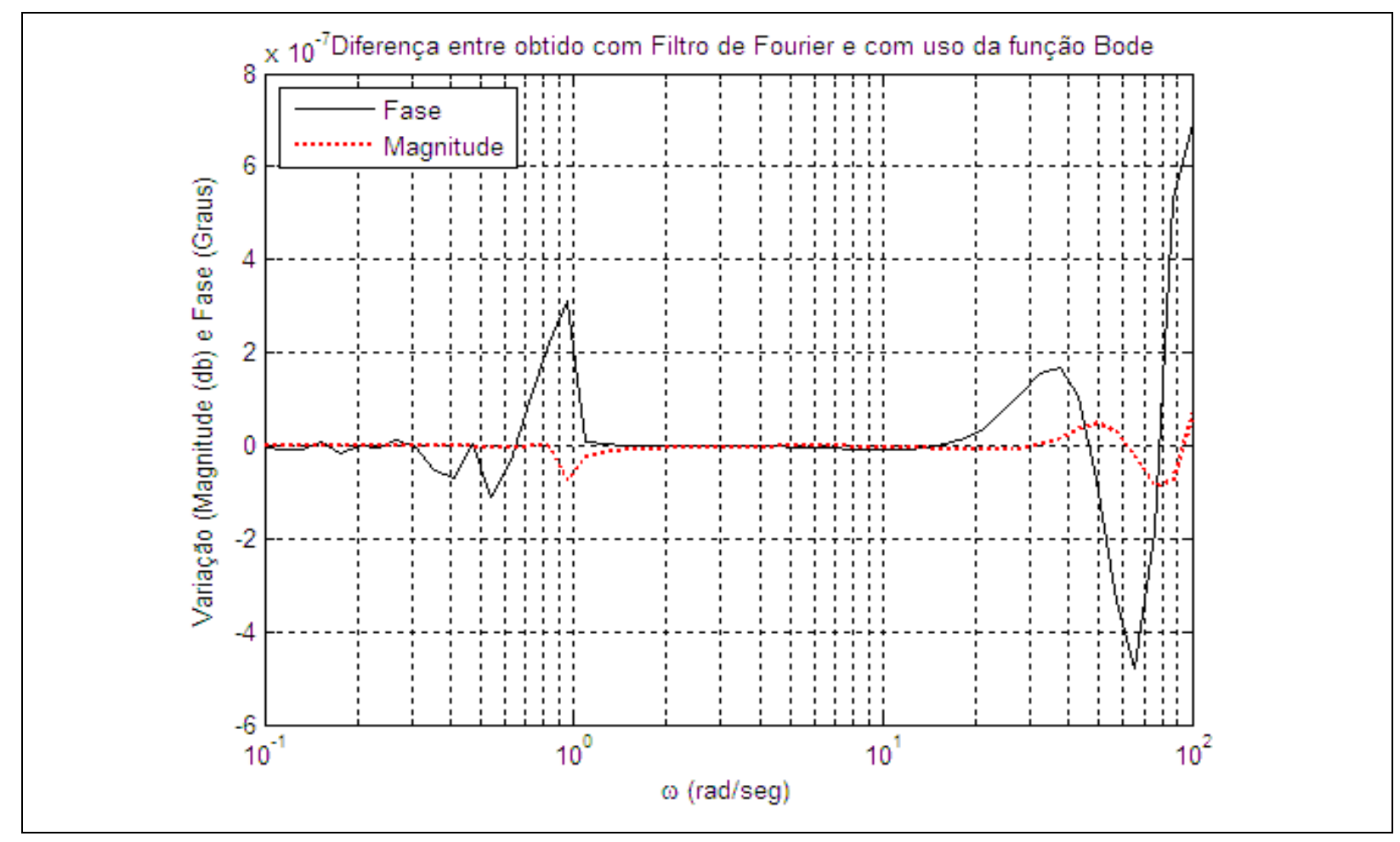

FIGURA 4.26 - Gráfico da diferença (da Fase e Magnitude) entre obtido pelo filtro de Fourier e com o uso da função bode para sistema de primeira ordem com $\tau=0,01 \mathrm{seg}$. 


\subsubsection{Sistema de Segunda Ordem}

O último sistema testado para garantir a acuracidade do método para obtenção da RF através do filtro de Fourier implementado no Simulink foi o sistema de segunda ordem. Mais uma vez o bloco Transfer Fcn foi empregado para criar um sistema de segunda ordem, como pode ser observado na FIGURA 4.27, com os fatores $\mathrm{A}$ e $\mathrm{B}$, onde $\mathrm{A}=1 / \omega_{n}^{2}$ e $\mathrm{B}=2 \zeta / \omega_{n}$.

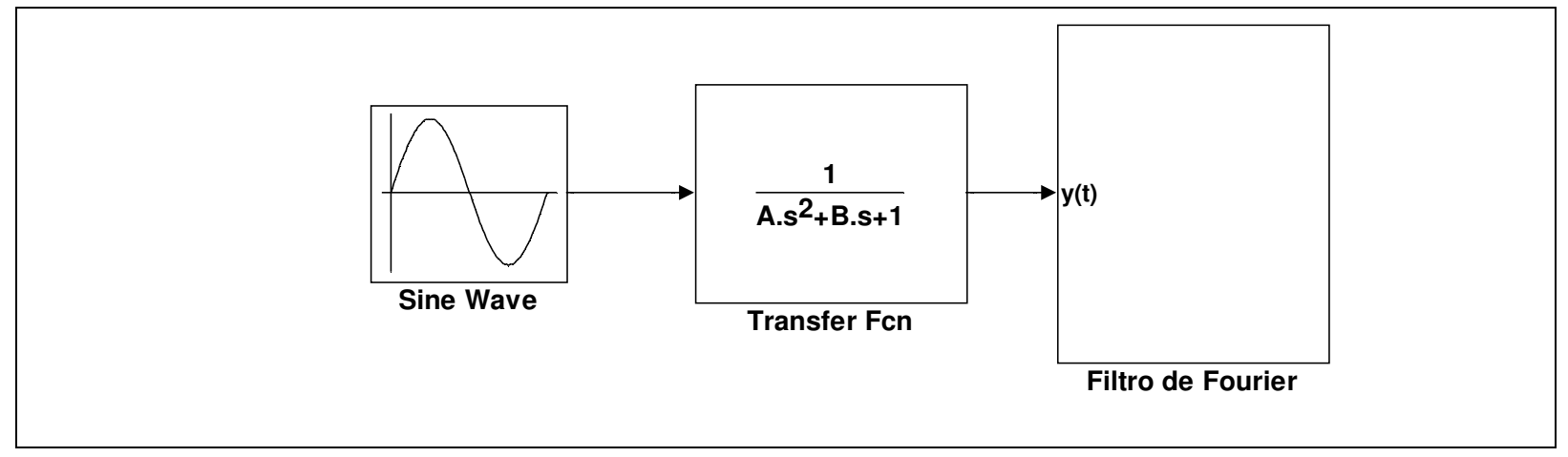

FIGURA 4.27 - Blocos para o teste do sistema de segunda ordem.

Para calcular os fatores A e B o programa do Matlab solicita ao usuário a freqüência natural $\left(\omega_{n}\right)$ e o coeficiente de amortecimento $(\zeta)$ do sistema de segunda ordem que se deseja obter a resposta em freqüência. Esses fatores são calculados automaticamente, dentro do programa do Matlab, assim que o usuário fornece as informações.

O filtro de Fourier para obtenção da RF foi testados para quatro sistemas de segunda ordem. Todos possuíam freqüência natural igual a $10 \mathrm{rad} / \mathrm{s}$ e coeficientes de amortecimento diferentes, valendo 0,$1 ; 0,01 ; 0,004$ e 0,001 . Os gráficos da RF para estes quatros sistemas de segunda ordem obtidos pelo filtro de Fourier podem ser observados nas FIGURAS 4.28, 4.29, 4.30 e 4.31 . 


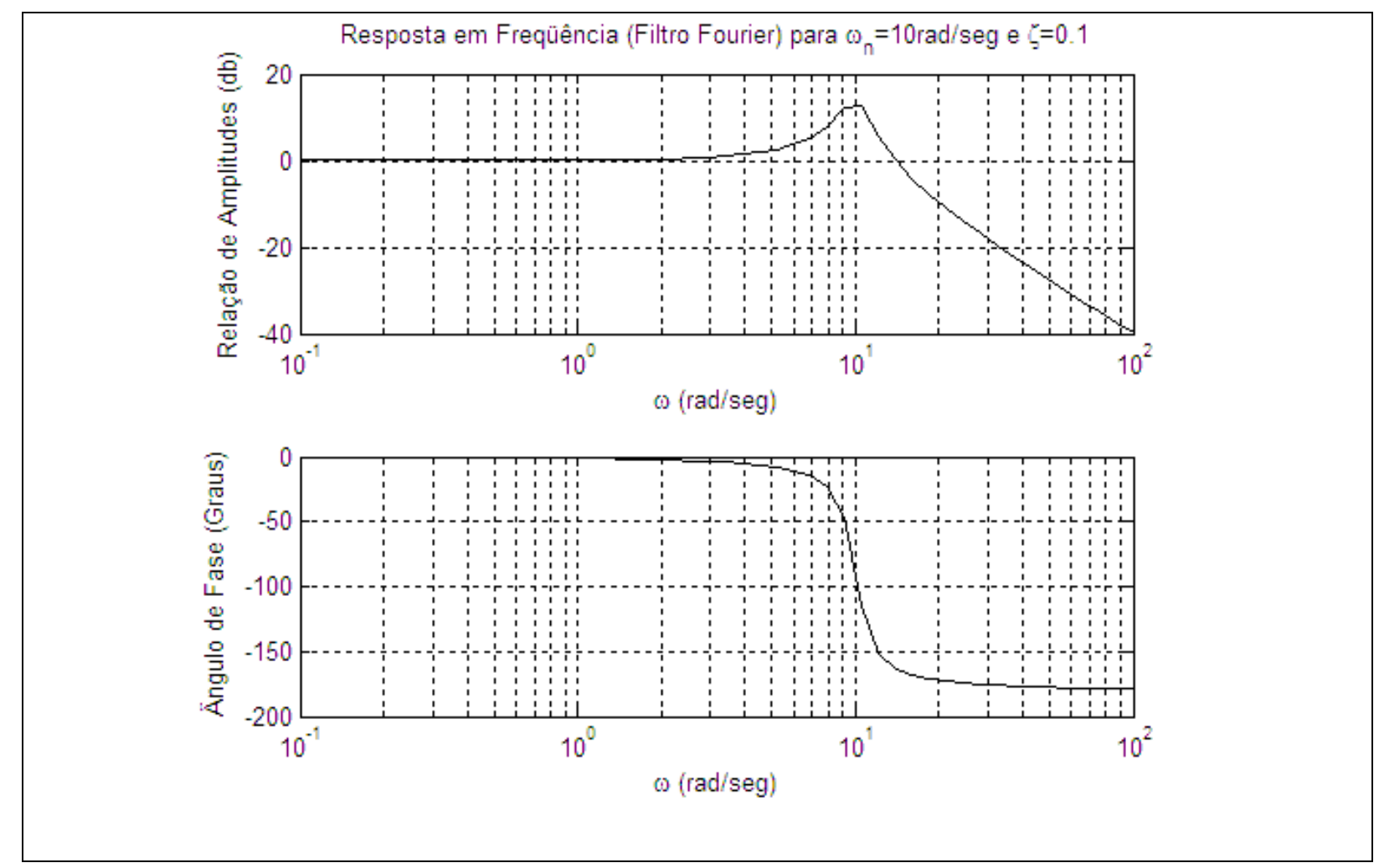

FIGURA 4.28 - Gráficos da RF obtidos através do Filtro de Fourier implementado no Simulink para o sistema de segunda ordem com $\omega_{n}=10 \mathrm{rad} / \mathrm{seg}$ e $\zeta=0,1$

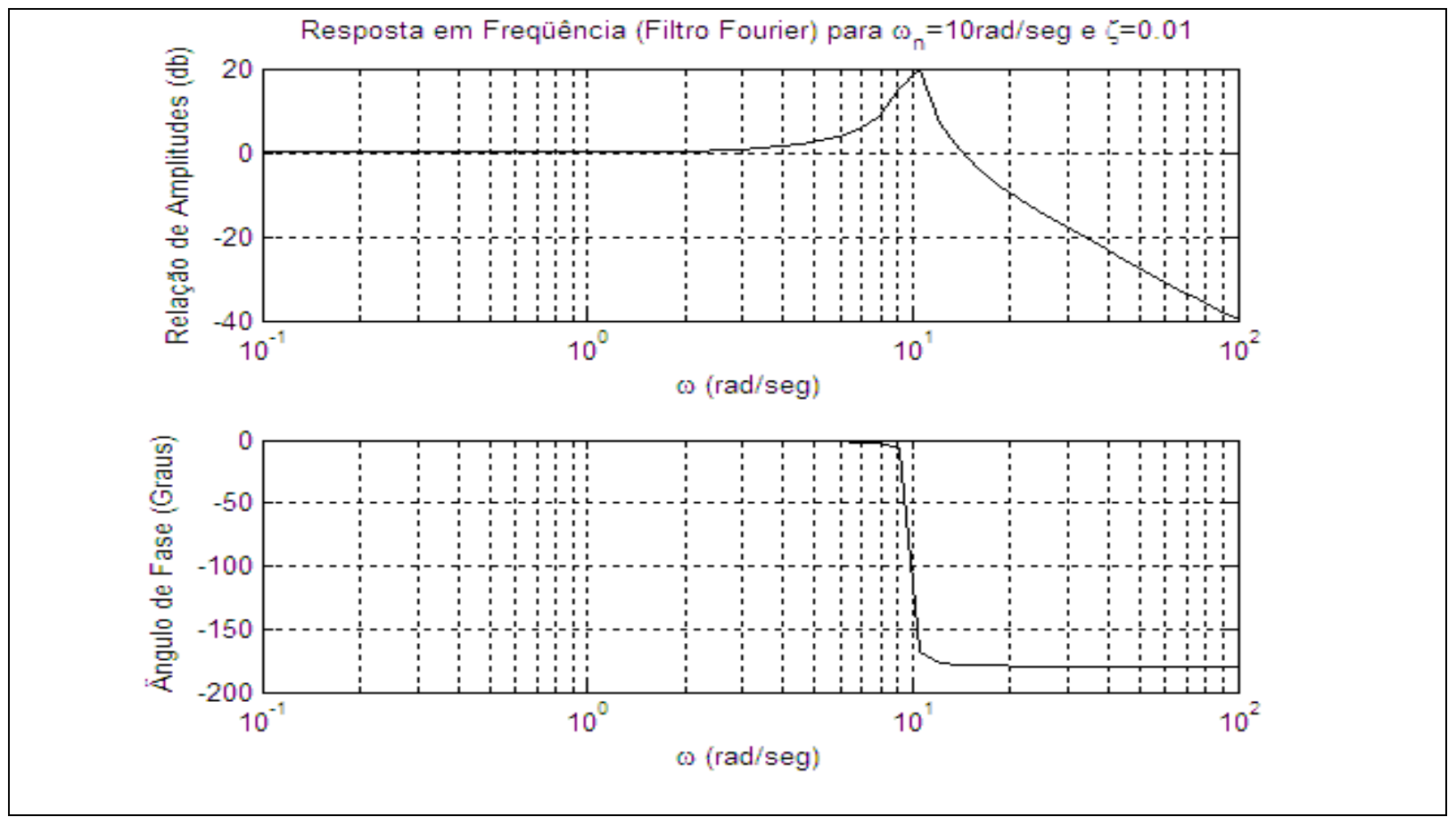

FIGURA 4.29 - Gráficos da RF obtidos através do Filtro de Fourier implementado no Simulink para o sistema de segunda ordem com $\omega_{n}=10 \mathrm{rad} / \mathrm{seg}$ e $\zeta=0,01$ 

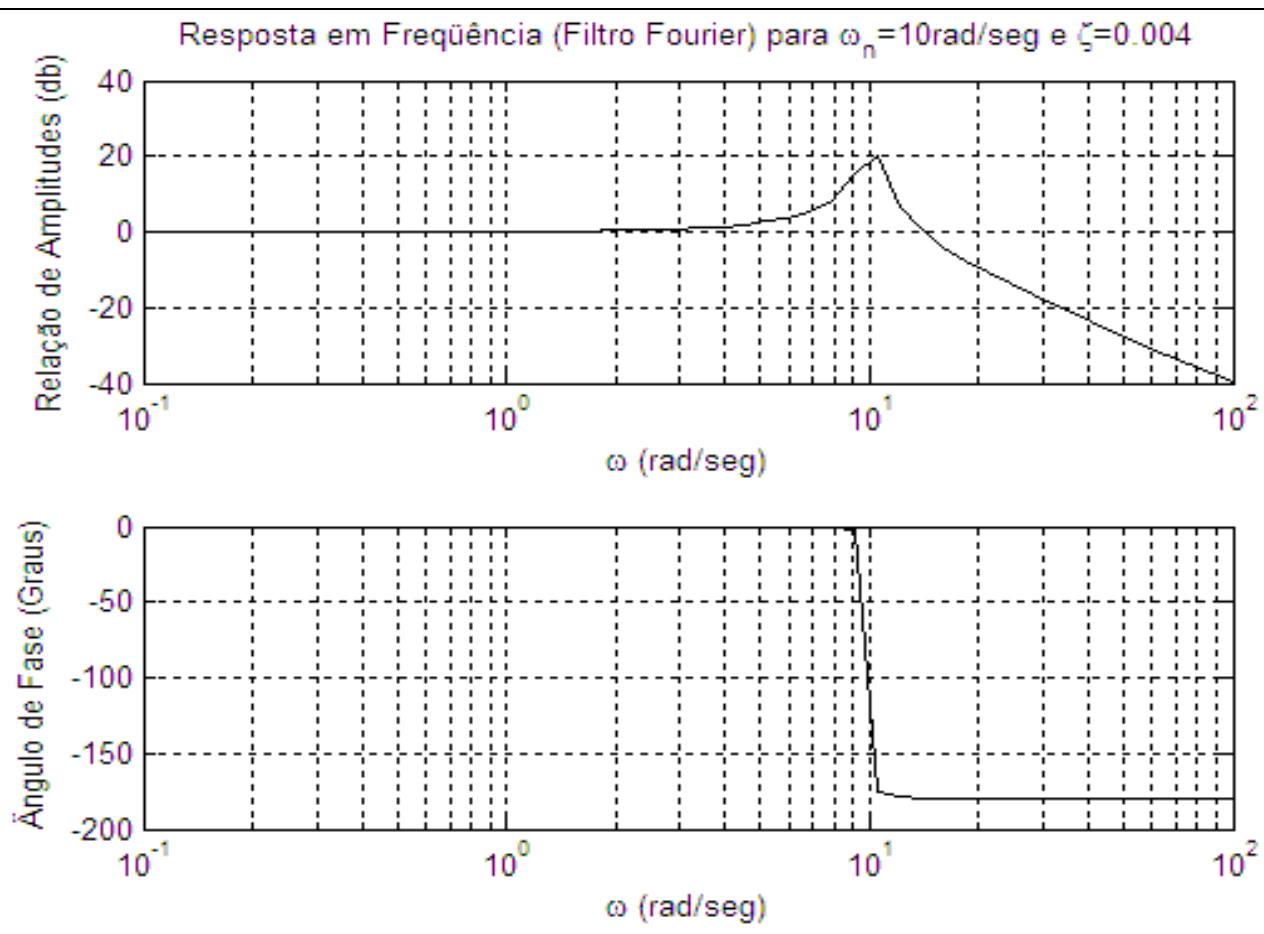

FIGURA 4.30 - Gráficos da RF obtidos através do Filtro de Fourier implementado no Simulink para o sistema de segunda ordem com $\omega_{n}=10 \mathrm{rad} / \mathrm{seg}$ e $\zeta=0,004$
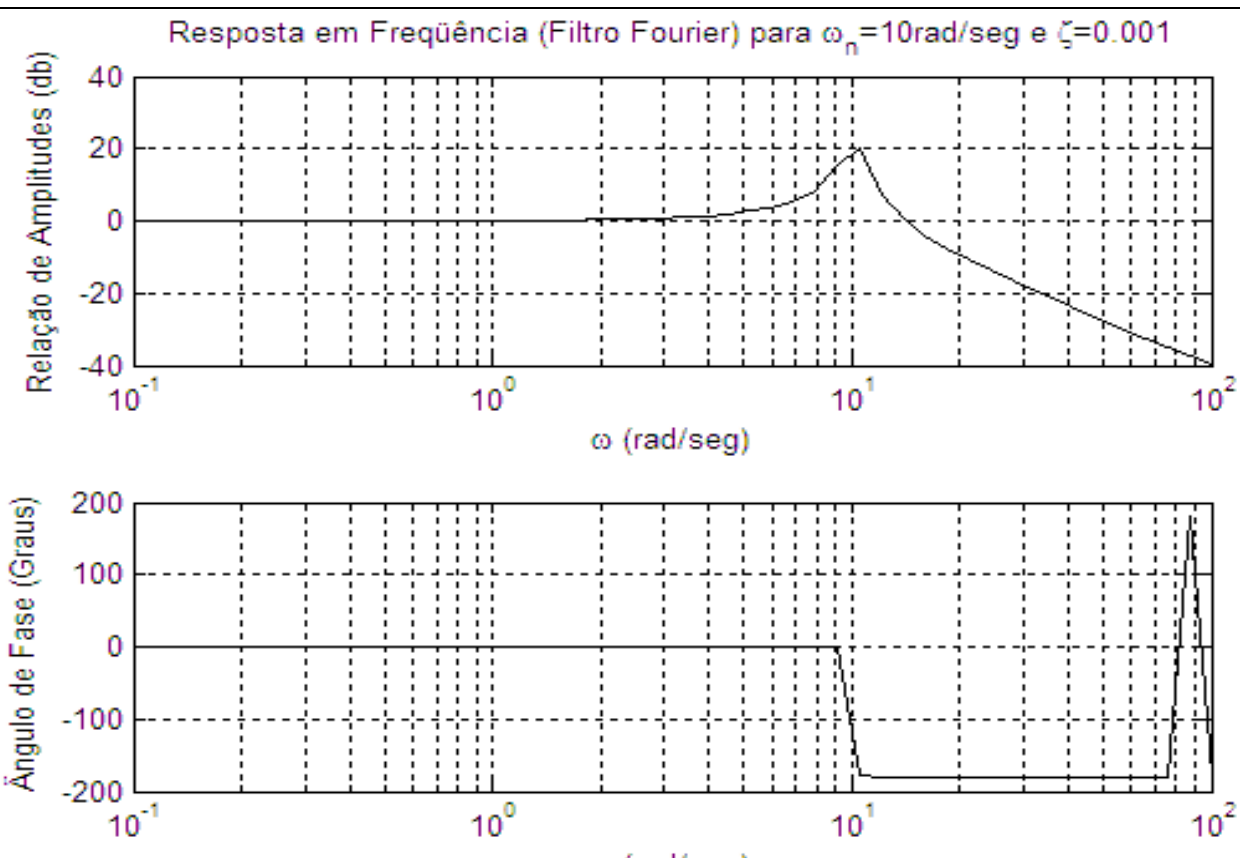

$\omega(\mathrm{rad} / \mathrm{seg})$

FIGURA 4.31 - Gráficos da RF obtidos através do Filtro de Fourier implementado no Simulink para o sistema de segunda ordem com $\omega_{n}=10 \mathrm{rad} / \mathrm{seg}$ e $\zeta=0,001$ 
As FIGURAS 4.32, 4.33, 4.34 e 4.35 mostram os gráficos da RF, obtidos através da função bode do Matlab, para os sistemas de segunda ordem com freqüência natural igual a 10 $\mathrm{rad} / \mathrm{seg}$ e coeficientes de amortecimento iguais a 0,$1 ; 0,01 ; 0,004$ e 0,001 , respectivamente.

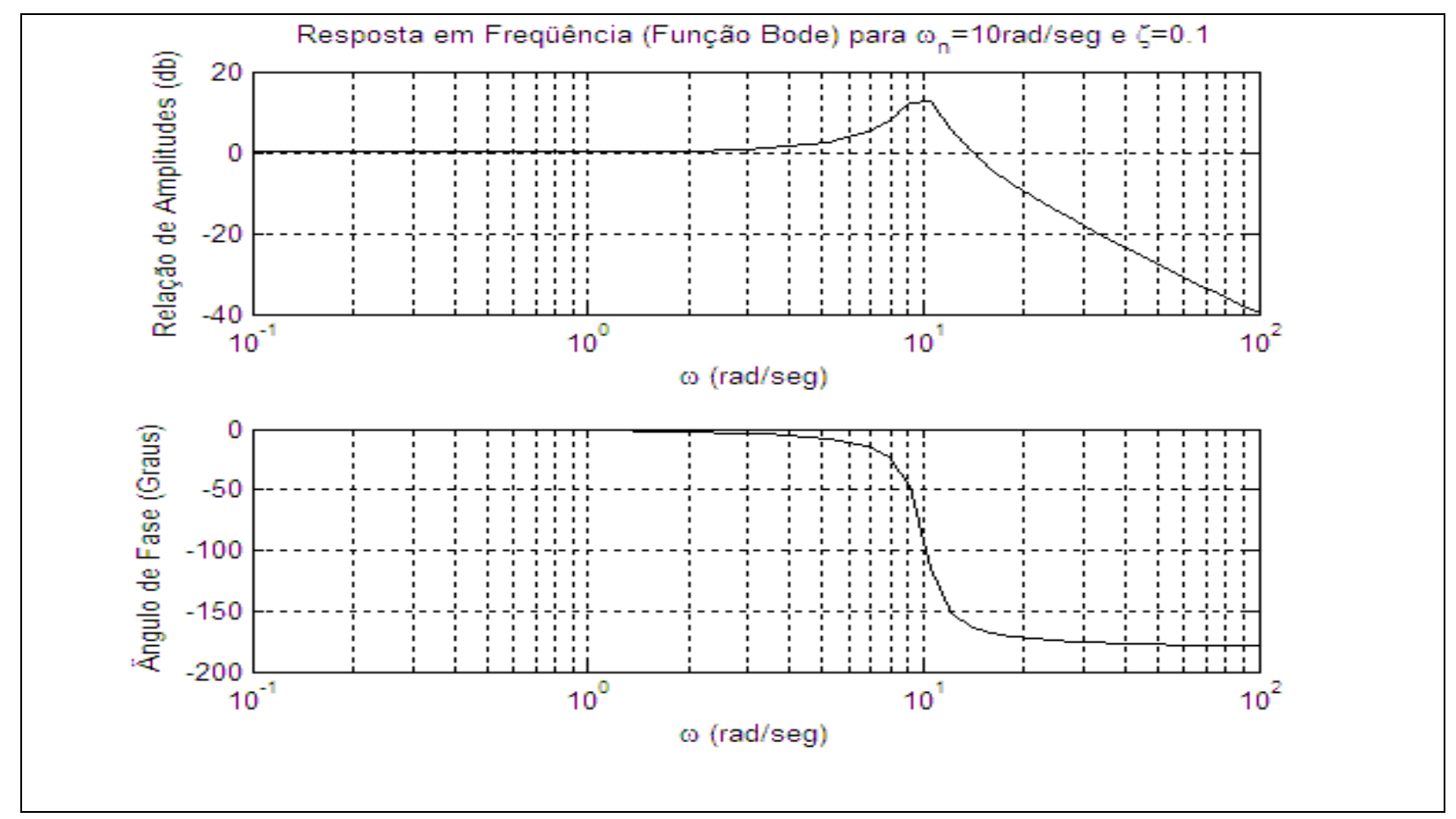

FIGURA 4.32 - Gráficos de Bode para o sistema de segunda ordem com $\omega_{n} 10 \mathrm{rad} / \mathrm{seg} \zeta=0,1$. 

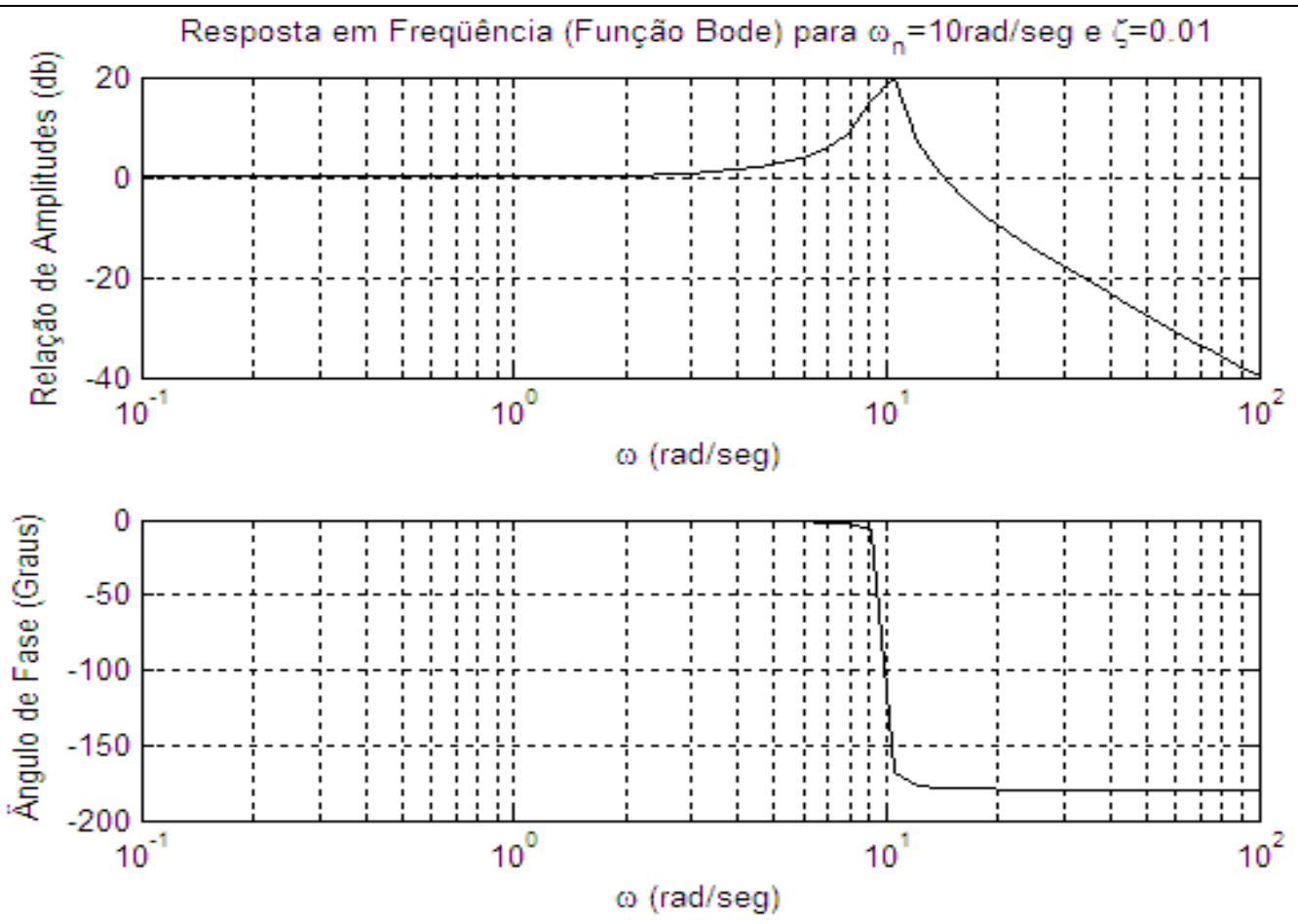

FIGURA 4.33 - Gráficos de Bode para o sistema de segunda ordem com $\omega_{n} 10 \mathrm{rad} / \mathrm{seg} \zeta=0,01$.

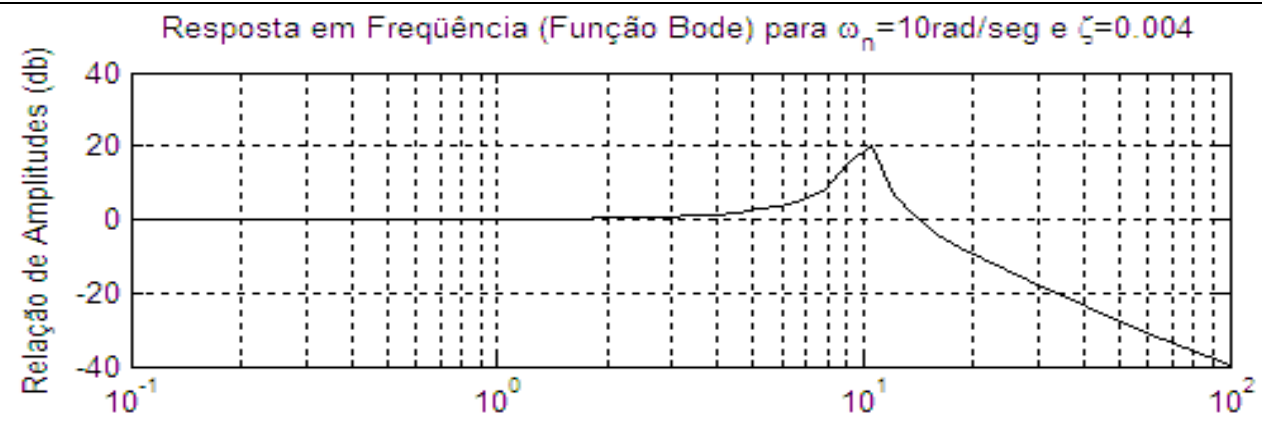

$\omega(\mathrm{rad} / \mathrm{seg})$

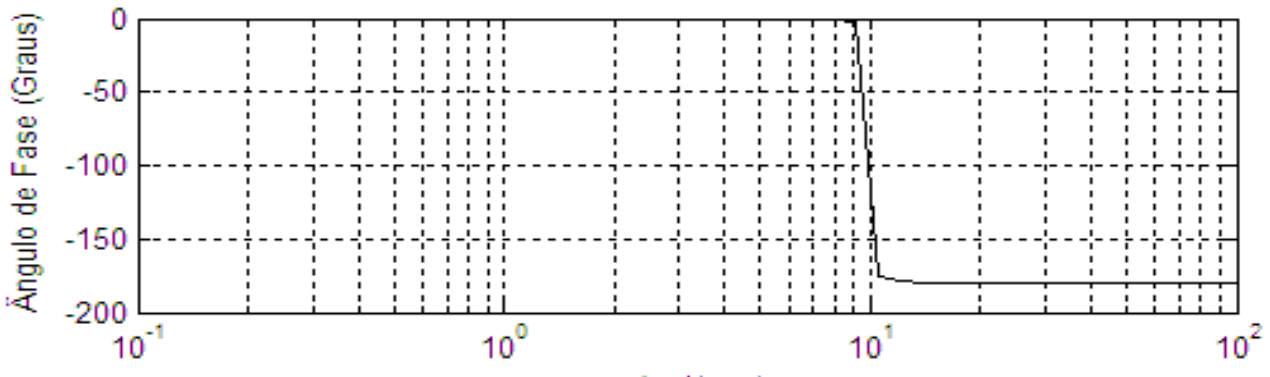

FIGURA 4.34 - Gráficos de Bode para o sistema de segunda ordem com $\omega_{n} 10 \mathrm{rad} / \mathrm{seg}$ $\zeta=0,004$. 


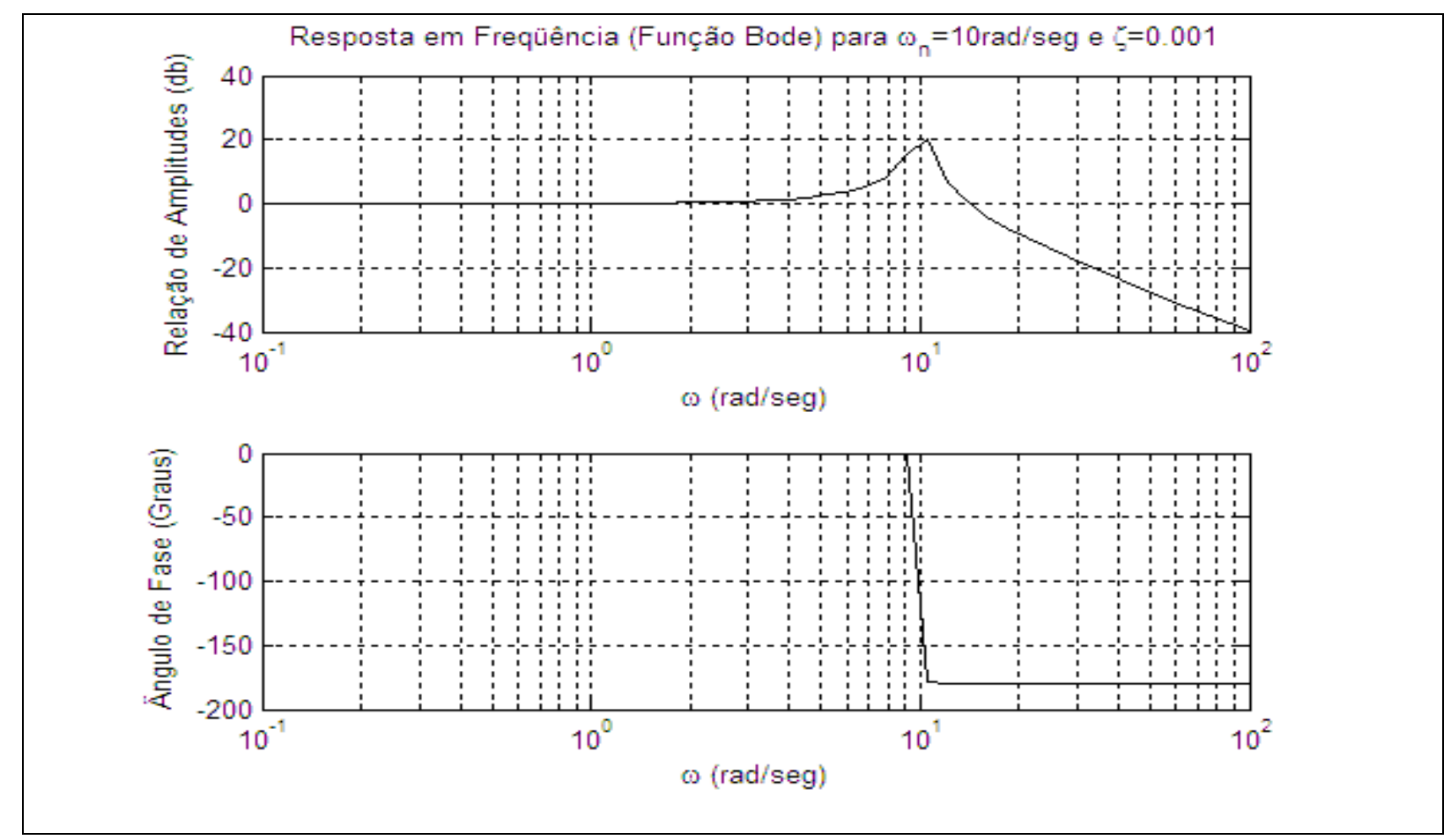

FIGURA 4.35 - Gráficos de Bode para o sistema de segunda ordem com $\omega_{n} 10 \mathrm{rad} / \mathrm{seg}$ e $\zeta=0,001$.

As FIGURAS 4.36, 4.37, 4.38 e 4.39 trazem os gráficos da variação da magnitude e fase entre o obtido através de simulação e através da função bode, do Matlab para os sistemas de segunda ordem com freqüência natural igual a $10 \mathrm{rad} / \mathrm{seg}$ e coeficiente de amortecimento iguais a 0,$1 ; 0,01 ; 0,004$ e 0,001 , respectivamente. 


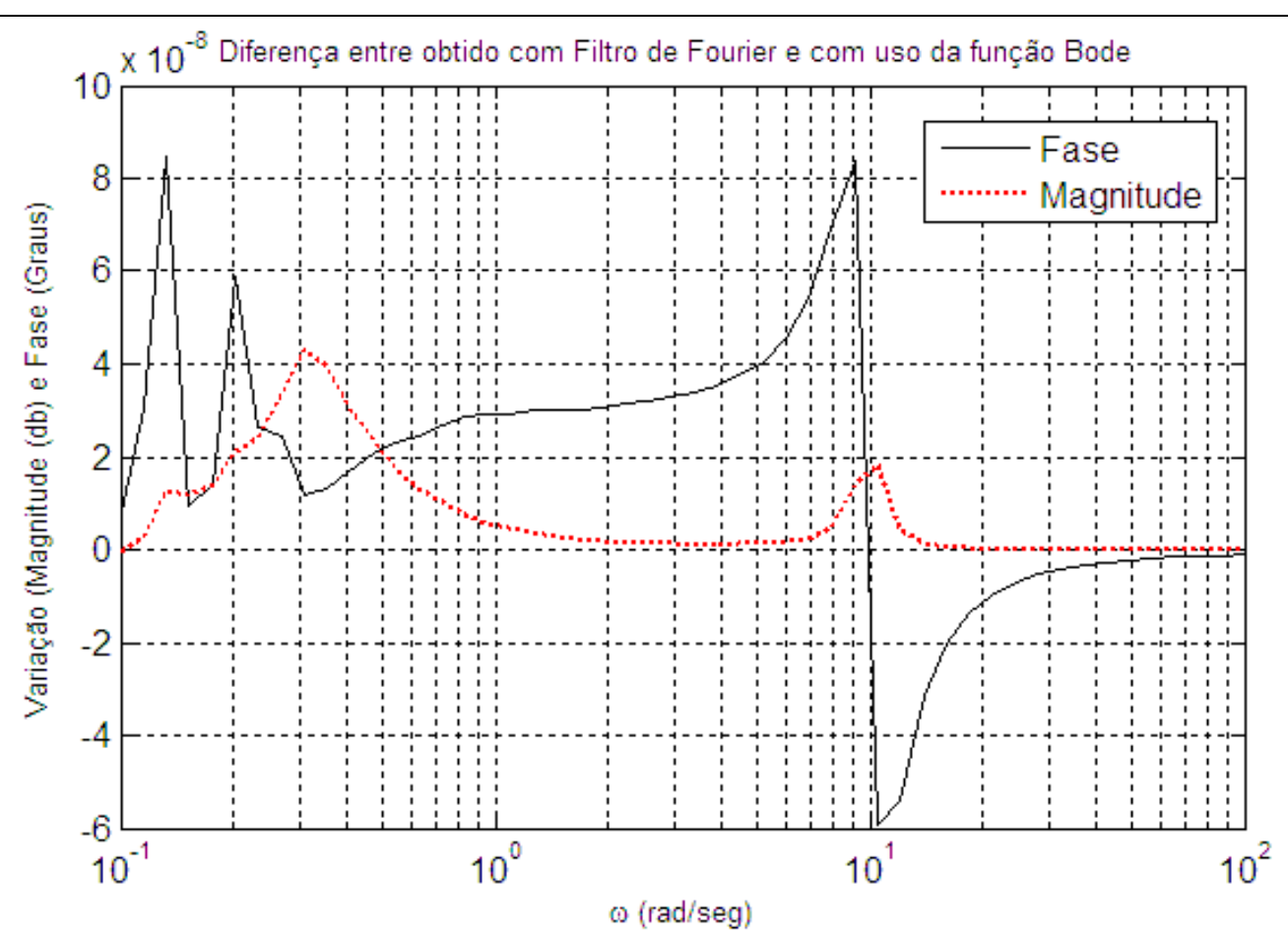

FIGURA 4.36 - Gráfico da diferença entre o obtido pelo filtro de Fourier e com o uso da função bode para um sistema de segunda ordem com $\omega_{n} 10 \mathrm{rad} / \mathrm{s}$ e $\zeta=0,1$

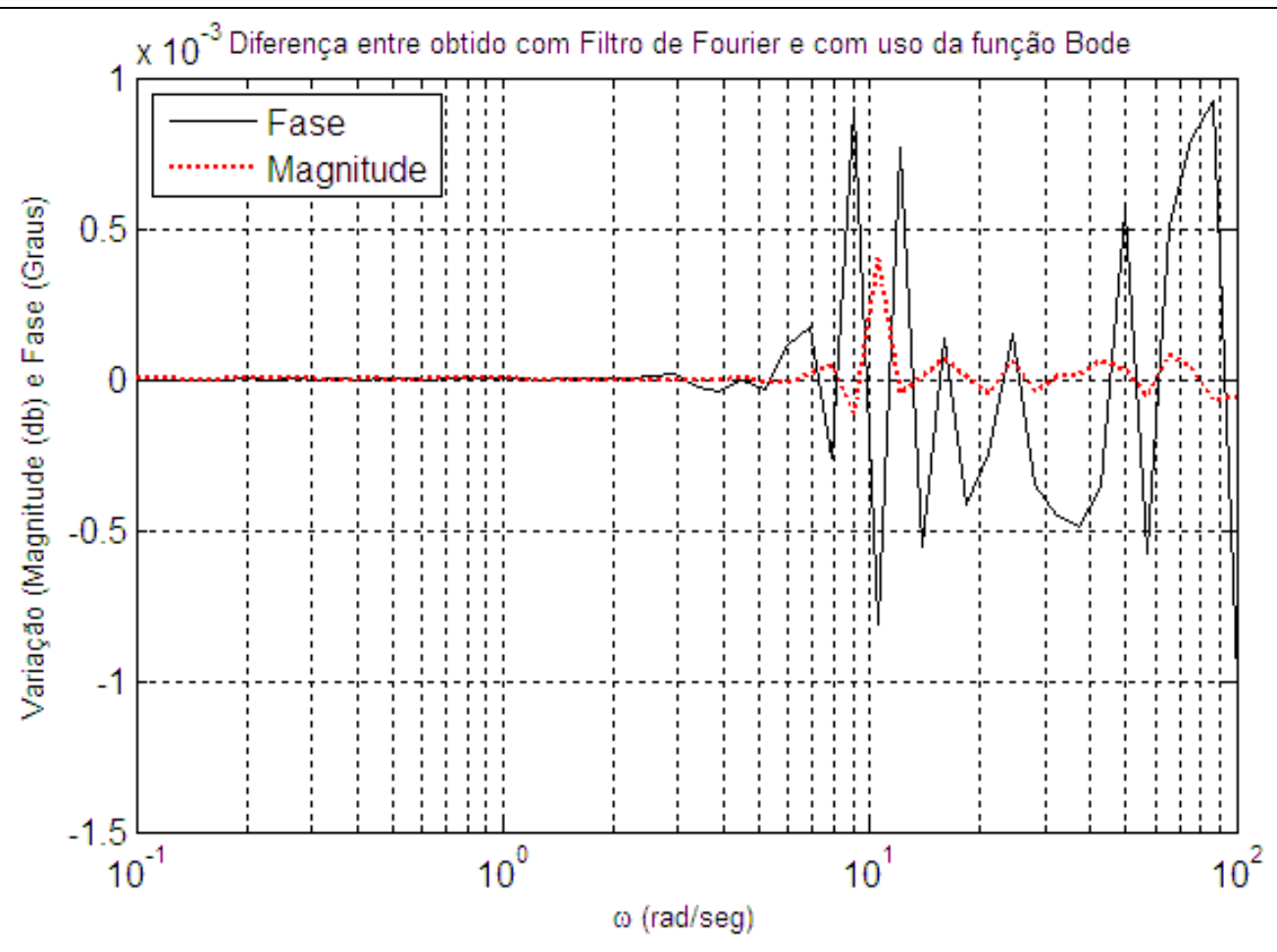

FIGURA 4.37 - Gráfico da diferença entre o obtido pelo filtro de Fourier e com o uso da função bode para um sistema de segunda ordem com $\omega_{n} 10 \mathrm{rad} / \mathrm{s}$ e $\zeta=0,01$. 


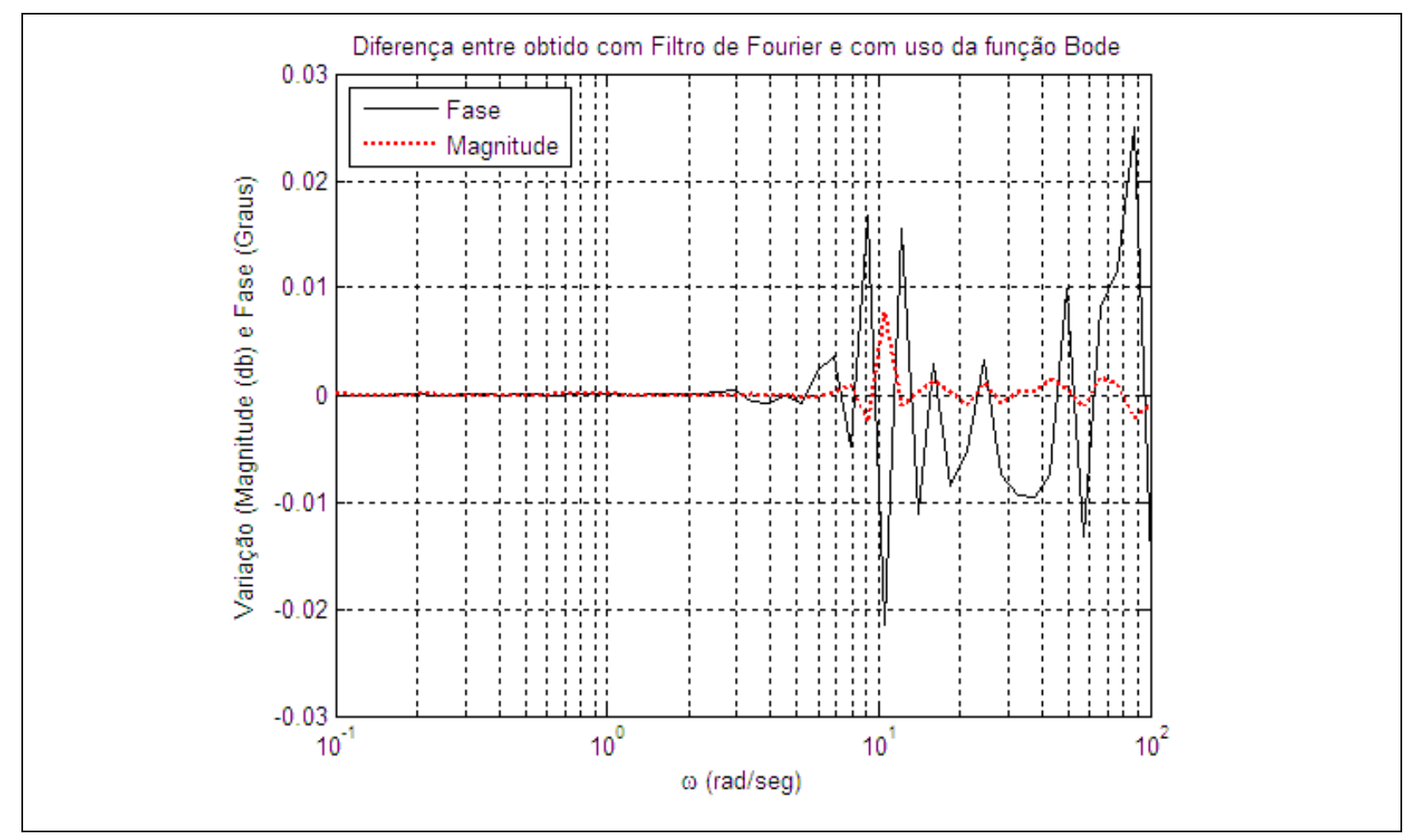

FIGURA 4.38 - Gráfico da diferença entre o obtido pelo filtro de Fourier e com o uso da função bode para um sistema de segunda ordem com $\omega_{n} 10 \mathrm{rad} / \mathrm{s} \mathrm{e} \zeta=0,004$

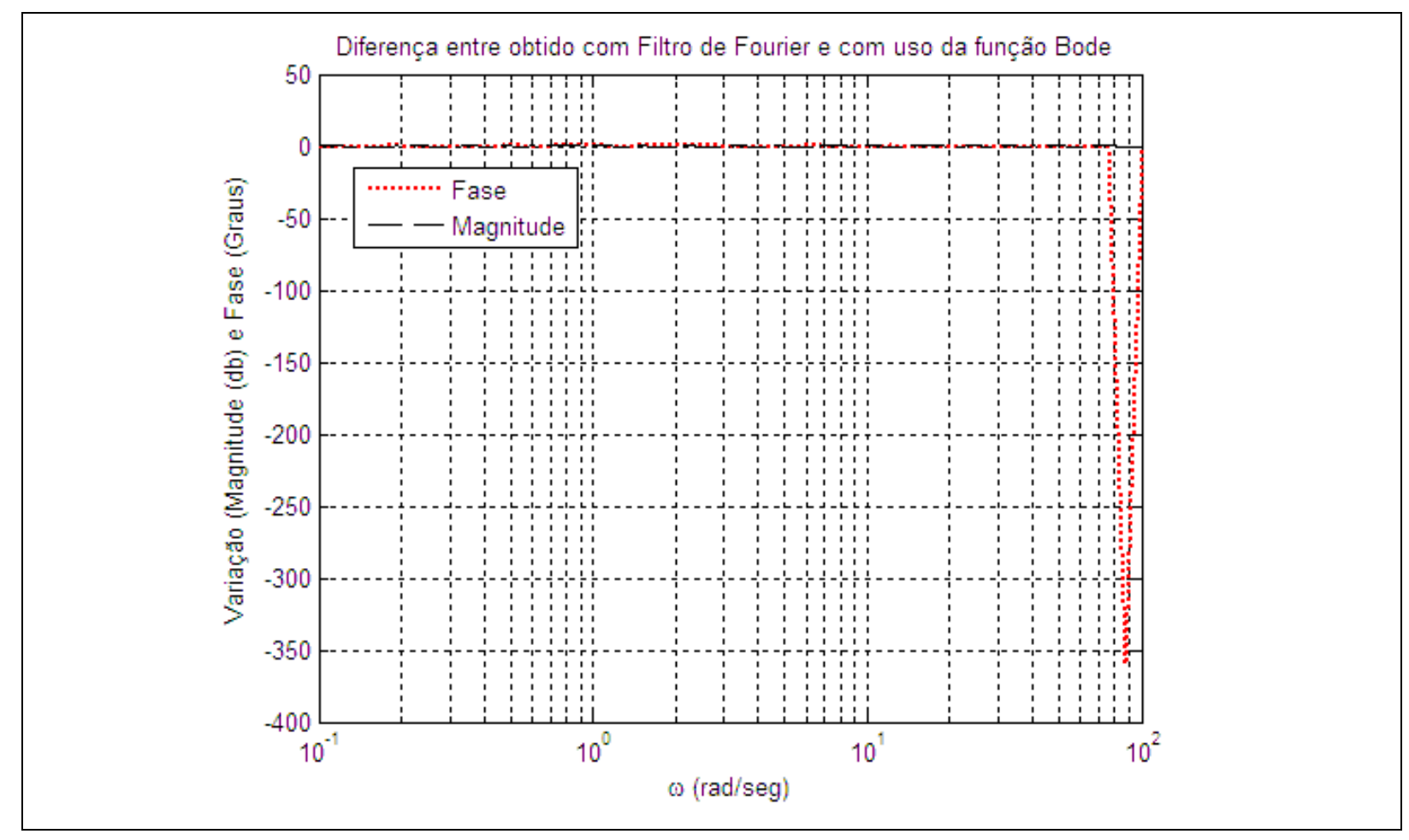

FIGURA 4.39 - Gráfico da diferença entre o obtido pelo filtro de Fourier e com o uso da função bode para um sistema de segunda ordem com $\omega_{n} 10 \mathrm{rad} / \mathrm{s}$ e $\zeta=0,001$ 
Para os três primeiros coeficientes de amortecimento, os resultados obtidos com a simulação tiveram uma ótima concordância com os obtidos pela função bode como pode ser constatado nos gráficos das FIGURAS 4.364 .37 e 4.38. Porém, para coeficiente de amortecimento valendo 0,001 , surgiu um pico no gráfico da fase na freqüência próxima a 100 $\mathrm{rad} / \mathrm{seg}$, como pode ser observado no gráfico da FIGURA 4.31 que não existe. Isso se deve a limitação do bloco que calcula o arco tangente (atan2).

\subsubsection{Conclusão}

Os testes realizados acima, para a obtenção da resposta em freqüência através do uso do filtro de Fourier mostram que os resultados obtidos são bem precisos quando comparados à função bode do Matlab, tanto para os gráficos da fase quanto para os gráficos da magnitude. Apenas uma ressalva é feita com relação a obtenção de gráficos da fase, quando o sistema apresenta fase muito próximo de mais ou menos $180^{\circ}$ ou maiores que este valor. Devido ao bloco do Simulink atan2 poder medir ângulos somente entre o intervalo de mais ou menos $180^{\circ}$, sistemas que possuem uma fase maior que este intervalo sofreram oscilações bruscas de fase que não existem, tornando necessário a implementação de um algoritmo para eliminar este problema. Já sistemas que apresentam fases muito próximas de mais ou menos $180^{\circ}$, em alguma faixa de freqüência, como foi o caso do sistema de segunda ordem, picos de fase podem surgir devido ao erro de arredondamento quando o bloco atan2 divide a parte imaginária do número complexo pela parte real. Portanto torna-se necessário tomar cuidado, analisando se o sistema que se deseje obter a resposta em freqüência se enquadre nos casos descritos acima. 


\section{MODELAGEM MATEMÁTICA}

Antes da modelagem do sistema hidráulico proposto algumas considerações são feitas quanto ao seu funcionamento e a sua estrutura.

O esquema do amortecedor proposto está ilustrado na FIGURA 5.1.

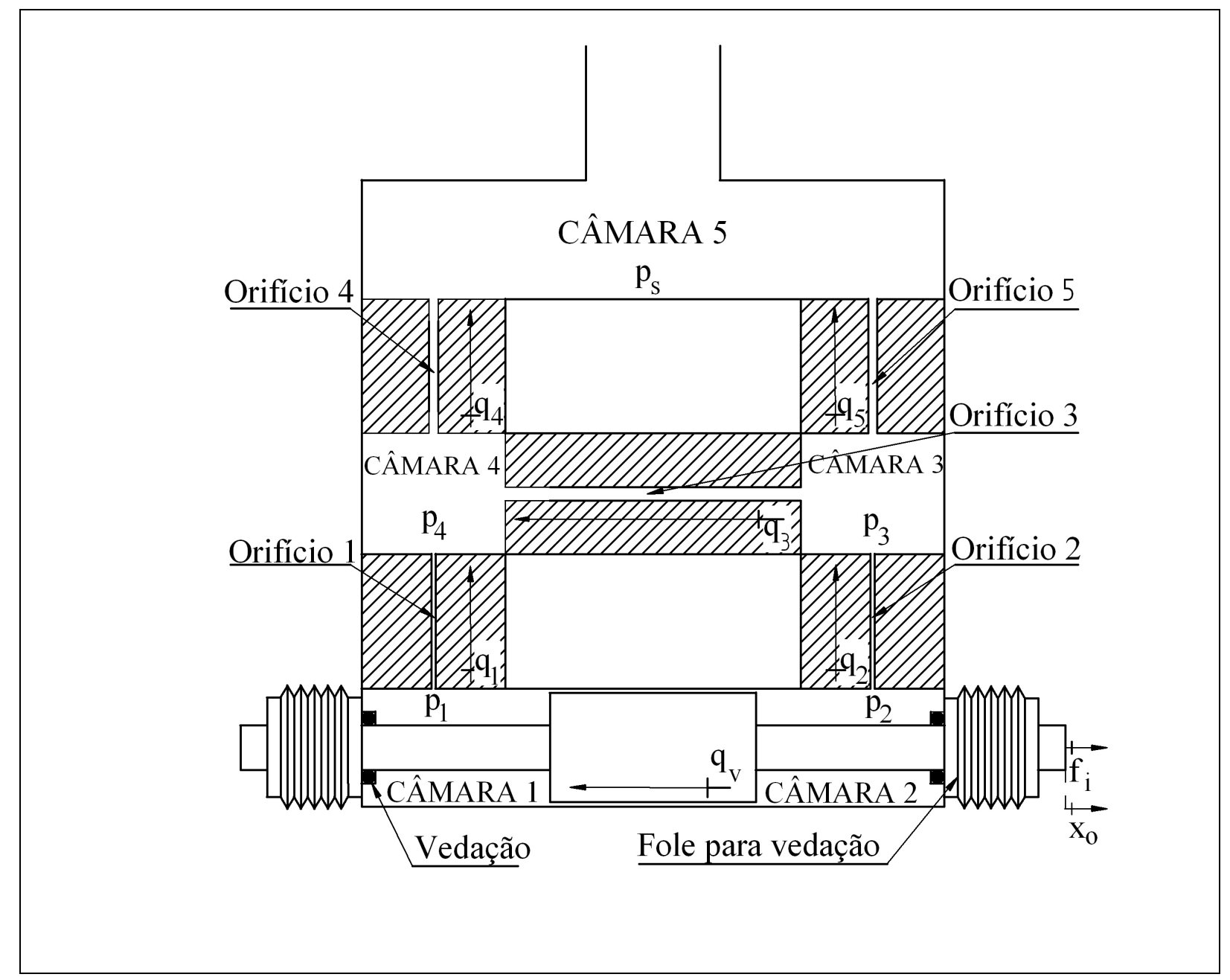

FIGURA 5.1 - Esquema do amortecedor proposto. 
A FIGURA 5.1 mostra os principais elementos, algumas variáveis envolvidas na modelagem matemática e indica, através das setas, os sentidos positivos das vazões. Um sistema com dimensões propostas está apresentando na seção 6.

Como condição inicial de funcionamento, o sistema será considerado em repouso, com o pistão no centro, fazendo com que o volume inicial da câmara 1 seja igual ao volume inicial da câmara 2.

No ponto de operação do sistema, todas as pressões serão iguais a pressão $p_{S}$ fornecida por uma bomba. Então $p_{1}, p_{2}, p_{3}$ e $p_{4}$ terão variações dinâmicas em torno dessa pressão de equilíbrio $p_{S}$.

A área efetiva $A$ do pistão onde as pressões $p_{1}$ e $p_{2}$ atuam é a diferença entre a área da secção transversal do pistão $A_{P}$ e a área da secção transversal da haste $A_{H}$.

Para que o sistema hidráulico proposto apresente simetria com relação ao seu funcionamento, os orifícios 1 e 2 devem ser idênticos, assim como o 3 e o 4 . Isto significa que os coeficientes que relacionam vazão e pressão para os orifícios 1 e 2 têm que ser iguais. O mesmo raciocínio vale para os orifícios 3 e 4 . Isso na prática pode ser facilmente obtido através da implementação nos orifícios de um dispositivo mecânico, como uma agulha micrométrica que ajusta a abertura do orifício.

Feitas essas considerações, as grandezas que aparecem na FIGURA 5.1 podem ser definidas:

$p_{1}, p_{2}, p_{3}$ e $p_{4} \stackrel{\Delta}{=}$ pressões nas câmaras $1,2,3$ e 4 , respectivamente, consideradas uniforme nas suas respectivas câmaras.

$$
p_{S} \stackrel{\Delta}{=} \text { pressão da alimentação, considerada constante. }
$$


$q_{1}, q_{2}, q_{3}, q_{4}$ e $q_{5} \stackrel{\Delta}{=}$ vazões nos orifícios $1,2,3,4$ e 5 respectivamente, considerada positiva se forem conforme indicam as setas da FIGURA 5.1.

$q_{V} \stackrel{\Delta}{=}$ vazão total de vazamento entre as câmaras 2 e 1 , devido a folga entre o pistão e o cilindro, considerada positiva se for conforme indica a seta da FIGURA 5.1.

$f_{i} \stackrel{\Delta}{=}$ força externa sobre a haste. É a entrada do sistema. O seu sentido positivo está indicado na FIGURA 5.1.

$x_{o} \stackrel{\Delta}{=}$ deslocamento do conjunto pistão-haste. $\mathrm{O}$ seu sentido positivo está indicado na

\section{FIGURA 5.1.}

$v \stackrel{\Delta}{=} \dot{x}_{o} \stackrel{\Delta}{=}$ velocidade do conjunto pistão-haste. Tem o mesmo sentido de $x_{o}$.

As seguintes hipóteses são feitas inicialmente para a modelagem:

1. A folga entre o pistão e o cilindro é pequena que o vazamento entre as câmaras 1 e 2 ocorre em regime laminar.

2. O atrito seco entre as vedações e a haste é desprezível.

3. O material dos foles de borracha é demasiadamente flexível e sua rigidez desprezível.

4. As deformações elásticas sofridas por todas as peças, partes e parede são levadas em consideração, através do bulk modulus equivalente.

5. A temperatura do sistema é considerada constante.

6. Os efeitos de inércia do fluído são negligenciados.

7. A única parte móvel do sistema é o conjunto pistão-haste.

8. As únicas forças que atuam no conjunto pistão-haste, na direção de $x_{o}$ são a força de atrito viscoso $f_{V}$, as forças $f_{1}$ e $f_{2}$ exercidas, respectivamente, pelas pressões $p_{1}$ e $p_{2}$, e a força $f_{i}$, sendo que todas as demais são consideras 
desprezíveis. Nas demais direções ortogonais o sistema está em equilíbrio estático.

Na FIGURA 5.2 estão apresentadas as forças que atuam no conjunto pistão-haste e as definições dos sentidos positivos das grandezas adotados conforme indicam as setas, a saber:

$$
\begin{aligned}
& f_{1} \stackrel{\Delta}{=} \text { força causada pela pressão } p_{1} \text { sobre a área efetiva esquerda do pistão; } \\
& f_{2} \stackrel{\Delta}{=} \text { força causada pela pressão } p_{2} \text { sobre a área efetiva direita do pistão; } \\
& f_{V} \stackrel{\Delta}{=} \text { força de atrito viscoso, considerada linear, proporcional a velocidade. }
\end{aligned}
$$

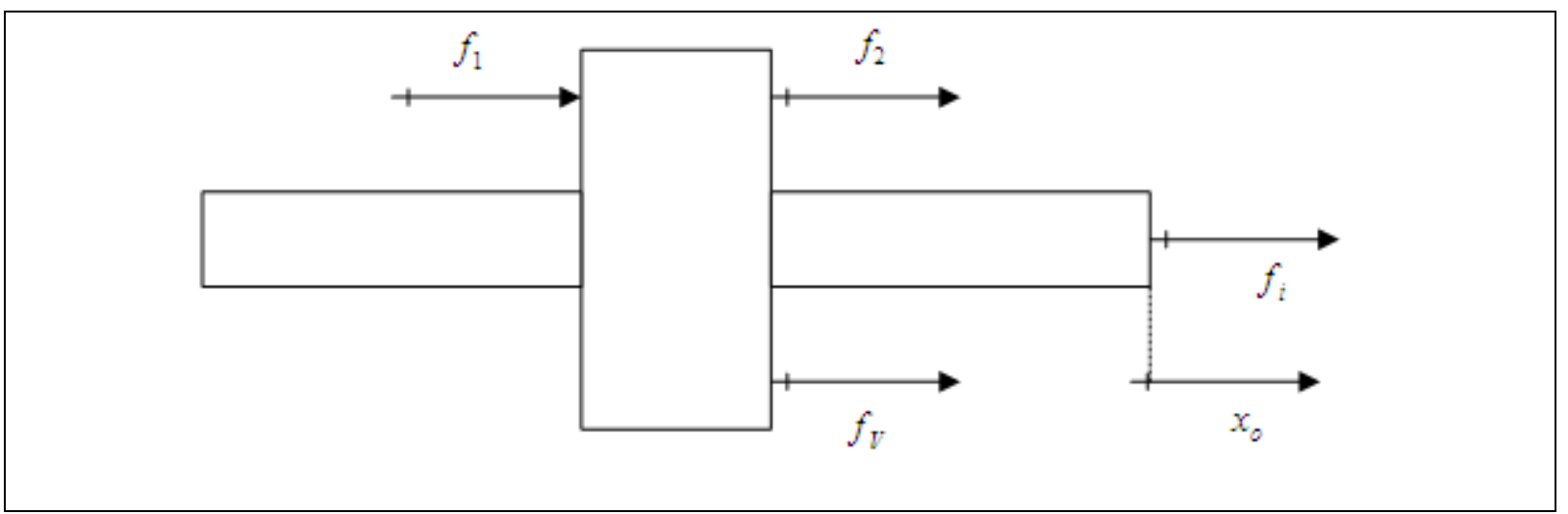

FIGURA 5.2 - Diagrama de corpo livre do conjunto pistão-haste, na direção de $x_{0}$.

Do diagrama de forças da FIGURA 5.2, aplicando a lei de Newton a massa $M$ do conjunto pistão-haste tem-se:

$$
f_{i}+f_{1}+f_{2}+f_{V}=M \ddot{x}_{o}
$$

em que

$\mathrm{M} \stackrel{\Delta}{=}$ massa do conjunto pistão-haste. 
Considerando que a entrada $f_{i}$ no ponto de operação é nulo, definindo as grandezas de perturbação em torno do ponto de operação, tem-se:

$$
\begin{gathered}
f_{1} \stackrel{\Delta}{=} f_{1 o}+f_{I p} \\
f_{2} \stackrel{\Delta}{=} f_{2 o}+f_{2 p} \\
f_{V} \stackrel{\Delta}{=} f_{V o}+f_{V p} \\
x_{o} \stackrel{\Delta}{=} x_{o o}+x_{o p}
\end{gathered}
$$

Onde os subscrito “ $o$ ” e “ $p$ ” denotam, respectivamente, os valores de operação e perturbação das referidas variáveis.

Substituindo (5.2), (5.3), (5.4) e (5.5) em (5.1) obtém-se:

$$
f_{i}+\left(f_{1 o}+f_{1 p}\right)+\left(f_{2 o}+f_{2 p}\right)+\left(f_{V o}+f_{V p}\right)=M \frac{d^{2}\left(x_{o o}+x_{o p}\right)}{d t^{2}}
$$

Como no ponto de operação as pressões em todas as câmaras são iguais a $p_{S}$, então:

$$
p_{1 o}=p_{2 o}=p_{3 o}=p_{4 o}=p_{S}
$$

Portanto, as forças devido as pressões $p_{10}$ e $p_{20}$, no ponto de operação são:

$$
f_{1 o}=-f_{2 o}
$$

Adicionalmente, como o sistema encontra-se em repouso no ponto de operação, temse que $\dot{x}_{o o}$ e $\ddot{x}_{o o}$ são nulos. Isto implica que nesta condição $f_{V o}$ também é nulo. Então, aplicando estes resultados e combinando as equações (5.6), (5.7) e (5.8) vem: 


$$
f_{i}+f_{1 p}+f_{2 p}+f_{p}=M \ddot{x}_{o p}
$$

Determinando as grandezas de perturbação tem-se:

$$
\begin{gathered}
f_{1 p}=A p_{1 p} \\
f_{2 p}=-A p_{2 p} \\
f_{V p}=-B_{V} \dot{x}_{o p}
\end{gathered}
$$

em que,

$B_{V} \stackrel{\Delta}{=}$ coeficiente de atrito viscoso, considerado constante.

Substituindo as equações (5.10), (5.11) e (5.12) em (5.9) obtém-se:

$$
M \ddot{x}_{o p}+B_{V} \dot{x}_{o p}-A p_{1 p}+A p_{2 P}=f_{i}
$$

Aplicando a transformada de Laplace à equação (5.13), lembrando que as condições iniciais são iguais a zero, tem-se:

$$
\left[M s+B_{V}\right] V_{o p}-[A] P_{1 p}+[A] P_{2 p}=F_{i}
$$

em que

$$
\begin{aligned}
& s \stackrel{\Delta}{=} \text { variável de Laplace; } \\
& V_{o} \stackrel{\Delta}{=} V_{o o}+V_{o p} \stackrel{\Delta}{=} \text { transformada de } \dot{x}_{o}=\dot{x}_{o o}+\dot{x}_{o p} \text {, mas } \dot{x}_{o} \text { é nula. }
\end{aligned}
$$

Agora, aplicando as relações de vazão laminar nos orifícios 1, 2, 3.4 e 5, utilizando variáveis de perturbação em torno do ponto de equilíbrio, para o orifício 1 tem-se: 


$$
q_{1}=K_{1}\left(p_{1}-p_{4}\right)
$$

em que

$K_{1} \stackrel{\Delta}{=}$ coeficiente que relaciona a vazão e o diferencial de pressão, no regime laminar, para o orifício 1 e também para o orifício 2. É o inverso da resistência fluídica.

Sendo $q_{1 o}$ nulo no ponto de operação e as pressões $p_{1 o}$ e $p_{4 o}$ iguais a $p_{S}$, então:

$$
q_{1 p}=K_{1}\left(p_{1 p}-p_{4 p}\right)
$$

Agora, para os orifícios 2 e 3 , determinando $q_{2 p}$ e $q_{3 p}$ de forma análoga a $q_{1 p}$, obtémse:

$$
\begin{aligned}
& q_{2 p}=K_{1}\left(p_{2 p}-p_{3 p}\right) \\
& q_{3 p}=K_{3}\left(p_{3 p}-p_{4 p}\right)
\end{aligned}
$$

em que

$K_{3} \stackrel{\Delta}{=}$ coeficiente que relaciona a vazão e o diferencial de pressão, no regime laminar, para o orifício 3. É o inverso da resistência fluídica.

A relação entre vazão e pressão para o orifício 4 tem o desenvolvimento um pouco diferente do efetuado para os orifícios 1, 2 e 3. Assim:

$$
q_{4}=K_{4}\left(p_{4}-p_{S}\right)
$$

em que 
$K_{4} \stackrel{\Delta}{=}$ coeficiente que relaciona vazão e diferencial de pressão, no regime laminar, para os orifícios 4 e 5 . É o inverso da resistência fluídica.

Como, no ponto de operação, $q_{4 o}$ é nulo e $p_{4 o}=p_{S}$, então:

$$
q_{4 p}=K_{4} p_{4 p}
$$

Procedimento idêntico é aplicado ao orifício 5, logo:

$$
q_{5 p}=K_{4} p_{3 p}
$$

Agora, equacionando a vazão de vazamento entre as câmaras 2 e 1e lembrando que por hipótese, esta vazão é laminar, então:

$$
q_{V}=K_{V}\left(p_{2}-p_{1}\right)
$$

em que

$$
K_{V} \stackrel{\Delta}{=} \text { coeficiente que relaciona vazão de vazamento e o diferencial de pressão, no }
$$

regime laminar, para a folga radial entre o cilindro e o pistão. É o inverso da resistência fluídica.

Sendo no equilíbrio $p_{1 o}$ igual a $p_{2 o}$ e $q_{v o}$ nulo, então:

$$
q_{V p}=K_{V}\left(p_{2 p}-p_{1 p}\right)
$$

O balanço de vazões nas câmaras $1,2,3$, e 4 pode ser obtida através da equação (5.24). Essa equação provém da equação da conservação da massa combinada com a equação de estado dos líquidos. 


$$
\sum_{j=1}^{z}\left(q_{\text {in }}\right)_{j}-\sum_{r=1}^{w}\left(q_{\text {out }}\right)_{r}=\frac{d V}{d t}+\frac{V}{\beta} \frac{d p}{d t}
$$

em que

$j, r, w$ e $z \stackrel{\Delta}{=}$ são números naturais;

$q_{\text {in }} \stackrel{\Delta}{=}$ vazão que entra no volume de controle;

$q_{\text {out }} \stackrel{\Delta}{=}$ vazão que sai do volume de controle;

$V \stackrel{\Delta}{=}$ volume de controle;

$\beta \stackrel{\Delta}{=}$ “bulk módulus” equivalente.

$p \stackrel{\Delta}{=}$ pressão no volume de controle.

O saldo de vazão no volume de controle (que é a diferença entre as vazões que entram e as vazões que saem do volume de controle) é usado para suprir duas "saídas", a saber: (1) a vazão devido à variação do volume de controle no tempo, que corresponde ao primeiro termo do lado direito da igualdade da equação (5.24); (2) a vazão devido à compressibilidade do fluído, correspondente ao segundo termo da direita da igualdade da equação (5.26).

Com base nos sentidos positivos das vazões adotados na FIGURA 5.1, a equação da conservação da vazão (equação 5.24) irá ser aplicada ao volume de controle definido pela câmara 1 , ou seja, o volume sobre pressão $p_{1}$. Sabendo que para essa câmara, no ponto de operação, os termos referentes às grandezas de operação da equação (5.24) são nulos, tem-se:

$$
q_{V p}-q_{1 p}=A \frac{d x_{o p}}{d t}+\frac{V_{1}}{\beta} \frac{d p_{1 p}}{d t}
$$


em que

$V_{1} \stackrel{\Delta}{=}$ volume inicial de óleo da câmara 1 .

Substituindo as equações (5.16) e (5.25) em (5.27) obtém-se:

$$
K_{V}\left(p_{2 p}-p_{1 p}\right)-K_{1}\left(p_{1 p}-p_{4 p}\right)=A \dot{x}_{o p}+\frac{V_{1}}{\beta} \dot{p}_{1 p}
$$

Aplicando a transformada de Laplace, lembrando que as condições iniciais são iguais a zero e rearranjando os termos obtêm-se:

$$
[-A] V_{o p}-\left[K_{V}+K_{1}+C_{1} s\right] P_{1 p}+\left[K_{V}\right] P_{2 p}+\left[K_{1}\right] P_{4 p}=0
$$

Onde $C_{1}$ é o compliance das câmaras 1 e 2 , que é dado por:

$$
C_{1} \stackrel{\Delta}{=} \frac{V_{1}}{\beta}=\frac{V_{2}}{\beta}
$$

em que

$$
V_{2} \stackrel{\Delta}{=} \text { volume inicial de óleo da câmara } 2 \text {. }
$$

O mesmo procedimento para o balanço de vazões é aplicado ao volume de controle da câmara 2, obtendo:

$$
[A] V_{o p}+\left[K_{V}\right] P_{1 p}-\left[K_{V}+K_{1}+C_{1} s\right] P_{2 p}+\left[K_{1}\right] P_{3 p}=0
$$

Para a câmara 3, o procedimento para obtenção da equação do balanço de vazões é um pouco diferente daquele adotado para as câmaras 1 e 2 devido a ausência da parcela de vazão, proveniente da variação do volume de controle, que para esta câmara é nula. Portanto, para a câmara 3, tem-se: 


$$
q_{2 p}-q_{3 p}-q_{5 p}=\frac{V_{3}}{\beta} \dot{p}_{3 p}
$$

em que

$$
V_{3} \stackrel{\Delta}{=} \text { volume de óleo da câmara } 3 .
$$

Substituindo (5.17), (5.18) e (5.21) em (5.30) e aplicando Laplace, vem:

$$
\left[K_{1}\right] P_{2 p}-\left[K_{1}+K_{3}+K_{4}+C_{3} s\right] P_{3 p}+\left[K_{3}\right] P_{4 p}=0
$$

Onde $C_{3}$ é o compliance da câmara 3 e 4 dado por:

$$
C_{3} \stackrel{\Delta}{=} \frac{V_{3}}{\beta}=\frac{V_{4}}{\beta}
$$

em que

$V_{4} \stackrel{\Delta}{=}$ volume de óleo da câmara 4 .

Agora, para a câmara 4, usando procedimento análogo ao adotado para câmara 3 , obtem-se:

$$
\left[K_{1}\right] P_{1 p}+\left[K_{3}\right] P_{3 p}-\left[K_{1}+K_{3}+K_{4}+C_{3} s\right] P_{4 p}=0
$$

Finalmente, o modelo do sistema hidráulico é composto por 5 equações, que são 4 vezes a aplicação da lei da conservação da mesma (equações (5.27), (5.29), (5.31) e (5.33)) e uma equação proveniente da aplicação da lei de Newton aplicada ao conjunto pistão-haste (equação (5.14)).

Colocando as 5 equações do modelo na forma matricial , tem-se: 


$$
\left[\begin{array}{ccccc}
(M s+B) & -A & A & 0 & 0 \\
-A & -\left(K_{V}+K_{1}+C_{1} s\right) & K_{V} & 0 & K_{1} \\
A & K_{V} & -\left(K_{V}+K_{1}+C_{1} s\right) & K_{1} & 0 \\
0 & 0 & K_{1} & -\left(K_{1}+K_{3}+K_{4}+C_{3} s\right) & K_{3} \\
0 & K_{1} & 0 & K_{3} & -\left(K_{1}+K_{3}+K_{4}+C_{3} s\right)
\end{array}\right]\left[\begin{array}{c}
V_{o p} \\
P_{1 P} \\
P_{2 P} \\
P_{3 P} \\
P_{4 P}
\end{array}\right]=\left[\begin{array}{c}
F_{i} \\
0 \\
0 \\
0 \\
0
\end{array}\right]
$$

Aplicando a regra de Crannner para obter $V_{0 p}$ tem-se que:

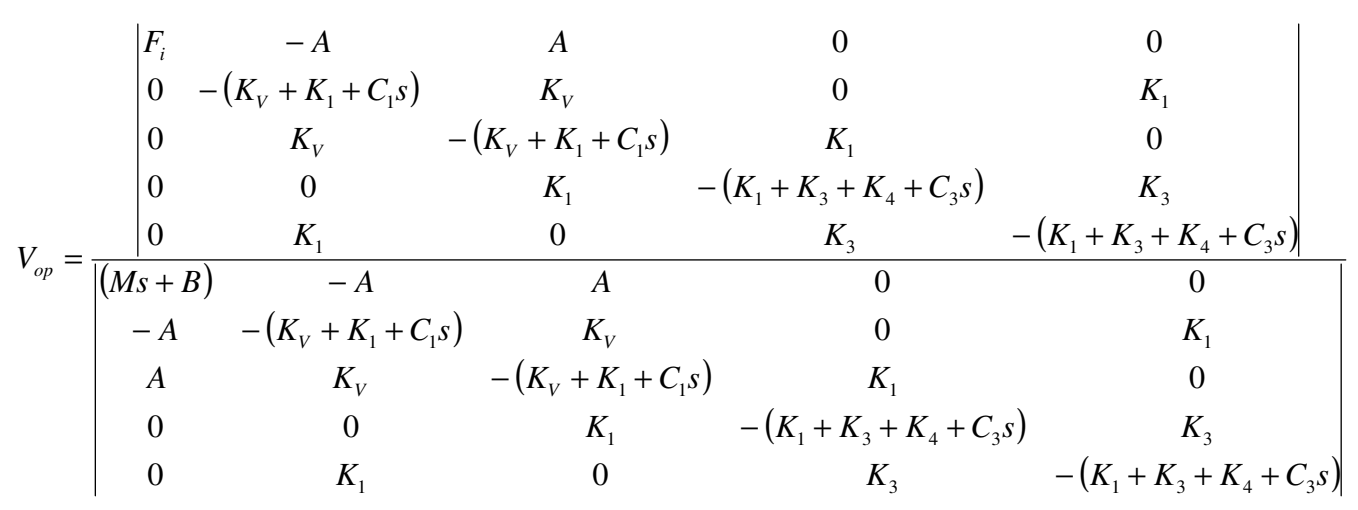

Resolvendo os determinantes do numerador e denominador e além disso, isolando $F_{i p}$ para encontrar a função de transferência do modelo tem-se:

$$
\frac{V_{P}}{F_{i p}}(s)=\frac{a_{4} s^{4}+a_{3} s^{3}+a_{2} s^{2}+a_{1} s+a_{0}}{b_{5} s^{5}+b_{4} s^{4}+b_{3} s^{3}+b_{2} s^{2}+b_{1} s+b_{0}}
$$

em que

$$
\begin{aligned}
& a_{4} \stackrel{\Delta}{=} C_{1}^{2} C_{3}^{2} \\
& a_{3} \stackrel{\Delta}{=} 2 C_{1}^{2} K_{1} C_{3}+2 C_{1}^{2} K_{4} C_{3}+2 C_{1}^{2} K_{3} C_{3}+2 K_{V} C_{1} C_{3}^{2}+2 K_{1} C_{1} C_{3}^{2} \\
& a_{2} \stackrel{\Delta}{=}\left(2 K_{V} C_{3}^{2}+2 C_{1}^{2} K_{3}+4 C_{1} K_{3} C_{3}+4 C_{1} K_{V} C_{3}+2 C_{1}^{2} K_{4}+4 C_{1} K_{4} C_{3}\right) K_{1}+ \\
& +4 K_{V} C_{1} C_{3}\left(K_{3}+K_{4}\right)+C_{1}^{2} K_{4}\left(K_{4}+2 K_{3}\right)+\left(C_{3}^{2}+2 C_{1} C_{3}+C_{1}^{2}\right) K_{1}^{2}
\end{aligned}
$$




$$
\begin{aligned}
& a_{1} \stackrel{\Delta}{=}\left(K_{V} C_{1}+K_{4} C_{3}+K_{3} C_{3}+C_{1} K_{3}+K_{V} C_{3}+C_{1} K_{4}\right) 2 K_{1}^{2}+ \\
& +\left(C_{1} K_{4}^{2}+2 K_{V} K_{4} C_{3}+2 K_{V} K_{3} C_{1}+2 K_{3} K_{4} C_{1}+2 K_{V} K_{3} C_{3}+2 K_{V} K_{4} C_{1}+\right) 2 K_{1}+ \\
& +2 K_{V} C_{1} K_{4}\left(K_{4}+2 K_{3}\right) \\
& a_{0} \stackrel{\Delta}{=} K_{1} K_{4}\left(K_{1} K_{4}+2 K_{V} K_{4}+2 K_{V} K_{1}+2 K_{1} K_{3}+4 K_{v} K_{3}\right) \\
& b_{5} \stackrel{\Delta}{=} M C_{1}^{2} C_{3}^{2} \\
& b_{4} \stackrel{\Delta}{=} C_{1} C_{3}\left(2 M C_{1} K_{3}+2 M K_{V} C_{3}+2 M C_{1} K_{4}+2 M K_{1} C_{3}+B C_{1} C_{3}+2 M C_{1} K_{1}\right) \\
& b_{3} \stackrel{\Delta}{=}\left(\begin{array}{c}
2 C_{1} K_{1}^{2} C_{3}+K_{1}^{2} C_{3}^{2}+4 K_{1} C_{1} K_{4} C_{3}+2 C_{1}^{2} K_{1} K_{4}+2 C_{1}^{2} K_{1} K_{3}+ \\
+4 K_{1} C_{1} K_{3} C_{3}+C_{1}^{2} K_{1}^{2}+4 K_{V} C_{1} K_{4} C_{3}+2 K_{V} K_{1} C_{3}^{2}+ \\
+2 C_{1}^{2} K_{4} K_{3}+C_{1}^{2} K_{4}^{2}+4 K_{V} C_{1} K_{3} C_{3}+4 K_{V} C_{1} K_{1} C_{3}
\end{array}\right) M+ \\
& +2 B K_{V} C_{1} C_{3}^{2}+2 B C_{1}^{2} K_{4} C_{3}+2 B K_{1} C_{1} C_{3}^{2}+2 B C_{1}^{2} K_{3} C_{3}+2 A^{2} C_{1} C_{3}^{2}+2 B C_{1}^{2} K_{1} C_{3} \\
& b_{2} \stackrel{\Delta}{=}\left(\begin{array}{c}
K_{v} C_{1} K_{1}^{2}+K_{1}^{2} K_{3} C_{3}+C_{1} K_{1}^{2} K_{4}+K_{V} K_{1}^{2} C_{3}+K_{V} C_{1} K_{4}^{2}+2 K_{V} C_{1} K_{1} K_{3}+ \\
+C_{1} K_{1}^{2} K_{3}+K_{1}^{2} K_{4} C_{3}+2 K_{V} C_{1} K_{1} K_{4}+2 K_{V} C_{1} K_{4} K_{3}+2 K_{V} K_{1} K_{4} C_{3}+ \\
+K_{1} C_{1} K_{4}^{2}+2 K_{V} K_{1} K_{3} C_{3}+2 K_{1} C_{1} K_{4} K_{3}
\end{array}\right) 2 M+ \\
& +4 B K_{V} C_{1} K_{1} C_{3}+2 B C_{1} K_{1}^{2} C_{3}+B C_{1}^{2} K_{1}^{2}+B C_{1}^{2} K_{4}^{2}+B K_{1}^{2} C_{3}^{2}+2 A^{2} K_{1} C_{3}^{2}+ \\
& +4 A^{2} C_{1} K_{1} C_{3}+4 A^{2} C_{1} K_{4} C_{3}+4 A^{2} C_{1} K_{3} C_{3}+2 B C_{1}^{2} K_{4} K_{3}+4 B K_{V} C_{1} K_{4} C_{3}+ \\
& +2 B C_{1}^{2} K_{1} K_{4}+2 B C_{1}^{2} K_{1} K_{3}+4 B K_{1} C_{1} K_{4} C_{3}+2 B K_{V} K_{1} C_{3}^{2}+4 B K_{V} C_{1} K_{3} C_{3}+ \\
& +4 B K_{1} C_{1} K_{3} C_{3} \\
& b_{1} \stackrel{\Delta}{=} 2 A^{2} K_{1}^{2} C_{3}+2 A^{2} C_{1} K_{1}^{2}+2 A^{2} C_{1} K_{4}^{2}+2 B C_{1} K_{1}^{2} K_{4}+2 B C_{1} K_{1}^{2} K_{3}+ \\
& +2 B K_{1}^{2} K_{4} C_{3}+2 B K_{1}^{2} K_{3} C_{3}+2 B K_{V} C_{1} K_{4}^{2}+2 B K_{V} C_{1} K_{1}^{2}+2 B K_{V} K_{1}^{2} C_{3}+ \\
& +2 B K_{1} C_{1} K_{4}^{2}+4 A^{2} C_{1} K_{4} K_{3}+4 A^{2} C_{1} K_{4} K_{1}+4 A^{2} C_{1} K_{1} K_{3}+4 A^{2} K_{1} K_{4} C_{3}+ \\
& +4 A^{2} K_{1} K_{3} C_{3}+4 B K_{V} C_{1} K_{1} K_{4}+4 B K_{V} C_{1} K_{1} K_{3}+4 B K_{V} C_{1} K_{3} K_{4}+ \\
& +4 B K_{V} C_{3} K_{1} K_{4}+4 B K_{V} C_{3} K_{1} K_{3}+4 B C_{1} K_{1} K_{3} K_{4}+ \\
& +\left(2 K_{V} K_{1}^{2} K_{4}+2 K_{V} K_{1} K_{4}^{2}+4 K_{V} K_{1} K_{4} K_{3}+K_{1}^{2} K_{4}^{2}++2 K_{1}^{2} K_{4} K_{3}\right) M \\
& b_{0} \stackrel{\Delta}{=} K_{1} K_{4}\left(\begin{array}{l}
2 A^{2} K_{4}+B K_{1} K_{4}+2 B K_{V} K_{1}+2 A^{2} K_{1}+ \\
+4 B K_{V} K_{3}+4 A^{2} K_{3}+2 B K_{V} K_{4}+2 B K_{1} K_{3}
\end{array}\right)
\end{aligned}
$$




\section{DIMENSIONAMENTO DE PEÇAS E DEFINIÇÃO DE PARÂMETROS PROPOSTOS PARA UM SISTEMA HIDRÁULICO}

Uma vez que as equações literais que descrevem a dinâmica do sistema hidráulico foram obtidas no capítulo anterior, torna-se necessário atribuir dimensões das peças, bem como definir parâmetros para simular o comportamento dinâmico do sistema hidráulico em computador. A FIGURA 6.1 mostra as dimensões básicas do sistema que foram escolhidas.

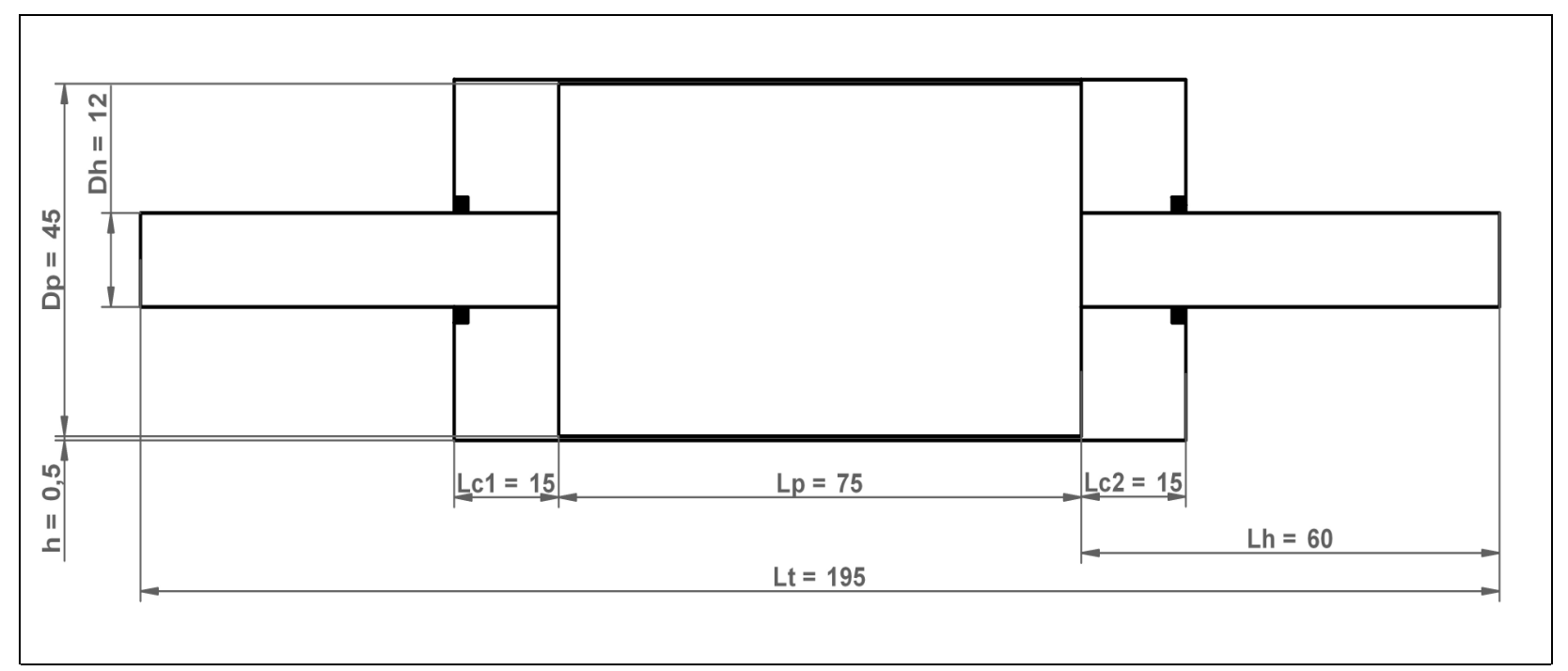

FIGURA 6.1 - Desenho esquemático da parte inferior do sistema hidráulico

Foram calculados os seguintes parâmetros:

(I). Massa $M$ do conjunto pistão-haste;

(II). Área efetiva $A$, do pistão;

(III). Volumes iniciais de óleo $V_{1}, V_{2}, V_{3}$ e $V_{4}$; 
(IV). Compliance $C_{1}$ e $C_{3}$

(V). Dimensionamento dos orifícios 1, 2, 3, 4 e 5 e da folga radial $h$;

(VI). Coeficientes que relacionam vazão, no regime laminar, e diferencial de pressão;

(VII). Coeficiente de atrito viscoso $B$.

O desenvolvimento das determinações está apresentado a seguir:

a) Área efetiva $A$, do pistão:

A área efetiva $A$ do pistão é dada por:

$$
A=A_{P}-A_{h}
$$

em que

$A_{P} \stackrel{\Delta}{=}$ área do pistão;

$A_{h} \stackrel{\Delta}{=}$ área da haste.

A área $A_{P}$ do pistão é igual a:

$$
A_{P}=\frac{\pi D_{P}^{2}}{4}
$$

Assim como a área $A_{h}$ da haste é dada por:

$$
A_{h}=\frac{\pi D_{h}^{2}}{4}
$$

Substituindo (6.2) e (6.3) em (6.1) obtém-se a área efetiva $A$ em termos dos diâmetros da haste e do pistão ficando:

$$
A=\frac{\pi\left(D_{P}^{2}-D_{h}^{2}\right)}{4}
$$


Para as dimensões adotadas na FIGURA 6.1 a área efetiva $A$ do pistão é igual a:

$$
A=1,477 \times 10^{-3} \mathrm{~m}^{2}
$$

b) Massa $M$ do conjunto pistão-haste:

A escolha do material do conjunto pistão-haste é um compromisso entre o efeito de mola real, relacionado com o módulo de elasticidade do material, e o efeito da massa do conjunto móvel (pistão-haste), pois um amortecedor ideal não possui massa e nem efeito de mola. Por exemplo, mudando o material de aço para alumínio, mantendo constante o mesmo efeito de mola, a massa praticamente se mantém a mesma, mas o volume de material empregado na construção do conjunto pistão-haste aumenta. Por exemplo, estudando uma barra sob ação de uma força de $3000 \mathrm{kgf}$ com dimensões mostradas na FIGURA 6.2.

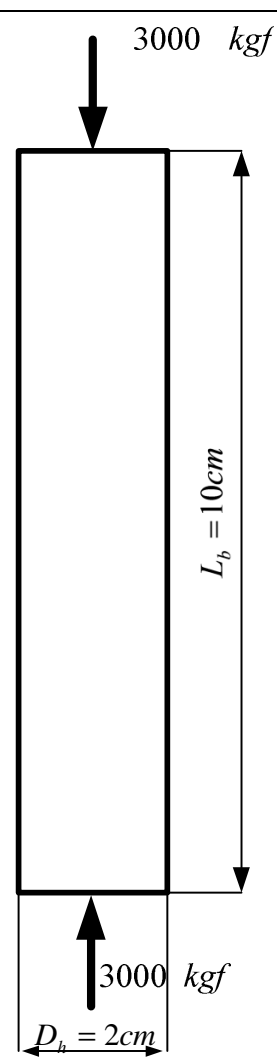

FIGURA 6.2 - Barra sob ação de uma força aplicada de $3000 \mathrm{kgf}$. 
A massa $M_{b}$ da barra é dada por:

$$
M_{b}=A_{b} L_{b} \rho
$$

em que

$A_{b} \stackrel{\Delta}{=}$ área da secção transversal da barra;

$L_{b} \stackrel{\Delta}{=}$ comprimento da barra;

$\rho \stackrel{\Delta}{=}$ massa específica do material que constitui a barra.

A área $A_{b}$ da barra é igual a:

$$
A_{b}=\frac{\pi D_{b}^{2}}{4}
$$

Substituindo (6.6) em (6.5) obtém-se:

$$
M_{b}=\frac{\pi D_{b}^{2} L_{b} \rho}{4}
$$

Admitindo que a barra com as dimensões adotadas na FIGUIRA 6.2 seja feita de aço e sabendo que a massa específica do aço é igual a 7,85 $\mathrm{g} / \mathrm{cm}^{3}$ a massa da barra resulta:

$$
M_{\text {aço }}=247,2361 \mathrm{~g}
$$

em que

$$
M_{\text {aço }} \stackrel{\Delta}{=} \text { massa da barra constituída de aço. }
$$

A tensão $\sigma$ devido a ação de uma força $F$ aplica sobre uma área $A_{1}$ é dada por: 


$$
\sigma=\frac{F}{A_{1}}
$$

A área $A_{\text {aço }}$ da secção transversal da barra de aço da FIGURA 6.2 é:

$$
A_{\text {aço }}=3,1415 \mathrm{~cm}^{2}
$$

Para a força de $3000 \mathrm{kgf}$ aplicada na barra de aço sobre a área $A_{\text {aço }}$, calculada acima, tem-se uma tensão $\sigma_{\text {aço }}$ de:

$$
\sigma_{\text {aço }}=954,9578 \mathrm{Kgf} / \mathrm{cm}^{2}
$$

Da relação entre tensão e deformação tem-se:

$$
\sigma=E \varepsilon
$$

em que

$$
\begin{aligned}
& E \stackrel{\Delta}{=} \text { módulo de elasticidade do material; } \\
& \varepsilon \stackrel{\Delta}{=} \text { alongamento da barra. }
\end{aligned}
$$

Sabendo que o módulo de elasticidade do aço é $2,1 \times 10^{6} \mathrm{kgf} / \mathrm{cm}^{2}$, a deformação $\varepsilon$ sofrida pela tensão $\sigma_{\text {aço }}$ é:

$$
\varepsilon=454,7418 \times 10^{-6}
$$

Agora, trabalhando com a barra feita em alumínio. Para a mesma força de $3000 \mathrm{kgf}$ aplicada sobre a barra, para se manter a mesma deformação $\varepsilon_{\text {aço }}$ da barra de aço, sabendo que o módulo de elasticidade do alumínio é de $0,7 \times 10^{6} \mathrm{kgf} / \mathrm{cm}^{2}$, ou seja, três vezes menor do que 
o módulo de elasticidade de aço, pode-se obter equação (6.9) que a tensão $\sigma_{A l}$ no bloco de alumínio será também três vezes menor. Portanto, a tensão $\sigma_{A l}$, no bloco de alumínio resulta:

$$
\sigma_{\mathrm{Al}}=318,3193 \mathrm{kgf} / \mathrm{cm}^{2}
$$

Aplicando o valor de $\sigma_{A l}$ á equação (6.8), lembrando que a força aplicada é de 3000 kgf obtém-se uma área $A_{\mathrm{Al}}$, da seção transversal de alumínio igual a:

$$
A_{\mathrm{Al}}=9,4245 \mathrm{~cm}^{2}
$$

Sabendo que a massa específica do alumínio é igual a $2,71 \mathrm{~kg} / \mathrm{cm}^{3}$, a massa $M_{\mathrm{Al}}$ da barra confeccionada em alumínio para o valor obtido de $A_{\mathrm{Al}}$ acima, com comprimento $L_{b}$ igual ao da FIGURA 6.2 é igual a:

$$
M_{A l}=255,404 \mathrm{~g}
$$

Portanto, a massa da barra feita em alumínio, a fim de se obter o mesmo efeito de mola do aço é um pouco maior que a massa da barra confeccionada em aço, porém, tem um volume maior, que pode ser observado quando se compara as áreas das secções transversais do aço e do alumínio. Pelo exposto, o material escolhido para o conjunto pistão-haste foi o aço carbono.

Considerando as dimensões iguais para os dois lados da haste e, portanto, as massas também iguais, a massa $M$, do conjunto pistão-haste é dada por: 
110

$$
M=M_{P}+2 M_{h}
$$

em que

$M_{P} \stackrel{\Delta}{=}$ massa do pistão;

$M_{h} \stackrel{\Delta}{=}$ massa da haste.

As massas do pistão e da haste podem ser calculadas pela equação (6.5). A equação (6.5) para o cálculo da massa da haste fica:

$$
M_{h}=A_{h} L_{h} \rho_{\text {aço }}
$$

em que

$$
L_{h} \stackrel{\Delta}{=} \text { comprimento da haste. }
$$

Procedimento análogo é adotado para o cálculo da massa do pistão que é dado por:

$$
M_{P}=A_{P} L_{P} \rho_{\text {ạ̧o }}
$$

em que

$$
L_{P} \stackrel{\Delta}{=} \text { comprimento do pistão. }
$$

Substituindo as equações (6.11) e (6.12) em (6.10) obtém-se:

$$
M=\rho_{\text {aço }}\left(A_{P} L_{P}+2 A_{h} L_{h}\right)
$$

Finalmente substituindo (6.2) e (6.3) em (6.11) obtém-se a massa $M$ do conjunto pistão-haste em termos das dimensões primárias da FIGURA 6.1, ficando: 


$$
M=\frac{\pi \rho_{a c ̧ o}}{4}\left(D_{P}^{2} L_{P}+2 D_{h}^{2} L_{h}\right)
$$

Para as dimensões adotadas e cotadas na FIGURA 6.1 a massa $M$ do conjunto pistãohaste fica:

$$
M=1,0429 \mathrm{~kg}
$$

c) Volumes iniciais de óleo $V_{1}, V_{2}, V_{3}$ e $V_{4}$, nas câmaras $1,2,3$, e 4, respectivamente:

O volume inicial de óleo da câmara 1, que por hipótese é igual ao volume da câmara 2 é dado por:

$$
V_{1}=V_{C 1}-V_{h i}
$$

em que

$V_{C 1} \stackrel{\Delta}{=}$ volume geométrico da câmara $1 ;$

$V_{h i} \stackrel{\Delta}{=}$ volume inicial da haste imersa no óleo.

$\mathrm{O}$ volume $V_{C 1}$ é igual a:

$$
V_{C 1}=A_{c} L_{c 1}
$$

em que

$L_{c 1} \stackrel{\Delta}{=}$ comprimento da câmara $1 ;$

$A_{c} \stackrel{\Delta}{=}$ área do cilindro.

A área $A_{c}$ do cilindro é igual a: 


$$
A_{c}=\frac{\pi\left(D_{P}+2 h\right)^{2}}{4}
$$

em que

$h \stackrel{\Delta}{=}$ folga radial entre o pistão e o cilindro;

Agora, determinando $V_{h i}$, tem-se:

$$
V_{h i}=A_{h} L_{c 1}
$$

Substituindo (6.16) e (6.18) em (6.15) obtém-se $V_{1}$ que fica:

$$
V_{1}=L_{c 1}\left(A_{c}-A_{h}\right)
$$

Finalmente, substituindo (6.15) e (6.3) em (6.17), tem-se $V_{1}$ em termos das dimensões primárias da FIGURA 6.1, que fica:

$$
V_{1}=\frac{L_{c 1} \pi}{4}\left[\left(D_{P}+2 h\right)^{2}-D_{h}^{2}\right]
$$

Para as dimensões adotadas na FIGURA 6.1 o valor de $V_{1}$ é:

$$
V_{1}=2,323 \times 10^{-5} \mathrm{~m}^{3}
$$

Todos os volumes inicias de óleo nas câmaras 1, 2, 3 e 4 serão considerados iguais, isto é:

$$
V_{1}=V_{2}=V_{3}=V_{4}=2,32310^{-5} \mathrm{~m}^{3}
$$

d) Compliance $C_{1}, C_{2}, C_{3}$ e $C_{4}$ das câmaras $1,2,3$ e 4, respectivamente: 
Para o cálculo do compliance é necessário conhecer-se o valor do Bulk Módulus equivalente do sistema. Segundo Felício (2007), um valor prático do Bulk Modulus equivalente é de 100000 psi $\left(6,8948 \times 10^{8} \mathrm{~Pa}\right)$. Considerando este valor de Bulk Modulus equivalente e os valores de volumes iniciais calculados acima, das equações (5.28) e (5.32), obtém-se:

$$
C_{1}=C_{2}=C_{3}=C_{4}=3,369 \times 10^{-14} \mathrm{~m}^{3} / \mathrm{Pa}
$$

e) Diâmetro e comprimento dos orifícios 1, 2, 3, 4 e 5:

A verificação do diâmetro dos orifícios 1 e 2 cotados na FIGURA 6.3 tem o objetivo de confirmar a existência de escoamento laminar, a fim de se obter um modelo linear. Deve-se lembrar que para atingir simetria de funcionamento, eles são considerados iguais. Na FIGURA 6.3 é mostrado um desenho representativo do orifício com as dimensões em milímetros.

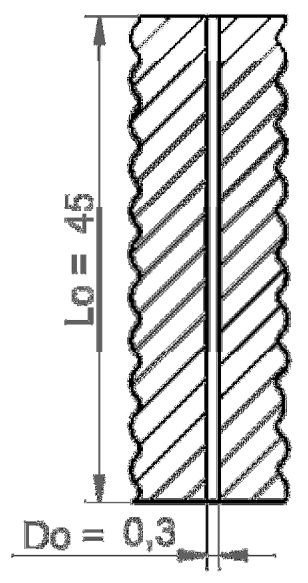

FIGURA 6.3 - Desenho representativo do orifício. 
Inicialmente, faz se necessário a escolha de um óleo e o conhecimento de algumas de suas propriedades físicas que serão usadas nos cálculos de verificação da dimensão dos orifícios 1 e 2 .

O óleo escolhido para o sistema hidráulico é o Shell Tellus T 100 que possui viscosidade cinemática $v$, a 50 graus Celsius (que será considerada a temperatura de operação do fluído no sistema), igual a $65 \times 10^{-6} \mathrm{~m}^{2} / \mathrm{seg}$ (SHELL OIL). Devido a ausência por parte do fabricante do óleo de um gráfico da viscosidade absoluta ou mesmo da massa específica em função da temperatura precisou-se recorrer a literatura existente para se calcular a viscosidade absoluta $\mu$ a temperatura de 50 graus Celsius.

Segundo Merritt (1967), óleos a base de petróleo aumentam em 5\% seu volume, para um acréscimo de 100 graus Fahrenheit na temperatura. Portanto, para uma variação de 63 graus Fahrenheit (de 15 para 50 graus Celsius, que é equivalente a variação de 59 para 122 graus Fahrenheit) através de uma regra de três simples chegou-se a uma variação de, aproximadamente, $2,9 \%$ no aumento do volume do óleo. Isto equivale a multiplicar a massa específica dada a 15 graus Celsius $\left(\rho=886 \mathrm{~kg} / \mathrm{m}^{3}\right)$, fornecida pelo fabricante, por um fator de 0,971 , obtendo assim uma massa específica $\rho$ de $860,306 \mathrm{~kg} / \mathrm{m}^{3}$, a temperatura de 50 graus Celsius.

Sabendo que, por definição, a viscosidade absoluta $\mu$ é igual ao produto da viscosidade cinemática $v$ pela massa específica $\rho$ do óleo, chegou-se ao valor de $5,59 \times 10^{-2} \mathrm{~kg} / \mathrm{m} . \mathrm{seg}$ para a viscosidade absoluta $\mu$, a 50 graus Celsius.

Para garantir que ocorra escoamento laminar nos orifícios, o número de Reynolds para orifício circular $N_{R}$, dado pela equação (6.21) precisar ser menor ou igual a 2000. 


$$
N_{R}=\frac{4 Q_{o}}{v \pi D_{o}}
$$

em que

$Q_{o} \stackrel{\Delta}{=}$ vazão no orifício.

$D_{o} \stackrel{\Delta}{=}$ diâmetro do orifício.

Considerando o diâmetro de 0,3 mm da FIGURA 6.3, com as características do óleo adotado, necessita-se encontrar somente a vazão no próprio orifício a fim de encontrar um número de Reynolds menor ou igual a 2000, para garantir que o escoamento seja do tipo laminar. Abaixo, na FIGURA 6.4, pode-se observar a onda senoidal do deslocamento do conjunto pistão-haste adotado para provocar um deslocamento de óleo em um intervalo de tempo, isto é, uma vazão.

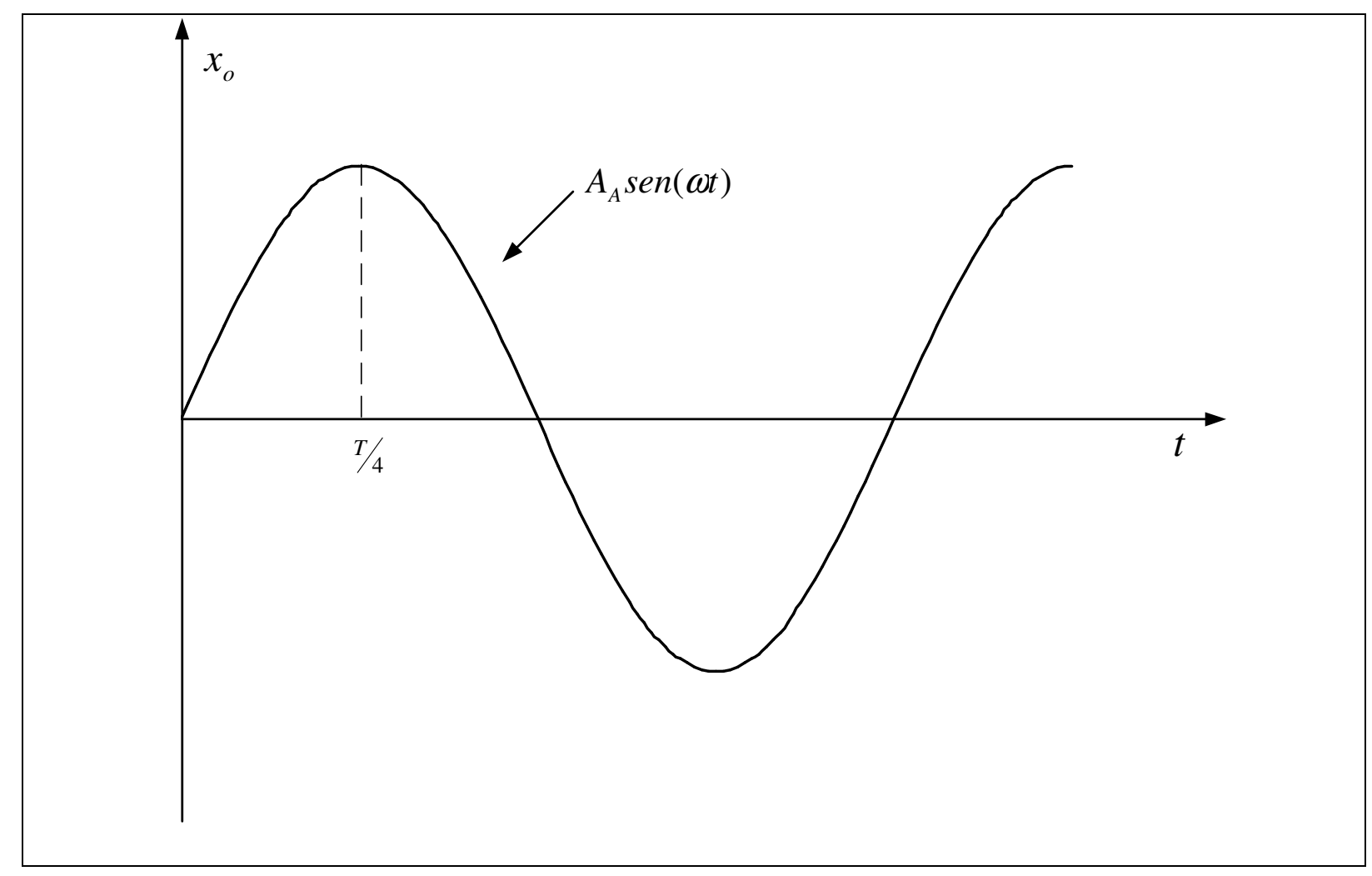

FIGURA 6.4 - Deslocamento senoidal do conjunto pistão-haste. 
Na FIGURA 6.4, $T$ é o período da onda, e $A_{A}$ é a amplitude do deslocamento.

O volume máximo $V_{\max }$ de óleo deslocado em $1 / 4$ de ciclo pelo conjunto pistão-haste é dado pela equação:

$$
V_{\max }=A_{A \max } A
$$

em que

$$
A_{A_{\max }} \stackrel{\Delta}{=} \text { amplitude máxima de deslocamento do conjunto pistão-haste; }
$$

Para a área efetiva calculada no item "a", admitindo-se uma amplitude máxima de deslocamento do conjunto pistão-haste de $1,00 \times 10^{-3} \mathrm{~m}$, o volume máximo deslocado de óleo em $1 / 4$ de ciclo é :

$$
V_{\max }=1,477 \times 10^{-6} \mathrm{~m}^{3}
$$

Neste cálculo é admitido a hipótese conservativa que o volume $V_{\max }$ de óleo deslocado pelo conjunto pistão-haste passa somente pelo orifício 1 . Isto significa que tem-se vazões nulas tanto para o vazamento entre o pistão e o cilindro como também para a parcela devido à compressibilidade do óleo e deformações das partes do sistema.

Face a estas considerações, a vazão $Q_{o}$ no orifício 1 é dada por:

$$
Q_{o}=\frac{V_{\max }}{\Delta t}
$$

em que

$$
\Delta t \stackrel{\Delta}{=} \text { variação de tempo. }
$$

Para efeito do cálculo da vazão no orifício, será considerado o primeiro quarto de onda da FIGURA 6.4, pois é neste intervalo que o conjunto pistão-haste atinge sua amplitude 
máxima, sendo o que ocorre nos demais quartos de onda subseqüentes iguais, para efeitos do cálculo de vazão. A variação de tempo $\Delta t$ será de $1,250 \times 10^{-2}$ segundos, correspondente a 1/4 de onda, admitindo uma freqüência máxima de excitação de $20 \mathrm{~Hz}$. Portanto, pela equação (6.23), obtém-se:

$$
Q_{o}=1,1819 \times 10^{-4} \mathrm{~m}^{3} / \mathrm{seg}
$$

Para dividir a vazão total deslocada pela área efetiva $A$ do conjunto pistão-haste, optou-se por construir um conjunto de 7 orifícios, ao invés de apenas um. Isto permite obter para um orifício, um número de Reynolds menor, visto que a vazão é diretamente proporcional ao número de Reynolds. Portanto, a vazão em cada um desses orifícios, supondo todos eles iguais, será a vazão $Q_{o}$ divida por 7, o que dá uma vazão média $Q_{f}$ para cada orifício igual a:

$$
Q_{f}=1,6884 \times 10^{-5} \mathrm{~m}^{3} / \mathrm{seg}
$$

Verificando o número de Reynolds dado pela equação (6.21), para a vazão $Q_{f}$ e para o diâmetro de orifício proposto inicialmente de $0,3 \mathrm{~mm}$ obtém-se:

$$
N_{R}=1102
$$

Portanto, o diâmetro de $0,3 \times 10^{-3}$ metros produz o número de Reynolds menor que 2.000, garantindo assim o regime laminar, nos orifícios 1 e 2 .

Uma vez comprovado que o diâmetro de $0,3 \times 10^{-3}$ metros garante o escoamento laminar para os orifícios 1 e 2, uma relação entre o diâmetro e o comprimento do orifício para que o escoamento laminar esteja perfeitamente desenvolvido é proposto por Merritt (1967), é dada por: 


$$
\frac{L_{o}}{D_{o}} \geq 115
$$

em que

$$
L_{o} \stackrel{\Delta}{=} \text { comprimento do orifício. }
$$

Por motivos de segurança adotar-se-á um comprimento $L_{o}$ de orifício 150 vezes o diâmetro. Portanto, para os orifícios 1 e 2 , o comprimento do orifício será de $45 \times 10^{-3}$ metros.

Para os demais orifícios (3, 4 e 5), a verificação dos diâmetros para constatar se produzirão regime laminar torna-se muito complicado por envolver não só a vazão de fluido devido ao deslocamento do conjunto pistão-haste mas também vazões devido a vários diferenciais de pressão, tornando muito complicado o cálculo da vazão total desses orifícios. Pelo exposto, adotou-se todos os demais orifícios com a mesma configuração (diâmetro e comprimento) dos orifícios 1 e 2, ou seja:

$$
\begin{gathered}
D o_{1}=D o_{2}=D o_{3}=D o_{4}=D o_{5}=D_{o}=0,3 \times 10^{-3} \mathrm{~m} \\
L o_{1}=L o_{2}=L o_{3}=L o_{4}=L o_{5}=L_{o}=45 \times 10^{-3} \mathrm{~m}
\end{gathered}
$$

em que

$$
D o_{1}, D o_{2}, D o_{3}, D o_{4} \text { e } D o_{5} \stackrel{\Delta}{=} \text { diâmetros dos furos que formam os orifícios } 1,2,3,4
$$

\section{e 5, respectivamente}

$$
L o_{1}, L o_{2}, L o_{3}, L o_{4} \text { e } L o_{5} \stackrel{\Delta}{=} \text { comprimentos dos furos que formam os orifícios } 1,2,3,
$$


f) Cálculo dos coeficientes que relacionam vazão-pressão $K_{1}, K_{2}, K_{3}$ e $K_{V}$ :

Para os furos circulares que formam os orifícios 1, 2, 3, 4 e 5, os respectivos coeficientes que relacionam vazão e pressão no regime laminar é dado por Merritt (1967):

$$
K_{1}=K_{2}=K_{3}=K_{4}=K_{o}=\frac{\pi D_{o}^{4}}{128 \mu L_{o}}
$$

em que

$K_{o} \stackrel{\Delta}{=}$ coeficiente que relaciona vazão e diferencial de pressão, no regime laminar, para os furos que formam os orifícios 1, 2, 3, 4 e 5.

Como são considerados um conjunto de 7 orifícios iguais, o coeficiente equivalente do conjunto $K e_{o}$ será obtido de forma análoga ao cálculo da resistência elétrica equivalente, quando os resistores estão associadas em paralelo, ou seja:

$$
K e_{1}=K e_{2}=K e_{3}=K e_{4}=K e_{5}=K e_{\text {orif }}=7 K_{o}
$$

em que

$K e_{1}, K e_{2}, K e_{3}, K e_{4}$ e $K e_{5} \stackrel{\Delta}{=}$ coeficientes equivalentes que relacionam vazões e diferenciais de pressão, no regime laminar, para os orifícios $1,2,3,4$ e 5, respectivamente. É o inverso da resistência fluídica equivalente.

Portanto, substituindo os valores $D_{o}, L_{o}$, calculados anteriormente, juntamente com os valores de $\mu$ e $v$ do óleo em (6.25), e posteriormente aplicando (6.26), obtém-se:

$$
K e_{o}=5,5322 \times 10^{-13} \mathrm{~m}^{3} / \text { Pa.seg }
$$

Para a folga radial entre o cilindro e pistão, o orifício desenvolvido é mostrado na FIGURA 6.5, onde o comprimento do orifício é o perímetro do pistão, ou seja, $\pi D_{P}$ e a altura $h$ é a folga radial entre o pistão e o cilindro, adotada como sendo $0,5 \times 10^{-3}$ metro. 


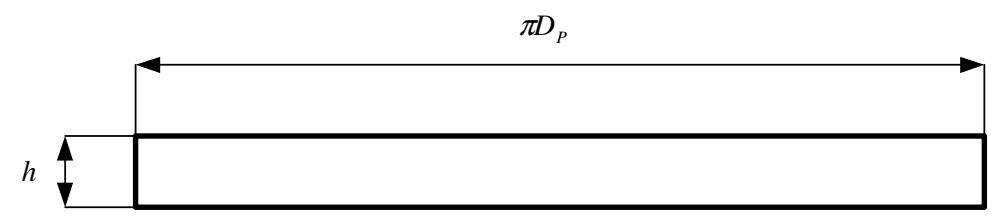

FIGURA 6.5 - Orifício desenvolvido para a folga entre o pistão e o cilindro

Como a folga entre o cilindro e o pistão é bem pequena, provavelmente ocorrerá escoamento laminar. Segundo Merritt (1967), para orifícios do tipo retangular, com comprimento muito maior que a altura, o coeficiente de vazão pressão $K_{V}$ é dado pela equação:

$$
K_{V}=\frac{w h^{3}}{12 \mu L}
$$

em que

$\mathrm{w} \stackrel{\Delta}{=}$ largura do orifício (perímetro do diâmetro do pistão);

$\mathrm{h} \stackrel{\Delta}{=}$ altura do orifício (folga radial entre o cilindro e o pistão);

$\mathrm{L} \stackrel{\Delta}{=}$ comprimento do orifício (comprimento do pistão).

Para a folga radial $h$ e comprimento do orifício igual ao comprimento do pistão $L_{P}$ dados na FIGURA 6.1, juntamente com os parâmetros do óleo escolhido, obtém-se:

$$
K_{V}=3,5515 \times 10^{-10} \mathrm{~m}^{3} / \text { Pa.seg }
$$

g) Coeficiente de atrito viscoso $B_{V}$

Segundo Merritt (1967), o coeficiente de atrito viscoso $B_{V}$ é dado por: 


$$
B_{V}=\frac{\pi D_{P} L_{P} \mu}{h}
$$

Substituindo as dimensões $D_{P}, L_{P}$ e $h$ da FIGURA 6.1, juntamente com o $\mu$ do óleo a temperatura de $50^{\circ} \mathrm{C}$ na equação (6.32), obtém-se:

$$
B_{V}=1,1854 \mathrm{Nseg} / \mathrm{m}
$$

Os valores dos parâmetros assim determinados servirão de base para realizações de simulações e determinação da resposta em freqüência.

Deve-se salientar que as dimensões e materiais foram escolhidos com a preocupação de possibilitar uma eventual construção. 


\section{SIMULAÇÃO DO SISTEMA HIDRÁULICO PROPOSTO}

\subsection{INTRODUÇÃO}

Este capítulo apresenta simulações do sistema hidráulico proposto com as dimensões e parâmetros adotados e calculados no Capítulo 6. São realizadas simulações para dois valores de bulk modulus com o objetivo de analisar o comportamento dinâmico do sistema. Além das simulações obtidas através do sistema hidráulico mencionado, foi proposto um novo arranjo de orifícios para o mesmo sistema hidráulico, também com o objetivo de avaliar o efeito na dinâmica do sistema. Para fins didáticos, o sistema hidráulico dimensionado no Capítulo 6 foi chamado de Sistema Hidráulico 1 e o outro, com um novo arranjo de orifícios, de Sistema Hidráulico 2 Quatro simulações foram geradas. Como resultado, são apresentadas as curvas de resposta em frequiência, lembrando que a entrada do sistema é a força aplicada sobre o amortecedor e a saída é a velocidade da haste.

Todas as simulações foram executadas com o método de integração ode23t do Simulink, com passo de integração variável e com passo máximo igual ao período da força de excitação divido por cem (100), para que houvesse maior precisão nos cálculos. Esta configuração foi a que se apresentou mais eficiente e, portanto aplicada a todos as simulações.

Foram implementados em um programa no Matlab:

- Dimensões primárias do sistema; 
- Constantes do sistema;

- Cálculo de parâmetros do sistema;

- Parâmetros da simulação;

- Interface com o usuário;

- Laço para obtenção da Resposta em Freqüência através do filtro de Fourier no Simulink;

- Armazenamento dos dados da Resposta em Freqüiência;

- Geração dos gráficos da Resposta em Freqüência.

Esse programa baseou-se no programa de testes do Capítulo 4.2. O programa do Matlab pode ser visto no APÊNDICE B deste trabalho.

A FIGURA 7.1 mostra os blocos dos Simulink utilizados para se obter juntamente com o programa no Matlab, a resposta em freqüência do sistema.

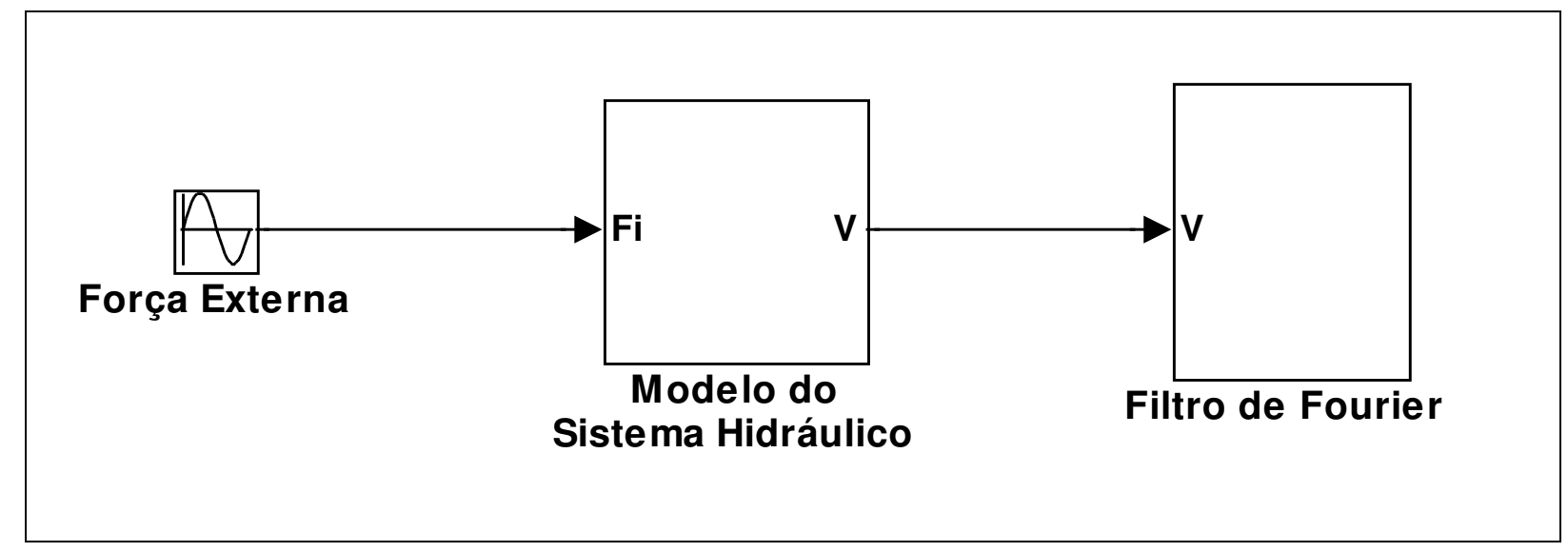

FIGURA 7.1 - Blocos do Simulink utilizados para simular o modelo

Assim como o bloco "Filtro de Fourier", o bloco "Modelo do Sistema Hidráulico" também é do tipo subsystem e, portanto, possui blocos contidos internamente. A FIGURA 7.2 mostra os blocos contidos dentro do bloco "Modelo do Sistema Hidráulico". 


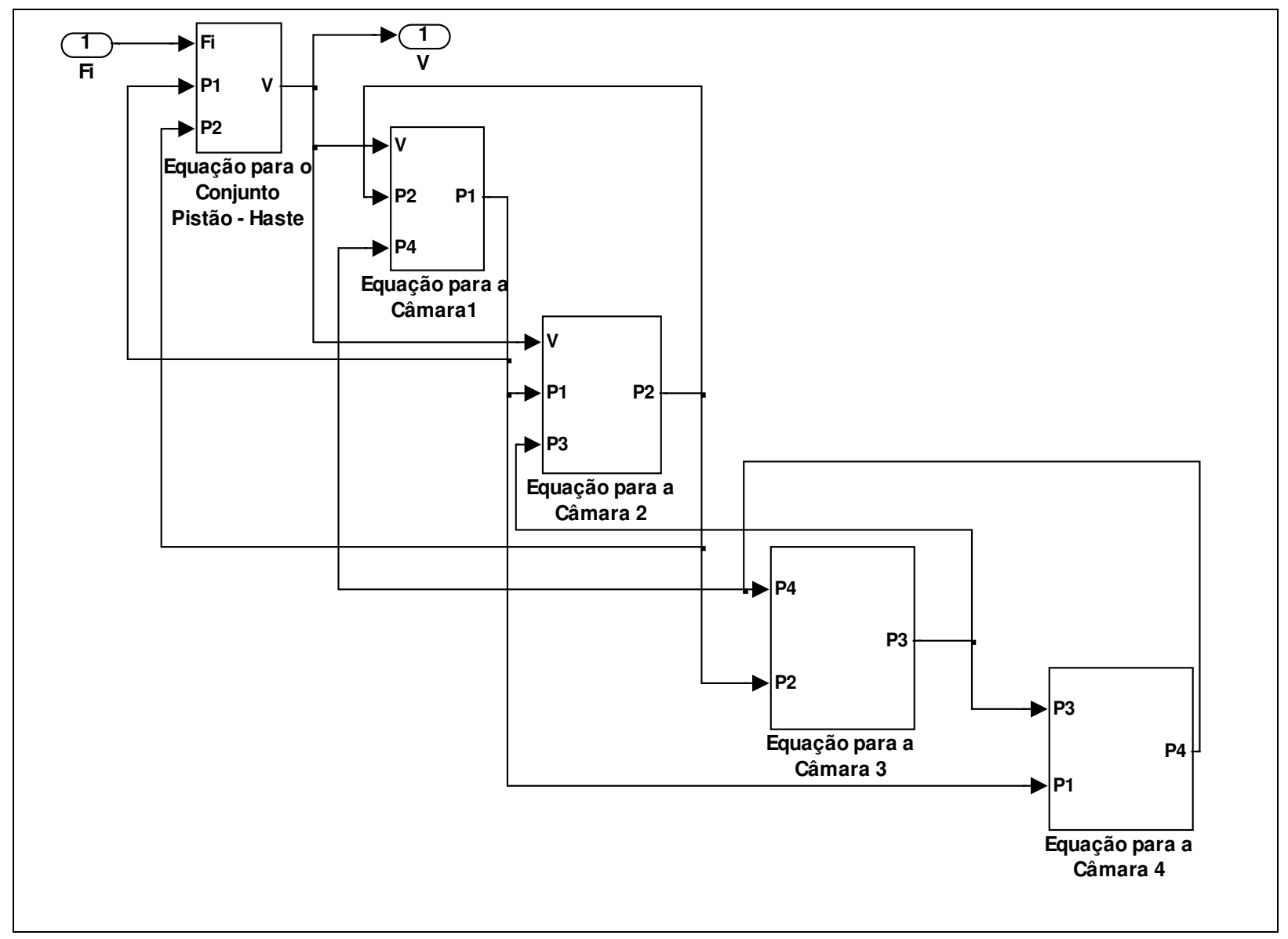

FIGURA 7.2 - Blocos contidos no bloco "Modelo do Sistema Hidráulico"

Excluindo-se os blocos $F i$ e $V$, todos os demais são do tipo subsystem, na FIGURA 7.2. Neles estão inseridos blocos que implementam as equações (5.14), (5.27), (5.29), (5.31) e (5.33) do modelo matemático do sistema hidráulico proposto obtidas no Capítulo 5. Os blocos contidos nestes subsystem podem ser vistos no APÊNDICE C deste trabalho. 


\subsection{SIMULAÇÃO DO SISTEMA HIDRÁULICO 1}

O sistema hidráulico 1 teve seus parâmetros calculados no capítulo anterior. A tabela 7.1 mostra os parâmetros para este sistema.

TABELA 7.1 - Parâmetros do Sistema Hidráulico 1.

\begin{tabular}{|c|c|}
\hline Parâmetro & Valor \\
\hline$h$ & $5 \times 10^{-4} \mathrm{~m}$ \\
\hline$M$ & $1,043 \mathrm{~kg}$ \\
\hline$C_{1}=C_{3}\left(\right.$ para $\left.\beta_{e}=100000 \mathrm{psi}\right)$ & $3,369 \times 10^{-14} \mathrm{~m}^{3} / \mathrm{Pa}$ \\
\hline$C_{1}=C_{3}\left(\right.$ para $\left.\beta_{e}=30000 \mathrm{psi}\right)$ & $1,123 \times 10^{-13} \mathrm{~m}^{3} / \mathrm{Pa}$ \\
\hline$K_{e_{1}}=K_{e_{3}}=K_{e_{4}}$ & $1,477 \times 10^{-3} \mathrm{~m}^{2}$ \\
\hline$K_{V}$ & $5,532 \times 10^{-13} \mathrm{~m}^{3} / \mathrm{seg} \cdot \mathrm{Pa}$ \\
\hline$B_{V}$ & $3,513 \times 10^{-10} \mathrm{~m}^{3} / \mathrm{seg} \cdot \mathrm{Pa}$ \\
\hline
\end{tabular}

Nas FIGURAS 7.3 e 7.4 podem ser observadas as curvas das respostas em frequiência para a configuração acima e para os dois valores de bulk modulus equivalente, obtidos através do filtro de Fourier. 

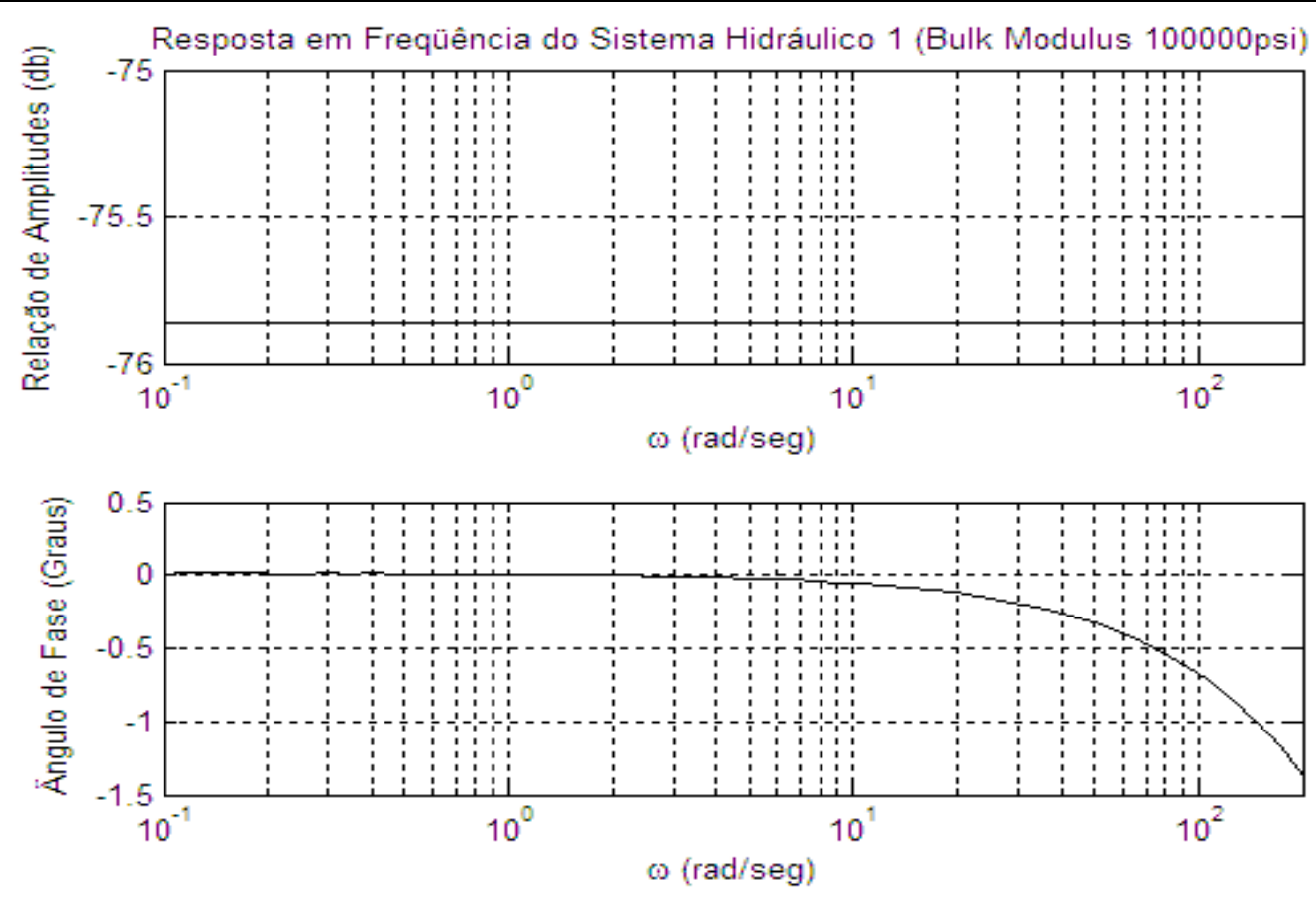

FIGURA 7.3 - Gráficos da RF do Sistema Hidráulico 1 para o Bulk Modulus equivalente igual a 100000 psi.

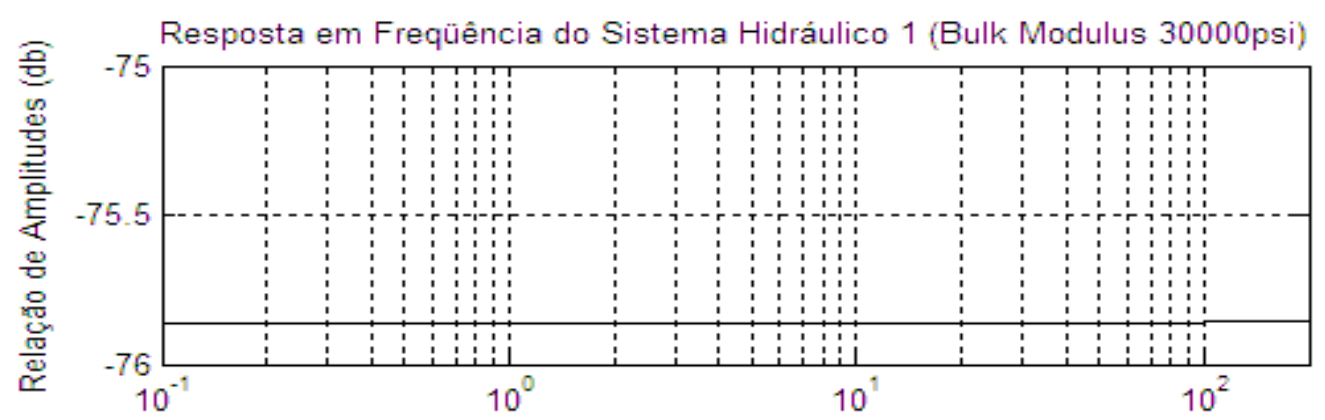

$\omega(\mathrm{rad} / \mathrm{seg})$

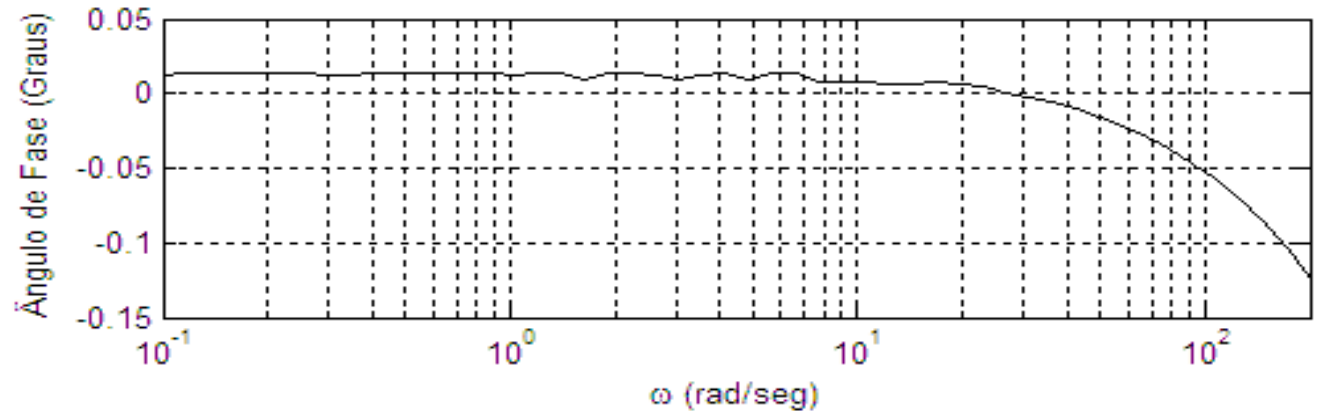

FIGURA 7.4 - Gráficos da RF do Sistema Hidráulico 1 para um Bulk Modulus equivalente igual a 30000 psi. 
Pode-se observar nas FIGURAS 7.3 e 7.4 que a magnitude, ou seja, a relação de amplitudes entre a força de excitação e a velocidade da haste é plana e igual -75,9 db para todas as freqüências. Já a fase, para ambas as figuras possui uma região plana próxima do zero e começa a cair para valores negativos. Na comparação entre os gráficos da fase, na região não plana, nota-se uma diminuição da fase quando comparados os gráficos do sistema com bulk moddulus de 30000 psi com o de 100000 psi.

Comparando os gráficos das respostas em freqüência das FIGURAS 7.3 e 7.4 com os gráficos da resposta em freqüência do amortecedor ideal (FIGURA 2.3), a região que mais se assemelha a este amortecedor, adotando um critério de tolerância de \pm 1 db para a magnitude e \pm 1 grau para fase, é:

- Para o sistema hidráulico com bulk modulus de 100000 psi a faixa de freqüência que vai de 0,1 a $150 \mathrm{rad} / \mathrm{seg}$;

- Para o sistema hidráulico com bulk modulus de 30000 psi a faixa de freqüência que vai de 0,1 a $200 \mathrm{rad} / \mathrm{seg}$, isto é, para toda a faixa de freqüência.

Portanto, o Sistema Hidráulico 1 tem comportamento próximo a de uma amortecedor ideal para as faixas de freqüência acima.

\subsection{SIMULAÇÃO DO SISTEMA HIDRÁULICO 2}

O sistema hidráulico 2 difere do sistema hidráulico 1 por possuir um arranjo de orifícios diferente do primeiro. O sistema hidráulico 2 possui 4 furos nos orifícios 1 e 2, 3 furos nos orifícios 4 e 5 e 7 furos no orifício 3, enquanto o sistema 1 possui 7 furos para todos os orifícios. Portanto, os coeficientes equivalentes de vazão pressão $K_{1}$ e $K_{4}$ possuem 
valores diferentes do sistema hidráulico 1. Esses coeficientes podem ser novamente recalculados para esse novo arranjo pela equação (6.26). Os novos coeficientes equivalentes de vazão pressão juntamente com os demais parâmetros do sistema hidráulico 2 podem ser visualizados na TABELA 7.2.

TABELA 7.2 - Parâmetros do Sistema Hidráulico 2.

\begin{tabular}{|c|c|}
\hline Parâmetro & Valor \\
\hline$h$ & $5 \times 10^{-4} \mathrm{~m}$ \\
\hline$M$ & $1,043 \mathrm{~kg}$ \\
\hline$C_{1}=C_{3}\left(\operatorname{para} \beta_{e}=100000 p s i\right)$ & $3,369 \times 10^{-14} \mathrm{~m}^{3} / \mathrm{Pa}$ \\
\hline$C_{1}=C_{3}\left(\right.$ para $\left.\beta_{e}=30000 p s i\right)$ & $1,123 \times 10^{-13} \mathrm{~m}^{3} / \mathrm{Pa}$ \\
\hline$A$ & $1,477 \times 10^{-3} \mathrm{~m}^{2}$ \\
\hline$K_{e_{1}}$ & $3,1613 \times 10^{-13} \mathrm{~m}^{3} / \mathrm{seg} . \mathrm{Pa}$ \\
\hline$K_{e_{3}}$ & $5,532 \times 10^{-13} \mathrm{~m}^{3} / \mathrm{seg} . \mathrm{Pa}$ \\
\hline$K_{e_{4}}$ & $2,3709 \times 10^{-13} \mathrm{~m}^{3} / \mathrm{seg} . \mathrm{Pa}$ \\
\hline$K_{V}$ & $3,552 \times 10^{-10} \mathrm{~m}^{3} / \mathrm{seg} . \mathrm{Pa}$ \\
\hline$B$ & $1,185 \mathrm{Nseg} / \mathrm{m}$ \\
\hline
\end{tabular}

Os gráficos das respostas em freqüência do sistema hidráulico 2, obtidos pela simulação usando o filtro de Fourier podem ser vistos nas FIGURAS 7.5 e 7.6, para os dois valores de bulk modulus. 


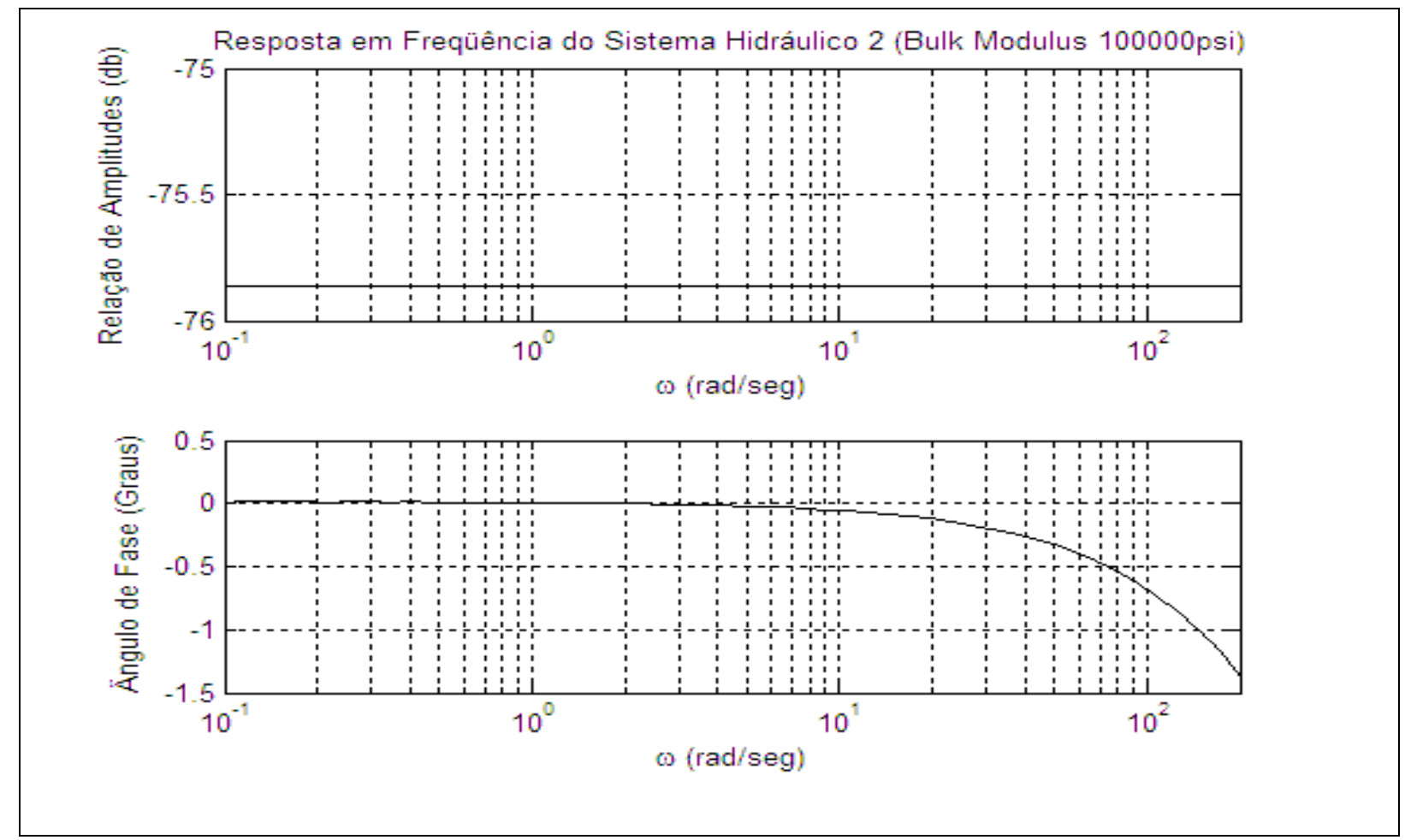

FIGURA 7.5 - Gráficos da RF do Sistema Hidráulico 2 para o bulk modulus equivalente igual a 100000 psi

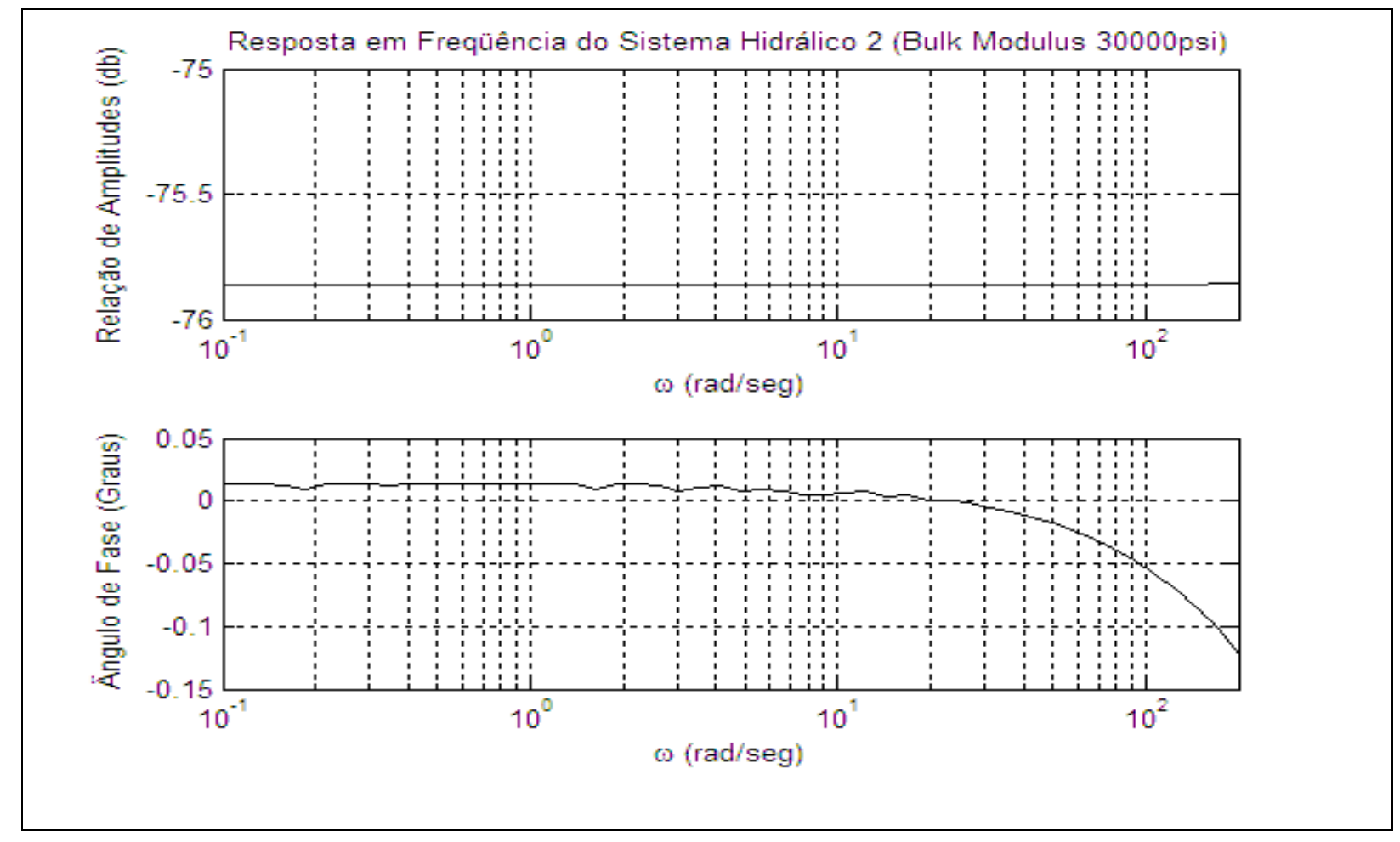

FIGURA 7.6 - Gráficos da RF do Sistema Hidráulico 2 para o bulk modulus equivalente iguala a 30000 psi 
Nas FIGURAS 7.5 e 7.6, para o sistema hidráulico 2 pode-se identificar uma região plana para a magnitude igual a $-75,9 \mathrm{db}$ para todas as freqüências. Também, uma região plana próxima a zero graus nos gráficos da fase pode ser visualizada nestas figuras.

Assim como ocorreu para o sistema hidráulico 1, houve uma diminuição do ângulo de fase quando o bulk modulus do sistema hidrúalico 2 foi de 100000 psi para 30000psi.

Utilizando o mesmo critério que foi utilizado para o sistema 1 para o sistema hidráulico 2 de tolerâncias de \pm 1 db para a magnitude e \pm 1 grau para a fase , a região que possui comportamento semelhante a de um amortecedor ideal é:

- Para o sistema hidráulico com bulk modulus de 100000 psi a faixa de freqüência que vai de 0,1 a $150 \mathrm{rad} / \mathrm{seg}$;

- Para o sistema hidráulico com bulk modulus de 30000 psi a faixa de freqüência que vai de 0,1 a $200 \mathrm{rad} / \mathrm{seg}$, isto é, para toda a faixa de frequiência. 


\section{CONCLUSÃO}

Um modelo teórico linear do sistema hidráulico proposto foi obtido através da aplicação de leis e relações pertinentes ao sistema. Duas configurações de sistemas hidráulicos com dimensões foram propostos e seus parâmetros definidos e calculados. Através de um programa implementado no MATLAB/Simulink foi possível obter a resposta em freqüência desses sistemas para dois valores de bulk modulus equivalente (100000 psi e 30000 psi). Pela comparação das curvas da resposta em frequiência dos sistemas hidráulicos propostos obtidos através do MATLAB/Simulink com as do amortecedor ideal, assumindo uma tolerância de variação da fase e da magnitude de \pm 1 grau e $\pm 1 \mathrm{db}$, respectivamente, pode-se concluir que o sistema comportou-se como um amortecedor para pequenas amplitudes (para amplitudes de no máximo $1 \mathrm{~mm}$ de deslocamento de curso do conjunto pistão-haste) para a seguinte faixa de freqüência:

- De 0,1 a $150 \mathrm{rad} / \mathrm{seg}$, no caso do sistema com bulk modulus equivalente igual a 100000 psi para as duas configurações de sistema hidráulico (sistemas hidráulicos 1 e 2);

- De 0,1 a $200 \mathrm{rad} / \mathrm{seg}$, no caso do sistema com bulk modulus equivalente igual a 30000 psi para as duas configurações de sistema hidráulico (sistemas hidráulicos 1 e 2).

A simulação implementada em MATLAB/Simulink mostrou-se eficiente na obtenção das respostas em frequiência de sistemas que possuem respostas com ângulo de fase entre o 
intervalo de $-180^{\circ}$ a $+180^{\circ}$ graus, sendo que para intervalos fora desta faixa faz-se necessário um aprimoramento do algoritmo. A concepção da simulação implementada e testada neste trabalho possibilita também a obtenção de respostas em frequiência de sistema não-lineares, bastando para tanto somente implementar a não-linearidade que se deseja considerar. Para se obter um comportamento dinâmico mais realista do sistema hidráulico proposto neste trabalho, a não-linearidade causada pelo atrito a seco entre a haste e as vedações pode ser facilmente implementada inserindo apenas um conjunto de blocos no diagrama do Simulink que contém as equações do modelo, obtendo-se um comportamento dinâmico ainda mais próximo do real A literatura existente menciona a importância dos efeitos do atrito a seco no comportamento dinâmico para pequenas amplitudes. Fica como proposta de trabalhos futuros a implementação da não-linearidade do tipo atrito a seco no modelo teórico, bem como o aprimoramento do programa para obtenção da resposta em freqüência, a fim de que se possa trabalhar com sistemas que possuam resposta com ângulo de fase em qualquer intervalo e também a construção e teste dos sistemas hidráulicos propostos a fim de se validar um modelo teórico. 


\section{REFERÊNCIAS}

AUDENINO, A.L.; BELINGARDI, G. (1995). Modelling the dynamic behaviour of a motorcycle damper. Proceedings of Institution of Mechanical Engineers- Part D Journal of Automobile Engineering, London, v.209, n.3, p.249-262.

DAVIS, P. et al. (1994). Adaptable passive viscous damper (na adaptable D-Strut ${ }^{\circledR}$ ). In: CONFERENCE ON SMART STRUCTURES AND INTELLIGENT SYSTEMS, 1994, Orlando. Proceendings... Bellingham: SPIE Optical Engineering. p.47-58. (SPIE Paper, 2193).

DIXON, J.C. (1999). Shock absorber handbook. Warrendale:SAE.

DOEBELIN, E.O. (1962). Dynamic analysis and feedback control. New York: McGrawHill.

. (1998). System dynamics. New York: Marcel Dekker.

ELLIS, J.T.; KARBOWNICZEK, S. (1962). Hydraulic shock absorber. Machine Design, Cleveland, v.34, p.150-157, May.

FELÍCO, L.C. (1981). A Theoretical and experimental study of the static and dynamic behavior of vane-type pressure compensated hydraulic pumps with proportional-type. PhD. Thesis - The Ohio State University, Ohio, 1981.

RiMa. (2007). Modelagem da dinâmica de sistemas e estudo da resposta. São Calos:

HONG, S.R. et al. (2005). A hydro-mechanical model for hysteretic damping force prediction of ER damper: experimental verification. Journal of Sound and Vibration, London, v.285, n.4/5, p.1180-1188.

MATSUMOTO, E.Y. (2002). Simulink 5: fundamentos. 2.ed. São Paulo. Érika. (2004). MATLAB ${ }^{\circledR}$ 7: fundamentos. São Paulo. Érika.

MERRITT, H.E. (1967). Hydraulic control systems. New York. Wiley. 
MOLICA, R. (1997). Nonlinear dynamic model and simulation of a high pressure monotube shock absorber using the bond graph method. MsC. Dissertation Massachusetts Institute of Technology, Massachusetts, 1997.

OGATA, K. (1993). Engenharia de controle moderno. Tradução de Ivan Jose de Albuquerque. Rio de Janeiro: Prentice Hall do Brasil.

PATTEN, W.N. et al. (1998). A Primer on design of semiactive vibration absorbers (SAVA). Journal of Engineering Mechanics, New York, v.124, n.1, p.61-68.

SHELL OIL (2003). Disponível em:<http://www.shell.com/static/twcn/downloads/shell_for_businesses/industry/product_data_sheet/english_version/tellus_t.pdf > . 20 Oct. 2006.

SPENCER JR., B.F. et al. (1996). Phenomenological model of a magntorheological damper. Journal of Engineering Mechanics, New York, v.123, n.3, p.230-238.

WANG, X.; GORDANINEJAD, F. (2001). Dynamic modeling of semi-active ER/MR fluid dampers. In: CONFERENCE ON SMART STRUCTURES AND MATERIALS: damping and isolation. Proceedings... Bellingham: SPIE Optical Engineering. p.82-91. (SPIE Paper , 3331). 


\section{APÊNDICE A - PROGRAMA DO MATLAB PARA OS TESTES}

\section{DOS SISTEMAS}

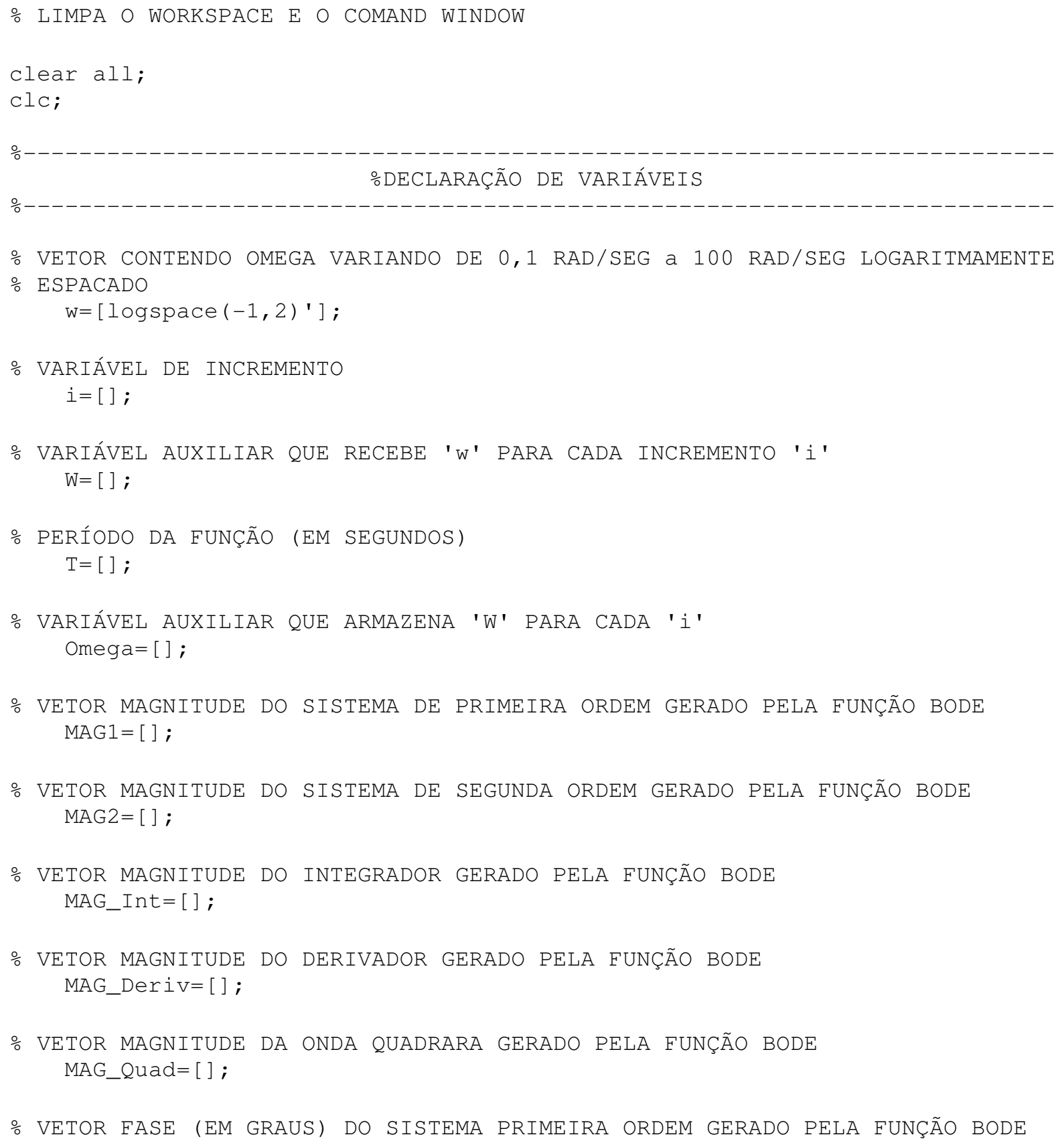


$\operatorname{PHASE} 1=[] ;$

○ VETOR FASE (EM GRAUS) DO SISTEMA DE SEGUNDA ORDEM GERADO PELA FUNÇÃO BODE PHASE2 $=[]$;

VETOR FASE (EM GRAUS) DO INTEGRADOR GERADO PELA FUNÇÃO BODE PHASE_Int $=[]$;

VETOR FASE (EM GRAUS) DO DERIVADOR GERADO PELA FUNÇÃO BODE PHASE_Deriv=[];

\% VETOR FASE (EM GRAUS) DA ONDA QUADRADA PHASE_Quad=[ ] ;

\% NÚMERO DE CICLOS EM REGIME PERMANENTE NCpermanente $=[500]$;

\% FASE (EM GRAUS) DO INTEGRADOR GERADO PELO BLOCO DO SIMULINK F_Int $=[]$;

\% FASE (EM GRAUS) DO DERIVADOR GERADO PELO FILTRO DE FOURIER F_Derive[];

\% FASE (EM GRAUS) DO SISTEMA DE PRIMEIRA ORDEM GERADO PELO BLOCO DO ㅇ SIMULINK; F_Prim=[];

\% FASE (EM GRAUS) DO SISTEMA DE SEGUNDA ORDEM GERADO PELO FILTRO DE FOURIER F_Seg=[] ;

\% FASE (EM GRAUS) DA ONDA QUADRADA GERADO PELO FILTRO DE FOURIER F_Quad= [ ] ;

\% TEMPO PARA O FIM DA SIMULAÇÃO (EM SEGUNDOS) Timefim=[];

AMPLITUDE DA EXCITACAO Amplitude $=[]$;

\% RELAÇÃO DE AMPLITUDES DO INTEGRADOR Rel_Ampl_Int $=[]$;

\% RELAÇÃO DE AMPLITUDES DO DERIVADOR Rel_Ampl_Deriv=[];

\% RELAÇÃO DE AMPLITUDES DO SISTEMA DE PRIMEIRA ORDEM Rel_Ampl_Prim=[] ;

RELAÇÃO DE AMPLITUdES DO SISTEMA DE SEGUNDA ORDEM Rel_Ampl_Seg=[] ;

\% RELAÇÃO DE AMPLITUDES DA ONDA QUADRADA; Rel_Ampl_Quad=[] ; 


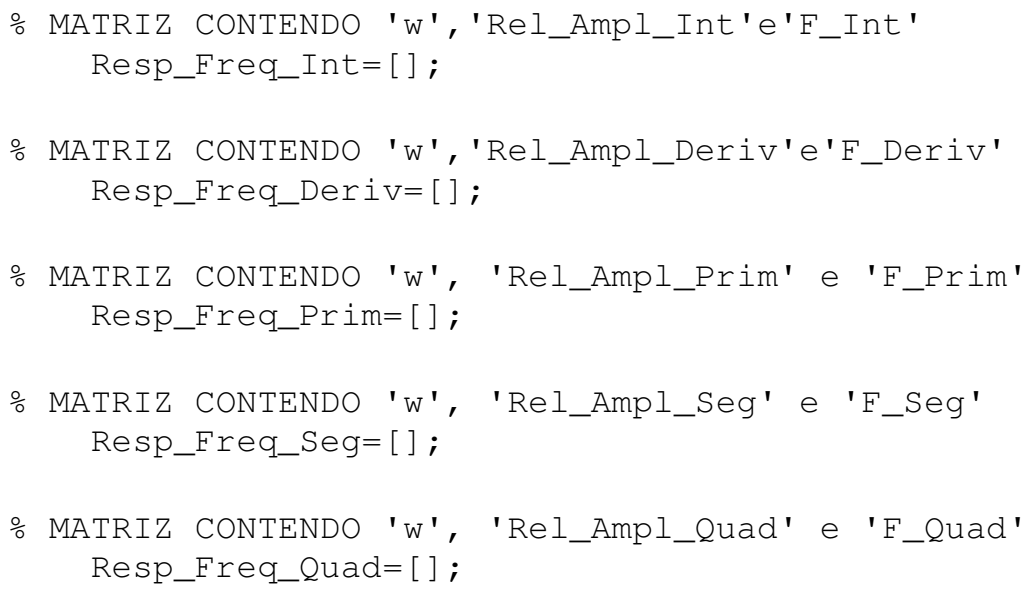

\%MATRIZ CONTENDO AS DIFERENÇAS DA MAGNITUDE E FASE DA RESPOSTA EM ○FREQUENNCIA, PARA UM SISTEMA DE PRIMEIRA ORDEM GERADO PELA FUNÇÃO BODE NO ○MATLAB, E O GERADO PELO SIMULINK EM FUNÇÃO DE 'W' (PRIMEIRA COLUNA 'W' ○SEGUNDA COLUNA MAGNITUDE E TERCEIRA COLUNA FASE)

Dif_Prim=[];

\%MATRIZ CONTENDO AS DIFERENÇAS DA MAGNITUDE E FASE, DA RESPOSTA EM ○FREQÜÊNCIA, PARA UM SISTEMA DE SEGUNDA ORDEM GERADO PELA FUNÇÃO BODE NO ○MATLAB, E O GERADO PELO SIMULINK EM FUNÇÃO DE 'W' (PRIMEIRA COLUNA 'W' ○SEGUNDA COLUNA MAGNITUDE E TERCEIRA COLUNA FASE)

Dif_Seg=[];

\% MATRIZ CONTENDO AS DIFERENÇAS DA MAGNITUDE E FASE, DA RESPOSTA EM ○FREQÜÊNCIA, PARA UM INTEGRADOR GERADA PELA FUNÇÃO BODE E O GERADO SIMULINK EM FUNÇÃO DE 'W'(PRIMEIRA COLUNA ' $w$ ' SEGUNDA COLUNA MAGNITUDE E ERCEIRA COLUNA FASE)

Dif_Int $=[]$;

\% MATRIZ CONTENDO AS DIFERENÇAS DA MAGNITUDE E FASE, DA RESPOSTA EM FREQUE-

NCIA, PARA UM DERIVADOR GERADA PELA FUNÇÃO BODE E O GERADO PELO SIMULINK

EM FUNÇÃO DE ' $w$ ' (PRIMEIRA COLUNA ' $w$ ' SEGUNDA COLUNA MAGNITUdE E TERCEIRA

- COLUNA FASE)

Dif_Deriv=[];

\% MATRIZ CONTENDO AS DIFERENÇAS DA MAGNITUDE E FASE DO PRIMEIRO HARMÔNICO

○ PARA UMA ONDA QUADRADA E O GERADO PELO SIMULINK EM FUNÇÃOACAO DE ' $W$ '

- (PRIMEIRA COLUNA ' $w$ ' SEGUNDA COLUNA MAGNITUdE E TERCEIRA COLUNA FASE) Dif_Quad=[ ] ;

TEMPO NECESSÁRIO PARA TRANSIENTES DESAPARECEREM

Tempo_fim_trans $=50$;

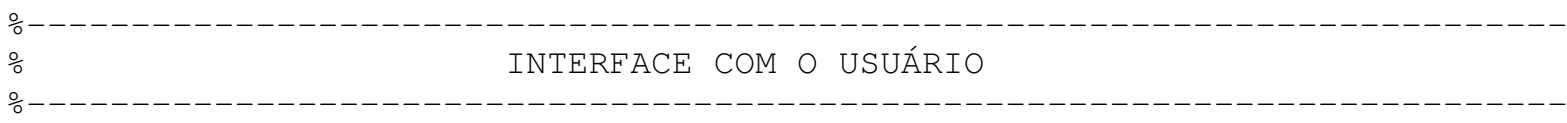

○PERGUNTA AO USUÁRIO A AMPLITUDE DO INPUT

Msg=\{'Amplitude do Input' $\}$;

Titulo1=' Input' ;

NumeroLinhas $=[1]$;

ValPreDef $=\{1$ ' $\}$;

Amplitude=inputdlg(Msg, Titulo1, NumeroLinhas, ValPreDef); 
A_input=str2double (Amplitude);

○PERGUNTA AO USUÁRIO QUAL SISTEMA ELE DESEJA OBTER A RESPOSTA EM FREQÜÊNCIA

Prompt='Sistemas prara Caculo da $\mathrm{RF}^{\prime}$;

Lista $=\{$ 'Integrador' 'Derivador' 'Sistema Primeira Ordem' 'Sistema Segunda

Ordem' 'Relay sem histerese'\};

Inicial $=[5]$;

Selecao='single';

Tamanho $=\left[\begin{array}{ll}200 & 100\end{array}\right]$;

Titulo2='Resposta em Freqüência';

[ind, ok] =listdlg( 'PromptString', Prompt, ...

'ListString', Lista, ...

'Initialvalue', Inicial,...

'SelectionMode', Selecao,...

'ListSize', Tamanho,....

'Name', Titulo2);
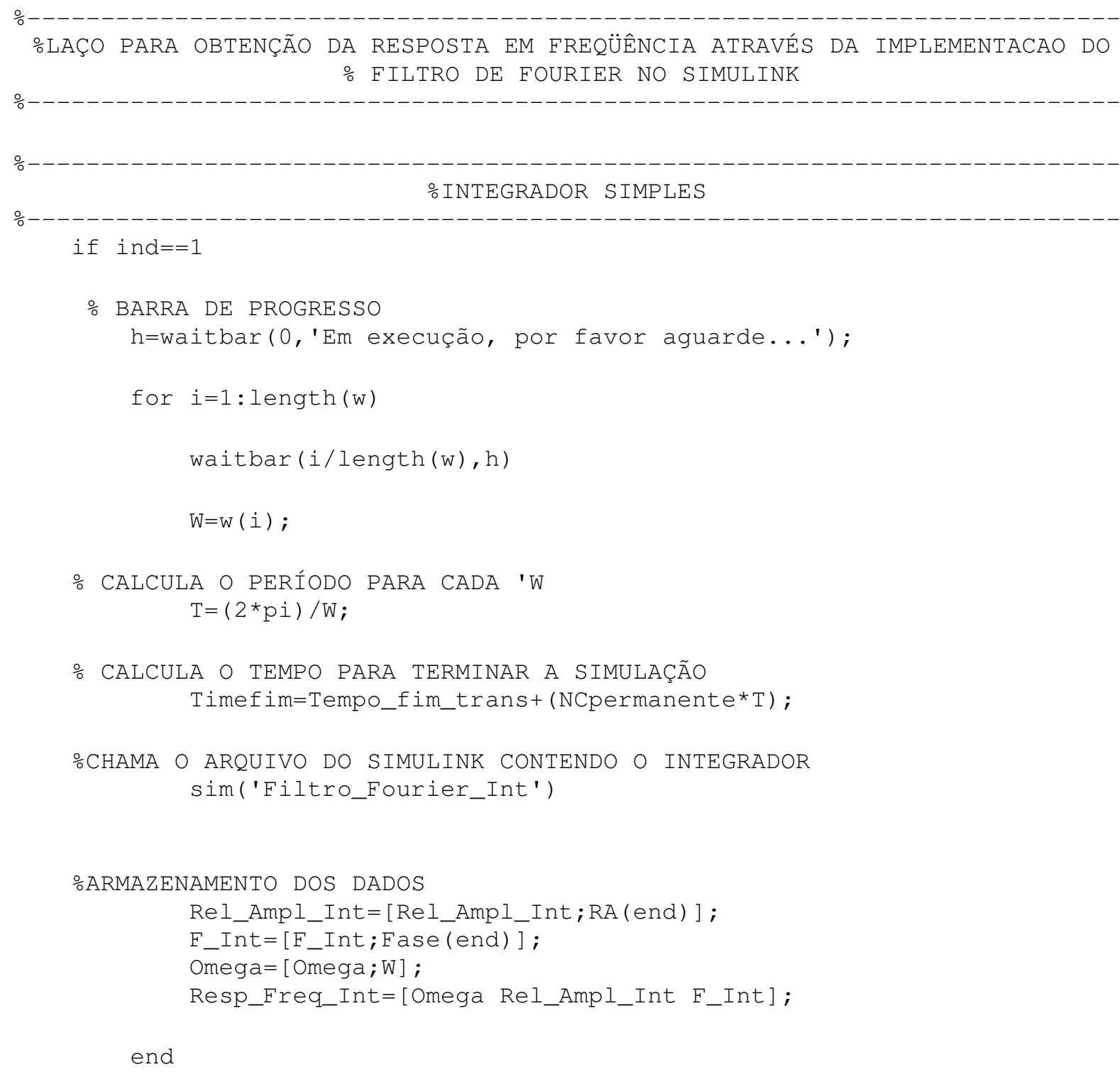
close (h)

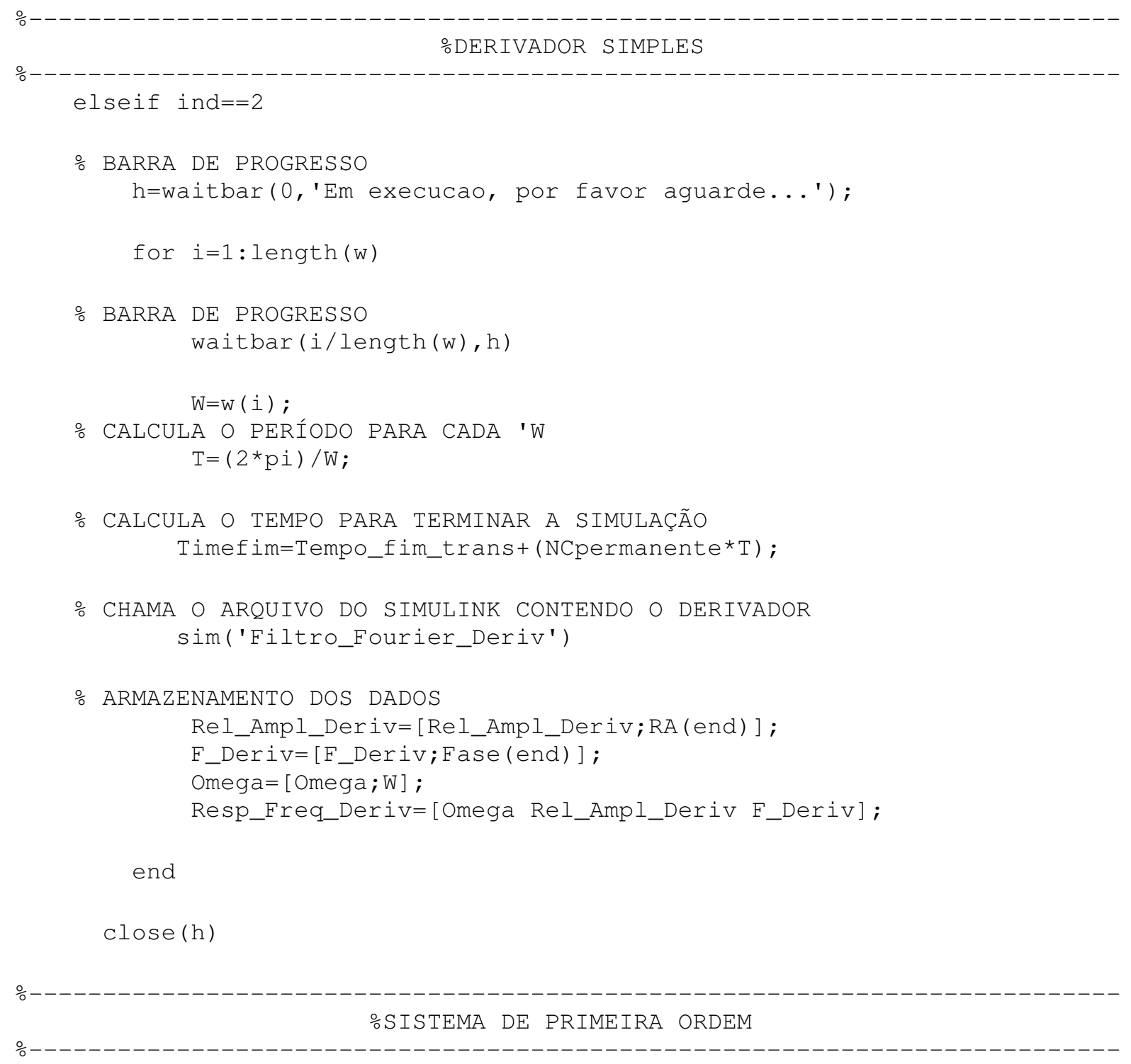

elseif ind $==3$

○PERGUNTA AO USUÁRIO O VALOR DA CONSTANTANTE DE TEMPO

Msg $=\{$ 'Valor da Constante de tempo'\};

Titulo1='Sistema de Primeira Ordem';

NumeroLinhas $=[1]$;

ValPreDef $=\{1$ ' 1 ; ;

TAL=inputdlg(Msg, Titulo1, Numerolinhas, ValPreDef);

tal=str2double (TAL);

Tempo_fim_trans $=10 *$ tal

○ BARRA DE PROGRESSO

h=waitbar (0,'Em execução, por favor aguarde...');

for $i=1:$ length $(w)$

waitbar (i/length (w), h) 


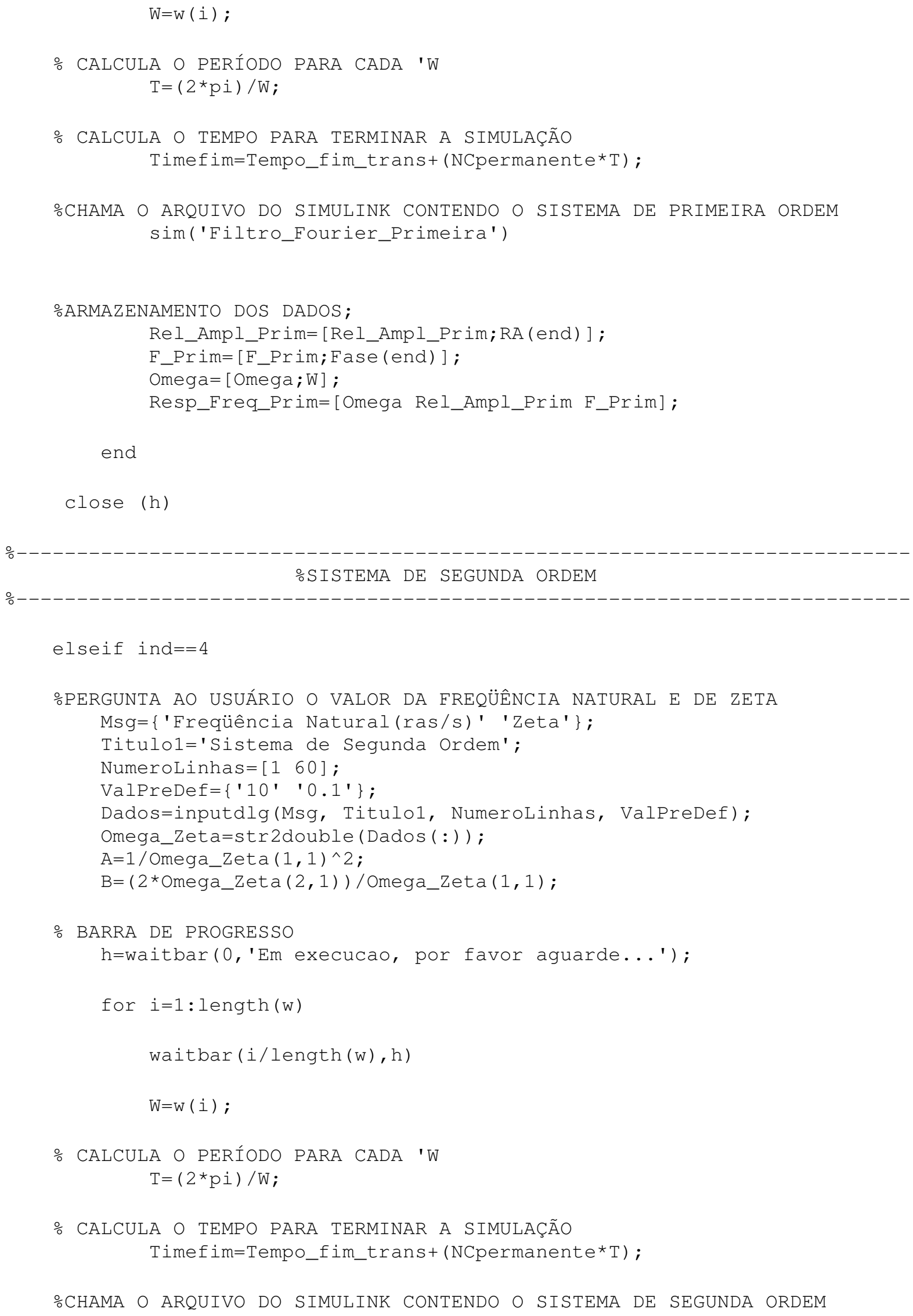




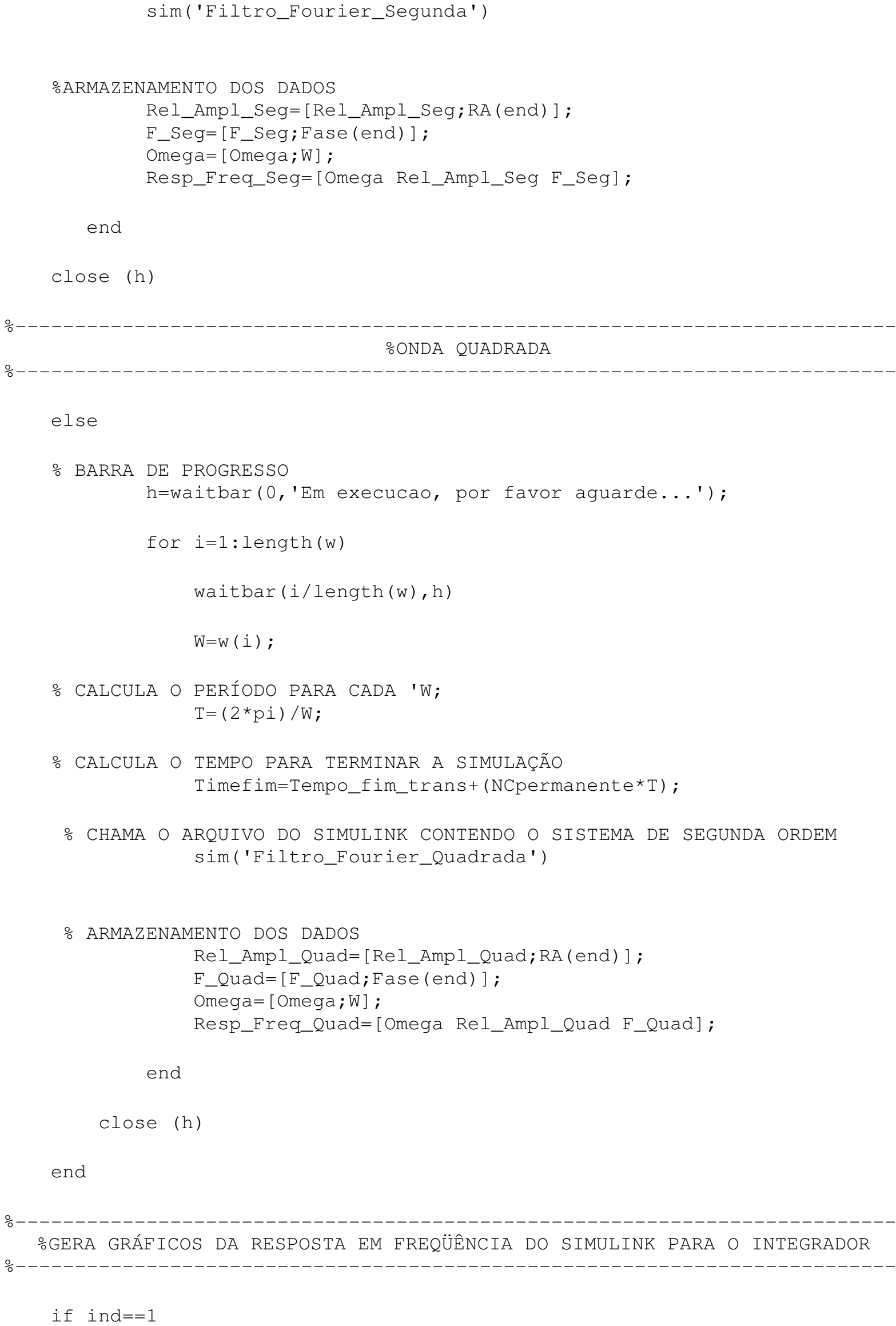




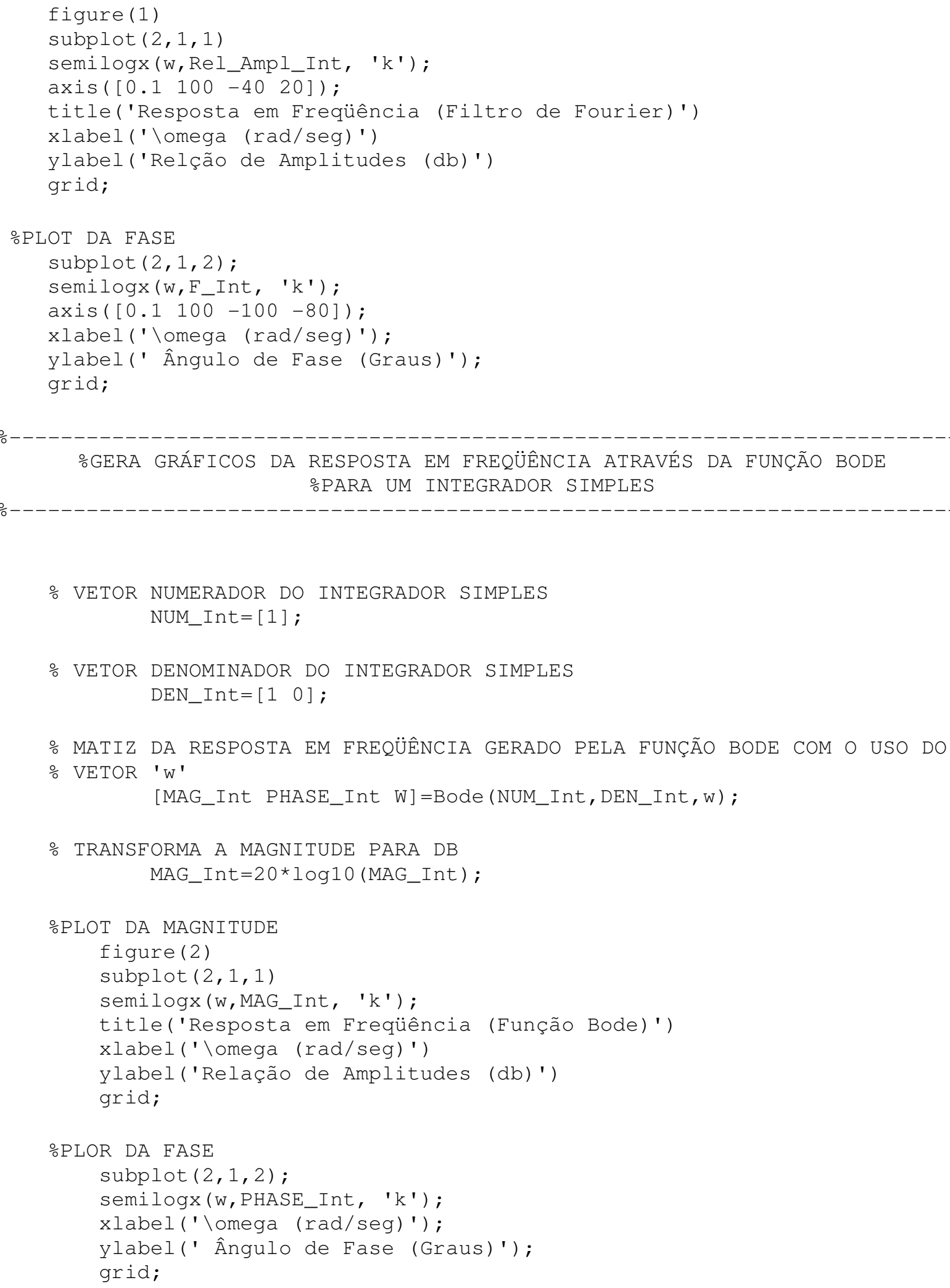

VETOR NUMERADOR DO INTEGRADOR SIMPLES NUM_Int $=[1]$;

- VETOR DENOMINADOR DO INTEGRADOR SIMPLES DEN_Int $=\left[\begin{array}{ll}1 & 0\end{array}\right]$;

MATIZ DA RESPOSTA EM FREQÜÊNCIA GERADO PELA FUNÇÃO BODE COM O USO DO 


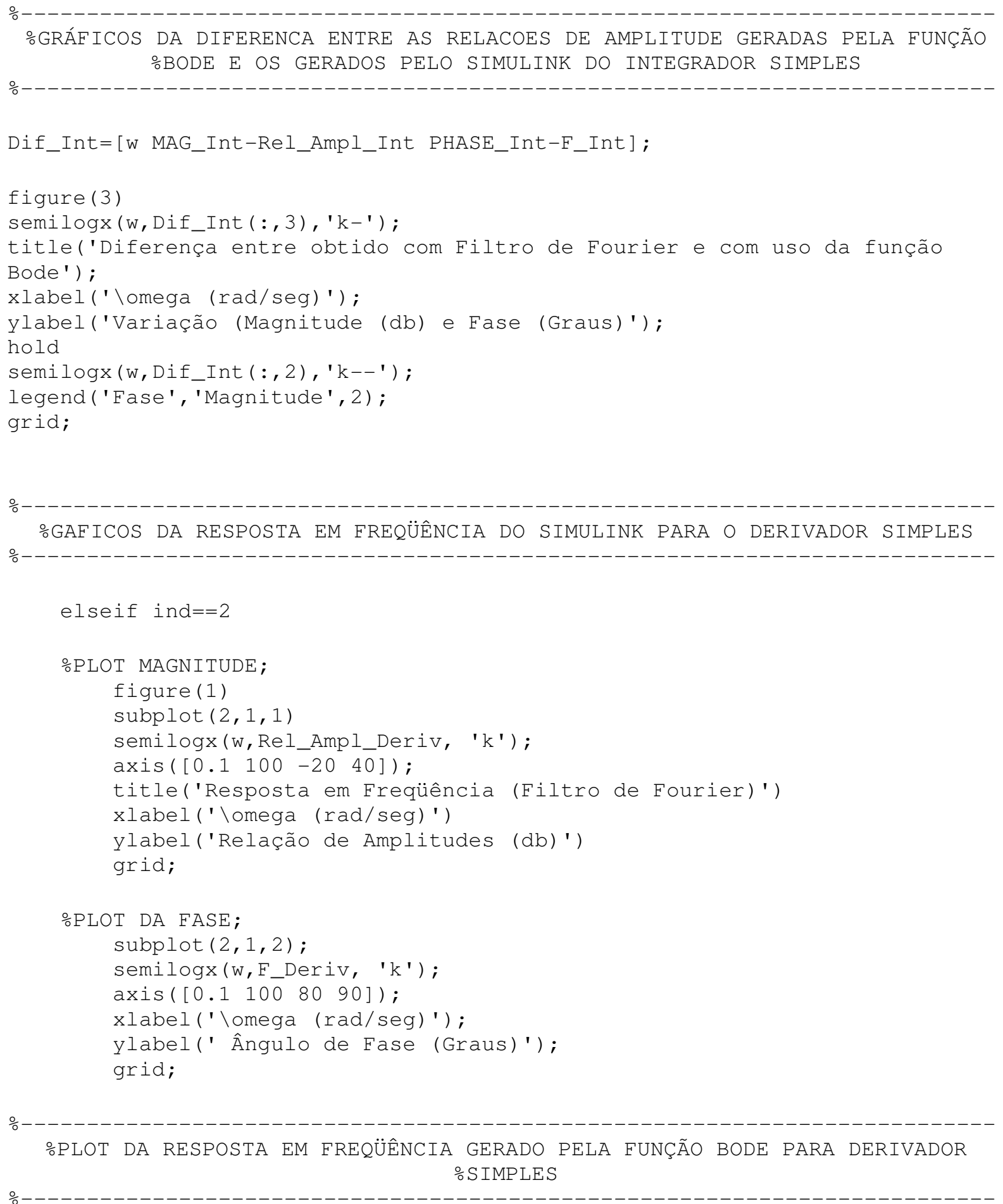

VETOR NUMERADOR DO DERIVADOR SIMPLES

NUM_Deriv=[1 0$]$;

○ VETOR DENOMINADOR DO DERIVADOR SIMPLES

DEN_Deriv=[1];

\% MATIZ DA RESPOSTA EM FREQÜÊNCIA GERADO PELA FUNÇÃO BODE COM O USO DO

VETOR ' $W$ ' 
[MAG_Deriv PHASE_Deriv W] =Bode (NUM_Deriv,DEN_Deriv,w) ;

TRANSFORMA A MAGNITUDE PARA DB

MAG_Deriv=20* $\log 10$ (MAG_Deriv);

$\because$ PLOT DA MAGNITUDE

figure (2)

subplot $(2,1,1)$

semilogx (w, MAG_Deriv, 'k') ;

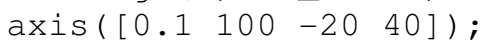

title('Resposta em Freqüência (Função Bode)')

xlabel ('\omega (rad/seg)')

ylabel ('Relação de Amplitudes (db)')

grid;

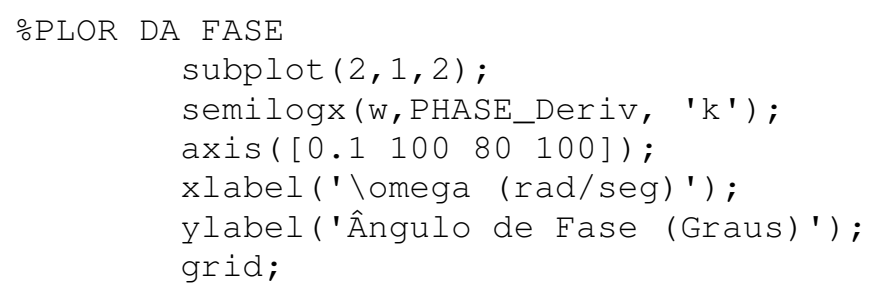

○PLOT DOS DA DIFERENCA ENTRE AS RELACOES DE AMPLITUDE TEORICO E OS GERADOS PELO SIMULINK DO DERIVADOR

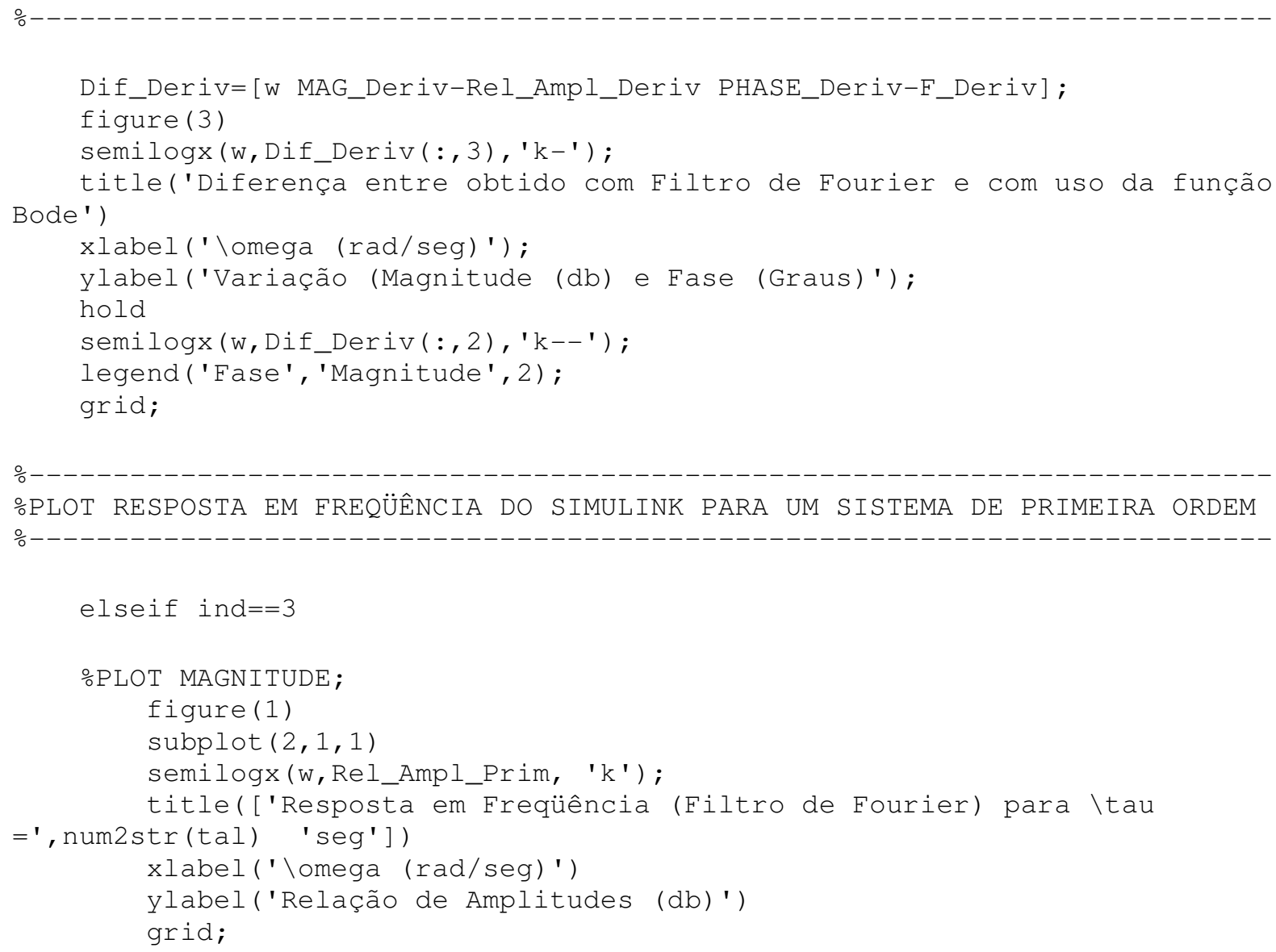


subplot $(2,1,2)$;

semilogx (w, F_Prim, 'k');

xlabel (' 'omega (rad/seg)');

ylabel(' Ângulo de Fase (Graus)') ;

grid;

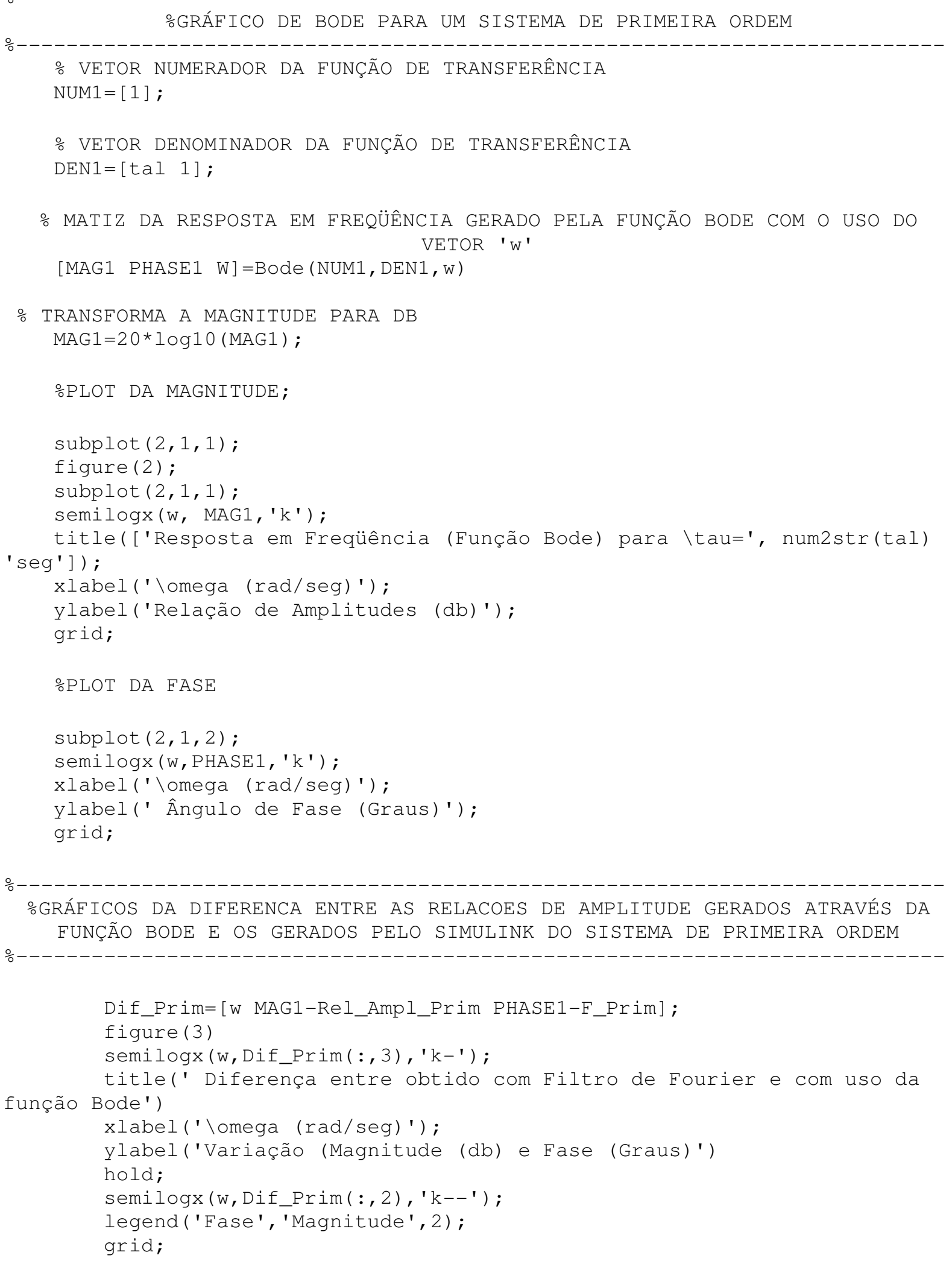




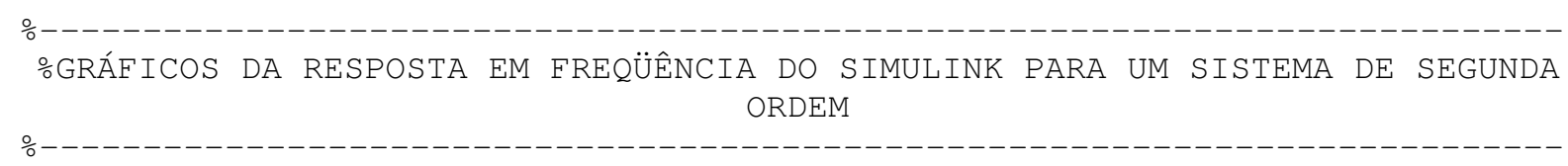

elseif ind $==4$

PLOT MAGNITUDE;

figure (1)

subplot $(2,1,1)$

semilogx (w, Rel_Ampl_Seg, 'k') ;

title(['Resposta em Freqüência (Filtro Fourier) para \omega_n=',

num2str(Omega_Zeta (1,1)) 'rad/seg e \zeta=', num2str(Omega_Zeta(2,1)) ])

xlabel ('\omega ( $\mathrm{rad} / \mathrm{seg})$ ')

ylabel ('Relação de Amplitudes (db) ')

grid;

PLOT DA FASE;

subplot $(2,1,2)$;

semilogx (w, F_Seg, 'k');

xlabel ('\omega (rad/seg)');

ylabel (' Ângulo de Fase (Graus)');

grid;

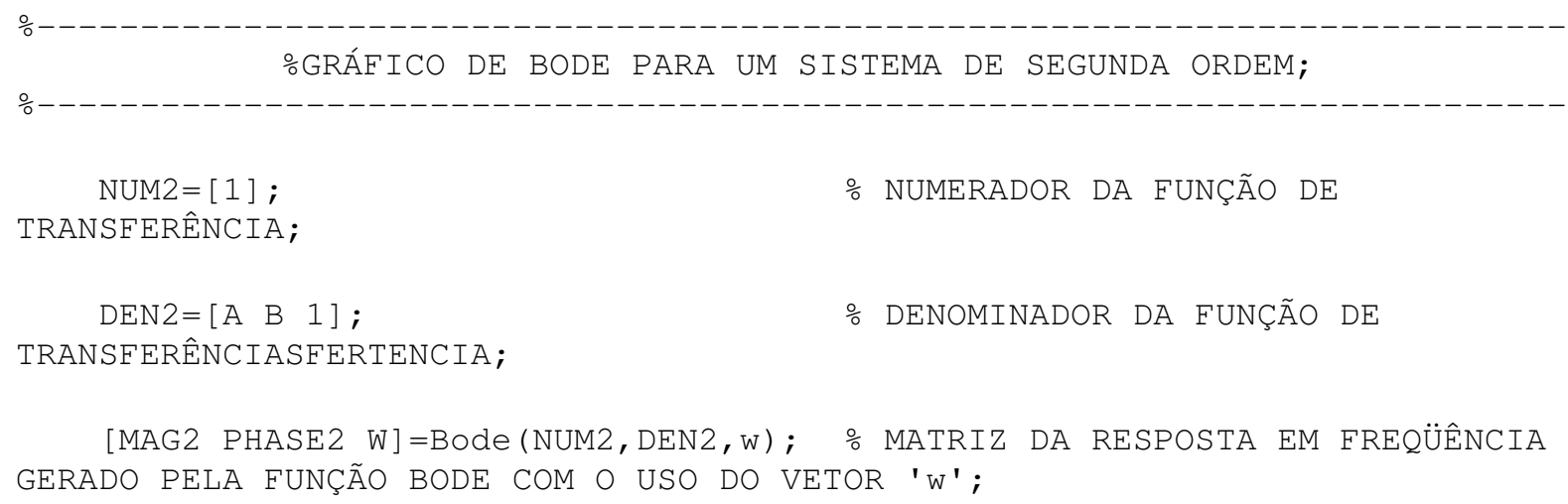

GERADO PELA FUNÇÃO BODE COM O USO DO VETOR ' $W$ ';
$\operatorname{MAG} 2=20 * \log 10(\mathrm{MAG} 2)$;
\% TRANSFORMA A MAGNITUDE PARA DB;

○PLOT DA MAGNITUDE;

figure (2);

subplot $(2,1,1)$;

semilogx (w, MAG2, 'k');

title(['Resposta em Freqüência (Função Bode) para lomega_n=',

int2str(Omega_Zeta(1,1)) 'rad/seg e \zeta=', num2str(Omega_Zeta(2,1)) ]);

xlabel ('\omega (rad/seg)');

ylabel ('Relação de Amplitudes (db) ') ;

grid; 
○ PLOT DA FASE;

subplot $(2,1,2)$;

semilogx ( $w$, PHASE2, ' k') ;

xlabel ('\omega (rad/seg)') ;

ylabel(' Ângulo de Fase (Graus)');

grid;

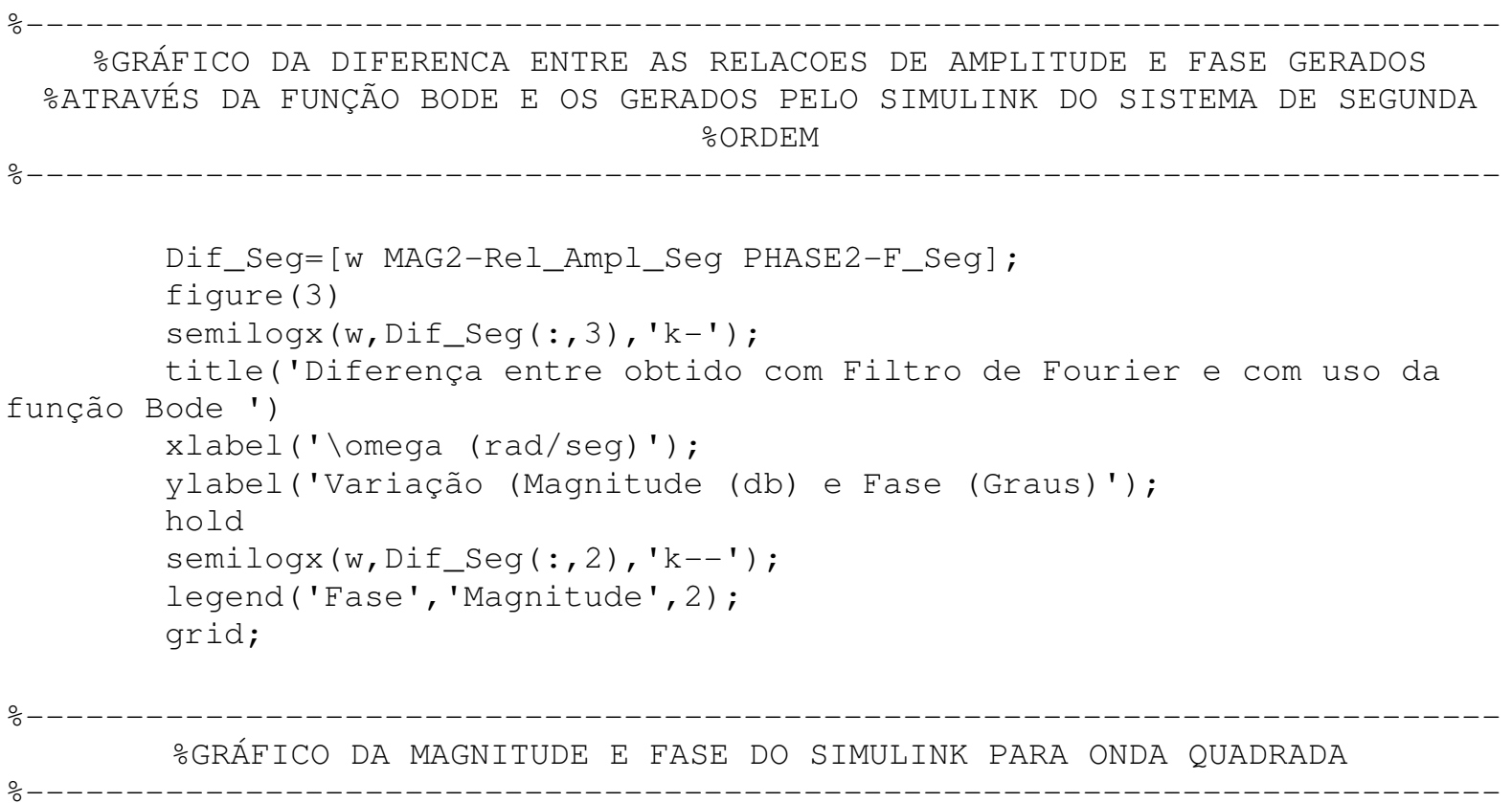

else

figure (1)

subplot $(2,1,1)$

semilogx (w, Rel_Ampl_Quad, 'k') ;

axis([0.1 $100 \overline{2} 2.2])$;

title('Magnitude e Fase da componete harmônica fundamenatal (Filtro de Fourier)')

xlabel ('\omega (rad/seg)')

ylabel ('Magnitude (db)')

grid;

PLOT DA FASE;

subplot $(2,1,2)$;

semilogx (w, F_Quad, 'k');

$\operatorname{axis}\left(\left[\begin{array}{llll}0.1 & 100 & -1 & 1\end{array}\right]\right)$;

xlabel ('\omega (rad/seg)');

ylabel(' Ângulo de Fase (Graus)');

grid; 


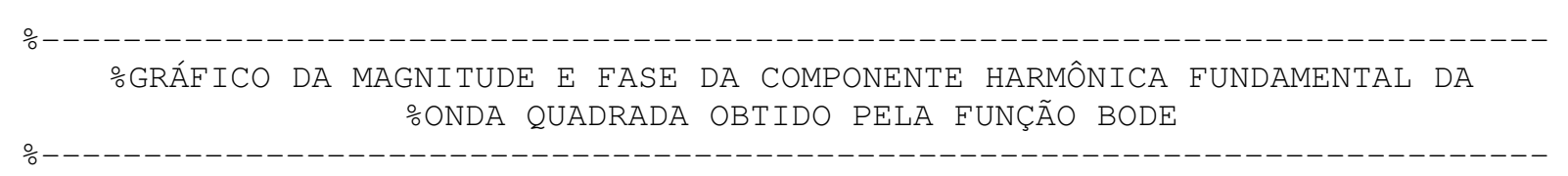

○PLOT DA MAGNITUDE;

NUM_Quad=[4*A_input $] ; \quad$ N NUMERADOR DA FUNÇÃO DE TRANSFERÊNCIA

DEN_Quad=[pi]; $\quad$ ․ DENOMINADOR DA FUNÇÃO DE

TRANSFERÊNCIASFERTENCIA

[MAG_Quad PHASE_Quad $W]=$ bode (NUM_Quad, DEN_Quad, w) ; \% MATRIZ DA RESPOSTA EM FREQÜÊNCIA GERADO PELA FUNÇÃO BODE COM O USO DO VETOR ' $w$ '

MAG_Quad=20*log10 (MAG_Quad); $\%$ TRANSFORMA A MAGNITUDE PARA DB;

figure (2);

subplot $(2,1,1)$;

semilogx (w, MAG_Quad,'k');

title('Magnitude e Fase da componete harmônica fundamenatal (Fução

Bode) ');

xlabel ('\omega (rad/seg)');

ylabel ('Magnitude (db)');

grid;

PLOT DA FASE

subplot $(2,1,2)$;

semilogx (w, PHASE_Quad, 'k') ;

xlabel ('\omega (rad/seg)');

ylabel (' Ângulo de Fase (Graus)');

grid;

○PLOT DA DIFERENCA ENTRE A MAGNITUDE E FASE TEÓRICO E OS GERADOS PELO SIMULINK PARA ONDA QUADRADA

função Bode' )

Dif_Quad=[w MAG_Quad-Rel_Ampl_Quad PHASE_Quad-F_Quad] ;

figure (3)

semilogx (w, Dif_Quad (:,3), 'k-');

title('Diferença entre obtido com Filtro de Fourier e com uso da

xlabel ('\omega (rad/seg)');

ylabel ('Variação (Magnitude (db) e Fase (Graus)');

hold

semilogx (w, Dif_Quad (:,2), 'k--') ;

legend ('Fase', 'Magnitude', 2 ) ;

grid;

end 


\section{APÊNDICE B - PROGRAMA DO MATLAB PARA A SIMULAÇÃO DO SISTEMA HIDRÁULICO}

○ LIMPA O WORKSPACE E O COMAND WINDOW;

clear all; clc;

DECLARAÇÃO DE VARIÁVEIS

○VARIÁVEL PARA ARMAZENAR A RELAÇÃO DE AMPLITUDES (db)

Rel_Ampl=[ ] ;

VARIÁVEL PARA ARMAZENAR O ÂNGULO DE FASE (graus)

$\mathrm{F}=[]$;

○VARIÁVEL PARA ARMAZENAR AS FREQUÊNCIAS DE EXCITAÇÃO DO SISTEMA (rad/s)

Omega $=[]$;

MATRIZ PARA ARMAZENAR A RESPOSTA EM FREQUÊNCIA

Resp_Freq=[] ;

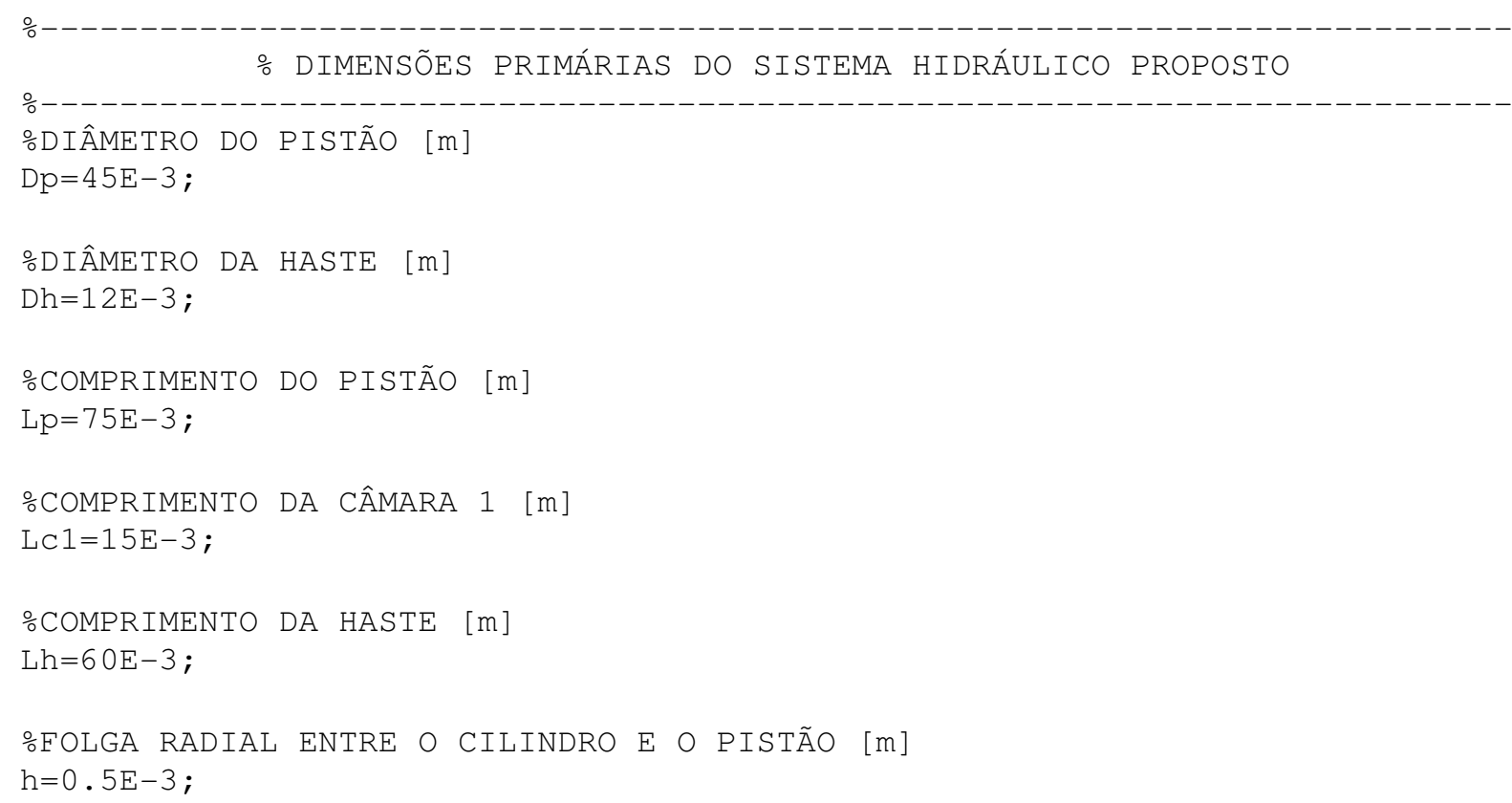


VOLUME DE ÓLEO NA CÂMARA 3 [m^3]

$\mathrm{V} \circ 3=\mathrm{V} \circ 2$;

○VOLUME DE ÓLEO NA CÂMARA 4 [m^3]

$\mathrm{V} \circ 4=\mathrm{V} \circ 3$;

○MASSA DO PISTÃO $[\mathrm{Kg}]$

$\mathrm{Mp}=\mathrm{Vp} * \mathrm{Ro}$;

○MASSA DA HASTE [KG]

$\mathrm{Mh}=\mathrm{Vh} * \mathrm{Ro}$;

○MASSA DO CONJUNTO PISTÃO-HASTE [KG]

$\mathrm{M}=\mathrm{Mp}+(2 \star \mathrm{Mh})$;

○COEFICIENTE DE ATRITO VISCOSO [Kg/seg]

$B v=(p i * D p * L p * M i) / h$;

\% LARGURA DO OIFÍCIO DESENVOLVIDO PARA A FOLGA RADIA ENTRE O PISTÃO E O ㄷILINDRO $(\mathrm{m})$

$\mathrm{L}=\mathrm{p} i * \mathrm{Dp}$;

○COEFICIENTE QUE RELACIONA VAZÃO PRESSÃO PARA ORIFÍICO 1 (m^3/seg.Pa) $\mathrm{K} 1=((\mathrm{pi} *(\mathrm{DO} \wedge 4)) /(128 * \mathrm{Mi} * \mathrm{LO})) * \mathrm{~N}$;

COEFICIENTE QUE RELACIONA VAZÃO PRESSÃO PARA ORIFÍCIO 2 (m^3/seg.Pa) $\mathrm{K} 2=\mathrm{K} 1$;

COEFICIENTE QUE RELACIONA VAZÃO PRESSÃO PARA ORIFÍCIO 3 (m^3/seg.Pa) $\mathrm{K} 3=\left(\left(\mathrm{pi} *\left(\mathrm{DO}^{\wedge} 4\right)\right) /(128 * \mathrm{Mi} * \mathrm{LO})\right){ }^{\mathrm{N}} \mathrm{N}$;

○COEFICIENTE QUE RELACIONA VAZÃO PRESSÃO PARA ORIFÍCIO 4 (m^3/seg.Pa) $\mathrm{K} 4=((\mathrm{pi} *(\mathrm{DO} \wedge 4)) /(128 * \mathrm{Mi} * \mathrm{LO})){ }^{*} \mathrm{~N}$;

COEFICIENTE QUE RELACIONA VAZÃO PRESSÃO PARA ORIFÍCIO 5 (m^3/seg.Pa) $\mathrm{K} 5=\mathrm{K} 4$;

○COEFICIENTE DE VAZÃO DE VAZAMENTO ENTRE O PISTÃO E O CILINDRO

$\div\left(\mathrm{m}^{\wedge} 3 / \mathrm{seg} \cdot \mathrm{Pa}\right)$

$\mathrm{KV}=(\mathrm{L} *(\mathrm{~h} \wedge 3)) /(12 * \mathrm{Mi} * \mathrm{LP})$;

○COMPLIANCE DA CÂMARA $1 \quad\left[\mathrm{~m}^{\wedge} 3 / \mathrm{Pa}\right]$

$\mathrm{C} 1=\mathrm{Vol} / \mathrm{Be}$;

○COMPLIANCE DA CÂMARA $2[\mathrm{~m} \wedge 3 / \mathrm{Pa}]$

$\mathrm{C} 2=\mathrm{C} 1$;

○COMPLIANCE DA CÂMARA $3\left[\mathrm{~m}^{\wedge} 3 / \mathrm{Pa}\right]$

$\mathrm{C} 3=\mathrm{Vo} 3 / \mathrm{Be}$;

○COMPLIANCE DA CÂMARA 4 [m^3/Pa]

$\mathrm{C} 4=\mathrm{C} 3$; 


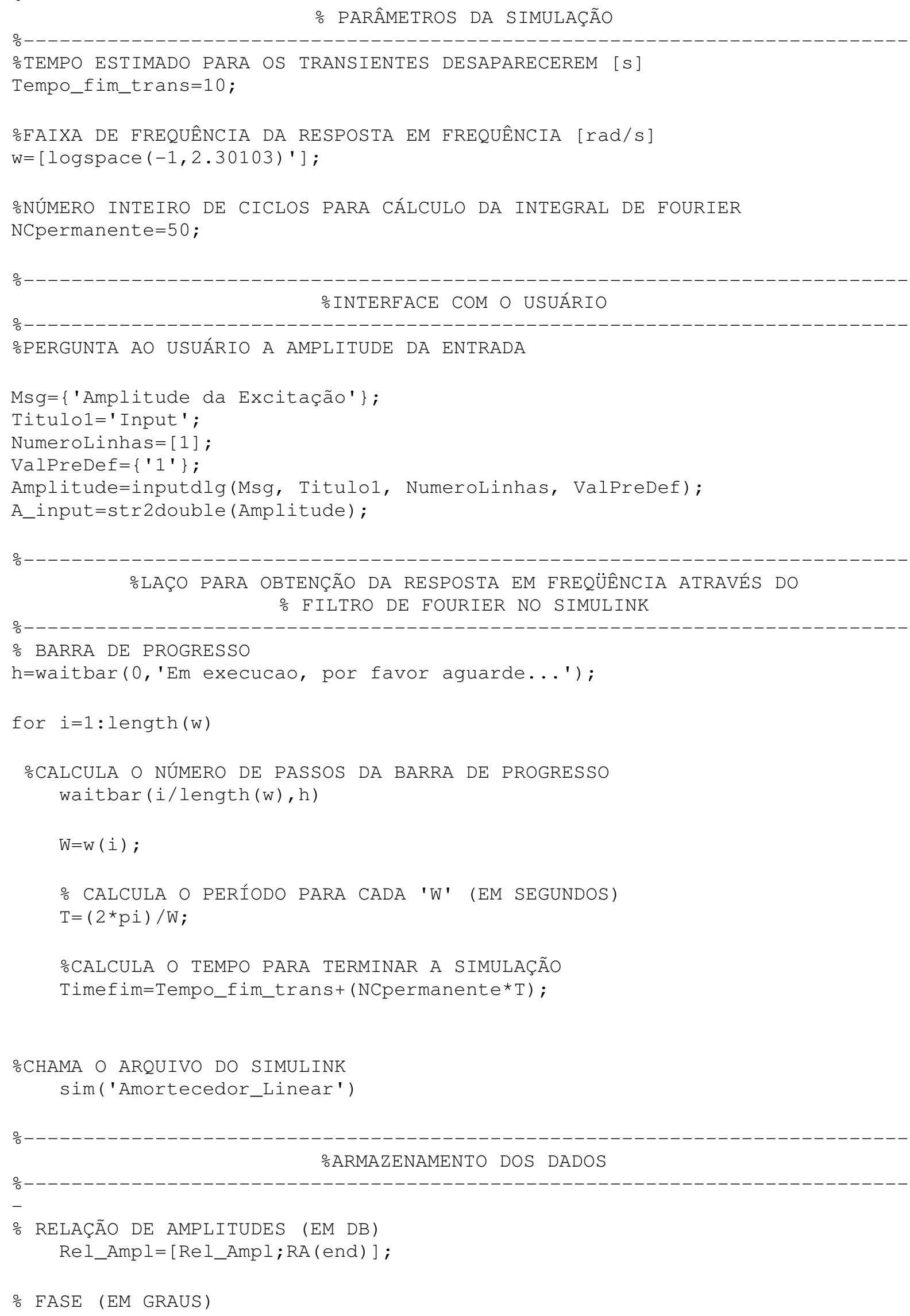


$\mathrm{F}=[\mathrm{F} ; \mathrm{Fase}(\mathrm{end})]$;

○ VARIÁVEL AUXILIAR QUE ARMAZENA 'W

Omega $=[$ Omega; $W]$;

MATRIZ CONTENDO A RESPOSTA EM FREQUÊNCIA

Resp_Freq=[Omega Rel_Ampl F];

end

close $(\mathrm{h})$

GERAÇÃO DOS GRÁFICOS DA RESPOSTA EM FREQÜÊNCIA

○GRÁFICO DA MAGNITUDE

figure (1)

subplot $(2,1,1)$

semilogx (w, Rel_Ampl, 'k');

title('Resposta em Freqüência')

xlabel ('\omega ( $\mathrm{rad} / \mathrm{seg}$ )')

ylabel ('Relação de Amplitudes (db) ')

grid;

○GRÁFICO DA FASE

subpl ot $(2,1,2)$;

$\operatorname{semilogx}\left(w, F,{ }^{\prime} k^{\prime}\right)$;

xlabel (' \omega (rad/seg)');

ylabel (' Ângulo de Fase (Graus)');

grid; 


\section{APÊNDICE C - PROGRAMA DO SIMULINK CONTENDO AS EQUAÇÕES DO MODELO}

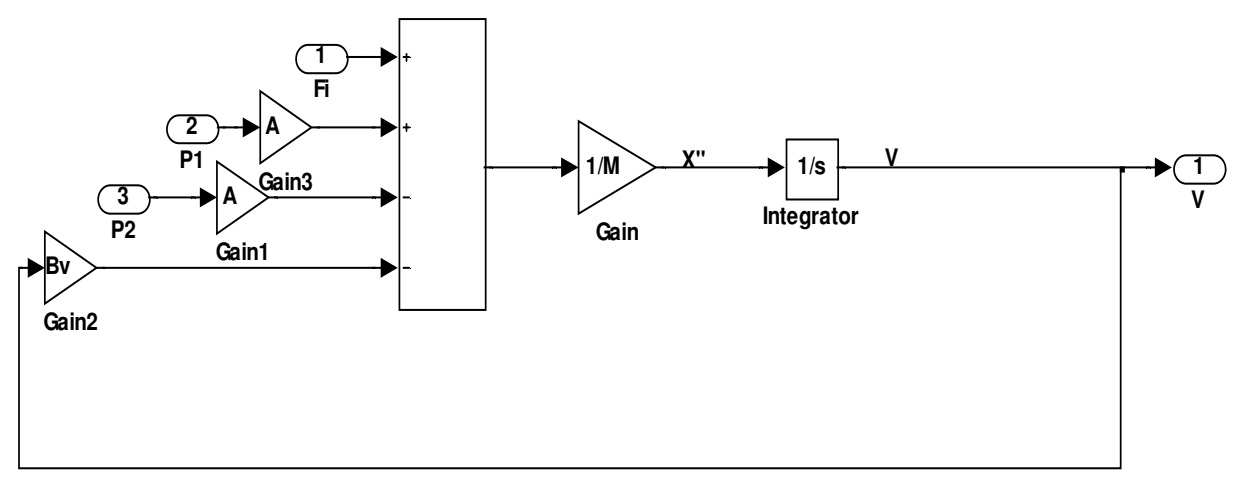

FIGURA C1 - Implementação da equação (5.14) no Simulink

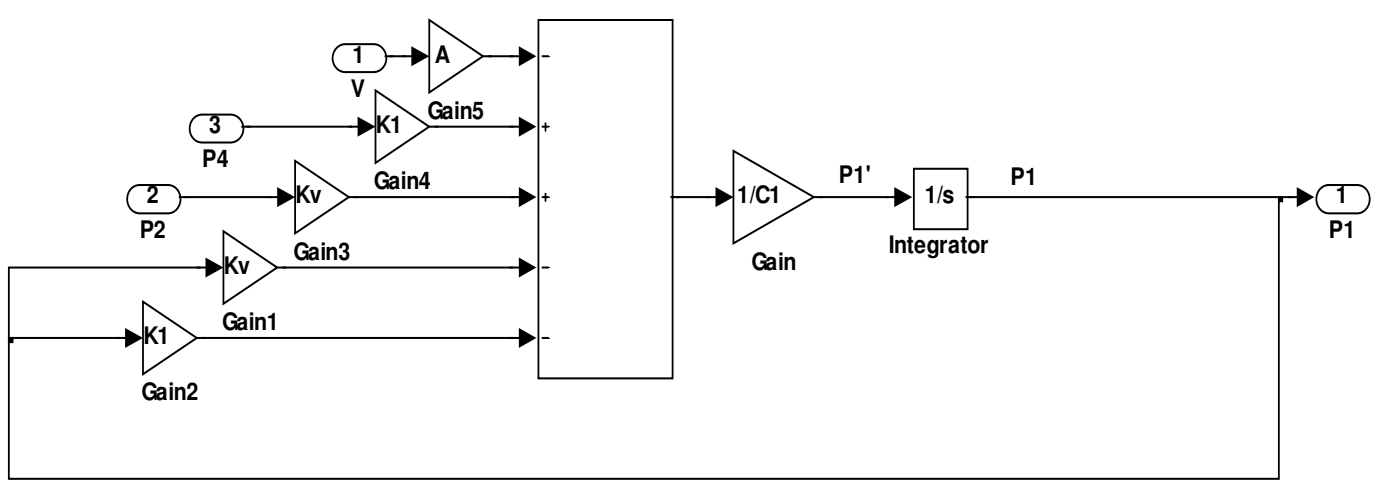

FIGURA C2 - Implementação da equação (5.27) no Simulink 


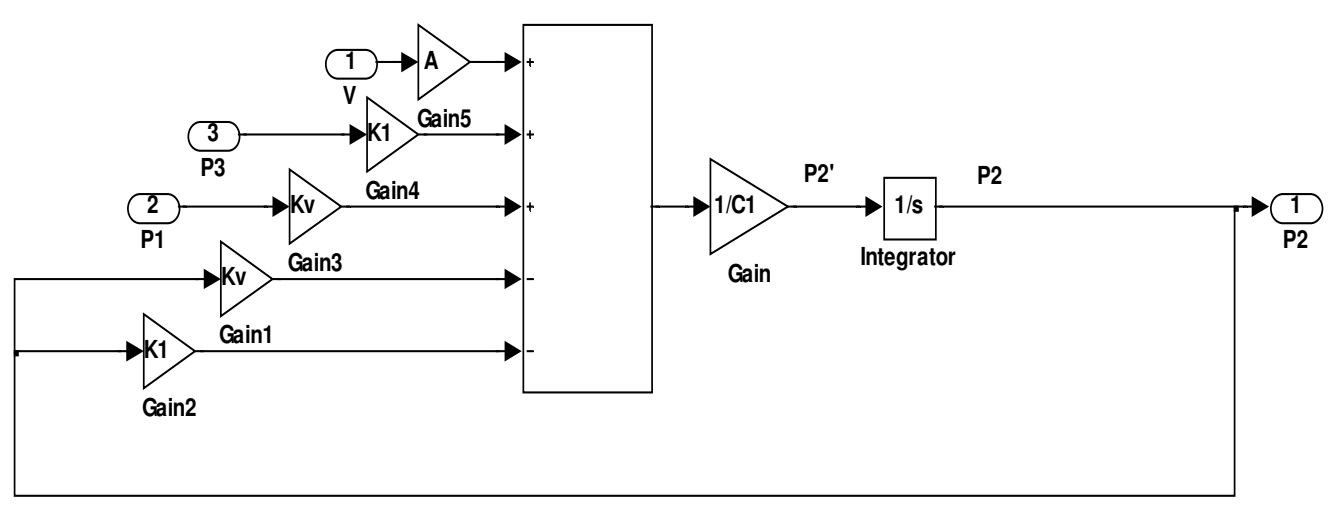

FIGURA C3 - Implementação da equação (5.29) no Simulink

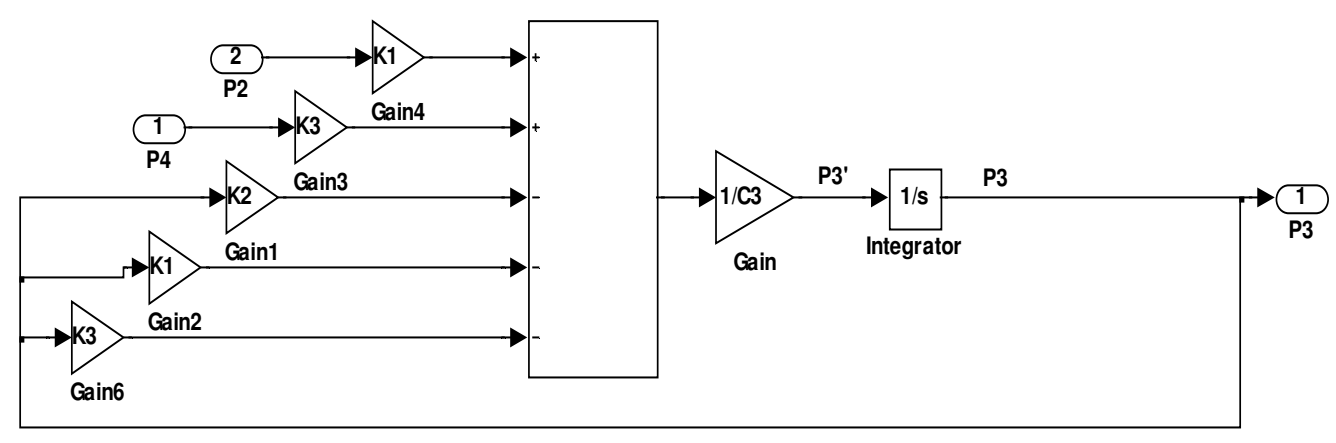

FIGURA C4 - Implementação da equação (5.31) no Simulink

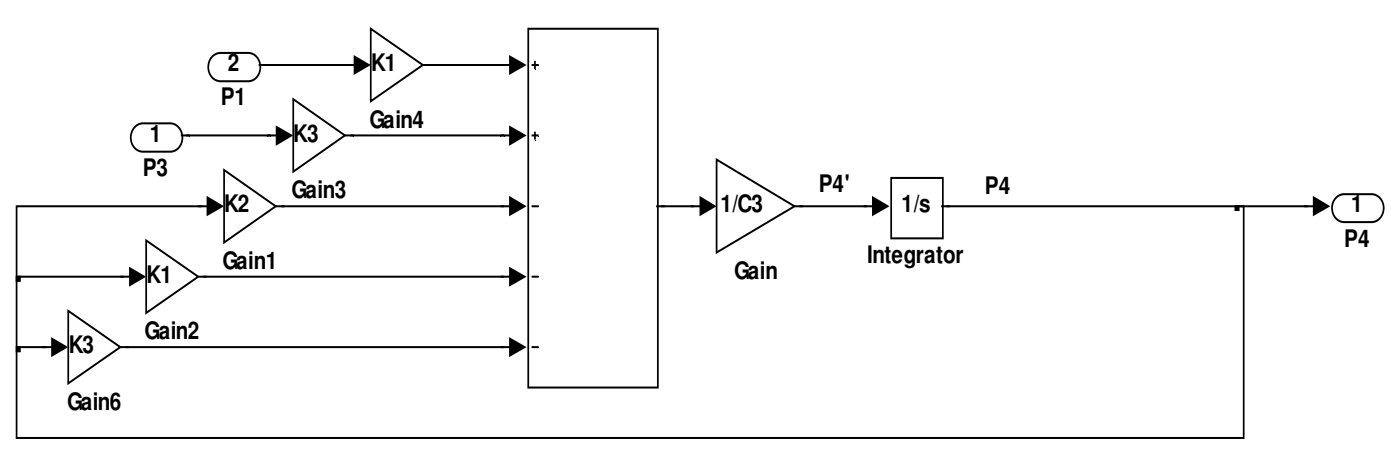

FIGURA C5 - Implementação da equação (5.33) no Simulink 